\begin{abstract}
UNIVERSIDADE DE SÃO PAULO
FACULDADE DE FILOSOFIA, LETRAS E CIÊNCIAS HUMANAS

DEPARTAMENTO DE LETRAS MODERNAS

PROGRAMA DE PÓS-GRADUAÇÃO EM ESTUDOS LINGUÍSTICOS E

LITERÁRIOS EM INGLÊS
\end{abstract}

SANDRA LAGO MARTINEZ NAVARRO

Glossário bilíngue de colocações da hotelaria:

um modelo à luz da Linguística de Corpus

VERSÃO CORRIGIDA

São Paulo

2011 
UNIVERSIDADE DE SÃO PAULO

FACULDADE DE FILOSOFIA, LETRAS E CIÊNCIAS HUMANAS

DEPARTAMENTO DE LETRAS MODERNAS

PROGRAMA DE PÓS-GRADUAÇÃO E EM ESTUDOS LINGUÍSTICOS E

LITERÁRIOS EM INGLÊS

\title{
Glossário bilíngue de colocações da hotelaria: um modelo à luz da Linguística de Corpus
}

\author{
VERSÃO CORRIGIDA
}

Sandra Lago Martinez Navarro

\begin{abstract}
Dissertação apresentada ao Programa de Pós-Graduação em Estudos Linguísticos e Literários em Inglês do Departamento de Letras Modernas da Faculdade de Filosofia, Letras e Ciências Humanas da Universidade de São Paulo, para a obtenção do título de Mestre em Letras.
\end{abstract}

Orientadora: Profa. Dra. Stella Esther Ortweiler Tagnin

São Paulo 
AUTORIZO A REPRODUÇÃO TOTAL OU PARCIAL DESTE TRABALHO, POR QUALQUER MEIO CONVENCIONAL OU ELETRÔNICO, PARA FINS DE ESTUDO OU PESQUISA, DESDE QUE CITADA A FONTE.

Navarro, Sandra Lago Martinez

$\mathrm{Ng}$ Glossário bilínque de colocações da hotelaria: um modelo à luz da Linguística de Corpus / Sandra Lago Martinez Navarro; orientador Stella Esther ortweiler Tagnin. - São Paulo, 2011.

$$
249 \mathrm{f} \text {. }
$$

Dissertação (Mestrado)- Faculdade de Filosofia, Letras e Ciências Humanas da Universidade de São Paulo. Departamento de Letras Modernas. Área de concentração: Estudos Linguísticos e Literários em Inglês.

1. Língua inglesa. 2. Hotelaria - terminologia. 3 . Colocações. 4. Tradução. I. Tagnin, Stella Esther Ortweiler, orient. II. Título. 


\section{FOLHA DE APROVAÇÃO}

Sandra Lago Martinez Navarro

Glossário bilíngue de colocações da hotelaria: um modelo à luz da Linguística de Corpus

Dissertação submetida ao Programa de Pós-Graduação da Faculdade de Filosofia, Letras e Ciências Humanas, Departamento de Letras Modernas, Área de Estudos Linguísticos e Literários em Inglês, da Universidade de São Paulo, como requisito parcial à obtenção do grau de Mestre em Letras.

Aprovada em: 1 I

Banca Examinadora

Prof. Dr.:

Instituição:

Assinatura:

Prof. Dr.:

Instituição:

Assinatura:

Prof. Dr.:

Instituição:

Assinatura: 
Dedico este trabalho às pessoas essenciais em minha vida - mãe, pai, irmãs, sobrinhos, familiares e amigos queridos. 


\section{Agradecimentos}

Um agradecimento especial à Prof ${ }^{a}$. Dra. Stella Esther Ortweiler Tagnin, por ter acreditado neste projeto e prestado sua valiosa orientação.

À minha mãe Rosa, pelo investimento na minha educação e apoio em todos os momentos.

Aos meus chefes Vinícius Cruz e Alan Kuhn, da agência Mandarin, pela flexibilidade de horários tão necessária para a conclusão desta pesquisa.

Aos meus chefes na agência All Tasks, pela oportunidade de gerenciar um projeto de tradução na área de hotelaria, experiência que foi o embrião deste estudo.

À querida colega de projeto Comet e happy hours, Carmen Dayrell, pelas orientações paralelas aos bate-papos sempre divertidos.

À Sabrina Matuda, pela ajuda com a etiquetagem do corpus e tantas outras.

A todos os colegas do projeto Comet, pelos trabalhos brilhantes que serviram de inspiração para esta pesquisa.

A todos que tiveram paciência comigo nesta reta final!

Enfim, a todos aqueles que estiveram presentes nesta importante etapa dos meus estudos, meus sinceros agradecimentos. 
HORATIO

$O$ day and night, but this is wondrous strange!

\section{HAMLET}

And therefore as a stranger give it welcome.

There are more things in heaven and earth,

Horatio,

Than is dreamt of in your philosophy.

shakespeare 


\section{Resumo}

O objetivo desta pesquisa é elaborar uma proposta de glossário bilíngue (inglês português) de colocações da hotelaria, voltado às necessidades do tradutor. Esta proposta justifica-se por abordar uma área técnica com grande volume de traduções e escassez de estudos terminológicos e por dar destaque a um elemento constitutivo e de alta incidência nas comunicações especializadas - as colocações.

$\mathrm{Na}$ base do fenômeno das colocações está o princípio de que a linguagem é padronizada e integra um sistema probabilístico, ou seja, tende a funcionar por meio de unidades pré-fabricadas convencionalizadas pelo uso. Conhecer esses padrões é de suma importância ao tradutor que pretende produzir um texto natural na língua de chegada.

Esta pesquisa encontra-se no escopo dos estudos em Linguística de Corpus, Terminologia Textual, Tradução e Fraseologia, áreas que compartilham o interesse em observar a linguagem real em seu contexto de ocorrência.

Para este trabalho, construímos um corpus comparável de textos extraídos de sites de estabelecimentos hoteleiros no Brasil e nos Estados Unidos. Foram compilados 321 textos e 546.106 palavras em inglês, 710 textos e 514.449 palavras em português, conteúdo subdividido por categorias de estabelecimentos.

Para a exploração do corpus, utilizamos o software WordSmith Tools (Scott, 2007, versão 5), em especial, ferramentas como listas de palavras-chave, listas de colocados e concordâncias.

Realizamos um estudo aprofundado da palavra room, fazendo um levantamento de suas principais colocações e explicitando o caminho percorrido para o estabelecimento dos equivalentes. A partir desses dados, apresentamos nossa proposta de glossário, que privilegiou aspectos de interesse ao tradutor.

PALAVRAS-CHAVE: Hotelaria. Linguística de Corpus. Terminologia. Colocações. Tradução. 


\section{Abstract}

This research presents a proposal for a bilingual glossary (English-Portuguese) of collocations typical of the hotel industry, aimed at meeting the needs of the translator. This way, we address a technical area in which translation is a constant need while there is a real lack of reference materials and we also focus on an element that constitutes specialized communications - the collocations.

This linguistics phenomenon represents the principle according to which language is standardized and makes up a probalistic system, which tends to function by means of pre-fabricated conventionalized units. A good command of such standards is of utmost importance for the translator who wishes to produce a natural translation in the target language.

This research draws on the principles of Corpus Linguistics, Textual Terminology, Translation and Phraseology, areas which share the interest of observing real language in context.

We have built a comparable corpus comprising texts extracted from websites of hotel properties in Brazil and the USA. The corpus is divided up into hotel categories and contains 321 texts and 546,106 words in English; 710 texts and 514,449 words in Portuguese.

This corpus was explored with the aid of WordSmith Tools program (Scott, 2007, version 5) and tools such as keywords, lists of collocations and concordance lines.

We have carried out a thorough investigation of the word room, determining its major collocates and outlining the procedures to establish their equivalents. This study concludes with our proposal for a glossary entry that focused on the interests of our target audience, the translator.

KEYWORDS: Hotel Industry. Corpus Linguistics. Terminology. Collocations. Translation. 


\section{Lista de figuras}

Figura 1 - Sites de reserva de hotéis com traduções para diferentes idiomas $\quad 8$

$\begin{array}{ll}\text { Figura } 2 \text { - Entrada de room no dicionário bilíngue de hotelaria } & 10\end{array}$

Figura 3 - Site em inglês do Hotel Líder, de Manaus 13

Figura 4 - Categorias de colocações em Tagnin (2005: 37-46). Exemplos nossos 42

Figura 5 - Verbete de hotel no The BBI Combinatory Dictionary of English 47

Figura 6 - Verbete parcial de hotel no Oxford Collocations Dictionary for

Students of English 49

Figura 7 - Verbete de hotel no Longman Dictionary of Contemporary English $\quad 50$

Figura 8 - Verbete de garlic no Vocabulário para culinária, inglês/português 51

Figura 9 - Verbete de Reserve [a, your, this] room, em nossa proposta

de glossário

Figura 10 - Tipologia do corpus de estudo $\quad 55$

Figura 11 - Exemplo de site de estabelecimento hoteleiro nos Estados

Unidos, de onde o texto foi extraído para compor o corpus em inglês

Figura 12 - Aba Accommodations, de onde o texto é extraído para

integrar o corpus

Figura 13 - Exemplo de site de estabelecimento hoteleiro no Brasil, de onde é extraído o texto para compor o corpus em português 58

Figura 14 - Aba Acomodações, de onde é extraído o texto para o corpus $\quad 59$

Figura 15 - Design do corpus e composição final $\quad 60$

Figura 16 - Lista de nomes de estabelecimentos fornecida pelo site

hotels.com; no destaque, categorias que basearam a classificação

de nosso corpus em inglês

Figura 17 - Planilha em Excel (parcial), com organização das

informações do corpus

Figura 18 - Exemplo de cabeçalho preenchido $\quad 65$

Figura 19 - Exemplo de texto do corpus com etiquetas 68

Figura 20 - Etiquetador Tree-Tagger disponível pelo site do LAEL (PUC-SP) 69

$\begin{array}{ll}\text { Figura } 21 \text { - Interface do Tree-Tagger } & 70\end{array}$

Figura 22 - Linhas de concordância parciais de apartamentos + adjetivos

no corpus etiquetado

Figura 23 - Site do snow resort Beaver Creek, nos Estados Unidos 80

Figura 24 - Site do hotel Sheraton, em Foz do Iguaçu 83

Figura 25 - Descrição das acomodações do Cobb Lane Bed and Breakfast 86

Figura 26 - Descrição das acomodações do Hotel Fazenda Clube dos $200 \quad 86$

Figura 27 - Tela inicial do WordSmith Tools, versão 5 (Scott, 2007) 88

Figura 28 - Lista de palavras parcial do corpus em inglês em ordem

$\begin{array}{ll}\text { decrescente de frequência } & 89\end{array}$

Figura 29 - Estatísticas do corpus em inglês $\quad 89$

Figura 30 - Estatísticas do corpus em português $\quad 90$

Figura 31 - Lista de palavras-chave do corpus em inglês 91

Figura 32 - Ajustes da ferramenta Keywords $\quad 92$

Figura 33 - Lista de colocados de $\operatorname{room}(s)$, por ordem de frequência,
na ferramenta Concord 
Figura 34 - Lista de clusters de room(s), por ordem de frequência, na ferramenta Concord

Figura 35 - Lista de concordâncias de room, ordenadas pelos colocados à direta, na ferramenta Concord 95

Figura 36 - Número de ocorrências da palavra suite(s) no corpus 97

Figura 37 - Número de ocorrências da palavra room(s) no corpus 98

Figura 38 - Parte das linhas de concordância de in-room safe 98

$\begin{array}{ll}\text { Figura } 39 \text { - Lista parcial de colocados de cofre } & 100\end{array}$

Figura 40 - Candidatos a equivalentes de in-room safe 101

Figura 41 - Parte das linhas de concordância de cofre. Total de 297 ocorrências 102

$\begin{array}{ll}\text { Figura } 42 \text { - Equivalentes validados para in-room safe } & 102\end{array}$

$\begin{array}{ll}\text { Figura } 43 \text { - Modelo de ficha terminológica } & 103\end{array}$

Figura 44 - Modelo de ficha terminológica preenchida parcialmente com $\begin{array}{lr}\text { a colocação in-room safe } & 105\end{array}$

Figura 45 - Modelo de verbete de in-room safe 106

Figura 46 - Parte das linhas de concordância de accessible room(s)

Figura 47 - Parte das linhas de concordância de portadores de

necessidades especiais, ordenadas pelas palavras à esquerda 109

Figura 48 - Lista de colocados de banquete(s) 110

Figura 49 - Lista dos adjetivos em inglês mais frequentes no corpus 112

$\begin{array}{ll}\text { Figura } 50 \text { - Linhas parciais das concordâncias de apartamento(s) } & \\ \text { seguido de adjetivos, no corpus etiquetado } & 113\end{array}$

Figura 51 - Linhas parciais das concordâncias de convenções,

ordenadas pelo colocado à esquerda

Figura 52 - Linhas parciais das concordâncias de conferências, ordenadas

pelo colocado à esquerda

Figura 53 - Lista parcial dos colocados de pessoas $\quad 117$

$\begin{array}{ll}\text { Figura } 54 \text { - Lista parcial dos colocados de people } & 118\end{array}$

Figura 55- Linhas parciais de concordância de conjugados, ordenadas pelos

colocados à esquerda

Figura 56 - Linhas parciais de concordância de apartamento + adjetivos, no corpus etiquetado

Figura 57 - Linhas parciais de concordância de apartamento luxo 121

Figura 58-Clusters parciais de dining room 122

Figura 59 - Linhas parciais de concordância de "sala de *”. No destaque, as ocorrências de sala de ginástica

Figura 60 - Linhas parciais de concordância de fitness center. No destaque, a associação com spa

Figura 61 - Linhas parciais de concordância de eventos, ordenadas pelos

colocados à esquerda.

$\begin{array}{ll}\text { Figura } 62 \text { - Lista parcial de colocados de jogos } & 131\end{array}$

Figura 63 - Lista parcial dos colocados de room. No destaque, guest 132

Figura 64 - Clusters parciais de guest room(s) 133

$\begin{array}{ll}\text { Figura } 65-\text { Clusters parciais de apartamento(s) } & 134\end{array}$

Figura 66 - Lista parcial dos colocados de bedroom 136

$\begin{array}{ll}\text { Figura } 67-\text { Clusters parciais de bedroom } & 136\end{array}$

Figura 68 - Linhas parciais de concordância de bedroom 137

Figura 69 - Clusters parciais de room(s), destaque para in-room coffee maker 140 
Figura 70 - Linhas de concordâncias parciais de sala

Figura 71 - Linhas de concordâncias parciais de living room, ordenadas

pelo colocado à esquerda

Figura 72 - Linhas de concordâncias de sala de estar separada

Figura 73 - Linhas de concordâncias parciais de sala, ordenadas

pelos colocados à esquerda

Figura 74 - Listas dos adjetivos mais frequentes no corpus em português

Figura 75 - Linhas de concordância de luxuoso, ordenadas pelos

colocados à esquerda e à direita

Figura 76 - Linhas de concordância parciais de banheiro; no destaque, a referência a lavabo

Figura 77 - Linhas de concordância parciais de half; ordenadas pelos colocados à direita. Destaque para as colocações half bath(s) e

half bathroom(s)

Figura 78 - Linhas de concordância parciais de reserve;

no destaque, reserve a room

Figura 79 - Linhas de concordância parciais de reserve (em português)

Figura 80 - Linhas de concordância parciais de reserva, ordenadas

pelos dois colocados à esquerda

Figura 81 - Linhas de concordância parciais de room amenities

Figura 82 - Linhas de concordância parciais de equipados com

Figura 83 - Linhas de concordância parciais de room and tax, ordenados pelos colocados à esquerda

Figura 84 - Linhas de concordância parciais de features, ordenadas pelos dois

colocados à esquerda

Figura 85 - Linhas de concordância parciais de offers, ordenadas

pelos dois colocados à esquerda.

Figura 86 - Linhas de concordância parciais de tarifa, ordenadas

pelos dois colocados à direita

Figura 87 - Linhas de concordância parciais de taxa, ordenadas pelos

dois colocados à direita

Figura 88 - Site de estabelecimento hoteleiro no Brasil.

No destaque, o uso de tarifário

Figura 89 - Linhas de concordâncias parciais de room service, em português $\quad 178$

Figura 90 - Linhas de concordâncias parciais de apartamento standard $\quad 180$

Figura 91 - Principais categorias de apartamentos e suites, em inglês e português 181

Figura 92 - Linhas de concordância de single room

Figura 93 - Linhas de concordância de sauna, ordenadas pelos dois

colocados à direita

Figura 94 - Linhas de concordância de tratamento, ordenadas pelos dois colocados à esquerda 


\section{Lista dos quadros}

Quadro 1 - Etiquetas do Tree-Tagger (inglês) 71

Quadro 2 - Etiquetas do Tree-Tagger (português) 72 


\section{Lista de abreviaturas}

LC - Linguística de Corpus

TCT - Teoria Comunicativa da Terminologia

TST - Teoria Sociocognitiva da Terminologia 


\section{Sumário}

Introdução 1

Capítulo 1 - A hotelaria 5

$1.1 \mathrm{O}$ turismo 5

1.2 Breve histórico da hotelaria no Brasil e no mundo 6

1.3 Por que estudar a linguagem da hotelaria? 8

Capítulo 2 - Fundamentação teórica 15

2.1 Linguística de Corpus 15

$\begin{array}{ll}2.1 .1 \text { Corpus e sua tipologia } & 18\end{array}$

2.1.2 Status da LC e tipos de abordagem $\quad 21$

2.2 LC e Convencionalidade 23

2.3 LC, Tradução e Terminologia 25

2.4 Terminologia: histórico e conceitualização 29

2.4.1 Terminologia Textual 33

2.5 Colocações $\quad 34$

2.5.1 Conceitualização $\quad 34$

2.5.2 As colocações e os estudos de Fraseologia $\quad 37$

2.5.3 Definições e tipologia $\quad 40$

2.5.4 As colocações e os dicionários $\quad 46$

Capítulo 3 - Metodologia $\quad 54$

$3.1 \mathrm{O}$ corpus de estudo $\quad 54$

3.1.1 Tipologia $\quad 55$

3.1.2 Composição 56

3.1.2.1 Autenticidade $\quad 56$

$\begin{array}{ll}3.1 .2 .2 \text { Representatividade } & 60\end{array}$

3.1.2.3 Tratamento dos textos 95

$\begin{array}{ll}\text { 3.1.3 Critérios redefinidos } & 73\end{array}$

3.1.4 Aspectos culturais revelados pela compilação do corpus $\quad 77$

3.2 Exploração do corpus e procedimentos de análise $\quad 87$

3.2.1 Ferramentas do WordSmith Tools e parâmetros adotados 88

3.2.2 Procedimentos de identificação das colocações e seus equivalentes 95

$\begin{array}{ll}\text { 3.3 Metodologia exemplificada } & 97\end{array}$

3.3.1 Ficha terminológica 103 
Capítulo 4 - Apresentação dos resultados e modelo de verbete 107

4.1 Os colocados de room

4.1.1 Acessible room

4.1.2 Banquet room

109

4.1.3 Book [a, your, this] room

4.1.4 Comfortable room

4.1.5 Conference room

114

4.1.6 Connecting room

118

4.1.7 Deluxe room

120

4.1.8 Dining room

121

4.1.9 Elegant room

4.1.10 Fitness room

125

4.1.11 Function room

129

4.1.12 Game room

131

4.1.13 Guest room

132

4.1.14 Hotel room

139

4.1.15 In-room coffee maker

140

4.1.16 In-room dining

4.1.17 In-room safe

142

4.1.18 Laundry room

142

4.1.19 Living room

4.1.20 Luxurious room

146

4.1.21 Meeting room

149

4.1.22 Powder room

151

4.1.23 Reserve [a, your, this] room 153

4.1.24 Room amenities $\quad 158$

4.1.25 [one/first night's] room and tax 162

4.1.26 Room features $\quad 165$

4.1.27 Room rate 168

4.1.28 Room service $\quad 177$

$\begin{array}{ll}\text { 4.1.29 Spacious room } & 178\end{array}$

$\begin{array}{ll}\text { 4.1.30 Standard room } & 179\end{array}$

4.1.31 Steam room $\quad 182$

4.1.32 Treatment room 183

4.1.33 Well-appointed room 184

4.2 Modelo de verbete 188

Considerações finais $\quad 211$

Referências bibliográficas $\quad 214$

Anexos $\quad 222$ 


\section{Introdução}

O turismo é um setor de bastante expressão no cenário econômico e cultural do mundo. Fomentado em grande parte pelas viagens internacionais, este ramo movimenta diversos outros setores, em especial o hoteleiro. Se nos primórdios as pessoas paravam em casas à beira da estrada à procura de abrigo, hoje o objetivo de muitas viagens é hospedar-se em hotéis luxuosos, que reúnem todas as formas de entretenimento. A hotelaria é, portanto, um setor que evoluiu consideravelmente ao longo dos anos e, com o encurtamento das distâncias e maior deslocamento das pessoas, tornou-se cada vez mais multicultural. Para mediar essas relações entre indivíduos de diferentes nacionalidades e culturas, a comunicação, geralmente em inglês, exerce um papel crucial e a tradução é uma necessidade constante.

Uma das maiores fontes de demandas por tradução nessa área é a internet. No intuito de atingir um público maior, diversos sites de estabelecimentos hoteleiros, sites de reserva de hotéis, sites de guias de viagem, dentre outros, optam por traduzir seus conteúdos para diferentes idiomas. Nesse ponto, entra o trabalho do tradutor, que depara com inúmeros desafios próprios aos textos de hotelaria.

Um desses grandes desafios diz respeito à estreita relação que a hotelaria tem com diversos aspectos culturais de cada país e região. Nos dizeres de especialistas, "O turismo, além de constituir uma atividade econômica, é cultura em sua essência. A hotelaria está inserida nesse contexto" (Gregson, 2009: IX). Assim, quando falamos em hotelaria, fazemos referência a costumes, gastronomia, arquitetura, decoração, esportes, leis e até mesmo aspectos históricos e geográficos de uma região. Ou seja, traduzir textos de hotelaria é buscar aproximar duas realidades, dois mundos culturalmente diferentes.

A despeito dessa dificuldade e da grande demanda por traduções, a área padece de uma real escassez de obras terminológicas, situação que se agrava no tocante às publicações bilíngues inglês-português. Essa realidade pôde ser constatada ao longo de dois anos e meio de nossa experiência pessoal como tradutora da área de hotelaria. 
Durante esse período, não fizemos uso regular de nenhuma publicação terminológica bilíngue da área porque as obras disponíveis não respondiam aos nossos questionamentos, além de serem muito desatualizadas. Dentre as poucas disponíveis, nenhuma está destinada exclusivamente ao profissional da tradução e, portanto, não auxilia de fato o tradutor em sua tarefa fundamental: produzir uma tradução precisa do ponto de vista técnico e natural do ponto de vista da linguagem empregada naquela área de especialidade.

A fim de atender mais satisfatoriamente as necessidades de produção textual, tais obras precisam incluir informações que vão além de uma mera lista de termos e seus equivalentes. Ao profissional da tradução importa saber como o termo e tudo o mais que o circunda se realizam na língua de chegada. Nesse sentido, o tradutor precisa de exemplos de uso, sugestões de equivalentes e soluções de tradução, informações sobre as formas típicas de expressão em dado contexto, frequência dos equivalentes, informações culturais, enfim, as necessidades são diversas e reais.

Diante desse contexto, nossa pesquisa originou-se do desejo de ajudar a estreitar a lacuna que existe entre a alta demanda de tradução, a escassez de obras terminológicas e o complexo trabalho do tradutor da área de hotelaria. Para tanto, nosso principal objetivo é propor um modelo de glossário bilíngue (inglês - português) de colocações da hotelaria, direcionado ao tradutor.

Por colocações entende-se a associação recorrente entre itens lexicais (Sinclair, 1991). O interesse em estudá-las justifica-se pelo fato de serem um elemento constitutivo e de alta incidência nas comunicações especializadas. Há estudos que indicam a prevalência de colocações (sintagmas terminológicos) na língua de especialidade num percentual que gira em torno de $70 \%$ das ocorrências terminológicas (Krieger e Finato, 2004: 81). Daí a importância de elaborar produtos terminográficos que incluam as colocações.

Na base do fenômeno da colocação está o princípio de que a linguagem é padronizada e integra um sistema probabilístico, ou seja, tende a funcionar por meio de unidades pré-fabricadas cuja ocorrência está associada ao contexto comunicativo. No momento da tradução, essas unidades convencionalizadas não chegam a representar um problema de entendimento, mas certamente de produção, até mesmo para os mais experientes. Para citar apenas dois exemplos, como não associar complimentary breakfast a 'café da manhã de cortesia' quando a forma mais usual em português é 'café 
da manhã incluído [na diária]'. Ou ainda, como prever que a forma equivalente mais usual de reserve your room não é 'reserve seu quarto', mas 'faça sua reserva'? Esses exemplos servem para ilustrar brevemente que as colocações consistem de fato em um desafio no momento da tradução, justificando uma proposta de glossário que dê destaque central a elas.

Em consonância com a visão de linguagem descrita acima, esta pesquisa busca subsídios nos preceitos da Linguística de Corpus, uma abordagem empirista que se ocupa da identificação de padrões do léxico por meio da observação de textos autênticos, organizados em um corpus eletrônico. Este estudo faz ainda interface com as áreas de Terminologia Textual, que postula ser o texto o verdadeiro habitat das terminologias; Tradução, que contribui com reflexões sobre as necessidades do tradutor e noção de equivalência pelo contexto; e Fraseologia, que aprofunda a discussão sobre a constituição das colocações.

Para a realização deste estudo, compilamos um corpus comparável (textos originais em inglês e em português) de textos extraídos de sites de estabelecimentos hoteleiros no Brasil e nos Estados Unidos. Esse corpus está dividido em cinco categorias em cada idioma: hotels, resorts, bed and breakfasts, suites e condos em inglês; hotéis, resorts, pousadas, hotéis-fazenda e flats em português. Em termos numéricos, temos: 546.106 palavras e 321 textos em inglês; 514.449 palavras e 710 textos em português, totalizando 1.060 .555 palavras e 1.031 textos.

A fim de alcançar os objetivos propostos, esta pesquisa adotou uma metodologia dividida em etapas, a saber: a delimitação e compilação do corpus de estudo, a exploração do corpus por meio das ferramentas do software WordSmith Tools (Scott, 2007, versão 5), o levantamento e análise dos dados e, por fim, a proposta de um modelo de verbete do glossário bilíngue de colocações da área de hotelaria.

Nesta pesquisa, buscamos demonstrar, por meio de um estudo aprofundado da palavra room, que a abordagem teórica e metodológica adotada é eficaz para fornecer os resultados almejados e ainda ampliar o escopo desta pesquisa, suscitando reflexões relevantes para as áreas com as quais faz interface.

Esta dissertação está dividida em capítulos. Apresentaremos, no capítulo 1, um breve panorama da área de hotelaria, bem como nossas justificativas para estudar essa língua de especialidade. Em seguida, o capítulo 2 descreve os pressupostos teóricos que 
fundamentam este estudo, passando pelas áreas da Linguística de Corpus e Convencionalidade, Tradução e Terminologia Textual e discutimos mais aprofundadamente a conceitualização e formação das colocações, bem como seu tratamento nas obras lexicográficas. No capítulo 3, expomos a nossa metodologia de estudo, começando pelo detalhamento do corpus, em seguida, das ferramentas utilizadas e dos critérios estatísticos adotados, e terminamos com uma exemplificação do percurso para a extração das colocações e equivalentes. Acrescentamos ainda uma reflexão sobre como a etapa de compilação do corpus foi capaz de revelar aspectos culturais do âmbito da hotelaria até então desconhecidos por nós. Por fim, no capítulo 4, apresentamos os resultados e nossa proposta de verbete. O trabalho encerra-se com nossas Considerações Finais, seguidas da Bibliografia. 


\section{Capítulo 1 - A hotelaria}

Neste capítulo, apresentamos um breve panorama da área de especialidade sob investigação nesta pesquisa. Os seguintes tópicos serão abordados:

- Dados do turismo nos dias de hoje;

- Um breve histórico da hotelaria no Brasil e no mundo;

- Justificativa para o estudo da linguagem da hotelaria.

\section{1 - O turismo}

O turismo ocupa hoje uma posição de destaque no cenário econômico mundial. O setor triplicou em cinco décadas, as viagens internacionais saltaram de 25 milhões anuais em 1950 para 806 milhões em 2005, e os números giram em torno de 4 trilhões de dólares anuais em todo o mundo, segundo dados da Organização Mundial do Turismo ${ }^{1}$. Essa disparada do setor nas últimas décadas do século XX pode ser explicada por uma ampla teia de fatores que envolvem a evolução nas áreas da comunicação e dos transportes mundiais, decorrentes da internacionalização das economias (Andrade et al., 2007: 11).

Igualmente, no Brasil, o turismo é um setor bastante expressivo da economia; cresceu 76\% entre 2000 e 2005, de acordo com o Ministério do Turismo ${ }^{2}$. Tal expansão do mercado turístico nacional, associada à geração de milhares de empregos diretos e indiretos, contribui de maneira significativa para o desenvolvimento econômico, financeiro e social do país.

Mas, afinal, o que é o turismo?

Dentre as várias definições existentes, adotamos a apresentada pelo organismo máximo do turismo no mundo, a OMT - Organização Mundial do Turismo (em inglês, UNWTO): "Turismo compreende as atividades que as pessoas realizam durante suas

\footnotetext{
${ }^{1}$ http://www.unwto.org/aboutwto/why/en/why.php?op=1 acesso em 15/10/2010

2 http://www.turismo.gov.br/mtur/opencms/turismo/noticias/todas noticias/200907052.html. acesso em 02/08/2010
} 
viagens e estadias em lugares diferentes do seu local de residência, por um período consecutivo inferior a um ano, com propósitos de lazer, descanso, negócios ou outros" (Aldrigui, 2007:8).

A partir dessa definição, depreende-se que um dos componentes fundamentais do turismo é a indústria da hospedagem, pois a grande maioria das viagens envolve algum tipo de estadia. Em outras palavras, sem a hotelaria, não existe turismo. E juntamente com o turismo, essa atividade evoluiu consideravelmente desde o seu surgimento.

\subsection{Breve histórico da hotelaria no Brasil e no mundo}

A atividade de receber pessoas é bastante antiga, sendo o comércio e os meios de transporte os responsáveis históricos pelas primeiras formas de oferta hoteleira. Ainda na Antiguidade, as rotas comerciais deram origem a núcleos urbanos e centros de hospedagem para atendimento aos viajantes. Inicialmente, no entanto, a hospedagem era vista mais como um gesto de caridade do que um negócio. Na Idade Média, por exemplo, atender viajantes era uma obrigação moral e espiritual. Assim, o cidadão comum abrigava e alimentava estranhos em sua própria casa sem cobrar nada por tal gesto. Nessa época, a hospedagem também era feita em mosteiros e abadias, o que curiosamente forneceu o embrião para a diferenciação dos serviços, pois "como colocar em um mesmo ambiente os menos favorecidos e doentes e aqueles nobres que estão de passagem"? (Aldrigui, 2007: 22)

Mais tarde, com o advento das monarquias nacionais, a hospedagem era realizada pelo próprio Estado, nos palácios da nobreza ou nas instalações militares e administrativas. Curiosamente, a palavra 'hotel', de origem francesa (hôtel), significava inicialmente a residência do rei da França. O termo generalizou-se posteriormente para designar edifícios suntuosos e imponentes, alguns deles residências dos membros da nobreza, que costumavam receber hóspedes, no entanto, sem cobrar por isso. Com o tempo, institui-se a prática de hospedar não apenas convidados, mas quem pudesse pagar pela experiência. Daí o termo 'hotel' passou a ser associado a excelência na arte de receber. 
A partir da Revolução Industrial e expansão do capitalismo, a hospedagem torna-se uma atividade estritamente econômica a ser explorada comercialmente. Em 1774 surgiu o primeiro hotel de origem familiar, em Londres. Contudo, o primeiro hotel construído com essa finalidade surgiu apenas no início do século XIX. Já o conceito de quarto com banheiro privativo, hoje chamado de apartamento, foi introduzido em 1870, em Paris (Andrade et al., 2007: 18).

O turismo passa por uma grande evolução a partir da Segunda Guerra Mundial, com a expansão da economia, o aumento da renda da população e a melhoria dos sistemas de transportes e comunicação, principalmente com o advento dos aviões a jato para passageiros. Todo esse incremento no setor de turismo e lazer impulsionou paralelamente a rede hoteleira.

No Brasil, a evolução da hospedagem acompanhou as características do crescimento do país. No período colonial, os viajantes hospedavam-se nas casasgrandes dos engenhos e fazendas, nos casarões da cidade, nos conventos e, principalmente, nos ranchos construídos à beira da estrada. Essas paradas ao longo do caminho foram incorporando outras atividades comerciais, dando origem a aglomerados urbanos e, posteriormente, a cidades.

A chegada da corte portuguesa ao Rio de Janeiro, em 1808, e a abertura dos portos trouxeram um grande fluxo de estrangeiros, aumentando a demanda por alojamento na cidade. Nesse momento, muitos proprietários passaram a adotar o nome 'hotel' para elevar o padrão de suas casas de pensão, hospedarias e tavernas (Andrade et al., 2007: 20-21).

$\mathrm{Na}$ década de 30, passam a ser implantados grandes hotéis nas capitais, nas estâncias minerais e outras áreas de apelo turístico, cuja ocupação era promovida pelos cassinos que operavam junto aos hotéis. Vale mencionar ainda a entrada das cadeias hoteleiras internacionais no país na década de 1970, que abalou as estruturas tradicionais e deu ao mercado uma nova orientação, com novos padrões de serviços e preços. Atualmente, o setor segue em expansão, com uma oferta de cerca de 1 milhão de apartamentos em todo o país e faturamento da ordem de 2 bilhões de dólares anuais. ${ }^{3}$

De uma hospedagem rústica para grandes hotéis luxuosos, esse dinâmico setor sofreu uma evolução e diversificação consideráveis e ainda em andamento. Se antes

\footnotetext{
${ }^{3}$ http://www.abih.com.br/principal/historia.php?cod=007 Acesso em 30/10/2010
} 
parava-se no meio da estrada à procura de descanso, hoje é possível programar as paradas e conhecer os detalhes das acomodações pela internet. Tal evolução também se deu na linguagem da hotelaria, que se especializou juntamente com o ramo. É essa linguagem o foco deste estudo.

\subsection{Por que estudar a linguagem da hotelaria?}

Conforme destacamos anteriormente, a hotelaria é um setor que nasceu da necessidade de abrigar pessoas em suas viagens. Pode-se afirmar, portanto, que os hotéis são muitas vezes ponto de encontro de pessoas de diferentes nacionalidades, culturas e idiomas. Essa natureza multicultural exige, por sua vez, uma comunicação eficiente e é nesse ponto que a tradução exerce um papel fundamental, tanto para a captação como para o bom atendimento dos clientes.

Assim, a hotelaria é uma área com grande demanda por traduções. Inicialmente, podemos destacar uma grande diversidade de sites de reservas de hotéis, que servem como uma base de dados de estabelecimentos em diferentes localidades. Nesses sites, os hóspedes podem facilmente encontrar um hotel de interesse, verificar suas características e realizar reservas. A figura abaixo traz alguns exemplos de sites com essa finalidade e que divulgam seu conteúdo traduzido para mais de um idioma:

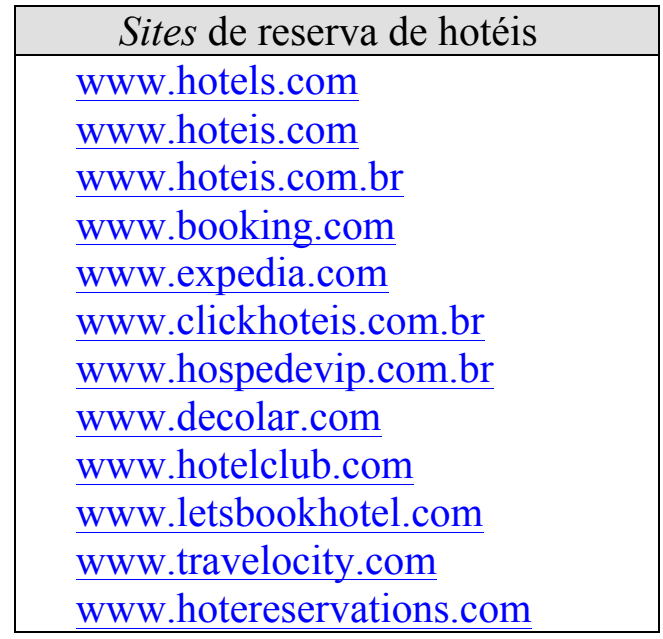

Figura 1 - Sites de reserva de hotéis com traduções para diferentes idiomas.

A grande demanda por traduções destinadas a esse tipo de site pôde ser constatada ao longo de nossa experiência pessoal como tradutora. Por cerca de dois anos 
e meio, gerenciamos um projeto de tradução do conteúdo do site hotels.com, que hoje possui seu equivalente em português, hoteis.com. Tendo sido responsável não apenas pela tradução, mas pelo gerenciamento da terminologia (elaboração de glossários e normas), pudemos constatar na prática como essa área carece de estudos e obras terminológicas. Daí o interesse de investigar mais a fundo essa língua de especialidade.

Outras fontes de demanda por tradução são os sites dos grandes grupos hoteleiros, como Accor Hotels, Sol Meliá, Blue Tree Hotels, Hilton, Marriott, dentre tantos outros. Essas empresas em geral disponibilizam um site principal, a partir do qual se pode acessar sites dos hotéis específicos nas diferentes cidades do mundo, no idioma do respectivo país, inclusive o português. Em maior número ainda são os sites das centenas de estabelecimentos hoteleiros que divulgam seus serviços na Internet em mais de um idioma, fato bastante frequente no caso de hotéis brasileiros que promovem o conteúdo de seus sites em inglês no intuito de atrair uma clientela internacional. Fora da esfera da Internet, destacam-se ainda outras fontes de tradução, como guias de viagem, revistas de bordo, brochuras, bem como comunicações internas nos estabelecimentos, como folders e orientações em geral.

A despeito de toda essa demanda por traduções, a área da hotelaria apresenta escassez de recursos terminológicos, conforme já apontamos. Dentre as poucas obras monolíngues em português disponíveis, destacam-se o Glossário Técnico: Gastronômico, Hoteleiro e Turístico de Elenara Viera De Viera e Indio Candido (2003) e a obra Hotelaria e Turismo de A a Z de Abinael Morais Leal (2002), um dicionário que reúne termos e expressões do setor. No idioma inglês, há uma oferta maior, como o Dictionary of Hotels, Tourism and Catering Management, de P. H. Collin (2002). A maioria das obras encontradas, porém, está destinada a profissionais da área e estudantes de inglês, como o High Season: English for The Hotel and Tourist Industry de Keith Harding, Paul Henderson e Michael Duckworth (1991) e o Enjoy Your Stay: English for the Hospitality and Travel Industry de Robin Nitzky Persiani e Randi Reppen (2007), esse último com tradução para o português (Enjoy Your Stay - Inglês para Hotelaria e Turismo, de Enaura de Biaggi, 2004).

As obras bilíngues inglês-português são ainda mais escassas, sendo as duas mais conhecidas: o Dicionário Inglês - Português de Turismo, Hotelaria e Comércio Exterior de Maria Genny Caturegli (1999) e o Vocabulário para Turismo - Português / Inglês de Maura Xavier Garcia (2004). 
É inegável o valor de todas as obras mencionadas acima. Entretanto, nenhuma delas destina-se primordialmente ao tradutor técnico da área de hotelaria. Os glossários bilíngues disponíveis consistem basicamente em uma lista de termos e seus equivalentes. A título de exemplificação, vejamos a seguir como está dicionarizado no Dicionário Inglês - Português de Turismo, Hotelaria e Comércio Exterior (Caturegli, 1999) um dos termos-chave da área, room. Em seguida, discutiremos alguns aspectos relativos à eficiência desse dicionário para a atividade tradutória.

\begin{tabular}{|l|l|}
\hline room (s.) & cômodo; quarto; espaço \\
\hline room clerk & $\begin{array}{l}\text { encarregado de registrar e distribuir as } \\
\text { chaves dos quartos aos hóspedes do } \\
\text { hotel }\end{array}$ \\
\hline room linen & lençóis, fronhas, toalhas etc. de um hotel \\
\hline room maid & camareira de hotel \\
\hline room-mate (s.) & companheiro de quarto \\
\hline room number & número do quarto \\
\hline room service & $\begin{array}{l}\text { serviço de quarto nos hotéis (entrega de } \\
\text { comidas e bebidas) }\end{array}$ \\
\hline
\end{tabular}

Figura 2 - Entrada de room no dicionário bilíngue de hotelaria.

Diversas questões podem ser levantadas:

a) ausência de contexto: não há referência à situação de comunicação em que estão inseridos os termos. Fica a dúvida: em que momento room é um cômodo ou um espaço?

b) ausência de exemplos de uso: não é possível observar como o termo é utilizado em seu contexto natural de ocorrência, tampouco as palavras com as quais coocorre;

c) termos equivalentes listados como sinômimos: a diferença de uso entre os termos não é considerada, o que pode levar o tradutor a pensar que cômodo e quarto, por exemplo, podem ser utilizados de maneira intercambiável;

d) ausência de sugestão do equivalente mais frequente: segundo nosso corpus de estudo, o termo mais frequente para a tradução de room seria apartamento; no entanto, esse equivalente não está sequer relacionado na entrada. $\mathrm{O}$ mesmo 
acontece com room service, que pode ser mantido em inglês, room service, conforme dados do corpus;

e) ausência de remissivas: não há informações sobre termos relacionados. Por exemplo, guest room, que também consta no dicionário, é um sinônimo de room, mas não há uma informação indicando isso. Além disso, como equivalente de guest room o dicionário sugere quarto de hóspede, que não consta em nosso corpus;

f) ausência de sugestão de tradução: nota-se aqui claramente a preocupação apenas com o conceito. Como traduzir room clerk afinal? Seria adequado traduzir room linen por lençóis, fronhas, toalhas etc.?;

g) sugestões de tradução que podem induzir ao erro: ao consultar o termo room service, o tradutor pode pensar que é necessário incluir 'nos hotéis' ao lado de serviço de quarto, ou pior ainda, incluir a informação entre parênteses "entrega de comidas e bebidas";

h) ausência de informações complementares: existe diferença entre os tipos de 'quartos' nos dois idiomas? Existem falsos cognatos nesse contexto?;

i) tratamento inadequado das colocações: consultamos em nosso corpus as colocações apresentadas na entrada acima e verificamos que, à exceção de room service, bastante recorrente, e room number, com duas ocorrências, nenhuma delas está presente no corpus. Ou seja, apesar de incluir algumas colocações, essas não são frequentes no domínio e parece-nos que não há um critério definido para determinar a inserção das colocações. Ademais, não são consideradas as colocações de room com outras classes gramaticais, como verbos, adjetivos e advérbios, informações importantes para auxiliar na produção textual que caracteriza o ato tradutório.

Essa breve análise nos permite afirmar que tal obra não é eficiente para a atividade tradutória por não apresentar os elementos necessários para que o tradutor realize sua tarefa primordial de produzir um texto preciso e natural na língua de chegada. Em alguns momentos, o dicionário chega a prestar um desserviço ao tradutor, fornecendo sugestões errôneas ou deixando de propor o equivalente mais adequado. Constata-se que tal obra, apesar de ser um dicionário bilíngue, tem o foco no profissional ou estudante da área de turismo, provavelmente interessado apenas em 
conhecer o significado das palavras em inglês, o que em si é certamente importante, mas insuficiente para auxiliar na tradução. Infelizmente, pela escassez de obras terminológicas mais adequadas, essa publicação acaba chegando às mãos do tradutor.

Teixeira (2008:i) corrobora nossa conclusão no contexto da Culinária:

"Os dicionários sempre foram e ainda são uma das principais ferramentas da tarefa tradutória. No entanto, a terminografia parece não ter se beneficiado ainda de forma sistemática, pelo menos no Brasil, da estreita relação entre dicionários técnicos e esse público-alvo específico e cada vez mais expressivo: os tradutores técnicos. $\mathrm{Na}$ área da Culinária, por exemplo, (...) os dicionários disponíveis no par de línguas inglês-português (...) não dão qualquer informação sobre como os termos são, de fato, usados em textos reais na área, ou seja, não auxiliam o tradutor numa etapa fundamental da atividade tradutória: a produção textual na língua de chegada."

Em virtude da escassez e deficiência dos materiais de referência, não é de se estranhar que muitas traduções resultem problemáticas. Uma breve análise das traduções para o inglês nos sites de hotéis brasileiros demonstrou que a maior parte dos problemas de tradução está relacionada não apenas à escolha do termo técnico mas à de seus colocados mais adequados e à estrutura mais usual na língua de chegada. Assim, a linguagem que deveria ser um veículo de promoção do estabelecimento acaba conferindo a ele uma imagem negativa diante dos potenciais clientes. Veja-se o seguinte exemplo concreto: 


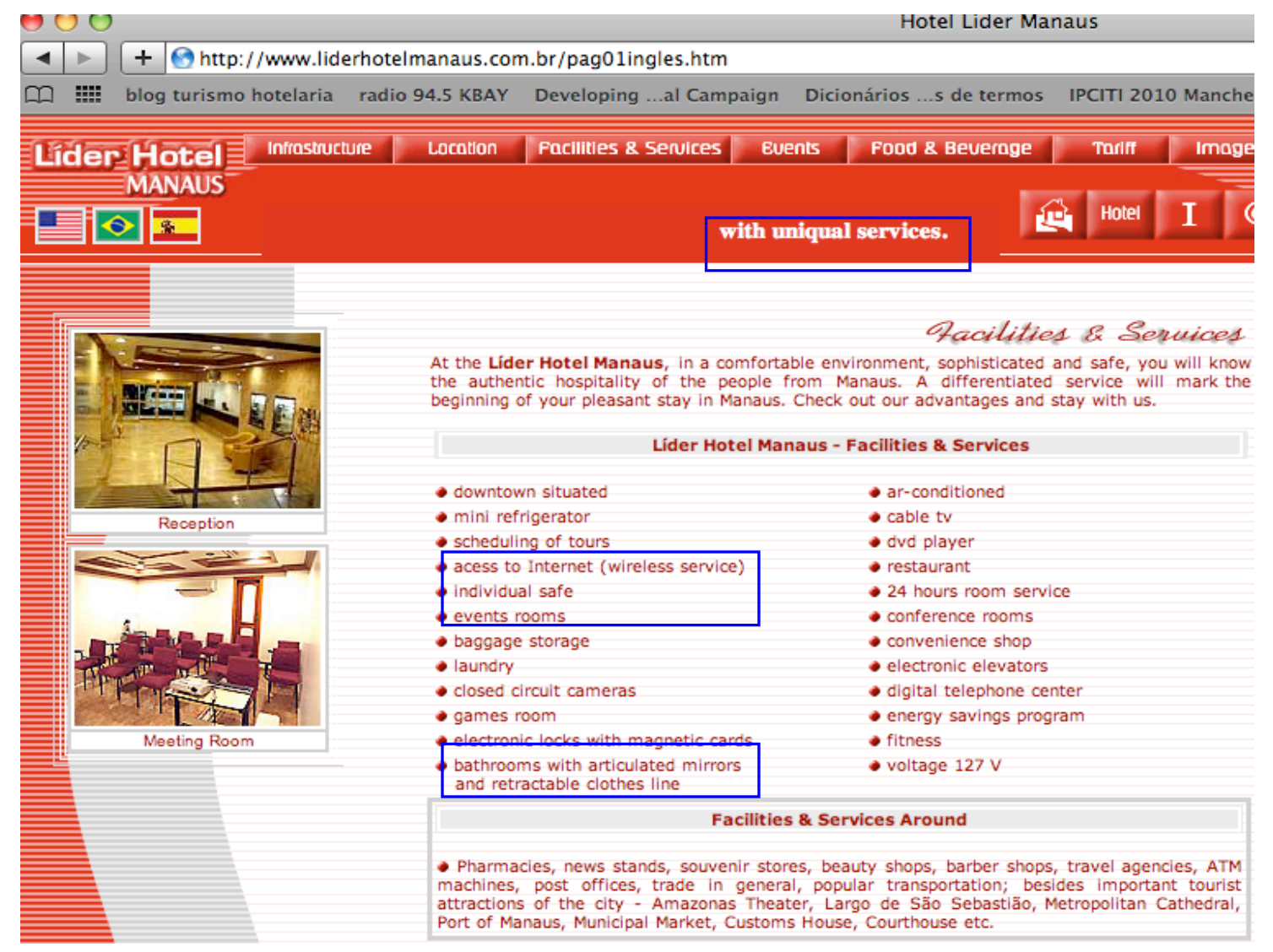

Figura 3 - Site em inglês do Hotel Líder, de Manaus.

Analisamos algumas das traduções acima à luz do corpus de estudo construído para esta pesquisa. Primeiramente, a chamada with uniqual services traz uma colocação adjetiva inexistente no corpus, onde verificamos unparalleled services como uma opção mais provável. A estrutura access to Internet (wireless service) tampouco foi encontrada, sendo wireless Internet access o padrão mais recorrente. Da mesma forma, o corpus não contém individual safe e events room, mas identificamos in-room safe e function room como alternativas de tradução. Por fim, articulated mirror, no contexto de um banheiro de hotel, teria como equivalente mais recorrente make-up mirror. Tais exemplos foram retirados do site de um hotel que se identifica como "o número 1 no ranking de operação de eventos de diferentes setores e serviços para turistas de todas as nacionalidades". Ou seja, a tradução tem como finalidade atrair clientes estrangeiros para que realizem eventos e se hospedem no hotel. No entanto, as inadequações na linguagem podem impactar negativamente tal objetivo. 
Para produzir um texto na língua de chegada que seja preciso e natural, ou seja, que possa ser lido como original (Fishback, 1998: 2 apud Byrne, 2006: 4-5), o tradutor necessita conhecer não só os conceitos e termos da área, mas suas convenções linguísticas. Assim, materiais de apoio ao tradutor mais completos e úteis devem trazer em seus verbetes informações como:

- equivalentes ou sugestões de tradução;

- exemplos de uso (contexto);

- padrões linguísticos e textuais;

- colocações;

- informações relativas à frequência de uso em caso de sinonímia;

- alertas para possíveis problemas de tradução;

- dados culturais da área técnica envolvida.

A fim de realizar uma investigação linguística que contemple todos os aspectos destacados acima, esta pesquisa encontra subsídios teóricos nas áreas de Linguística de Corpus, Terminologia e ainda nos estudos de Convencionalidade e Fraseologia. Esse assunto será tratado no capítulo de Fundamentação Teórica, que se segue. 


\section{Capítulo 2 - Fundamentação teórica}

O objetivo deste capítulo é fornecer um panorama do referencial teórico utilizado para fundamentar nossa pesquisa. Em linhas gerais, os seguintes tópicos serão tratados:

- Linguística de Corpus;

- Linguística de Corpus e Convencionalidade;

- Linguística de Corpus, Tradução e Terminologia;

- Terminologia Textual;

- As colocações;

- Os dicionários e as colocações.

\subsection{Linguística de Corpus}

Apesar de o termo Linguística de Corpus ser uma designação moderna, sua história é bastante antiga.

Importantes estudos com corpora - inicialmente, um conjunto de registros dos enunciados de uma língua coletados manualmente - já eram realizados ainda no século XIX. Na área de aquisição da linguagem, estudos de Preyer de 1889 investigavam as falas das crianças por meio de diários registrados pelos pais. Em 1897, Käding utilizou um corpus contendo incríveis 11 milhões de palavras para investigar a ortografia do alemão. Já no século XX, linguistas como Fries e Traver, em 1940, e Bongers, em 1947, realizavam estudos com corpora em pedagogia da língua estrangeira, fornecendo o embrião para a utilização de listas de vocabulário derivadas de corpora no ensino de língua estrangeira (McEnery \& Wilson, 2001: 3-4).

Guardadas as diferenças metodológicas e de enfoque, esses exemplos demonstram que os estudos empíricos com corpora constituem uma prática antiga. No 
entanto, o desenvolvimento da Linguística de Corpus perde o fôlego por volta do final da década de 50. Nos vinte anos que se seguiram, o uso de corpus como fonte de dados passou por uma fase de impopularidade. Esse período coincide com o aparecimento de Syntactic Structures de Chomsky (1957).

A teoria chomskyana provocou uma mudança de paradigma nos estudos linguísticos da época. Preocupado em verificar modelos que representassem a habilidade mental de fala e o processamento cognitivo da linguagem, Chomsky praticamente invalidou o uso de corpora como fonte de evidência na pesquisa linguística. Seu argumento era que o linguista deveria fazer um modelo da competência (conhecimento internalizado) e não do desempenho linguístico (evidência externalizada). Entrava em cena, assim, uma visão racionalista da linguagem, cujos estudos se fundamentavam na introspecção, ou seja, em observações artificiais e na intuição do linguista.

O apelo da teoria chomskyana aliado a outras críticas de ordem pragmática aos trabalhos com corpora - como a dificuldade de processamento manual de grandes quantidades de palavras, a alta probabilidade de erro e a falta de consistência nos trabalhos que exigiam equipes enormes - contribuíram para a falta de popularidade dos estudos de base empírica. De fato, os linguistas necessitavam de capacidades de processamento de dados que simplesmente não estavam disponíveis na época. Com o advento dos computadores, esse cenário começou a se reverter.

Dispondo de uma poderosa capacidade de armazenamento, memória e manipulação de dados, os computadores pessoais ajudaram a impulsionar uma nova revolução nos estudos linguísticos a partir dos anos 80 . O impacto da informática nas ciências humanas é comparado ao papel transformador do telescópio na física e ciências exatas (Stubbs, 1996). A idealização linguística passa a dar lugar à primazia das evidências empíricas, agora muito mais confiáveis e contundentes, fornecidas pelos corpora eletrônicos, "questionando assim paradigmas estabelecidos e mostrando novos caminhos ao linguista, ao professor, ao tradutor e muitos outros profissionais" (Berber Sardinha, 2004: XVII). Esse momento marca o ressurgimento de uma nova perspectiva da linguagem, na qual fundamentamos nossa pesquisa.

Em oposição a uma visão racionalista, a Linguística de Corpus baseia-se em uma abordagem empirista da linguagem (Halliday, 1991), ou seja, seu foco está no desempenho, na observação da evidência, na linguagem atestada por meio de exemplos 
reais extraídos de um corpus. Ainda nesse sentido, essa visão considera a língua como um sistema probabilístico. Isso significa dizer que embora muitos traços linguísticos sejam possíveis teoricamente, eles não ocorrem com a mesma frequência (Halliday, 1991). Em outras palavras, inúmeras estruturas linguísticas são possíveis (retomemos o exemplo de access to internet, wireless service), mas algumas são mais prováveis que outras (wireless internet access), formando padrões lexicais.

Assim, partimos de uma visão de que a linguagem é padronizada. E o mais importante, a frequência desses padrões não se dá de forma aleatória, mas apresenta regularidade e variação sistemáticas, que, por sua vez, estão intimamente relacionadas ao contexto comunicativo (Biber, 1988).

Firth (1957) enfatiza a relevância do contexto para a identificação do significado de um enunciado. $\mathrm{O}$ autor argumenta que os seres humanos se comportam de maneira sistemática e que os eventos linguísticos e papéis desempenhados pelos participantes em determinada situação influenciam a linguagem, por isso, cada enunciado deve ser considerado em seu contexto real. Tal entendimento da linguagem influencia a forma como ela é estudada: "Se a linguagem é sistêmica, o linguista pode identificar cientificamente as características dos eventos linguísticos recorrentes e classificá-las”4 (Firth 1950: 178 apud Manca 2008: 372).

Sinclair considera o contexto a partir da perspectiva linguística. Nos dizeres do autor, "as palavras estabelecem relações significativas umas com as outras"5 (1996: 75). Ou seja, o significado de uma palavra é influenciado e determinado pelas palavras com as quais co-ocorre. Analisando os padrões de co-ocorrência na linguagem, Sinclair identificou unidades pré-fabricadas, ou blocos de linguagem, que são selecionadas pelo falante em determinado contexto como um agrupamento indivisível. Essa perspectiva se concretizou como o idiom principle ${ }^{6}$ (princípio idiomático), que forma a base da tendência fraseológica da linguagem: as palavras tendem a agrupar-se e a construir significado por meio da combinação.

Esse e os demais princípios elencados acima fundamentam e norteiam todo o desenvolvimento de nossa pesquisa. Por fim, para a realização de uma investigação

\footnotetext{
${ }^{4}$ If language is systemic, the linguist may scientifically identify the features of the repeated linguistic events and classify them. [doravante, todas as traduções são de nossa autoria]

${ }^{5}$ Words enter into meaningful relations with other words around them.

${ }^{6}$ Esse princípio será retomado e exemplificado mais adiante, no item 2.5.1.
} 
linguística pautada nessa perspectiva da linguagem, é imprescindível a utilização de um corpus que represente a linguagem em uso. O corpus é, portanto, o assunto tratado a seguir.

\subsubsection{Corpus e sua tipologia}

Conforme mencionamos anteriormente, as pesquisas linguísticas de base empírica baseiam-se na observação de dados autênticos extraídos de um corpus. Um corpus é um conjunto de textos; todavia, no contexto da LC, essa definição passou a ter um significado mais especializado:

\footnotetext{
Um conjunto de dados linguísticos (pertencentes ao uso oral ou escrito da língua, ou a ambos), sistematizados segundo determinados critérios, suficientemente extensos em amplitude e profundidade, de maneira que sejam representativos da totalidade do uso linguístico ou de alguns de seus âmbitos, dispostos de tal modo que possam ser processados por computador, com a finalidade de propiciar resultados vários e úteis para a descrição e análise (Sanchez e Cantos, 1996: 8-9 apud Berber Sardinha, 2004: 18).
}

A definição acima aborda critérios que vão especificar a tipologia do corpus. Para os fins desta pesquisa, elegemos a tipologia proposta por Berber Sardinha (2004: 20 ), por incluir os principais tipos citados na literatura.

Os corpora podem ser classificados de acordo com:

\section{1. modo}

a. falado: composto por porções de fala transcritas;

b. escrito: compostos por textos escritos, impressos ou não;

\section{2. tempo}

a. sincrônico: compreende um período de tempo;

b. diacrônico: compreende vários períodos de tempo;

c. contemporâneo: representa um período de tempo corrente;

d. histórico: representa um período de tempo passado;

\section{3. seleção}


a. amostragem: composto por porções de textos ou de variedades textuais, planejado para ser uma amostra finita da linguagem como um todo;

b. monitor: a composição é atualizada para refletir o estado atual de uma língua;

c. dinâmico: o crescimento ou diminuição são permitidos, qualifica o corpus monitor;

d. estático: oposto de dinâmico, qualifica o corpus de amostragem;

e. equilibrado: os componentes (gêneros, textos, etc.) são distribuídos em quantidades semelhantes;

\section{4. conteúdo}

a. especializado: os textos são de tipos específicos (gênero ou registros definidos);

b. regional ou dialetal: os textos são provenientes de uma ou mais variedades sociolinguísticas específicas;

c. multilíngue: inclui idiomas diferentes;

\section{5. autoria}

a. de aprendiz: os autores dos textos não são falantes nativos;

b. de língua nativa: os autores são falantes nativos;

\section{6. finalidade}

a. de estudo: o corpus que se pretende descrever;

b. de referência: usado para fins de contraste com o corpus de estudo;

c. de treinamento ou teste: construído para permitir o desenvolvimento de aplicativos e ferramentas de análise. ${ }^{7}$

Em relação à disposição interna, adotamos a classificação de corpus apresentada por Tognini-Bonelli (2001: 6-7):

a. comparável: formado por textos originais em ambas as línguas, compilados de acordo com os mesmos critérios;

b. paralelo: formado por textos originais e suas respectivas traduções;

c. de tradução: composto apenas por textos traduzidos.

\footnotetext{
${ }^{7}$ A tipologia do nosso corpus de estudo encontra-se descrita na seção 3.1.1.
} 
Berber Sardinha (2004: 22-26) discute ainda outros dois critérios que devem ser atentados na compilação de um corpus: tamanho e representatividade.

Quanto ao tamanho, não há consenso acerca do número ideal de palavras em um corpus. Alguns defendem a posição de que quanto maior o corpus, melhor o resultado; outros ressaltam a importância de pequenos corpora altamente especializados. Nossa visão é que o número ideal está intimamente ligado à noção de representatividade e depende da tipologia textual: a terminologia de uma área altamente especializada pode ser estudada de modo eficaz com um número relativamente pequeno de textos; por outro lado, quando trabalhamos com a língua geral, por exemplo, um volume muito maior de palavras é necessário para que se possa fazer afirmações fundamentadas. Esse critério fica a cargo do pesquisador, considerando os objetivos de sua pesquisa.

A representatividade de um corpus está relacionada à noção de amostragem de uma porção da linguagem que se pretende estudar. Uma vez que o número de enunciados de uma língua é teoricamente infinito, seria utópico compilar um corpus com todas as palavras de uma variedade linguística. Por esse motivo, ao compilar um corpus, o pesquisador deve buscar obter uma amostra que forneça a visão mais precisa possível das tendências de uma variedade linguística (McEnery \& Wilson, 2001: 30) ${ }^{8}$.

Para alcançar essa finalidade, há dois enfoques que podem auxiliar o pesquisador: o corpus é representativo do quê e para quem? (Berber Sardinha, 2004: 23). No primeiro caso, deve-se conhecer ao máximo a população da qual a amostragem será derivada e buscar representar seus traços linguísticos o mais adequadamente possível. No segundo, o autor argumenta que "os usuários de um corpus atribuem a ele a função de ser representativo de certa variedade", e acrescenta que "o ônus de demonstrar a representatividade da amostra e de ser cuidadoso em relação à generalização é dos usuários do corpus" (Berber Sardinha, 2004: 25).

Apesar da ausência de critérios mais objetivos, o autor afirma que a representatividade pode ser aferida segundo três dimensões:
a. o número de palavras;
b. o número de textos;
c. o número de gêneros, registros ou tipos textuais.

\footnotetext{
${ }^{8} \mathrm{O}$ tamanho e a representatividade do nosso corpus de estudo serão abordados na seção 3.1.2.
} 
Vale ressaltar ainda outros dois fatores relevantes na compilação de um corpus: o balanceamento e a autenticidade dos textos.

Como o nome sugere, um corpus balanceado apresenta medidas e critérios semelhantes entre as diferentes categorias adotadas. No caso de um corpus comparável bilíngue, por exemplo, deve-se procurar obter um número aproximado de palavras, gêneros, registros, tipos textuais, etc. similar nos dois subcorpora. Na prática, contudo, um balanceamento exato nem sempre é possível em função das diferenças intrínsecas a cada gênero textual e realidade cultural sendo representadas. ${ }^{9}$ Mais uma vez, fica a critério do pesquisador determinar qual o melhor balanceamento para atender os objetivos de seu estudo.

O critério de autenticidade dos textos vai ao encontro do objetivo de investigar a linguagem real em uso. Em outras palavras, os textos que compõem o corpus devem ter sido produzidos em situações reais de comunicação, sem a finalidade de servirem à pesquisa linguística. Por exemplo, em nossa investigação da linguagem da hotelaria, optamos por compilar textos escritos para descrever estabelecimentos hoteleiros reais, daí considerarmos o material autêntico.

Por fim, uma vez compilado o corpus, respeitando todos os aspectos discutidos acima, ele se presta à análise linguística. As evidências empíricas fornecidas pelo corpus podem ser exploradas a partir de diferentes perspectivas, que determinam o status da LC.

\subsubsection{Status da LC e tipos de abordagem}

Não há consenso na literatura em relação à classificação da LC: ela deve ser considerada uma disciplina, uma metodologia ou uma abordagem?

Berber Sardinha (2004: 35) argumenta que a LC não constitui uma disciplina por não possuir um objeto de estudos delimitado como outras áreas, a exemplo da psicolinguística ou da semântica. O autor acrescenta que a LC investiga fenômenos pertencentes a outras áreas, como léxico e sintaxe. Na mesma direção, McEnery e Wilson (2001: 2) também não a consideram um ramo da linguística, como a sintaxe, a

\footnotetext{
${ }^{9}$ Os critérios definidos para o balanceamento e seleção dos textos de nosso corpus serão descritos na seção 3.1.2.
} 
semântica ou a sociolinguística, pois essas disciplinas concentram-se em descrever/explicar determinados aspectos da linguagem em uso.

McEnery e Wilson (2001: 2) consideram a LC apenas uma metodologia, pois ela não se ocupa da explicação ou descrição de aspectos da linguagem. Por outro lado, outras disciplinas da linguística podem adotar ou não abordagens baseadas em corpus, como a sintaxe, a semântica e a pragmática. Nesse ponto, entende-se metodologia como um instrumental, mantendo a orientação teórica da disciplina original.

Compartilhamos, contudo, da posição descrita por Berber Sardinha (2004: 36) segundo a qual a LC não se resume a um conjunto de ferramentas, mas representa "um modo típico de aplicar um conjunto de pressupostos teóricos". Além disso, seus achados muitas vezes não se encontram no escopo de nenhuma outra disciplina, a exemplo dos estudos de colocação entre itens lexicais, precisamente o objeto deste trabalho.

Hoey (1997), Leech (1992) e Quirk (1985 apud Berber Sardinha 2004: 37) advogam a favor da LC como uma abordagem, ou seja, trata-se de uma perspectiva para se chegar à linguagem, uma nova empreitada de pesquisa e uma nova abordagem filosófica. Biber (1988) refere-se à LC como uma abordagem baseada em corpus, o que leva a entendê-la ora como metodologia, ora como abordagem. Para os fins desta pesquisa, consideramos a LC uma abordagem, isto é, um instrumental a serviço de uma nova forma de estudar a língua pautada em uma visão probabilística e empírica.

A literatura diferencia também entre dois tipos de abordagens nas pesquisas realizadas com corpora: a abordagem baseada em corpus e a abordagem direcionada pelo corpus (Tognini-Bonelli, 2001). No primeiro caso, o corpus é utilizado para explicitar, testar, exemplificar teorias e hipóteses pré-existentes e para extrair exemplos. Parte-se, portanto, de um conhecimento prévio que é validado ou não por meio do corpus. Diferentemente, no segundo caso, o linguista utiliza o corpus sem formulações preestabelecidas. Os dados do corpus guiam o pesquisador na formulação de hipóteses e generalizações.

Por não considerar as duas abordagens excludentes, mas complementares, adotamos em nossa pesquisa um posicionamento híbrido. A abordagem direcionada pelo corpus fica evidente, por exemplo, quando partimos das palavras-chave ${ }^{10}$ do corpus para identificar os candidatos a colocações para o glossário. Por outro lado, a

\footnotetext{
${ }^{10}$ Mais detalhes sobre a metodologia serão fornecidos no capítulo seguinte.
} 
abordagem baseada em corpus é adotada quando selecionamos o melhor exemplo de uma colocação para compor o verbete ou quando partimos de uma tradução prima facie baseada em nosso conhecimento prévio da terminologia da área para identificar os equivalentes.

Independentemente da abordagem utilizada, é fato que a exploração eletrônica dos corpora facilitou sobremaneira a observação das recorrências de combinações de palavras, contribuindo significativamente para a prática léxico-terminográfica.

Por sua vez, a investigação desses padrões de recorrência na língua insere-se nos estudos de Convencionalidade.

\subsection{LC e Convencionalidade}

A convencionalidade na língua está associada ao uso que os falantes de uma comunidade fazem de convenções, expressões e blocos de palavras já preestabelecidos e consagrados. Tal noção de convenção aplica-se tanto ao nível social - quando dizer algo - quanto ao nível linguístico - como dizer algo. Por exemplo, na noite de Natal é costume cumprimentarmos as pessoas com a expressão Feliz Natal em português. Já em inglês, diz-se Merry Christmas. Mas por que não se diz Merry New Year para desejar Feliz Ano Novo em inglês? Porque não é assim que se convencionou a expressão (Tagnin, 2005).

O termo convencionalidade foi empregado por Fillmore (1979) para designar o conjunto dos elementos linguísticos cuja co-ocorrência não é explicada sintática ou semanticamente, mas sim pelo uso. O conhecimento dessas unidades convencionais está intimamente relacionado à noção de fluência na língua (Fillmore, 1979).

A Convencionalidade e a LC guardam estreita relação, pois compartilham a mesma visão da linguagem como sistema probabilístico - inúmeras combinações são gramaticalmente possíveis, mas algumas são mais prováveis, mais convencionais, do que outras. Assim, a convencionalidade manifesta-se pelos padrões linguísticos, o modus dicendi. E a LC, por sua vez, oferece uma metodologia que contribui grandemente para a identificação desses padrões na língua, por meio da análise empírica de dados extraídos de um corpus. 
Nossa pesquisa insere-se nos estudos de Convencionalidade por tratar de um tipo específico de padrão linguístico: as colocações, "casos de co-ocorrência sintática, ou as palavras que usualmente andam juntas" (Tagnin, 2005: 37). Podemos citar um exemplo esclarecedor dessa relação no contexto da hotelaria. Em inglês, costuma-se utilizar a colocação complimentary breakfast para designar o café da manhã servido como cortesia aos hóspedes. Em português, o usual é dizer café da manhã incluído (na diária). Ou seja, apesar de café da manhã de cortesia (nenhuma ocorrência no corpus) ser possível, café da manhã incluído (na diária) é a forma convencional.

Tagnin (1989) esclarece que existem diversos níveis de Convencionalidade, quais sejam, o sintático, o semântico, o pragmático, o fonológico e o morfológico. Esta pesquisa se ocupa do primeiro deles, que "compreende a combinabilidade dos elementos, sua ordem e sua gramaticalidade" (Tagnin, 2005: 17). Por combinabilidade, entende-se a faculdade que os elementos linguísticos têm de se associar naturalmente, sendo essa associação consagrada pelo uso, como, por exemplo, velha coroca e hermeticamente fechado. A ordem dos elementos também pode ser fruto de convenção, como em cama, mesa e banho, ou no contexto da hotelaria, apartamentos e suites. Por fim, a gramaticalidade refere-se às expressões consagradas cuja combinação dos elementos não pode ser explicada gramaticalmente, como em de quando em vez (Tagnin, 2005: 17-18).

Conhecer e empregar adequadamente as unidades convencionais da língua é desejável para o tradutor na sua condição de produtor de textos. Isso porque "caso o tradutor selecione uma das formas [combinações] possíveis, em detrimento da mais provável, produzirá uma tradução não natural, não fluente” (Tagnin, 2003: 193). Assim, esse profissional pode beneficiar-se muito de um respaldo prático pautado nos princípios da Convencionalidade. Nesse ponto, os estudos em LC e Terminologia têm muito a contribuir para a atividade tradutória no sentido de disponibilizar ao tradutor um suporte referencial terminológico que contemple as unidades convencionais da língua.

Outros aspectos da relação entre a LC, a Tradução e a Terminologia serão tratados a seguir. 


\subsection{LC, Tradução e Terminologia}

O objetivo de nossa pesquisa é elaborar uma proposta de glossário bilíngue de colocações da hotelaria, para tradutores, à luz da LC. Assim, nossa proposta faz interface com essas três áreas: LC, Tradução e Terminologia.

Conforme mencionamos anteriormente, o uso de corpora revolucionou os estudos linguísticos, com grande influência nas áreas de Tradução e Terminologia. Isso porque os corpora constituem um rico reservatório de dados, o que, aliado a novas capacidades tecnológicas, abriu novos caminhos ao pesquisador.

$\mathrm{Na}$ Tradução, os estudos com base em LC configuram uma das linhas de pesquisas mais atuantes (Berber Sardinha, 2004: 235), com aplicações nas áreas teórica e prática (Hunston, 2002: 123).

Em termos teóricos, podemos destacar o uso de corpora para a investigação de questões como equivalência, normalização, criatividade (Berber Sardinha, 2004: 236), processos, metodologias, abordagens, preferências e normas de tradução (Hunston, 2002: 123).

No que diz respeito à prática, os diferentes tipos de corpora vêm somar-se aos recursos disponíveis ao tradutor (Hunston, 2002). Por exemplo, corpora paralelos (originais e traduções) constituem fonte para identificação de equivalentes tradutórios ou de soluções para problemas de tradução; corpora comparáveis (textos originais de um assunto afim em diferentes idiomas) possibilitam igualmente a identificação de equivalentes tradutórios e ainda fornecem acesso a informações relacionadas a padrões linguísticos e expressões convencionais, compensando até mesmo a escassez de obras termino-fraseográficas bilíngues; vale mencionar ainda a grande quantidade de corpora monolíngues on-line ou a própria Web à disposição do tradutor. Em suma, dado o corpus adequado e as ferramentas de análise apropriadas, as possibilidades de pesquisas são bastante variadas e as chances de obter sucesso vão depender apenas da habilidade do usuário (Varantola, 2002 apud Orenha-Otainno, 2008: 148).

Tanto em termos teóricos como práticos, as pesquisas em tradução baseadas em LC influenciaram a noção de equivalência, questão central em nossa pesquisa de cunho terminológico. O conceito predominantemente estático de equivalência, entendida como correspondência formal de estruturas semânticas e sintáticas, perdeu lugar para a noção 
dinâmica de equivalência funcional entre o texto de partida e o de chegada (Laviosa, 2002: 18).

A noção de equivalência funcional de Laviosa está associada ao conceito de equivalência pelo contexto (equivalence in context), proposta por Chesterman (1998: 31). Sob essa ótica, os correspondentes devem cumprir o mesmo papel, dentro do mesmo contexto, entre os dois idiomas. É essa perspectiva de equivalência que adotamos para nossa pesquisa, pois ela amplia o conceito para além da fórmula "palavra $\mathrm{x}=$ palavra $\mathrm{y}^{\prime \prime}$, refletindo mais corretamente a complexidade da correspondência terminológica. $O$ objetivo passa a ser, portanto, aproximar contextos e não simplesmente termos. Vale mencionar mais uma vez o exemplo de complimentary breakfast, cujo equivalente funcional em português é café da manhã incluido [na diária].

Cotejar cuidadosamente o contexto permite estender as considerações para além das questões linguísticas e lança luz sobre a dimensão cultural, tão relevante para o ato tradutório. Essa abordagem está em consonância com a visão de que a tradução não opera exclusivamente entre códigos (Azenha, 1999: 22), mas se realiza no interior e através da linguagem, que "deve ser vista como um elemento integrante de uma cultura, como uma de suas manifestações mais poderosas, e não como um fenômeno desatrelado de uma realidade extralinguística" (Snell-Hornby, 1988: 39 apud Azenha, 1999: 28). Nos dizeres de Azenha (1999: 12), "a tradução de textos técnicos, para além dos domínios da terminologia, estabelece uma intersecção com os estudos culturais, cujas contribuições podem ser úteis para a fundamentação objetiva da estratégia de trabalho adotada na tradução."

Em nossa pesquisa, os aspectos culturais atinentes ao âmbito da hotelaria exerceram influência marcante, desde a estruturação do corpus até a escolha por um equivalente terminológico propriamente dito. $\mathrm{O}$ ato de hospedar-se em um hotel é o mesmo no Brasil ou nos EUA, mas os tipos de hotéis, os serviços, as políticas, as especificidades históricas e geográficas e, por que não dizer, as expectativas dos hóspedes, apresentam variações entre culturas, evidenciadas também pelos padrões linguísticos. Para citar um exemplo concreto, constatamos o uso recorrente da colocação one night's room and tax no corpus, utilizada para designar o tipo de cobrança pela garantia ou cancelamento de reserva; nesse caso, o valor de uma diária, mais impostos. $\mathrm{Na}$ busca pelo equivalente em português, verificamos que, para os casos de garantia ou 
cancelamento de reservas, ou seja, o mesmo contexto da colocação em inglês, o tipo de cobrança predominante é diferente - a política de muitos hotéis no Brasil é cobrar uma porcentagem sobre o valor total da estadia ${ }^{11}$.

Em vista da constatação acima, nossa proposta de glossário prevê a inclusão de aspectos linguísticos (colocações e seus equivalentes) e extralinguísticos (notas culturais, notas ao tradutor), fornecendo assim um repertório terminológico abrangente para apoiar a prática tradutória.

Essa empreitada só é possível graças ao uso da metodologia proposta pela LC. Conforme já mencionamos, a LC possui uma interface com a Terminologia. É o que discutiremos a seguir.

Diversos corpora são compilados para fins terminológicos e prestam-se eminentemente à descrição da linguagem. Este é um ponto crucial de confluência entre a LC e a Terminologia: ambas compartilham o caráter descritivo da linguagem, aspecto que ganhou ímpeto com os avanços tecnológicos dos últimos anos. De fato, a descrição da linguagem a partir da análise de um corpus com vistas à elaboração de dicionários é uma atividade bastante comum nas pesquisas com LC e na prática lexicográfica - todos os grandes dicionários em inglês atuais são feitos com base em LC (Berber Sardinha, 2004: XVIII).

No que tange a terminografia bilíngue, objeto de nossa pesquisa, Fonseca (2007: 54) discute a adequação de corpora paralelos para essa atividade. Nesse caso, o corpus é constituído de originais e traduções, e a partir delas são extraídos os equivalentes. Apesar de útil, acreditamos que esse tipo de corpus apresenta um conteúdo sujeito a variáveis incontroláveis capazes de comprometer sua qualidade e influenciar a confiabilidade do produto terminológico. Por conseguinte, corpora comparáveis se prestam melhor à função de refletir a ótica da LC sobre a linguagem, "trazendo noções como as de colocação, autenticidade, naturalidade e frequência, que podem exercer influência substancial sobre a escolha do paradigma da forma equivalente" (Fonseca, 2007: 54). Esse posicionamento justifica a construção de um corpus comparável para os fins de nossa pesquisa.

\footnotetext{
${ }^{11} \mathrm{O}$ estabelecimento desse equivalente está detalhado na seção 4.1.25.
} 
Por fim, gostaríamos de tecer alguns comentários sobre a relação entre a Terminologia e a Tradução, porquanto o tradutor é o público almejado para o produto terminológico que propomos.

A relação entre tradução especializada e terminologia é evidente e inevitável, apesar de esse ser um tema ainda recente e pouco estudado (Cabré, 1999: 177).

A partir de uma perspectiva mais ampla, Cabré destaca quatro pontos em comum nessa relação: primeiramente, ambas as áreas se caracterizam por uma larga tradição aplicada, em comparação a um caráter disciplinar bastante recente. Além disso, constituem campos interdisciplinares, nos quais confluem as ciências cognitivas, da linguagem e da comunicação. Outro ponto em comum é a motivação para o surgimento das áreas: a necessidade de expressar um pensamento especializado ou de resolver um problema de compreensão. Por fim, as duas áreas se propõem a avançar na reafirmação de seu caráter como disciplina (Cabré, 1999: 178).

Sob uma ótica mais aplicada, tradução e terminologia compartilham um objeto comum: o texto técnico (Krieger e Finatto, 2004: 66), o qual utilizaremos como ponto de comparação para estabelecer a relação entre essas áreas.

A tradução técnica realiza-se a partir do texto técnico, cujo elemento constitutivo importante é o léxico especializado. Em outras palavras, traduzir texto técnico é deparar com terminologia. Assim, a Tradução volta seu olhar à terminologia no momento em que aos tradutores interessa um manejo terminológico competente para realizar uma tradução de qualidade. Pode-se afirmar, portanto, que a Terminologia é imprescindível para a tradução na medida em que exerce um papel de suporte à boa prática tradutória.

Por sua vez, a prática terminológica parte do texto técnico para extrair as unidades lexicais especializadas. Nesse ponto, "a face aplicada da Terminologia direciona seu olhar para a tradução na medida em que se ocupa da elaboração de glossários, dicionários técnicos e bancos de dados bi ou multilingues" (Krieger e Finatto, 2004: 68). Ou seja, a Terminologia dialoga com a tradução ao preocupar-se com a busca e escolha de equivalências terminológicas (Krieger 2010: 172).

O exposto acima permite inferir que os tradutores estão presentes nos dois espectros dessa relação - de um lado, demandam um suporte referencial terminológico, e de outro, motivam a produção desses materiais. Dessa maneira, os tradutores integram o grupo de usuários por excelência das terminologias (Aubert, 1996: 14 apud Krieger e 
Finatto, 2004: 70), em especial as bilíngues. Daí nosso interesse em delimitar esse público-alvo para o produto terminológico que propomos.

Após essa breve descrição da interação que a Terminologia faz com a LC e com a Tradução, trataremos de sua conceitualização mais detalhadamente na seção a seguir.

\subsection{Terminologia: histórico e conceitualização}

O emprego de termos técnico-científicos para denominar e transmitir os saberes especializados é uma prática antiga. Em contrapartida, o estabelecimento de um campo de estudos dedicado aos termos técnico-científicos é mais recente, situando-se na segunda metade do século XX. A terminologia comporta, portanto, uma feição dupla, indicando tanto o conjunto de termos próprios a uma área científica e ou técnica, bem como o campo de estudos teóricos e metodológicos cujo objeto central é o sistema denominativo das ciências e técnicas (Krieger e Finatto, 2004).

O desenvolvimento desse campo de estudo está relacionado ao acelerado avanço da ciência e da tecnologia nos últimos tempos, o que, por sua vez, acarreta uma profusão e a consequente proliferação de termos técnico-científicos no âmbito da comunicação humana. Além disso, a história da terminologia está associada à consciência sobre a importância do processo denominativo e o papel das terminologias na fixação e circulação do saber especializado, como se pode depreender do pensamento exposto a seguir:

Para os especialistas, a terminologia é o reflexo formal da organização conceitual de uma especialidade, e um meio inevitável de expressão e comunicação profissional. (Cabré, 1993: 37 apud Krieger e Finatto, 2004: 17)

O léxico especializado exerce, portanto, duas funções essenciais: a de denominação e de transmissão do conhecimento especializado; é tanto o elemento constitutivo da produção do saber, quanto o recurso de expressão linguística que permite a univocidade comunicacional. Está, portanto, vinculado à prática e ao desenvolvimento do saber técnico e científico.

Ante a multiplicação e diversidade de novos conhecimentos técnicos, surge a preocupação em garantir a univocidade dos intercâmbios internacionais e, portanto, 
interlinguísticos sobre os temas técnicos e com repercussões econômicas (Cabré, 2010: 367). Nesse contexto, Eugen Wüster, engenheiro austríaco considerado o fundador da terminologia, reconhece a necessidade de normalização das denominações para os fins comerciais e produz o dicionário Machine Tool, em 1968, uma compilação dos termos sobre máquinas e ferramentas em diversas línguas (Cabré, 2010: 368). Nascia assim a atividade que viria a ser conhecida como normalização terminológica.

\section{Teoria Geral da Terminologia}

As proposições de Wüster resultaram na Teoria Geral da Terminologia (TGT), em torno da qual se desenvolveu a Escola de Viena, na década de 1960. Essa teoria visava à padronização e precisão terminológica no intuito de assegurar a perfeita comunicação científica em todo o mundo e objetivava unificar os métodos de trabalho em terminologia (Cabré, 2010: 367).

A Escola de Viena, assim como as demais escolas clássicas de Terminologia - a de Praga e a Russa -, caracterizava-se pela valorização da dimensão cognitiva dos termos, prevalecendo uma perspectiva terminológica normativa. Assim, seus estudiosos preocupavam-se em estabelecer diretrizes para o trabalho terminológico, segundo o princípio de que os termos são denominações de conceitos. Partem, portanto, de uma atitude onomasiológica e monossêmica, ou seja, a cada conceito corresponderia uma única denominação, um único termo. Em consequência dessa visão, os termos não são considerados elementos naturais das línguas naturais, mas são identificados por meio de rótulos ou etiquetas denominativas, estando isentos das ambiguidades do léxico comum (Krieger e Finatto, 2004).

É reconhecida a inegável contribuição da TGT para o estabelecimento da identidade da Terminologia e por suas reflexões em relação ao termo. No entanto, seus fundamentos foram fortemente contestados pelos teóricos posteriores, particularmente em relação aos seus postulados prescritivos e normalizadores e ao seu reducionismo diante do funcionamento da linguagem (Cabré, 1999: 69). 


\section{Teorias Sociocomunicativas da Terminologia}

A Terminologia assume um novo direcionamento na última década do século $\mathrm{XX}$, pautado nas pesquisas terminológicas de base linguístico-comunicacional (Krieger e Finatto, 2004: 34). Surge uma nova corrente de estudos cujas "teorias [...] não podem ser consideradas de um só autor ou de um único grupo de terminólogos. Tais teorias configuram-se no contexto de situações políticas e culturais e foram forjadas a partir da contribuição de muitos pesquisadores da linguagem da ciência e da tecnologia" (Maciel, 2010: 397).

As novas proposições criticam diversas insuficiências da Escola Vienense, tais como: a própria finalidade da teoria, que estudava os termos com vistas à normalização denominativa e conceptual; o modo de conceber a unidade terminológica, separando conceito (elemento independente das línguas e de valor universal) e significado (ligado às línguas particulares); o desinteresse pelas estruturas morfológicas, pelos aspectos sintáticos das unidades lexicais, além da supervalorização da função denominativa (Cabré, 1999: 77).

Sob esse novo prisma, estabelece-se a Teoria Sociocognitiva da Terminologia (TST), cujo nome mais representativo é Rita Temmerman. Sua crítica à teoria tradicional está inserida em sua obra Towards a new way of terminology description: The sociocognitive approach, publicada em 2000, na qual questiona "a realidade mentalista do conceito, a rigidez dos sistemas de árvore de domínio, a negação da variação, o desconhecimento das multiplicidades dos falares profissionais e a ausência do funcionamento linguístico dos termos no plano sintático e semântico" (Maciel, 2010: 403). Dentre seus argumentos, está a noção de que "o termo não existe a priori para denominar um conceito preexistente do mundo real, mas é um construto que se instaura no contexto sociocultural da comunicação especializada” (Maciel, 2010: 404). Ou seja, termos e conceitos são indissociáveis do espaço de interação social.

Outra linha de pesquisa que se une à contestação dos fundamentos da TGT é a Teoria Comunicativa da Terminologia (TCT), cujo pioneirismo deve-se a uma série de estudos encabeçados por Maria Teresa Cabré no final da década de 1990.

A crítica da TCT à teoria wüsteriana baseia-se em uma nova maneira de compreender o léxico especializado, considerando: i) sua poliedricidade (os termos integram ao mesmo tempo aspectos linguísticos, cognitivos e sociais); ii) sua dupla 
função (o termo denomina e comunica um conceito/significado); iii) a definição de seus elementos operantes (enfoque no comportamento real do léxico especializado); iv) diversidade de suas aplicações (de acordo com as características pragmáticas da comunicação) (Cabré, 1999a apud Teixeira, 2005:60).

Os fundamentos dessa teoria levam em consideração o comportamento dos léxicos terminológicos no âmbito das comunicações especializadas. A TCT introduz de modo sistemático a perspectiva linguística aos estudos terminológicos ao postular que uma das características do termo é pertencer às línguas naturais, isto é, uma unidade lexical só pode ser considerada um termo levando-se em conta seu uso no contexto comunicativo especializado.

As teorias de base sociocomunicativa reconhecem, portanto, o papel fundamental do contexto, representado pelo texto técnico, para a análise terminológica. Essa abordagem in vivo abre espaço para uma ampliação do escopo da descrição do fenômeno terminológico:

Os contextos linguísticos e pragmáticos exercem um papel fundamental para que a unidade lexical receba estatuto de termo e também explicam a ocorrência de sinonímias e variações nas terminologias especializadas (Krieger e Finatto, 2004: 78).

A abordagem textual é descritiva (analisa-se o funcionamento de unidades lexicais no corpus) e não mais normativa (...). $\mathrm{O}$ objetivo primeiro da Terminologia clássica era a normatização das linguagens técnicas por meio da significação a priori das palavras. Os textos reais, que proliferam e circulam em todas as direções, alterando as fronteiras entre as áreas, questionam esse projeto de, antes de tudo, colocar ordem nos termos. Tal programa de regulação prescritiva é contraditório pelo caráter fundamentalmente aberto dos textos e de seus signos. A constatação da plasticidade do que é dado linguisticamente conduz a uma nova fundamentação de uma "boa prática terminológica" sobre o descritivo (Bourigault e Slodzian, 1999 [2004: 107]).

É no âmbito desse redirecionamento da forma de entender e estudar o léxico especializado, a partir de uma proposta comunicativa e textual, que situamos esta pesquisa.

A ênfase no caráter textual da pesquisa terminológica caracteriza uma perspectiva que se pode chamar de Terminologia Textual, na qual também encontramos subsídios para nossa proposta, pelos motivos que descrevemos a seguir. 


\subsubsection{Terminologia Textual}

A terminologia de orientação linguístico-textual, ou Terminologia Textual, origina-se a partir de estudos germânicos sobre a língua de especialidade e encontra seu marco nos estudos e propostas de Hartwig Kalverkämper (1983 apud Zílio, 2010: 31) e Lothar Hoffmann (1988 apud Zílio, 2010: 31). Como o nome indica, o elemento fundamental para a análise linguística é o texto especializado, entendido em linhas gerais como:

(...) instrumento e, ao mesmo tempo, resultado da atividade comunicativa exercida em relação a uma atividade especializada sócio-produtiva. Compõe uma unidade estrutural e funcional (um todo) formado por um conjunto finito e ordenado de orações sintática, semântica e pragmaticamente coerentes (textema) ou por unidades de valor frasal que correspondem, na condição de signos linguísticos complexos, a enunciados complexos do conhecimento humano e a circunstâncias complexas da realidade objetiva (Hoffmann, 1988 [2004: 86]).

Sob esse prisma, assumir a centralidade do texto significa tirar a ênfase do termo, para considerar os mecanismos linguísticos, textuais e pragmáticos que caracterizam a linguagem de especialidade:

Na visão comunicativa, o texto é o signo linguístico primário, isto é, sob condições normais, a linguagem se realiza apenas a partir dos textos. E isso vale também para o texto especializado. Por isso, deve o texto, e não a palavra ou a frase, figurar como ponto central do estudo sobre linguagens especializadas. $\mathrm{O}$ que são lidos, traduzidos, resumidos e trabalhados são os textos. Todas as outras unidades linguísticas devem ser vistas como seus constituintes, como elementos que mantêm relações diferenciadas entre si, sem as quais a textualidade não se constitui verdadeiramente (Hoffmann, 1988 [2004: 87]).

Em consonância com essa visão, nos importa sobretudo averiguar o que é representativo nos textos. Acreditamos que uma das formas de se lograr isso é por meio do cotejo de suas palavras mais significativas, as quais, no contexto de nossa pesquisa, são as palavras-chave - palavras estatisticamente representativas - do corpus. Nesse 
sentido, nossa pesquisa tem como ponto de partida as palavras-chave, independente de seu estatuto de termo.

Não estamos afirmando que desconsideramos a presença dos termos técnicos em nosso trabalho. De fato, reconhecemos que palavras-chave coincidem muitas vezes com os termos. No entanto, não nos preocupamos em verificar a pertinência de um item lexical a um dado conceito especializado ou em adotar uma definição clássica de termo. Consideramos que a presença significativa de um item lexical no corpus é um critério suficiente para determinar sua investigação.

Esse posicionamento evidencia o papel fundamental que a LC ocupa em nossa pesquisa. É o corpus que aponta o que merece ser investigado e determina os rumos da pesquisa. Isso explica também o grande esforço e rigor aplicados na sua construção definição das categorias, escolha individual de cada texto, balanceamento, etiquetagem -, a fim de garantir a adequada representação do âmbito comunicativo sob investigação e a consequente confiabilidade dos dados e resultados.

Em conformidade com essa perspectiva, temos que:

o conjunto [de] constatações empíricas provoca mudanças profundas na prática terminológica: a atividade de construção de uma terminologia é (...) essencialmente uma análise de corpora textuais (Bourigault e Slodzian, 1999 [2004: 103]).

Tendo situado as bases teóricas que determinam nossa perspectiva para a análise terminológica, partimos agora para uma apresentação do objeto dessa análise: as unidades fraseológicas especializadas, em nossa pesquisa, as colocações.

\subsection{Colocações}

\subsubsection{Conceitualização}

Uma das primeiras pesquisas de que se tem conhecimento envolvendo associações linguísticas com base em corpus data do século XVIII. Trata-se do trabalho do britânico Alexander Cruden, que utilizou a Bíblia como um corpus e elaborou listas de palavras e concordâncias no intuito de demonstrar a consistência entre as diferentes partes dessa obra. A edição de 1769 registra, por exemplo, todos os casos de coocorrência de dry e ground. Posteriormente, obras de autores consagrados, como 
Shakespeare, também foram analisadas dessa forma para fins acadêmicos diversos (Kennedy, 1998: 13).

Na década de 1930, o linguista britânico H. E. Palmer, especialista no ensino da língua inglesa trabalhando no Japão, realizou um levantamento com base em corpus das combinações de palavras frequentes em inglês, trabalho que resultou na descrição de mais de seis mil colocações. Com esse estudo, Palmer concluiu que as colocações eram muito mais frequentes que as palavras simples no vocabulário cotidiano, apontando, assim, para a necessidade de uma reavaliação da natureza do vocabulário (Kennedy, 1998: 108).

No entanto, foi o linguista britânico J. R. Firth que, na década de 1950, deu destaque a esse fenômeno na teoria linguística. Em seu estudo Modes of Meaning (1957), Firth utiliza o termo 'colocação' para designar os casos de co-ocorrência léxicosintática, enfocando a dimensão (ou modo) lexical de significado. O significado oriundo dessa dimensão foi denominado significado por colocação (meaning by collocation).

$\mathrm{O}$ argumento de Firth é que o significado de uma palavra não é fixo e independente, mas está fortemente relacionado ao contexto em que ocorre. Essa concepção de dependência entre as palavras foi resumida em sua famosa frase: "you shall judge a word by the company it keeps" (diga-me com quem andas, e dir-te-ei que palavra és) (Firth, 1957). Isso equivale a dizer que as palavras influenciam e determinam o significado umas das outras mutuamente.

Significado por colocação é uma abstração no nível sintagmático e não implica diretamente uma abordagem conceitual ao significado das palavras. Um dos significados de noite é sua colocabilidade com escura e o de escura, obviamente, é sua colocação com noite. $(1957: 195-196)^{12}$

A tradição firthiana foi desenvolvida por Sinclair. Para esse autor, a noção de colocação alterou o conceito tradicional de palavra como unidade de significado, dando lugar à visão de que as palavras são co-selecionadas e não escolhidas uma a uma. Assim, retomando o exemplo de Firth, em realidade, night não distingue um dos

\footnotetext{
${ }^{12}$ Meaning by collocation is an abstraction at the syntagmatic level and is not directly concerned with the conceptual approach to the meaning of words. One of the meanings of night is its collocability with dark and of dark, of course, collocation with night.
} 
sentidos de dark e vice-versa, mas dark night tem seu próprio significado (Sinclair, 2004: xxi).

Os estudos de Sinclair com corpora representaram, portanto, uma mudança na concepção da linguagem, em especial no tocante à distinção entre o nível gramatical e lexical. Para Sinclair, a divisão entre esses níveis é arbitrária: "[...] um modelo de linguagem que separa a gramática do léxico e que utiliza a gramática para fornecer uma cadeia de pontos de escolhas lexicais é um modelo secundário" (1987: 324) ${ }^{13}$. Em outras palavras, o autor questiona a visão predominante de que o léxico se relaciona apenas com o significado, ao passo que a gramática fornece a estrutura (cadeias de pontos de escolhas lexicais, como na definição acima) para ser preenchida lexicalmente. Para Sinclair, há um espaço comum formado pela sintaxe e o léxico, no qual ambos são co-selecionados: a escolha de cada item lexical implica a redução das escolhas dos itens lexicais e das categorias gramaticais que podem segui-lo. Da mesma forma, a escolha de uma classe gramatical limita a escolha de classes gramaticais ou itens lexicais que podem ser empregadas na sequência (Berber Sardinha, 2004: 34).

Esse modelo de seleção lexical está embasado em dois princípios defendidos por Sinclair: o princípio idiomático (idiom principle) e o princípio da livre escolha (open choice principle).

Segundo o princípio da livre escolha, também denominado modelo slot and filler, a produção do falante é resultado de um grande número de opções complexas, tendo como única restrição a gramaticalidade da língua, ou seja, o falante tem a possibilidade de fazer quaisquer associações de palavras, desde que estejam gramaticalmente corretas.

Essa é uma forma de observar a produção da linguagem como sendo o resultado de um grande número de escolhas complexas. Em cada ponto em que uma unidade é selecionada (uma palavra, um sintagma ou uma oração), abre-se uma ampla gama de escolhas e a única restrição é a gramaticalidade (Sinclair, 1991: 109). ${ }^{14}$

\footnotetext{
13 [...] a model of language which divides grammar and lexis, and which uses the grammar to provide a string of lexical choice points is a secondary model.

${ }^{14}$ This is a way of seeing language text as the result of a very large number of complex choices. At each point where a unit is completed (a word or a phrase or a clause), a large range of choice opens up and the only restraint is grammaticalness.
} 
Por sua vez, o princípio idiomático reza que as palavras não ocorrem aleatoriamente e que as opções dos falantes são limitadas por diversos fatores, como registro, tipologia textual, área de especialidade.

Pelo princípio idiomático, o usuário da linguagem tem à sua disposição um grande número de expressões pré-construídas que constituem escolhas únicas, apesar de parecerem analisáveis em segmentos (Sinclair, 1991: 109). ${ }^{15}$

Sinclair vai mais além ao postular que os dois princípios coexistem, mas o idiomático é o dominante, constituindo um fenômeno linguístico difuso que reflete como a linguagem funciona de fato.

As colocações ilustram, portanto, o princípio idiomático. Tomem-se alguns exemplos citados por Baker (1992). Pelo seu sentido, o substantivo inglês visit poderia possivelmente vir acompanhado dos verbos carry out, undertake ou perform, todos com o sentido de 'realizar'. No entanto, a colocação mais provável em inglês é pay a visit, apesar de o sentido de pay ('pagar') não estar relacionado a visit, em um primeiro momento. Para citar um exemplo da hotelaria, to book a reservation tem o mesmo sentido de 'fazer uma reservar', apesar de to book significar 'reservar'.

\subsubsection{As colocações e os estudos de Fraseologia}

Conforme relatamos anteriormente, as colocações estão relacionadas ao fenômeno da associação recorrente entre os itens lexicais. O tema das colocações relaciona-se aos estudos de Fraseologia.

Welker (2004) pontua que o termo fraseologia tem duas acepções: a ciência que trata dos fraseologismos e o conjunto de fraseologismos. Em outras palavras, Fraseologia (grafada em maiúsculo) pode ser entendida como um ramo da ciência linguística, bem como o próprio objeto de estudo dessa ciência (fraseologia, em minúsculo).

\footnotetext{
${ }^{15}$ The principle of idiom is that a language user has available to him or her a large number of semipreconstructed phrases that constitute single choices, even though they might appear to be analysable into segments.
} 
Existe uma multiplicidade de enfoques possíveis para essa temática, o que se reflete na variedade de denominações para o fenômeno. A título de exemplificação, temos:

Em estudos de língua geral:

- $\quad$ multiword units ('unidades multipalavras') (Cowie, 1998);

- conventional expressions ('expressões convencionais'), phrasal (lexical) units ('unidades (lexicais) frasais') (Pawley, 2001);

- multiword expressions ('expressões multipalavras') (Lewis, 2000);

- lexicalized sentence stems ('estruturas formulaicas lexicalizadas') (Pawley \& Syder, 1983). ${ }^{16}$

Em estudos de língua de especialidade:

- Colocação (Heid, 1992, 1994, 1998; Martin, 1992; Schaetzen, 1993; Desmet, 1996);

- Colocação de linguagens de especialidade (L’Homme, 1998, 2000);

- Co-ocorrência (Lainé; Pavel, Boileau, 1992; Pesant, Thibault, 1993);

- $\operatorname{Frasema~(Gréciano,~1993);~}$

- Fraseologismo (Blais, 1993; Pavel, 1993);

- Unidade fraseológica (Gouadac, 1994; Bevilacqua, 1996);

- Unidade fraseológica especializada (Cabré; Lorente; Estopá, 1996). ${ }^{17}$

A relação acima aponta para duas questões pertinentes a nossa pesquisa.

A primeira refere-se a uma problemática inerente aos estudos de fraseologia: a ausência de consenso em relação à abrangência do fenômeno e aos critérios adotados para determinar os limites entre os diferentes tipos de combinatórias. As citações a seguir abordam essa questão:

A noção de fraseologia é vaga e modifica-se conforme a documentação consultada. Ela recobre, no todo ou em parte, o que se designa como compostos, colocações, expressões idiomáticas, locuções, expressões fixas, co-ocorrentes e outras expressões do gênero (Blais, 1993: 51 apud Krieger e Finatto, 2004: 84).

\footnotetext{
${ }^{16}$ Em Orenha (2004: 24-33).

${ }^{17}$ Em Bevilacqua (2004: 24) apud Matuda (2011: 63).
} 
Para alguns autores, a fraseologia limita-se às expressões idiomáticas próprias de uma língua; outros consideram que ela inclui os provérbios, os ditados, as locuções e as lexias compostas. Há ainda quem considere que tais unidades possuam estruturas extremamente variáveis, podendo incluir palavras, grupos de palavras, locuções, expressões, orações, segmentos de frases, frases, conjunto de frases e assim por diante (Bevilacqua, 2004: 74).

A ausência de um critério definitivo não significa total falta de unidade em relação ao conceito de fraseologia. Bevilacqua (2004: 78) salienta duas propriedades fundamentais comuns aos diferentes tipos de unidade fraseológica: a significação estabelecida entre o conjunto de seus elementos e seu elevado grau de lexicalização. Ou seja, trata-se de uma estrutura polilexical cristalizada (padronizada) cujo sentido extrapola o dos elementos isolados.

Em face dessas observações, justificamos a adoção de colocação como um termo guarda-chuva em nossa pesquisa para designar as unidades fraseológicas formadas por duas ou mais palavras.

A segunda questão evidenciada pela relação acima refere-se à existência de colocações da língua geral e colocações especializadas.

Em linhas gerais, as definições na literatura apontam dois aspectos que diferenciam a colocação especializada - o fato de pertencer a um domínio de especialidade e o de conter um termo entre os seus elementos constituintes. Nessa linha, Blais (1993: 52 apud Krieger e Finatto, 2004: 87) define colocação especializada como:

combinação de elementos linguísticos próprios de um domínio de especialidade, dos quais um é termo núcleo, que estão ligados semanticamente e sintaticamente e para os quais existe uma restrição paradigmática.

Por domínio ou linguagem de especialidade, entende-se:

[...] o uso de uma língua natural para dar conta tecnicamente de conhecimentos especializados [...]. A língua especializada é, em primeiro lugar, uma língua em situação de uso profissional (...). É a própria língua como sistema autônomo, mas a serviço de uma função maior: a transmissão de conhecimentos (Lerat, 1995: 221 apud Maciel, 2010: 9).

Assim como uma língua de especialidade constitui um uso peculiar da língua geral, não perfazendo uma língua à parte, as colocações especializadas também 
compartilham das mesmas características das colocações comuns, apesar de estarem inseridas em um tipo de comunicação de âmbito especializado; em outras palavras, "as propriedades apresentadas para as colocações da língua comum também são aplicadas às unidades utilizadas em textos especializados" (Bevilacqua, 2004: 80). Por conseguinte, podemos afirmar que estamos lidando com colocações especializadas, uma vez que nossa investigação incide sobre uma área de especialidade, a hotelaria. Todavia, as reflexões e o tratamento dado às colocações em nosso trabalho se aplicam ao fenômeno como um todo.

Ainda nesse sentido, analisaremos a seguir algumas definições de colocações bem como as tipologias e o tratamento dado por alguns autores às colocações nos dicionários.

\subsubsection{Definições e tipologia}

Em seu livro Corpus Concordance and Collocation (1991), Sinclair define colocação da seguinte maneira:

Colocação é a ocorrência de duas ou mais palavras, com um curto intervalo entre elas, em um texto. A medida usual de proximidade é um intervalo de no máximo quatro palavras. As colocações podem ser marcantes e interessantes por serem inesperadas, ou podem ser importantes na estrutura léxica da linguagem dada sua recorrência frequente. (...) A colocação, no seu sentido mais puro, conforme empregado neste livro, reconhece apenas a co-ocorrência lexical das palavras. ${ }^{18}$ $(1991: 170)$

Essa definição inclui referência à extensão do agrupamento lexical - duas ou mais palavras - e ao intervalo de texto considerado - curto, sendo como medida usual quatro palavras à direita e quatro à esquerda da palavra base (ou nódulo). Em nosso trabalho, adotamos um ponto de vista semelhante, especialmente por não considerarmos um limite específico para a extensão da colocação, o que reflete mais corretamente a realidade do fenômeno, segundo nosso entendimento.

\footnotetext{
${ }^{18}$ Collocation is the occurrence of two or more words within a short space of each other in a text. The usual measure of proximity is a maximum of four words intervening. Collocations can be dramatic and interesting because unexpected, or they can be important in the lexical structure of the language because of being frequently repeated. (...) Collocation, in its purest sense, as used in this book, recognizes only the lexical co-ocurrence of words.
} 
Partington, em consonância com a visão de colocação expressa acima, aponta três definições principais presentes na literatura, segundo enfoques diferentes - textual, psicológico e estatístico:

Textual: colocação é a ocorrência de duas ou mais palavras distantes um pequeno espaço de texto uma das outras; psicológica: o sentido colocacional consiste das associações que uma palavra faz por conta dos sentidos das outras palavras que tendem a ocorrer no seu ambiente; estatística: colocação tem sido o nome dado à relação que um item lexical tem com itens que aparecem com probabilidade significativa no seu contexto (textual) (1998: 16-7 apud Berber Sardinha, 2004: 41).

Partington resume três aspectos que consideramos fundamentais no entendimento de uma colocação: a associação de duas ou mais palavras, o sentido que emerge dessa combinação e sua recorrência significativa.

Além das definições, alguns autores propõem uma tipologia para o reconhecimento das colocações. As categorias variam segundo as inúmeras perspectivas possíveis, dentre elas, critérios morfológicos, estatísticos ou semânticos. Assim, procuramos reunir as diferentes classificações de acordo com o enforque de cada autor. Em seguida, discutiremos como esses critérios foram tratados em nossa proposta de glossário de colocações.

Hausmann (1989 apud Welker 2004: 141) apresenta uma concepção diferente de colocação (em alemão, Kollokation) em relação às definições expostas anteriormente. Para ele, uma colocação, ou combinação típica, não é identificada por meio da análise de frequência em um corpus, mas por meio da competência do falante nativo (ou conjunto de falantes nativos), ou seja, "o falante nativo, que domina bem sua língua materna, quando ouve ou pensa numa palavra, surgem logo palavras que com ela podem ser combinadas" (Welker, 2004: 141). Para Hausmann, uma colocação consiste de Base e Kollokator (base e colocado), em que a primeira é um elemento semanticamente autônomo e o segundo tem o sentido restrito por ela. $\mathrm{O}$ autor propõe estruturas morfossintáticas para categorizar as colocações (Welker: 143):

- substantivo + adjetivo: chuva torrencial

- substantivo + verbo: uma palavra escapole

- verbo + substantivo: executar uma lei

- verbo + advérbio: chorar copiosamente

- advérbio + adjetivo: densamente povoado

- substantivo + preposição + substantivo: enxurrada de documentos 
Tagnin (2005: 30) define colocação como "combinação lexical consagrada de duas ou mais palavras de conteúdo". À semelhança da classificação proposta por Hausmann, a autora apresenta as seguintes categorias de colocações:

\begin{tabular}{|c|c|c|}
\hline categoria & base + colocado & exemplos \\
\hline adjetiva & adjetivo + substantivo & $\begin{array}{c}\text { comfortable room } \\
\text { apartamento confortável }\end{array}$ \\
\hline verbal & $\begin{array}{c}\text { verbo + substantivo } \\
\text { verbo + preposição + substantivo }\end{array}$ & $\begin{array}{c}\text { book a room } \\
\text { fazer uma reserva }\end{array}$ \\
\hline nominal & $\begin{array}{c}\text { substantivo + substantivo } \\
\text { substantivo + preposição + substantivo }\end{array}$ & $\begin{array}{c}\text { room service } \\
\text { serviço de quarto }\end{array}$ \\
\hline adverbial & $\begin{array}{c}\text { advérbio }+ \text { adjetivo } \\
\text { verbo }+ \text { advérbio } \\
\text { [apartamento] totalmente } \\
\text { equipado }\end{array}$ \\
\hline
\end{tabular}

Figura 4 - Categorias de colocações em Tagnin (2005: 37-46). Exemplos nossos.

Outro autor que apresenta uma classificação semelhante é Palmer (1933: 5 apud Cowie, 2004: 211), para quem colocações são “uma sucessão de duas ou mais palavras que devem ser aprendidas como um todo e não como elementos separados"19 e estão classificadas em verbais, nominativas, adverbiais e prepositivas. $\mathrm{O}$ autor diferencia ainda as colocações das combinações livres, ou "manifestações do sistema linguístico capazes de serem reunidas pela simples aplicação das regras gramaticais mais conhecidas", ou seja, as combinações de palavras que não formam um padrão de uso.

Sinclair (1991: 115) caracteriza as colocações em nódulo - o item em foco na análise da colocação - e colocado. A partir de um critério estatístico, classifica-as em downward collocation, upward collocation e neutral collocation. No primeiro caso, o nódulo é mais frequente que o colocado; no segundo caso, o colocado é o mais frequente; no terceiro, as frequências são semelhantes. A relevância desse critério está em aferir a força da colocação para cada um dos itens lexicais - "quando duas palavras de frequências diferentes co-ocorrem de maneira significativa, a colocação tem um valor diferente na descrição de cada uma das palavras". ${ }^{20}$

Benson (1989) entende as colocações como combinações recorrentes e arbitrárias de palavras. A partir de uma perspectiva semântica, o autor distingue uma

\footnotetext{
${ }^{19}$ A collocation is a succession of two or more words that must be learned as an integral whole, and not pieced together from its component parts.

${ }^{20}$ When two words of different frequencies collocate significantly, the collocation has a different value in the description of each of the two words.
} 
escala de combinações lexicais, segundo seu grau de idiomaticidade, que varia entre combinações livres, colocações e expressões idiomáticas (1989 apud Orenha 2004: 30).

Semelhantemente, Cowie (2002: 192-193) refere-se às colocações como "porções pré-fabricadas de linguagem armazenadas no léxico do falante"21. O autor distingue entre open collocations (run a business), restricted collocations (entertain the idea), figurative idioms (change gear) e pure idioms (kick the bucket). Apesar dessa categorização, o autor reconhece que não há linhas divisórias nítidas entre os diferentes tipos de associação (1981: 226 apud Welker, 2004: 143).

Por fim, Mel'cuk baseia-se nas relações semânticas entre os elementos da colocação, estabelecendo funções léxicas para identificar e representar estas unidades em um dicionário. Essas funções são expressas por meio de fórmulas, como $f(X)=Y$, na qual $f$ é a função léxica, $X$ é a base e $Y$ é o colocado. Por exemplo, a expressão Magn (contrast) $=$ sharp significa que entre a base contrast e o colocado sharp, em sharp contrast, existe uma relação de intensidade (representada pelo código Magn). O autor identificou cerca de sessenta funções lexicais básicas (Fontenelle, 1998: 197).

Como é possível depreender do exposto acima, há uma série de diferenças de enfoque e denominações para lidar com um mesmo fenômeno. A partir desse levantamento, selecionamos alguns dos critérios abordados pelos autores para o reconhecimento e tratamento das colocações em nosso trabalho.

- Frequência e medidas estatísticas

Trata-se do critério mais relevante em nossa pesquisa. Conforme mencionamos anteriormente, partimos de uma palavra-chave - item lexical de recorrência representativa no corpus - e analisamos seus colocados segundo linhas de corte e medidas estatísticas preestabelecidas ${ }^{22}$.

\section{- Classes gramaticais}

Reconhecemos a validade dessa categorização, que de fato se mostrou bastante útil para a classificação das unidades formadas por dois itens lexicais, como accessible room ou room rate. Além disso, as categorias morfológicas foram amplamente empregadas para responder, por exemplo, perguntas como: quais os adjetivos mais utilizados para descrever 'apartamento'? Contudo, identificamos estruturas mais

\footnotetext{
21 "pre-fabricated chunks ol language stored in a speaker's lexicon."

${ }^{22}$ Mais detalhes na seção 3.2.1.
} 
complexas que extrapolavam essa categorização mais clássica. Por exemplo, uma variação de accessible room é wheelchair accessible room (substantivo + adjetivo + substantivo), com o mesmo sentido, porém estrutura diferente; da mesma forma, para room rate também temos night's room rate; e como classificar first night's room and tax? A problemática aumenta ao se buscar uma uniformidade entre dois idiomas, em que poucas vezes uma colocação típica de um lado corresponde a uma colocação típica do outro. Por exemplo, um dos equivalentes de accessible room é apartamento adaptado para portadores de necessidades especiais. Assim, optamos por não subdividir as colocações por classes gramaticais, mas incluir todos os padrões com frequência significativa. Desse modo, abarcamos todos os tipos de combinatórias recorrentes (incluindo colocações verbais, nominais, adjetivas, adverbiais e suas variações), porém sem as limitações de uma categorização $a$ priori.

Esse posicionamento encontra embasamento nos dizeres de John Sinclair, em entrevista a Wolfgang Teubert. Ao discutir a relação entre gramática e léxico, Sinclair esclarece que "o papel fundamental da gramática é 'juntar as coisas' para que se encaixem"23 (Sinclair et al., 2004: xxvii). Dessa forma, a gramática não cria o significado das unidades fraseológicas. Nesse ponto, Teubert indaga sobre o formato de um dicionário de colocações:

Teubert: Então, o dicionário de colocações que você tem em mente traria uma lista de quase todos os bigramas estatisticamente significativos, independente de suas fronteiras gramaticais?

Sinclair: Não apenas bigramas, mas n-gramas, ou tudo aquilo dentro de uma janela que seja significativa. (Sinclair et al., 2004: xxvii) ${ }^{24}$

Em outras palavras, segundo o autor, um dicionário de colocações deve trazer não apenas as combinações formadas por duas palavras, mas por n-palavras independente de sua categoria gramatical, ou seja, qualquer combinação estatisticamente relevante, dentro de um intervalo significativo.

\footnotetext{
${ }^{23}$ One of the basic roles of grammar is clipping things together so they fit.

${ }^{24} \mathrm{~T}$ : So the collocation dictionary you have in mind would list practically all statistically significant bigrams regardless of their grammatical boundaries? S: Not just bigrams, but n-grams, or anything within a window which is significant.
} 


\section{- Extensão}

Conforme justificamos, contemplamos associações formadas por n-palavras. Em relação ao intervalo significativo mencionado no item anterior, adotamos a medida usual 4x4 (Sinclair, 1991: 170), ou seja, com a utilização do programa WordSmith Tools (Scott, 2007, versão 5), buscamos os colocados dentro de um intervalo de quatro palavras à direita e quatro à esquerda da palavra de busca.

- Grau de fixação

O grau de fixação está relacionado ao nível de variação que a colocação comporta. Em nosso trabalho, analisamos as combinações mais recorrentes segundo os critérios que adotamos. Assim, as combinações livres ou aleatórias, ou seja, as que não formam um padrão, não chegam a ser consideradas. Por outro lado, incluímos as colocações fixas e semifixas, nesse último caso, destacando as variações mais recorrentes; por exemplo, first night's room and tax, one night room charge plus tax ou ainda one night room rate and tax.

\section{- Idiomaticidade}

A idiomaticidade refere-se ao grau de transparência ou opacidade das colocações. Em nosso glossário, mais uma vez, optamos por considerar todos os tipos de combinações, uma vez recorrentes. Vale ressaltar que não incluímos definições em nossa proposta, pois partimos do pressuposto de que o tradutor as conhece e deseja saber os padrões de uso equivalentes na língua-alvo.

\section{- Relações semânticas}

As relações semânticas estão representadas em nosso glossário quando identificamos nuances de sentido entre itens aparentemente sinônimos. Por exemplo, destacamos a diferença entre guest room, apartment, bedroom e suite, em inglês; quarto, apartamento e suite, em português; ou ainda room rate, fee e charge, em inglês; diária, tarifa, taxa e custo em português.

A adoção de critérios flexíveis evidencia nossa abordagem direcionada pelo corpus no sentido de uma terminologia comunicativa in vivo, ou seja, interessa-nos acima de tudo contemplar as regularidades linguísticas que caracterizam a linguagem da hotelaria.

Tendo esclarecido os critérios de reconhecimento das colocações, nossa preocupação seguinte é com a forma de representá-las no verbete. Nesse sentido, 
investigamos a questão da organização das colocações em dicionários na literatura e analisamos algumas obras a que tivemos acesso. Por fim, descrevemos em linhas gerais como essa questão foi definida em nossa proposta de glossário.

\subsubsection{As colocações e os dicionários}

A esta altura, esperamos ter esclarecido ao leitor o papel fundamental que as colocações exercem na linguagem. Portanto, não há dúvidas de que elas devem estar registradas nas obras lexicográficas, tanto nas monolíngues quanto nas bilíngues especializadas.

Em relação à organização e apresentação das colocações nos dicionários, quer sejam gerais ou fraseológicos, é fato que a diversidade de critérios para o reconhecimento do fenômeno também se reflete nas inúmeras possibilidades de arranjos, tendo em vista também o público-alvo, os idiomas envolvidos, preferências estilísticas, dentre outras questões.

Nosso objetivo nesta seção é relatar de maneira sucinta o tratamento dado às colocações em três obras monolíngues e uma bilíngue a que tivemos acesso. O intuito é observar tendências na organização dos verbetes, a fim de apontar caminhos para os critérios que adotamos em nossa proposta.

\section{Dicionários monolíngues:}

\section{1) The BBI Combinatory Dictionary of English: A Guide to Word Combinations}

(Benson, Benson e Ilson, 1986)

Trata-se de uma obra bastante extensa, com 90.000 colocações e expressões. No entanto, os exemplos são extraídos de material não autêntico, ou seja, o dicionário não é baseado em corpus. Não há informações no dicionário sobre a fonte dos dados.

A categorização é rigorosamente morfológica. As colocações são divididas em gramaticais e lexicais, que por sua vez são subdivididas em oito e sete categorias, respectivamente. A título de exemplificação, a categoria G1 (grammatical 1) inclui as combinações formadas por noun + preposition, como em apathy towards. A categoria 
L1 (lexical 1) compreende verbs + noun/pronoun (or prepositional phrase), por exemplo, make an impression.

As categorias acima não são indicadas para o usuário final - os colocados são apresentados por meio de locuções ou sentenças. Há apenas a indicação da classe gramatical da entrada (headword). As colocações lexicais precedem as gramaticais e as categorias de L1 a L7 e de G1 a G8 são apresentadas nessa sequência.

Em relação ao estilo, temos: a entrada aparece em negrito; o símbolo ( ) é utilizado para substituí-la; as colocações sinônimas aparecem em um bloco, separadas por vírgulas; as não sinônimas são separadas por ponto e vírgula. Por exemplo: na entrada de booth, temos: an information; phone, telephone; polling, voting; projection .

Em relação às unidades fraseológicas mais extensas, nota-se uma indefinição no dicionário, confirmando tratar-se de uma questão de difícil padronização. Os autores afirmam não incluir "normalmente" as expressões idiomáticas opacas, como to kill a bird with two stones, mas afirmam incluir "importantes" unidades em transição entre colocações e expressões idiomáticas, cujo sentido seja parcialmente depreendido dos elementos da combinação. É o caso de as free as a bird ou to check in at a hotel (vide verbete abaixo). Essas expressões são precedidas pela anotação misc.

O dicionário traz ainda as anotações AE e BE para American e British English; colloq., para expressões coloquiais; usage notes com informações adicionais sobre a entrada, e até mesmo transcrição fonética em alguns casos, como por exemplo para diferenciar bow /bau/de bow /bou/.

Um exemplo de verbete:

hotel $n$. 1. to manage, operate, run a $\sim 2$. a deluxe, five-star, luxury; first-class; four-star; run-down; seedy; swanky (colloq.); three-star $\sim 3$. at, in a $\sim$ (she works at/in $\mathrm{a} \sim$ ) 4. (misc.) to check in, register at a $\sim$; to check out of $\mathrm{a} \sim$

Figura 5 - Verbete de hotel no The BBI Combinatory Dictionary of English. 


\section{2 ) Oxford Collocations Dictionary for Students of English (2002)}

Como o nome indica, esta é uma obra destinada a aprendizes; entretanto, pretende ser útil a todos que desejam escrever de maneira fluente e natural em inglês. Contém 9.000 entradas e baseia-se no British National Corpus, com 100 milhões de palavras.

O dicionário adota critérios morfológicos para identificar os diferentes tipos de combinatórias (adjective + noun, quantifier + noun, verb + noun, noun + verb, noun + noun, preposition + noun, noun + preposition, adverb + verb, verb + verb, verb + preposition, verb + adjective, adverb + adjective, adjective + preposition $)$.

As entradas são formadas por substantivos, adjetivos, verbos e advérbios, e todos os tipos de colocações são contemplados. Entretanto, os autores esclarecem que não incluíram as colocações nominais nas entradas adjetivas e verbais. Por exemplo, a entrada do verbo meet não contém colocados como challenge. Essa decisão justifica-se pelo fato de que, segundo os autores, o usuário não consulta o dicionário para saber o que ocorre com o verbo meet, mas quais verbos ocorrem com o substantivo challenge. Assim, a colocação meet the challenge encontra-se somente na entrada de challenge.

São contempladas desde colocações mais fracas (see a film, enjoyable holiday), as de força mediana (see a doctor, highly intelligent), até as mais restritas (burning ambition, blindingly obvious). Combinações livres e expressões idiomáticas são excluídas. No entanto, assim como no $B B I$, há uma ressalva sobre a inclusão de expressões parcialmente idiomáticas, como drive a hard bargain.

As colocações em cada verbete estão divididas por classe gramatical; dentro de cada classe, estão agrupadas por sentido ou categoria. Os colocados aparecem em negrito; os sinônimos são separados por vírgula e os de sentido diferente pelo sinal ( | ). Por exemplo, na entrada de pollution, temos: cause | avoid, prevent | combat, control, fight, tackle. Dentro de cada grupo, as palavras aparecem em ordem alfabética, e a ordem de apresentação dos grupos pretende ser a mais intuitiva possível, ou seja, fácil de ser compreendida e consultada, mas não há um critério específico definido. Alguns grupos de colocados apresentam exemplos, em itálico, mostrando a colocação em contexto.

O dicionário não traz definições, apenas "discriminadores de sentido" quando necessário. Informações sobre o registro são indicadas por meio de etiquetas, como formal, informal e figurative. 
Vejamos a seguir um exemplo da entrada parcial (apenas colocados adjetivos) de hotel:

hotel noun

ADJ. big, large | little, small | cheap, expensive | five-star, four-star, etc. | attractive, beautiful, comfortable, delightful, deluxe, good, grand, elegant, excellent, fine, first-class, luxurious, luxury, pleasant, posh, quality, smart, top all the style and comfort that only the best hotels can provide. $\checkmark$ It was a luxury hotel with its own swimming pool and restaurant. | seedy | modern | air-conditioned The hotel is fully air-conditioned. | traditional | friendly | family, family-run a family hotel with a playground for small children $\diamond$ a friendly family-run hotel independent, private | international | country, country-house a small countryhouse hotel | holiday, resort, tourist | seafront, seaside | local, nearby | bed and breakfast homeless families living in bed and breakfast hotels.

Figura 6 - Verbete parcial de hotel no Oxford Collocations Dictionary for Students of English.

\section{3) Longman Dictionary of Contemporary English - Advanced Learners (2009)}

Este renomado dicionário destina-se a aprendizes de inglês, mas certamente alcança um público bem maior. Esta versão mais recente contém uma seção (collocation box) dedicada exclusivamente às colocações em algumas entradas, incluindo mais de 65 mil combinatórias. Além disso, traz uma seção denominada Thesaurus, com explicações sobre as diferenças de sentido entre palavras sinônimas ou quase-sinônimas.

Notamos que a organização da seção de colocações não é padronizada, pois observamos grandes variações entre as diferentes entradas. De maneira geral, as colocações estão subdivididas por categoria gramatical - sob a etiqueta verbs, por exemplo, são relacionados todos os colocados verbais da entrada. A maioria das colocações é acompanhada de exemplos.

Os colocados aparecem em negrito; os de sentido semelhante estão separados por uma barra, os de sentido diferente ficam em linhas separadas ou, por vezes, são isolados pelo símbolo ( | ). Em muitos casos, há uma breve definição entre parênteses ao lado do colocado. Os exemplos são indicados em itálico e há poucos símbolos ou etiquetas.

Para apresentar as colocações mais extensas, o dicionário traz uma categoria denominada phrases. Não está claro, porém, se o critério para diferenciar phrase está relacionado à extensão da colocação ou ao nível de idiomaticidade. Por exemplo, na 
entrada hope, temos: to cling to the hope that na categoria de colocados verbais e to be full of hope na categoria phrases.

Vejamos, a título de ilustração, a entrada hotel.

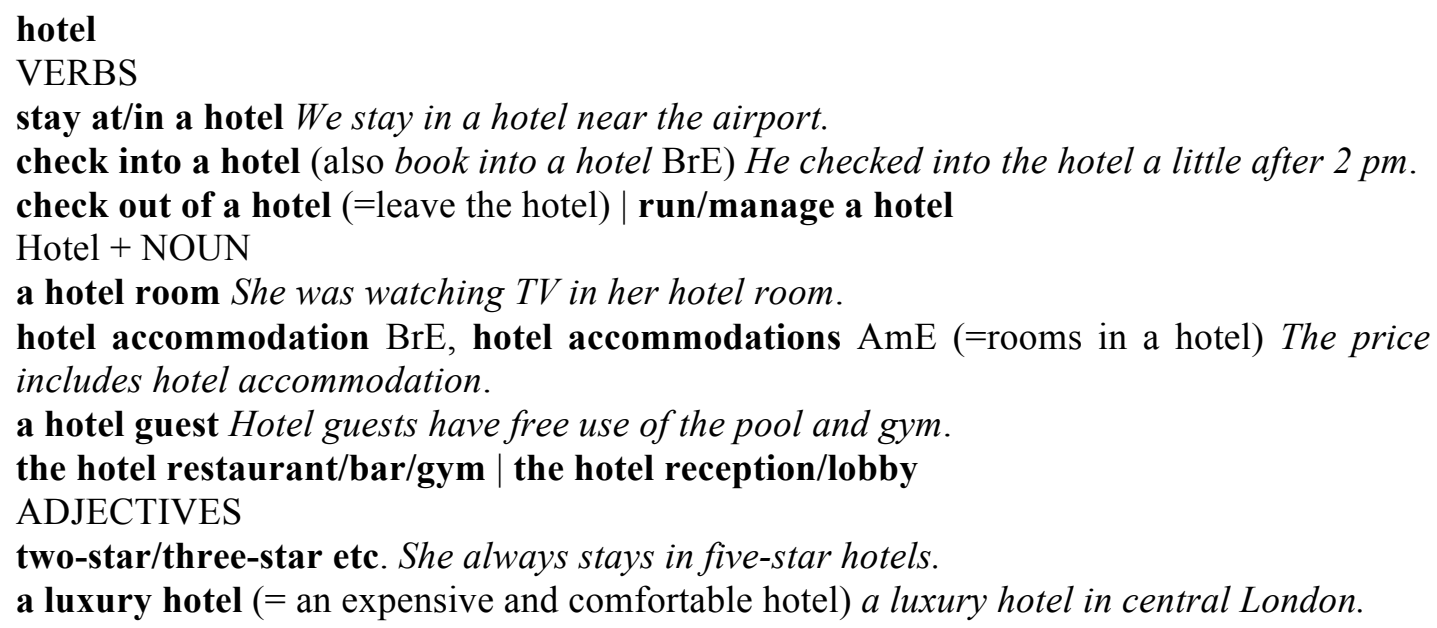

Figura 7 - Verbete de hotel no Longman Dictionary of Contemporary English.

Notamos fortes semelhanças entre os dicionários. A mais marcante é a subdivisão das colocações por categorias gramaticais. Chamou-nos a atenção o fato de os três dicionários trazerem, no verbete hotel, basicamente colocados formados por dois itens lexicais, não há expressões extensas, à exceção de to check out of a hotel, no BBI e no Longman. Além disso, os três dicionários demonstraram indefinição nos critérios para o tratamento de colocações mais extensas. Por fim, vale um comentário sobre a riqueza de informações nas entradas dos dicionários Oxford e Longman em comparação ao $B B I$, certamente por estarem baseados em um corpus bastante representativo.

Vejamos agora como as colocações são tratadas em um glossário bilíngue especializado, compilado segundo os princípios da LC.

\section{1) Vocabulário para culinária, inglês/português (Teixeira e Tagnin, 2008)}

Este glossário tem como público-alvo o tradutor. Foi compilado a partir de um corpus contendo cerca de 1,5 milhão de palavras em cada idioma, construído especialmente para servir à pesquisa terminológica. ${ }^{25}$

\footnotetext{
${ }^{25}$ Corpus construído por Teixeira (2008), para sua pesquisa de doutorado: A Linguística de Corpus a serviço do tradutor: proposta de um dicionário de Culinária voltado para a produção textual. Faculdade de Filosofia, Letras e Ciências Humanas, Universidade de São Paulo.
} 
A partir da lista de palavras-chave do corpus, foram levantadas as colocações mais recorrentes, privilegiando substantivos, verbos, adjetivos e advérbios. De uma maneira geral, as colocações são constituídas por duas palavras, a base e seu colocado, como em chopping board, mas as autoras também preveem a inclusão de combinações mais longas, as fraseologias, como freshly grated parmensan cheese.

Por ser voltado à produção textual, o glossário inclui ainda diversas informações adicionais, como exemplos de uso e a respectiva tradução, notas alertando sobre possíveis dificuldades de tradução, remissivas a termos sinônimos ou relacionados e tabelas complementares. O glossário conta ainda com ilustrações.

No que diz respeito à organização, as entradas podem ser termos isolados, com os colocados relacionados na sequência, ou uma colocação em si. Por exemplo, a letra G traz como entradas garlic e gas flame. Os equivalentes são relacionados ao lado dos termos ou colocados. Em cada verbete, os colocados são relacionados em ordem alfabética. Não há, portanto, para o usuário, a distinção entre tipos de colocação por classe gramatical.

As relações semânticas de sinonímia são indicadas por uma barra ( / ), como em chop finely/finely chop; as colocações possíveis são indicadas pelo símbolo ( | ), como red | white wine, e as palavras de presença opcional na colocação aparecem entre parênteses, como game (meat). Há ainda o sinal $(+)$ para indicar o equivalente mais frequente, bem como símbolos para destacar os exemplos, comentários, remissivas e notas ao tradutor.

Vejamos um exemplo de entrada parcial a título de ilustração:

garlic (n.) alho

galic bulb | head cabeça de alho

garlic chives nirá/cebolinha japonesa

garlic powder alho em pó

garlic clove | clove (of) garlic dente de alho

[comentário] Embora a maioria das receitas em inglês mencione que o alho (especialmente o dente) é descascado (peeled), em português, essa informação é redundante, e só deve ser mencionada no caso de a receita usar também dentes ou cabeças de alho inteiras e com a casca.

Figura 8 - Verbete de garlic no Vocabulário para culinária, inglês/português.

Por ser um glossário bilíngue especializado com base na LC, esse último é o que mais se aproxima da proposta que desenvolvemos para o âmbito da hotelaria. 
O levantamento acima possibilita contemplar diversos critérios e formas de organização das colocações em um dicionário, além de apontar ideias interessantes sobre informações que podem incrementar uma obra terminológica.

Em vista dessas considerações, buscamos definir as diretrizes para a organização de nosso dicionário com base em três perguntas:

\section{1) Como categorizar as colocações?}

As colocações (entradas na língua 1) estão organizadas por ordem alfabética, sem classificação por classe gramatical. Os equivalentes são registrados por ordem decrescente de frequência.

\section{2) Quais informações adicionais são úteis para o nosso público-alvo?}

Consideramos que o tradutor trabalhando na direção inglês - português se beneficiaria de: exemplos de uso da colocação original e especialmente dos equivalentes; mais de uma opção de equivalente, sempre que possível; indicação da diferença de frequência entre os equivalentes; informações sobre variantes de grafia ou colocações sinônimas; notas remissivas a palavras ou informações relacionadas; alertas ou soluções para possíveis problemas de tradução; dados sobre diferenças culturais; informações sobre nuances de sentidos entre palavras relacionadas.

\section{3) Como apresentar visualmente esses resultados?}

O objetivo é criar um verbete intuitivo, de fácil visualização e entendimento (userfriendly). Originais e equivalentes são dispostos paralelamente em duas colunas. Colocações maiores derivadas da entrada principal são indicadas na sequência. Os exemplos são sempre apresentados em itálico, com a colocação em negrito. Incluímos símbolos para destacar informações de frequência, possibilidade de inversão da colocação e remissivas. A seção Nota ao Tradutor traz soluções para possíveis problemas de tradução, dentre outras informações que julgamos úteis. A seção Você Sabia? destaca unidades de sentido semelhante e a diferença entre elas. Essas duas seções são indicadas por símbolos e cores diferenciadas e ainda recebem uma bandeira americana ou brasileira de acordo com o idioma ao qual a informação se refere. ${ }^{26}$

Vejamos a seguir, a título de ilustração, um verbete com a estrutura que propomos.

\footnotetext{
${ }^{26}$ Os verbetes estão apresentados na seção 4.2
} 


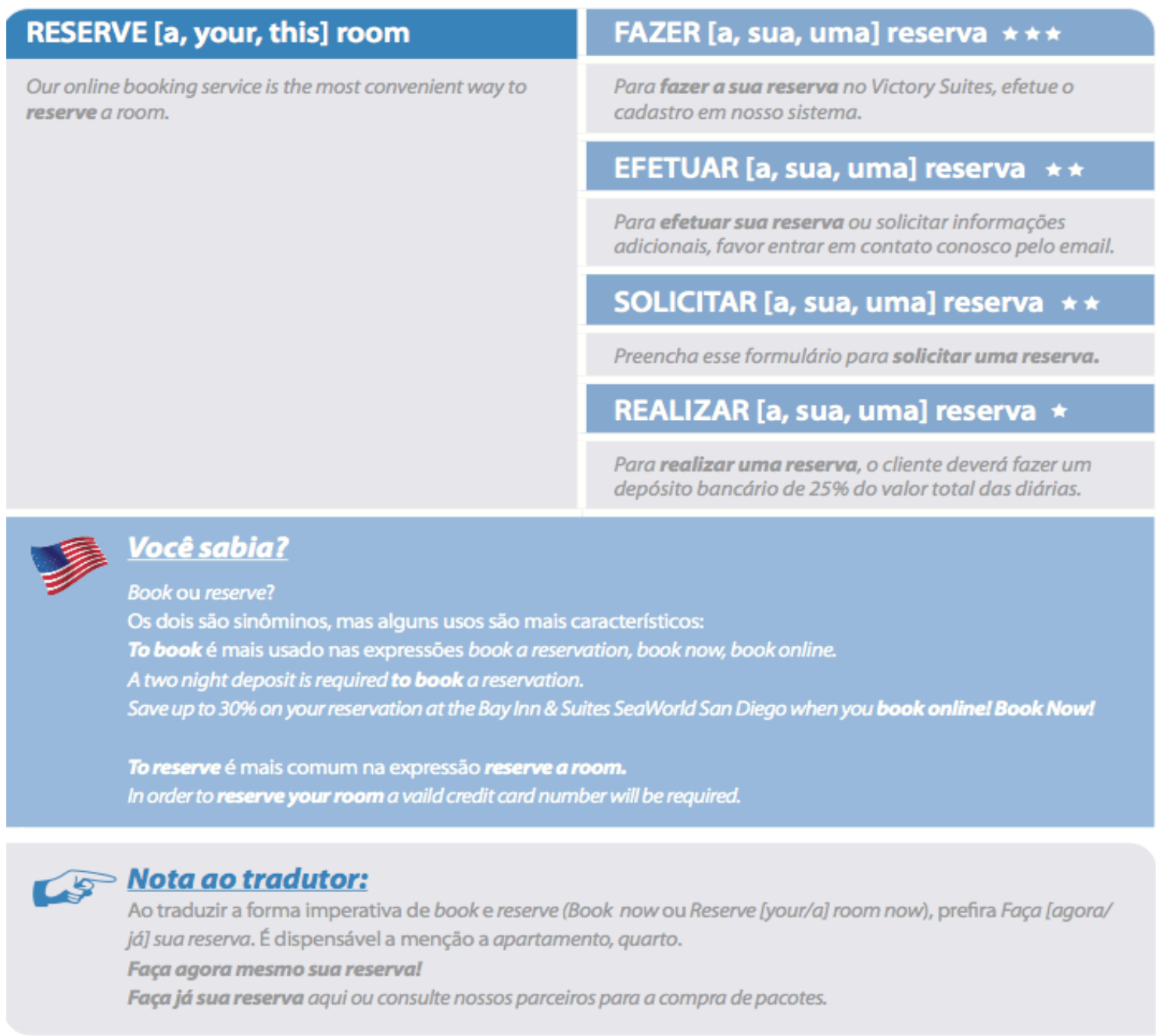

Figura 9 - Verbete de Reserve [a, your, this] room, em nossa proposta de glossário.

Neste capítulo, discutimos as proposições teóricas da LC, da Convencionalidade e da Terminologia. Em seguida, apresentamos a noção de colocação, bem como diferentes definições e tipologias existentes na literatura. Por fim, descrevemos o tratamento dado às colocações em algumas obras lexicográficas e propomos uma estrutura de verbete para o nosso glossário. Para chegarmos aos resultados almejados, empregamos a metodologia delineada no capítulo que se segue. 


\section{Capítulo 3 - Metodologia}

Fundamentada nas teorias discutidas no capítulo anterior, esta pesquisa almeja propor um modelo de glossário bilíngue (inglês - português) de colocações da hotelaria destinado a tradutores. Para tanto, adotamos a metodologia de pesquisa que passamos a descrever a seguir, incluindo os seguintes tópicos:

- Corpus de estudo

- Tipologia

○ Composição

- Tratamento dos textos

○ Critérios redefinidos

- Aspectos culturais revelados pela compilação do corpus

- Exploração do corpus e procedimentos de análise

- Metodologia exemplificada

\subsection{O corpus de estudo}

A fim de realizar um estudo terminológico bilíngue das colocações mais utilizadas na área da hotelaria, mais especificamente, nas descrições dos hotéis, fez-se necessária a construção de um corpus. De uma maneira geral, um corpus é definido como uma coleção de textos em formato eletrônico compilada segundo critérios específicos para se prestar à investigação linguística; além disso, é essencial que ele esteja afinado com os objetivos da pesquisa. Em nosso estudo, a finalidade precípua do corpus é representar a linguagem autêntica utilizada para descrever hotéis em inglês e em português.

A qualidade do corpus está intimamente ligada ao rigor empregado em sua construção, fator determinante para a confiabilidade e alcance dos resultados. Portanto, 
o planejamento e a compilação do corpus constituem uma etapa fundamental de qualquer pesquisa terminológica, em especial das baseadas em LC. É esse percurso que pretendemos relatar nesta seção.

Para tanto, detalharemos os seguintes pontos relativos ao corpus: tipologia, composição (categorias, conteúdo e balanceamento) e o tratamento dos textos (cabeçalhos, nomeações, etiquetagens).

\subsubsection{Tipologia}

Seguindo a tipologia proposta por Berber Sardinha (2004: 20-21), nosso corpus pode ser classificado da seguinte forma:

\begin{tabular}{|c|c|c|}
\hline \multicolumn{2}{|c|}{$\begin{array}{l}\text { tipologia de corpus } \\
\text { (Berber Sardinha 2004: 20-21) }\end{array}$} & corpus de estudo \\
\hline modo & falado / escrito & $\begin{array}{c}\text { escrito (conteúdo de sites de } \\
\text { hotéis) }\end{array}$ \\
\hline tempo & $\begin{array}{l}\text { sincrônico / diacrônico } \\
\text { contemporâneo / histórico }\end{array}$ & $\begin{array}{c}\text { sincrônico } \\
\text { contemporâneo }\end{array}$ \\
\hline seleção & $\begin{array}{c}\text { amostragem / monitor } \\
\text { dinâmico / estático / equilibrado }\end{array}$ & $\begin{array}{l}\text { amostragem (língua de } \\
\text { especialidade) } \\
\text { estático / equilibrado }\end{array}$ \\
\hline conteúdo & especializado / regional / multilíngue & especializado \\
\hline autoria & aprendiz / língua nativa & língua nativa (En-Us/Pt-Br) \\
\hline $\begin{array}{l}\text { disposição } \\
\text { interna }\end{array}$ & paralelo / comparável & $\begin{array}{c}\text { comparável (textos originais } \\
\text { nos dois idiomas) }\end{array}$ \\
\hline finalidade & estudo / referência / treinamento & estudo \\
\hline
\end{tabular}

Figura 10 - Tipologia do corpus de estudo.

A tabela acima resume algumas características importantes de nosso corpus. Primeiramente, ele é escrito, ou seja, os textos não incluem linguagem oral; é sincrônico e contemporâneo, pois seu conteúdo refere-se a um período de tempo delimitado entre os anos de 2010 e 2011 e representa a linguagem de uso corrente. Em relação à seleção, trata-se de um corpus de amostragem, ou seja, que representa uma 
porção finita da linguagem da hotelaria. Semelhantemente, trata-se de um corpus especializado da área de hotelaria, composto por textos descritivos de hotéis. Por conter textos originais nos dois idiomas, inglês e português, e ser construído para investigação linguística, o corpus configura-se como comparável e de estudo. Por fim, trata-se de um corpus de tamanho médio, com 1 milhão de palavras, segundo a classificação de Berber Sardinha (2004).

\subsubsection{Composição}

Além dos critérios acima, a construção do corpus pautou-se nos requisitos de: a) autenticidade dos textos, como vistas à investigação da linguagem natural; b) seleção criteriosa das categorias, norteada pelos objetivos da pesquisa; c) representatividade da língua que se pretende estudar (Berber Sardinha 2002: 19). Mostraremos a seguir como procuramos atender a esses requisitos.

\subsubsection{Autenticidade}

O critério de autenticidade está relacionado à representação da linguagem em seu contexto real de ocorrência, ou seja, a linguagem produzida em situação de comunicação genuína, sem vistas à pesquisa linguística. Observar esse critério é fundamental para atender nosso objetivo de estudar os padrões lexicais mais representativos na linguagem da hotelaria.

Nesse sentido, optamos por extrair os textos de sites de estabelecimentos hoteleiros. Essa decisão justifica-se pela facilidade de acesso a esses materiais, pela imensa variedade de conteúdo disponível on-line, mas principalmente por representar de maneira precisa a linguagem que almejamos investigar - descrições dos diversos aspectos de um hotel.

Para o idioma inglês, escolhemos hotéis localizados nos Estados Unidos. Temse, portanto, representada a variedade do inglês americano. Para o português, selecionamos estabelecimentos localizados no Brasil. Assim, construímos um corpus bilíngue comparável - textos equivalentes e originais nos dois idiomas. As imagens abaixo exemplificam o tipo de site de onde os textos foram extraídos: 


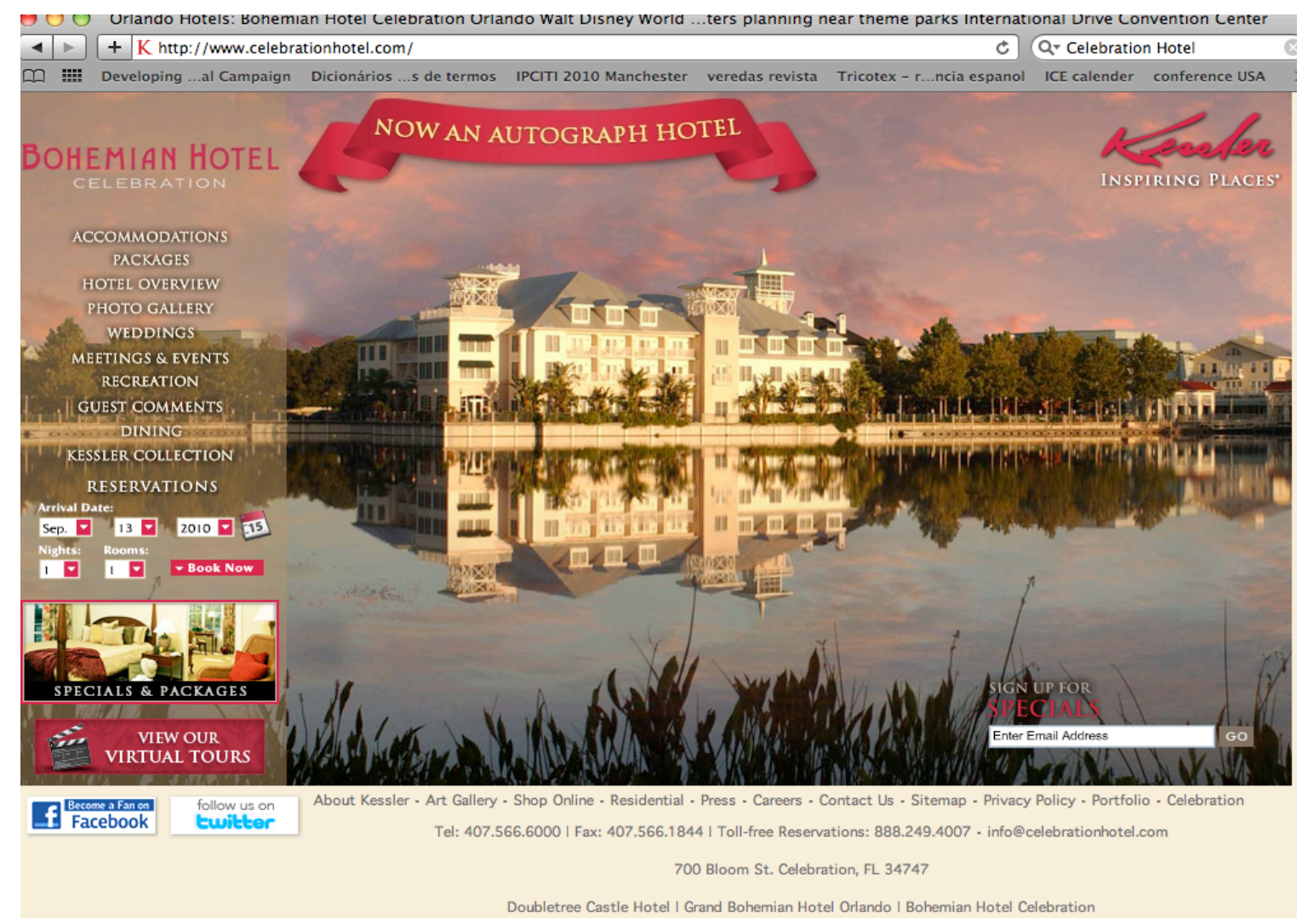

Figura 11 - Exemplo de site de estabelecimento hoteleiro nos Estados Unidos, de onde o texto foi extraído para compor o corpus em inglês.

A figura acima mostra o site do Bohemian Hotel Celebration, um hotel cinco estrelas localizado na Flórida, Estados Unidos. À esquerda da imagem, temos as seções do site, ou abas, indicando o tipo de informação que o cliente pode acessar: accommodations, packages, hotel overview, photo gallery, weddings, meeting \& events, recreation, guest comments, dining, Kessler Collection, reservations. Clicando em cada uma dessas abas, temos acesso ao texto descritivo, o qual é copiado manualmente para inserção no corpus. A título de ilustração, vejamos o texto da seção accommodations: 


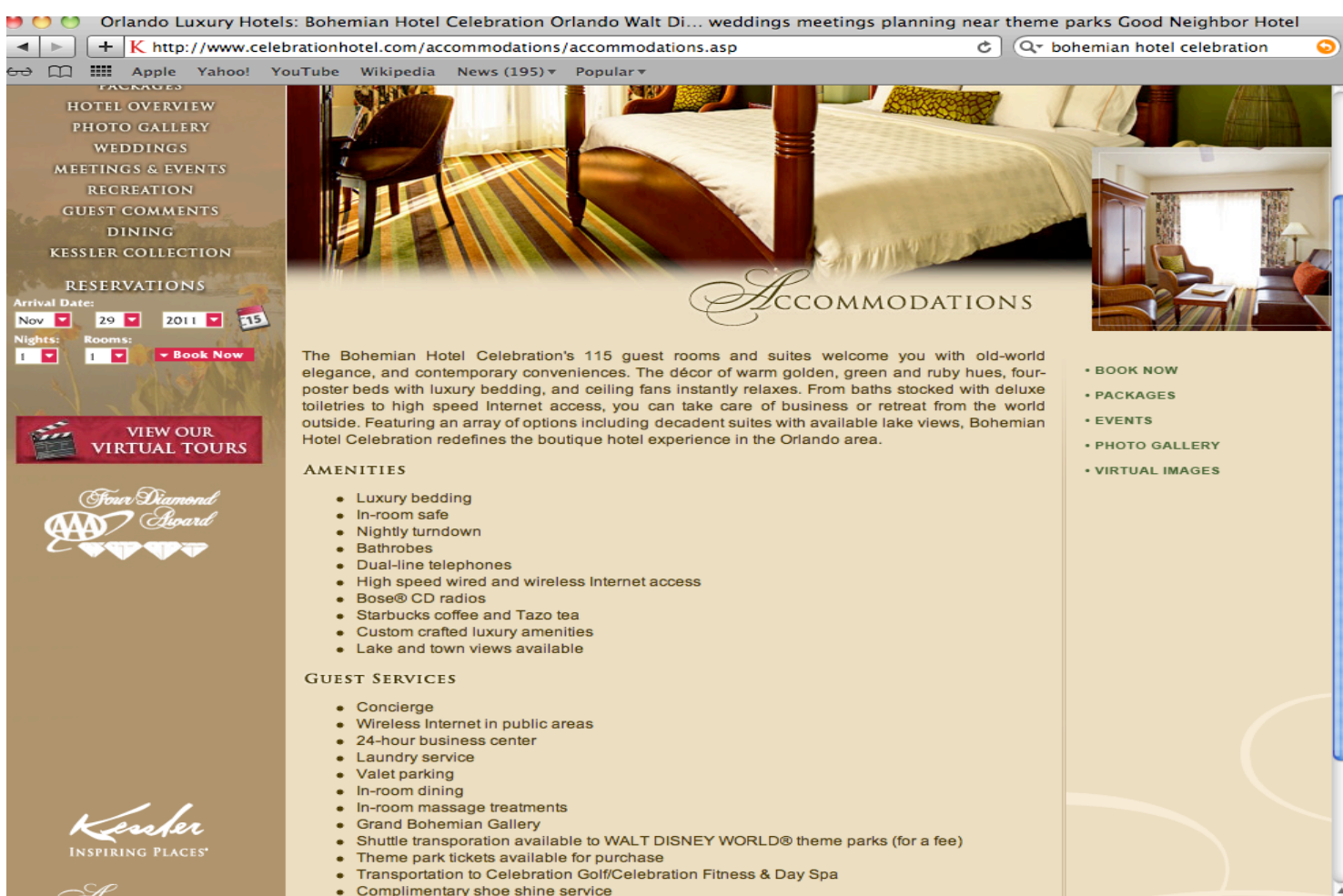

Figura 12 - Aba Accommodations, de onde o texto é extraído para integrar o corpus.

Em português, o procedimento é semelhante. Vejamos um exemplo de site de um estabelecimento no Brasil.

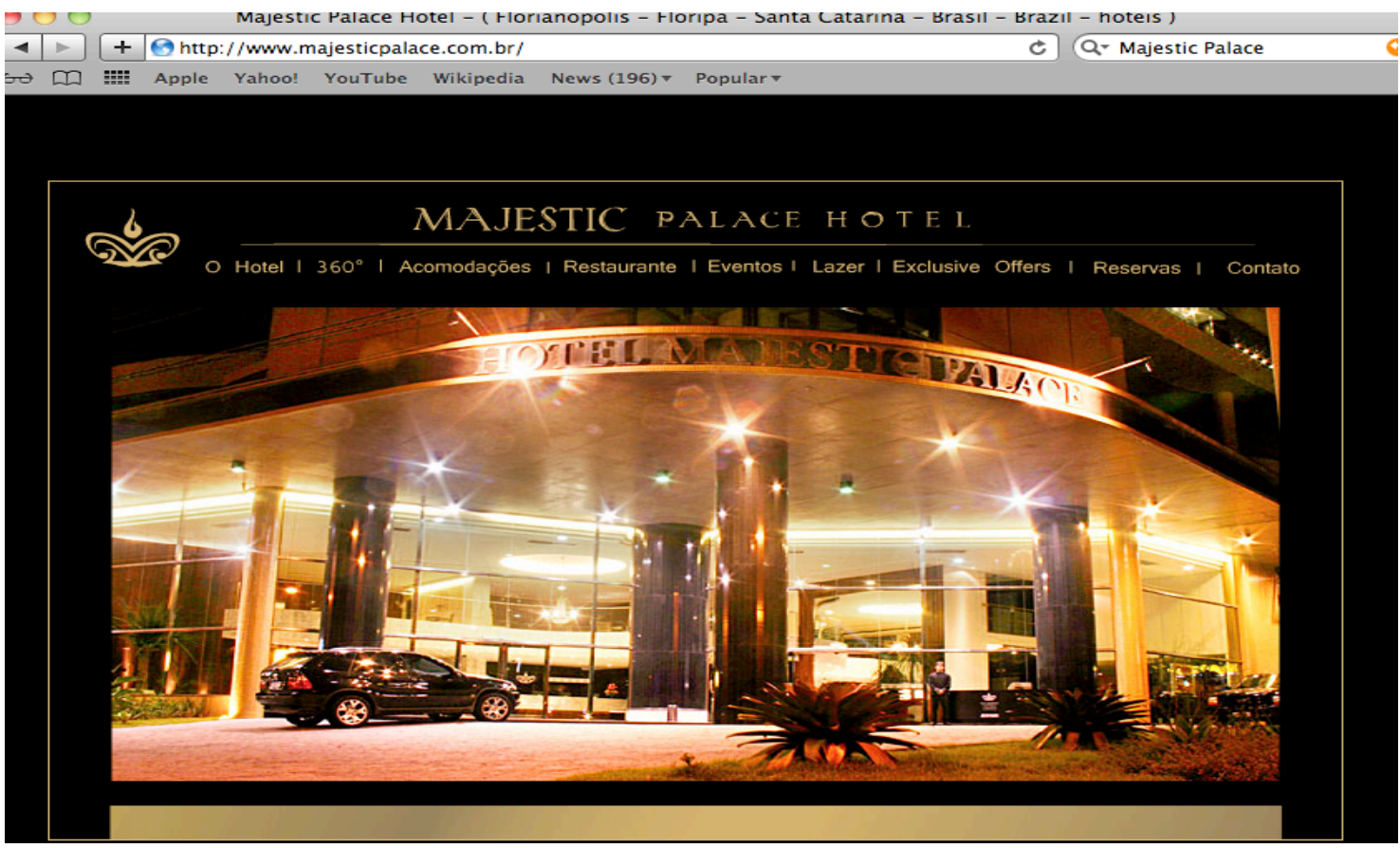

Figura 13 - Exemplo de site de estabelecimento hoteleiro no Brasil, de onde é extraído o texto para compor o corpus em português. 
A figura mostra o site do Majestic Palace Hotel, um hotel cinco estrelas em Florianópolis, Santa Catarina. As abas do site, localizadas na parte superior da imagem, destacam: o hotel, $360^{\circ}$ (fotos), acomodações, restaurante, eventos, lazer, exclusive offers, reservas, contato. A título de ilustração, vejamos o texto que coletamos ao clicar na aba acomodações:

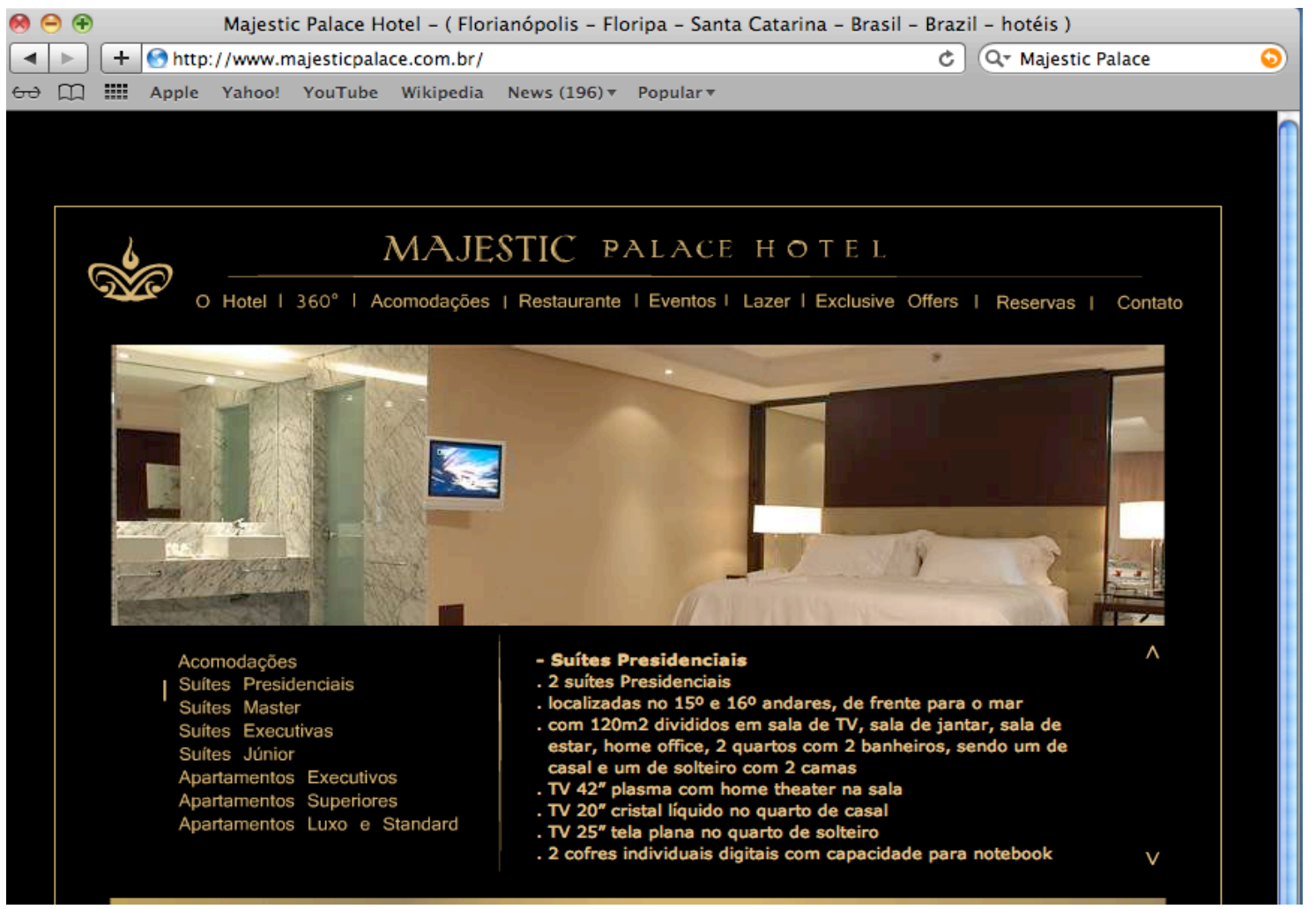

Figura 14 - Aba Acomodações, de onde é extraído o texto para o corpus.

As abas dos sites inspiraram as divisões dos textos também em seções, indicadas por tags ou etiquetas. Trataremos desse assunto mais adiante.

As imagens acima ilustram a essência de um corpus bilíngue comparável: textos autênticos de contexto semelhante em dois idiomas. A vantagem desse tipo de corpus para a prática terminológica é considerável, pois possibilita identificar os equivalentes colocacionais juntamente com outros padrões léxico-gramaticais típicos dos textos em seu respectivo idioma. Além disso, podemos observar as diferenças culturais entre os dois mundos retratados. Tais observações, quando pertinentes, são incluídas em nosso glossário.

Vale ressaltar que estamos lidando com a linguagem do ponto de vista do cliente (hóspede), veiculada no site do hotel, e não a partir da perspectiva do empreendedor 
hoteleiro. Em outras palavras, a linguagem sob investigação é a que descreve os hotéis e seus serviços para fins de marketing, destinada ao hóspede potencial; não incluímos, por exemplo, textos como o da Revista Hotéis, voltada para profissionais que atuam no segmento hoteleiro.

\subsubsection{Representatividade}

O critério de representatividade, como o nome indica, relaciona-se à função primordial do corpus de ser uma amostra adequada da linguagem que se pretende investigar. Nesse intuito, dois aspectos devem ser considerados - a extensão do corpus (Berber Sardinha, 2004: 22) e o recorte do âmbito da linguagem mais afinado com os fins da pesquisa. Tratam-se de critérios importantes, porém pouco objetivos. Fica, portanto, a cargo do pesquisar o julgamento quanto à extensão e conteúdo que melhor atendam aos objetivos do estudo.

Assim, com vistas à representatividade da linguagem da hotelaria e considerando os critérios mencionados, compilamos um corpus contendo as seguintes categorias, número de textos e palavras:

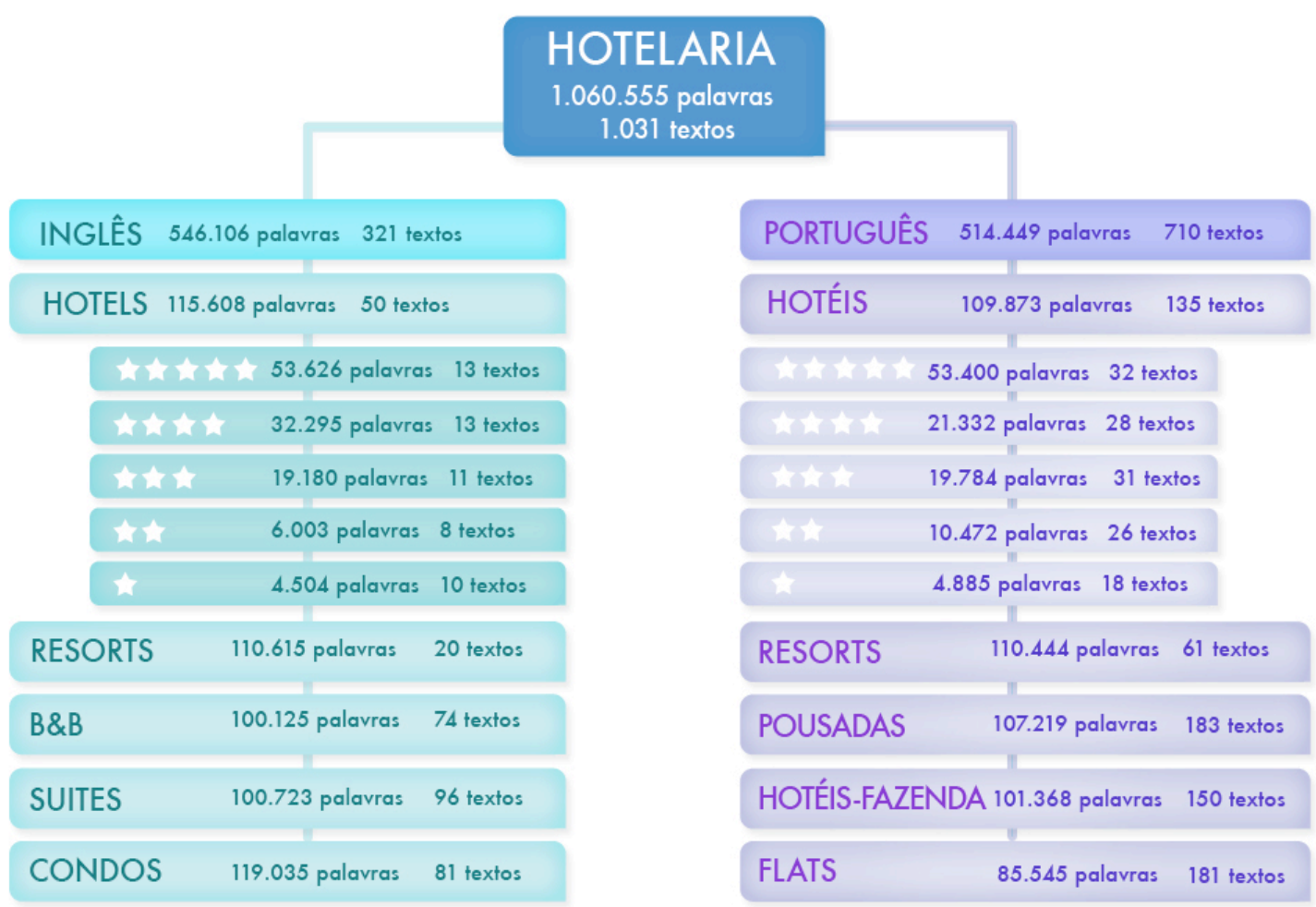

Figura 15 - Design do corpus e composição final. 
Como mostra a figura, o corpus está dividido em cinco categorias em cada idioma. Em inglês, temos hotels (1, 2, 3, 4, 5 estrelas), resorts, bed and breakfasts, suites e condos. Em português, as categorias são hotéis (1, 2, 3, 4, 5 estrelas), resorts, pousadas, hotéis-fazenda e flats.

A categorização acima baseou-se na classificação adotada por dois sites de reserva de hotéis: www.hotels.com, para as categorias em inglês, e www.hoteis.com.br, para português. Esses sites têm propósitos semelhantes: disponibilizar diversas opções de estabelecimentos - subdivididos nas categorias mencionadas - para que o cliente possa obter informações, escolher um hotel e realizar a reserva por meio do site.

Inicialmente, chama a atenção o fato de as categorias não serem exatamente equivalentes. Optou-se por manter essas diferenças para evidenciar que estão sendo representados dois mundos culturalmente distintos. Mesmo no caso de categorias correspondentes, como hotels - hotéis e resorts, também fica evidente a diferença cultural entre os dois países, pois muitos tipos de estabelecimentos são típicos de suas regiões e não encontram equivalentes totais em outro contexto cultural ${ }^{27}$. Para citarmos alguns exemplos, de um lado, temos luxuosos hotéis-cassino em Las Vegas, enquanto no Brasil, esse tipo de estabelecimento é ilegal. No Brasil, existem sofisticados hotéis de selva na região da floresta Amazônica ou hotéis-fazenda históricos na região de Minas Gerais, ao passo que nos Estados Unidos são muito populares os resorts temáticos da Disney na Flórida ou os resorts dedicados à prática de esqui em Denver.

Determinadas as categorias, a etapa seguinte foi levantar os estabelecimentos para compor cada uma delas. Para isso, nos valemos mais uma vez dos sites de buscas mencionados acima (hotels.com e hoteis.com.br), dentre outros sites semelhantes, nos quais é possível identificar nomes de estabelecimentos por categoria e cidade. Em relação à localização, buscamos, sempre que possível, selecionar estabelecimentos de cidades em todos os estados americanos e brasileiros.

A imagem a seguir mostra um exemplo de busca no site americano hotels.com. Para ilustrar, selecionamos estabelecimentos na cidade de Nova York; em seguida, o site retorna uma lista com nomes que se enquadram nessa especificação. De posse desses nomes, acessávamos o site oficial do hotel, de onde compilávamos o texto.

\footnotetext{
${ }^{27}$ Diferenças culturais observadas a partir da compilação do corpus serão tratadas mais adiante, na seção 3.1.4.
} 
Além desses sites, também realizamos buscas diretamente pelo Google, quando necessário.

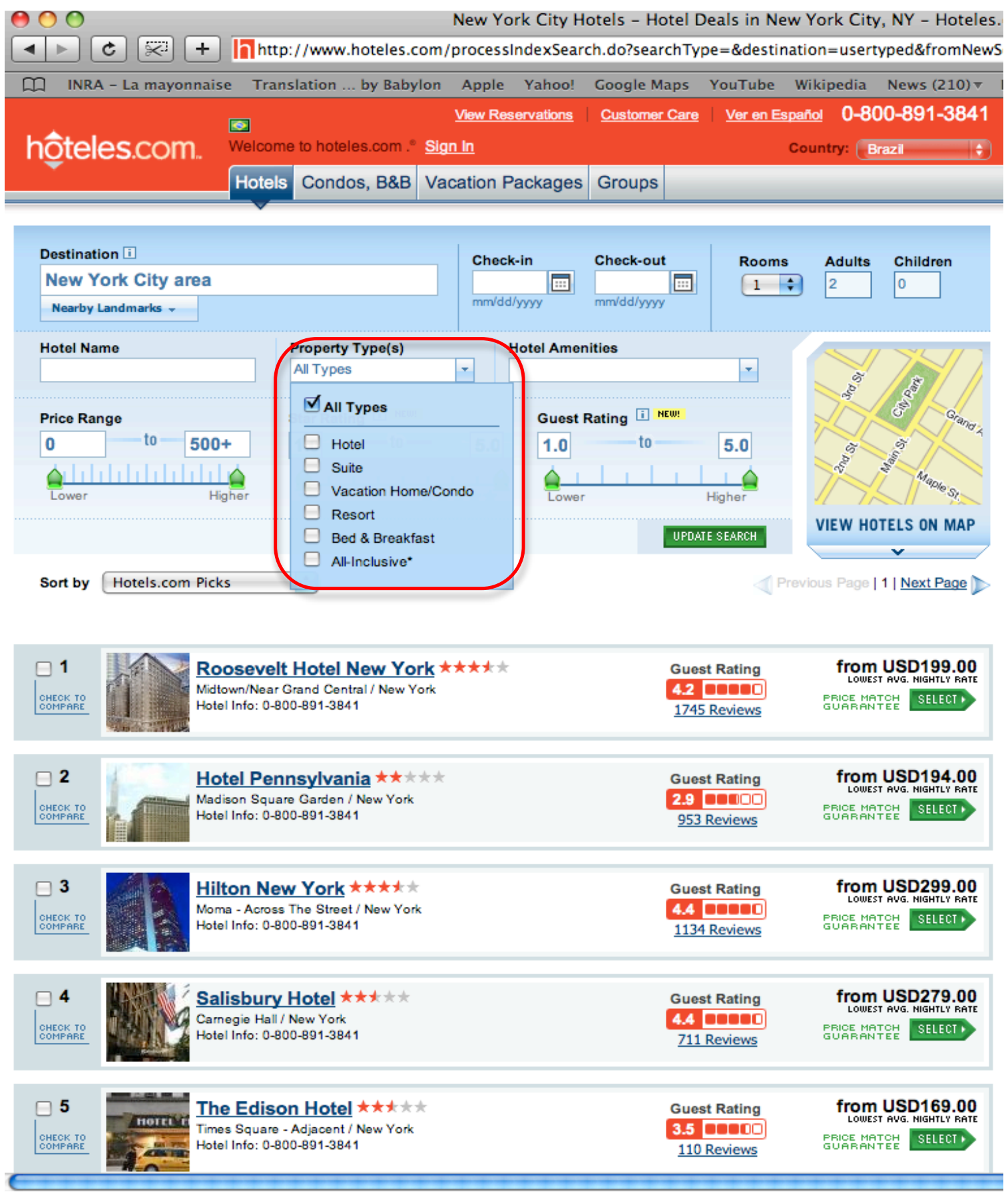

Figura 16 - Lista de nomes de estabelecimentos fornecida pelo site hotels.com; no destaque, categorias que basearam a classificação de nosso corpus em inglês.

Em termos numéricos (vide Figura 15), temos uma quantidade semelhante de palavras em cada idioma, 514.449 palavras em português e 546.106 em inglês, totalizando 1.060 .555 palavras. O número de textos é maior em português, 710 contra 321 em inglês, num total de 1.031 textos. 
Uma das características desejáveis a um corpus comparável é que ele seja balanceado, ou seja, possua um volume de dados semelhante entre os dois idiomas, o que pode ser aferido pelo número de palavras ou de textos. Como é possível notar pelos números mencionados, nosso corpus está balanceado pelo número de palavras, pois a quantidade de textos em português é mais que o dobro da quantidade de textos em inglês (710 vs. 321, respectivamente). No caso dos resorts em inglês, por exemplo, 20 textos somaram mais de 100 mil palavras; em português, foram necessários 67 textos para atingir essa marca, mais que o triplo. Esse dado demonstra que os textos em inglês são mais longos e descritivos, mas também evidencia uma marca cultural interessante, da qual trataremos mais adiante, ao relatar as diferenças culturais que o corpus possibilitou identificar.

\subsubsection{Tratamento dos textos}

Os textos que compõem o corpus são do gênero informativo e descritivo, voltados para fins de marketing. São salvos em formato .txt, para que possam ser processados pelo software WordSmith Tools (Scott, 2007, versão 5).

Os textos são categorizados primeiramente pela nomeação dos arquivos:

inglês

Categoria: Hotels

H-EN-H01-5s = Hotelaria, ENglish - Hote101-5stars

Categoria: Resorts

H-EN-R01 $=$ Hotelaria - ENglish - Resort01

Categoria: Bed \& Breakfasts

H-EN-BB01 = Hotelaria - ENglish - Bed \& Breakfast01

Categoria: Condos

H-EN-C01 $=$ Hotelaria - ENglish - Condos01

Categoria: Suites

H-EN-S01 = Hotelaria - ENglish - Suites01

português

Categoria: Hotéis

H-PT-H01-5s $=$ Hotelaria - Portuguese - Hotel01-5stars

Categoria: Resorts

H-PT-R01 $=$ Hotelaria - Portuguese - Resort01

Categoria: Pousadas

H-PT-P01 $=$ Hotelaria - Portuguese - Pousada01

Categoria: Hotéis-fazenda

H-PT-HF01 $=$ Hotelaria - Portuguese - HotelFazenda01

Categoria: Flats

H-PT-F01 $=$ Hotelaria - Portuguese - Flat01 
A identificação do tipo de estabelecimento no nome do arquivo traz vantagens no momento da exploração do corpus. Por exemplo, é possível selecionar facilmente apenas os arquivos de uma categoria específica, associar um dado a determinado tipo de hotel ou ainda evitar que uma colocação seja considerada recorrente quando aparece diversas vezes em apenas um ou dois arquivos.

Além da nomeação dos arquivos, foi necessária uma forma adicional de organizar e identificar os textos. Primeiramente, para evitar que um mesmo estabelecimento fosse compilado duas vezes e também para reunir de modo sistemático informações pertinentes sobre cada arquivo. Nesse intuito, elaboramos uma planilha em Excel contendo os seguintes campos:

- Data de coleta

- Nome do arquivo

- Nome do estabelecimento

- Cidade

- Tipo de estabelecimento

- Idiomas do site

- Observações gerais

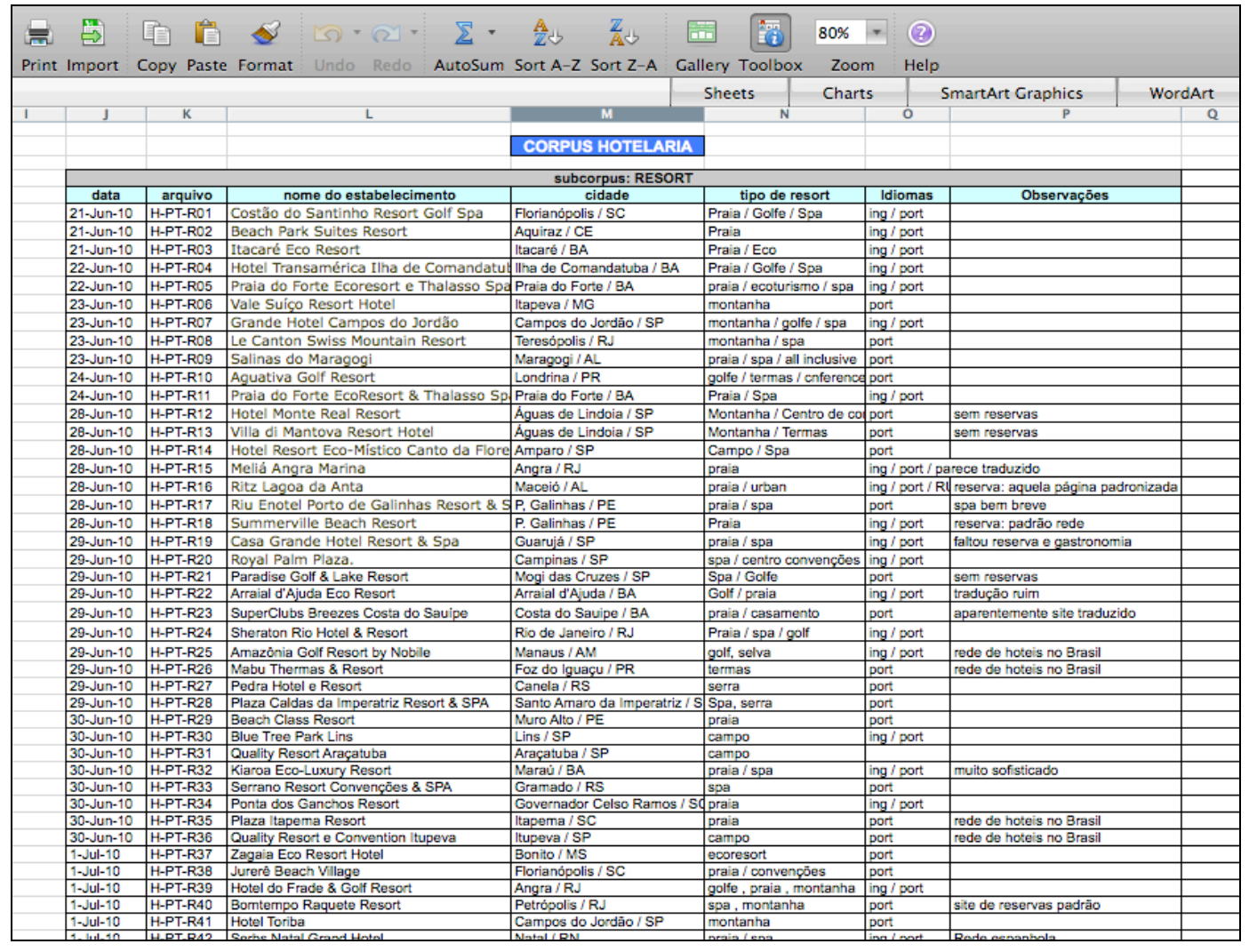

Figura 17 - Planilha em Excel (parcial), com a organização das informações do corpus. 
Internamente, os arquivos são identificados por meio de cabeçalhos, ou "trechos demarcados contendo informações não veiculadas verbalmente no evento comunicativo, que fornecem detalhes acerca de, por exemplo, proveniência, tipologia, autoria dos textos” (Berber Sardinha, 2004: 145). Essa marcação é feita manualmente, no momento da criação de cada arquivo. $\mathrm{O}$ intuito é identificar os textos de maneira sistemática, em especial com vistas a um reaproveitamento do corpus em futuras pesquisas. Em nosso caso, incluímos os seguintes dados no cabeçalho: nome do arquivo, domínio (hotelaria), nome do estabelecimento, localização, categoria do estabelecimento, idioma do texto, fonte (endereço do site), data da coleta, dentre outras informações sobre a tipologia textual, conforme pode-se observar na imagem a seguir:

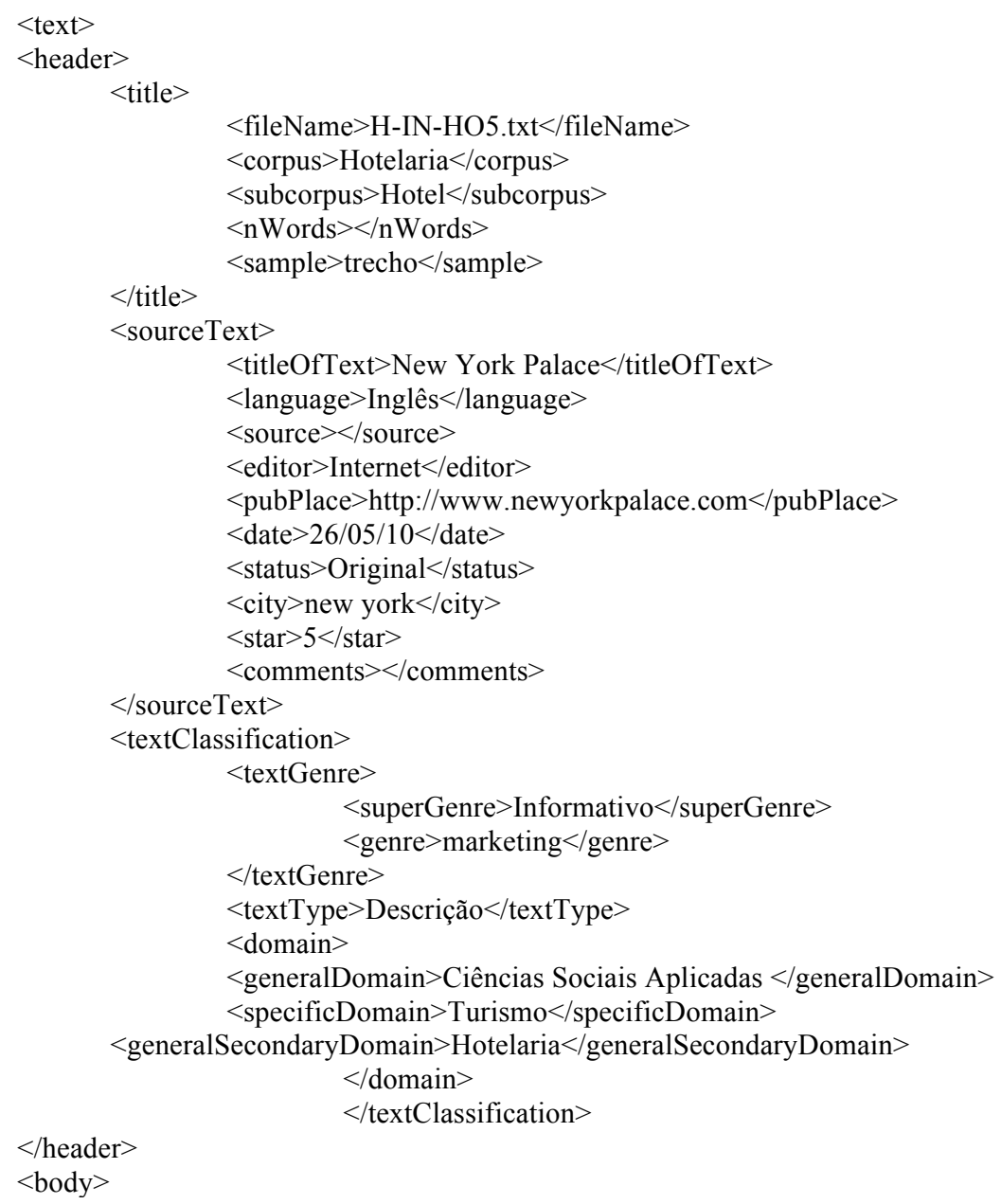

Figura 18 - Exemplo de cabeçalho preenchido. 
O conteúdo de cada texto varia de acordo com as informações veiculadas pelo estabelecimento. De maneira geral, os seguintes tópicos são abordados:

a) Introdução: informações gerais, como slogan, localização, promoções, etc.;

b) Acomodações: descrição das categorias e estrutura dos apartamentos, incluindo decoração, banheiros, comodidades, etc.;

c) Serviços e instalações: relação dos recursos e serviços do hotel, como estacionamento, piscina, serviço de quarto, spa, serviços de negócios, opções de lazer, etc.;

d) Gastronomia: informações sobre café da manhã, restaurantes, etc.;

e) Reservas e políticas: informações gerais sobre tarifas, promoções, procedimentos de reserva, política de pagamento, cancelamento, recebimento de animais de estimação, etc.;

Optamos por identificar esses tópicos no texto, o que foi possível por meio da inserção de etiquetas discursivas (Berber Sardinha, 2004: 114). O objetivo dessa categorização é garantir uma equivalência de conteúdo entre os dois idiomas, além de ampliar o leque de possibilidades de investigação, considerando, por exemplo, as seções individualmente no momento das pesquisas. Em nosso caso, as seguintes etiquetas foram utilizadas:

- $<$ site $>$ delimita as abas dos sites (Home, Acomodações, Reservas etc.);

- < intro> demarca informações gerais apresentadas logo na abertura do site;

- <accom> delimita as descrições das acomodações em geral;

- <amen_serv> delimita informações sobre comodidades e serviços;

- < dining > delimita informações sobre restaurantes e refeições;

- <reser_policy $>$ delimita a seção de reservas e políticas gerais do hotel.

Vale ressaltar que não incluímos nos textos todo o conteúdo dos sites. Foi necessário filtrá-lo manualmente no momento da coleta para que o corpus ficasse o mais equivalente possível entre os dois idiomas. Por exemplo, não incluímos as descrições das atrações turísticas locais, pois elas inchariam o corpus, mas com dados que não se referiam aos hotéis propriamente ditos. Da mesma forma, não incluímos conteúdos como: cardápios dos restaurantes, extensas listas de tratamentos e preços 
dos spas ou salões de beleza, orientações de como chegar até o hotel (nomes de ruas, estradas, aeroportos), seção "trabalhe conosco", histórico do estabelecimento, dentre outras que não julgamos pertinentes ao foco de nossa pesquisa.

Vejamos a seguir um exemplo de texto com as etiquetas. Algumas informações foram resumidas por questão de espaço.

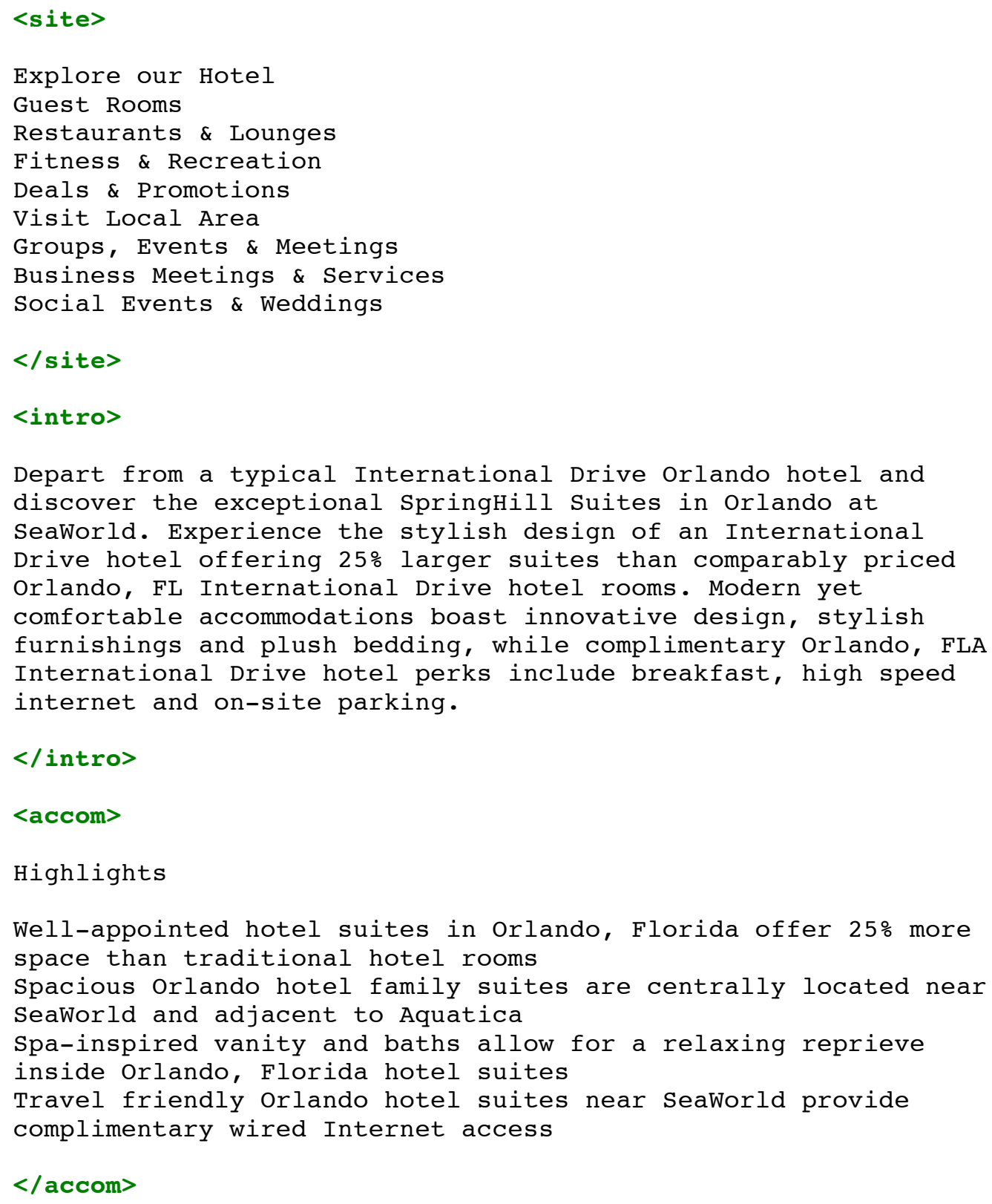




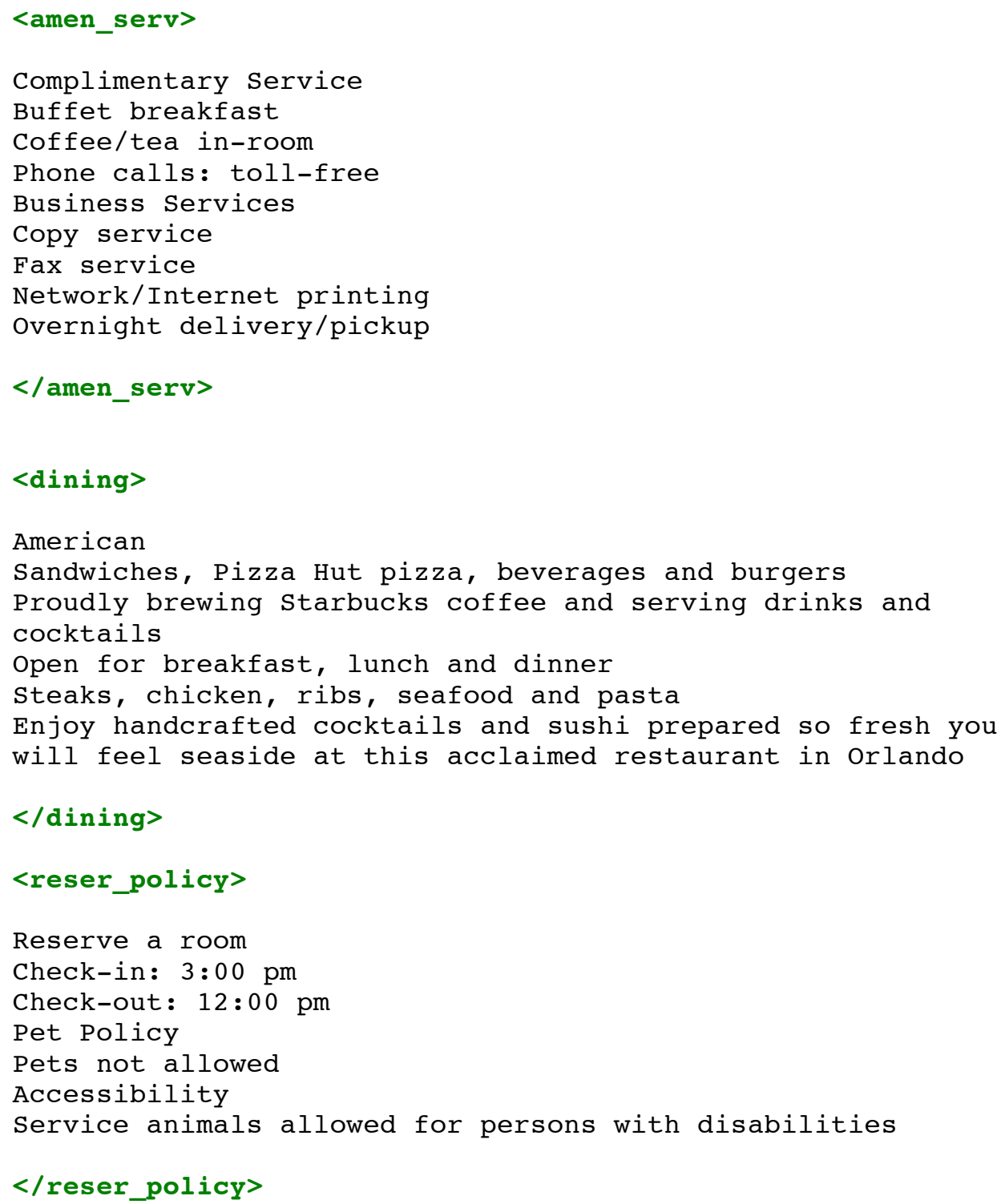

Figura 19 - Exemplo de texto do corpus com etiquetas.

Além das etiquetas discursivas demonstradas acima, nos valemos de um outro tipo de marcação que permite buscas no corpus segundo a classe gramatical das palavras. Trata-se da etiquetagem morfossintática.

Esse tipo de etiquetagem possibilita refinar e expandir os tipos de buscas realizadas no corpus. Por exemplo, é possível diferenciar os usos de um adjetivo e um verbo, como no caso de room features, em que pudemos investigar apenas os usos da colocação verbal (the room features) separadamente da colocação nominal (room 
features include). Além disso, esse tipo de etiquetagem também mostrou-se útil na identificação dos equivalentes colocacionais, expandindo seu número. Por exemplo, o corpus etiquetado permite fazer um levantamento de todos os adjetivos mais utilizados para qualificar apartamento. Assim, julgamos relevante trabalhar com as duas versões do corpus, uma sem e outra com as etiquetas morfossintáticas.

Esse tratamento é feito de forma automática, por meio de programas especializados denominados etiquetadores. Existem diversos etiquetadores disponíveis, em especial para o inglês, como WinBrill, Tosca, QTag, dentre outros (Berber Sardinha, 2004: 115-142). Para o nosso trabalho, utilizamos o Tree-Tagger, por ser um etiquetador gratuito e disponível on-line no site do LAEL (Programa de Linguística Aplicada e Estudos da Linguagem) ${ }^{29}$, criado pelo professor Tony Berber Sardinha, da Pontifícia Universidade Católica de São Paulo (PUC-SP).

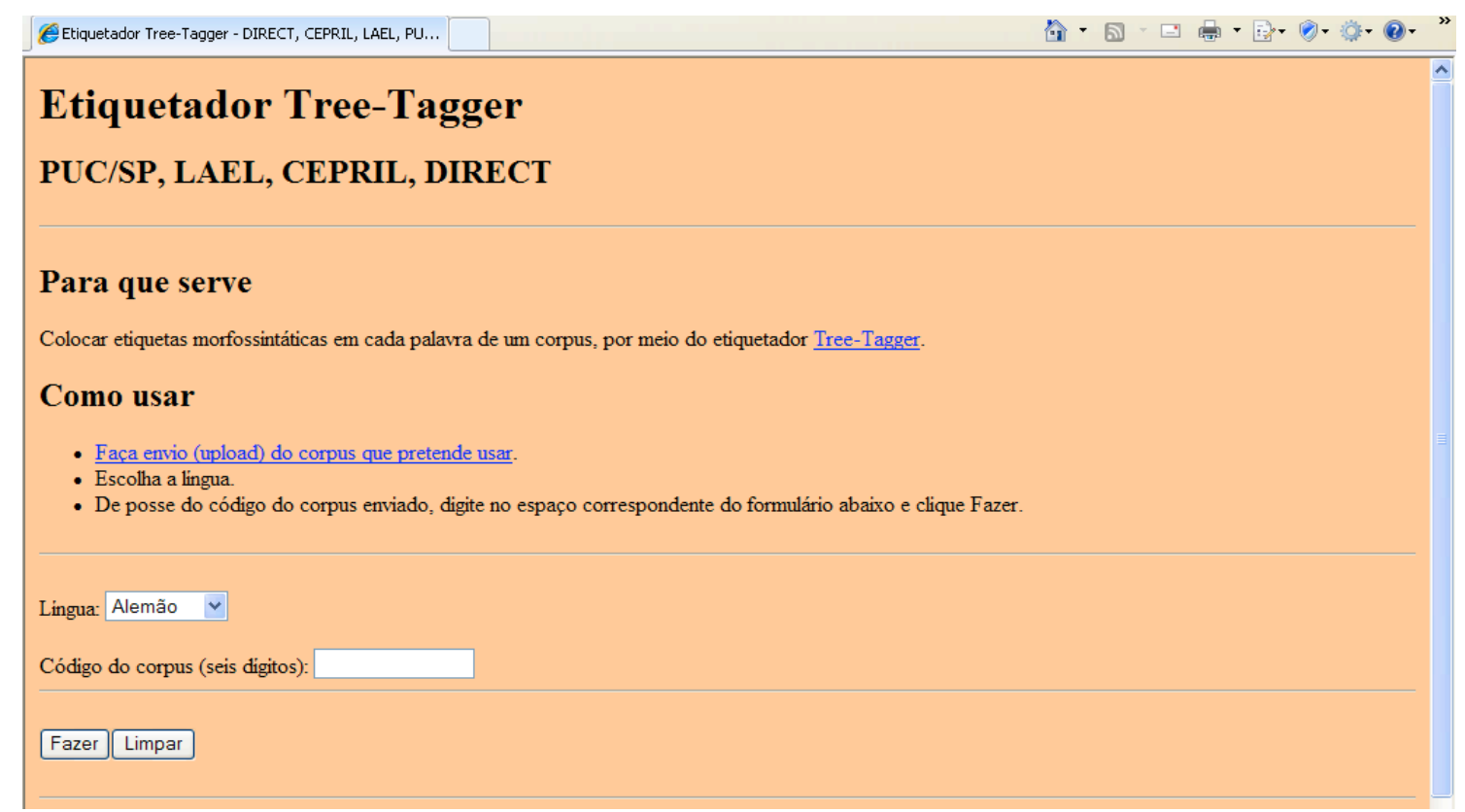

Figura 20 - Etiquetador Tree-Tagger disponível no site do LAEL (PUC-SP).

O próprio site fornece as instruções de como etiquetar os textos de modo simples e prático. Infelizmente, no momento de nossa utilização, o site estava fora do ar, sem previsão para o restabelecimento. Outra opção era utilizar o programa off-line, ou seja, instalá-lo no micro. Cientes da complexidade para a realização desse procedimento, nos

\footnotetext{
${ }^{29}$ Disponível em: <http://www2.lael.pucsp.br/corpora/etiquetagem/>.
} 
valemos do programa instalado por Sabrina Matuda para a realização de sua pesquisa de mestrado (Matuda, 2011), que gentilmente nos ajudou nessa etapa do trabalho.

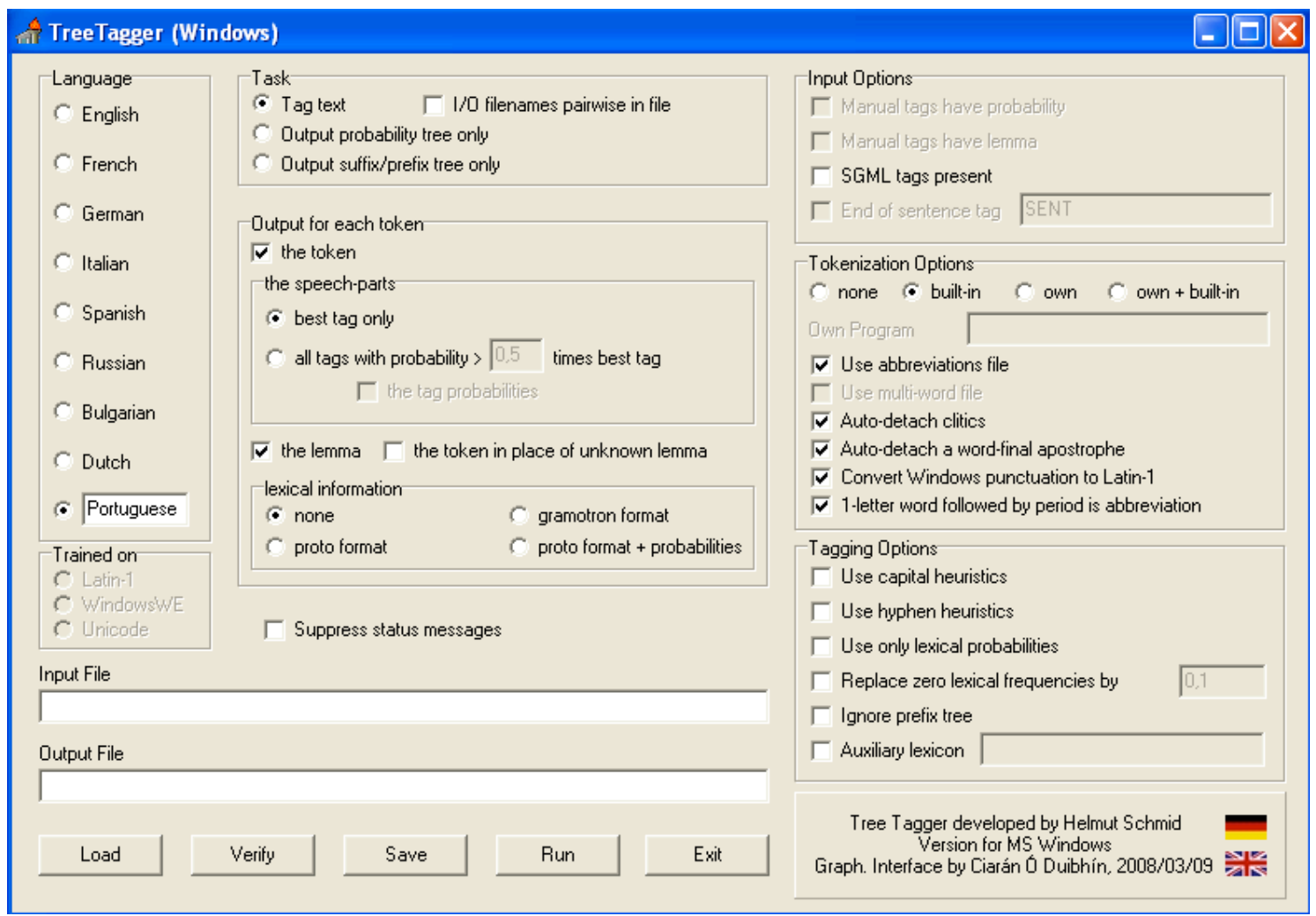

Figura 21 - Interface do Tree-Tagger. ${ }^{30}$

O primeiro passo [para etiquetar um texto] é selecionar a língua do texto a ser etiquetado. $\mathrm{Na}$ figura acima, selecionamos a opção em branco e digitamos "Portuguese". Após essa seleção, clicamos em "Input File" para selecionar o arquivo a ser etiquetado. Selecionado o arquivo, clicamos em "Output file" e o programa abre uma caixa de diálogo "Salvar Como" onde escolhemos a pasta de destino em que o arquivo seria armazenado. Por fim, nomeamos o arquivo, sempre acrescentando a terminação ".tag” para que o Tree-Tagger funcionasse corretamente. (Matuda, 2011: 116)

Uma vez etiquetados os textos, eles são processados pelo programa WordSmith Tools (Scott, 2007, versão 5), cujas ferramentas principais serão detalhadas na seção 3.2.1. As buscas são realizadas por meio de etiquetas específicas para cada classe morfossintática contemplada pelo etiquetador. É preciso consultar a tabela de etiquetas e

\footnotetext{
${ }^{30}$ Imagem cedida por Sabrina Matuda.
} 
identificar a expressão de acordo com a busca almejada. As etiquetas variam segundo o idioma e estão descritas a seguir (Matuda, 2011: 116 apud Santorini, 1991: 6-7).

Etiquetas para o idioma inglês:

\begin{tabular}{|c|c|}
\hline Etiqueta & Descrição \\
\hline $\mathrm{CC}$ & Coordinating conjunction \\
\hline $\mathrm{CD}$ & Cardinal Number \\
\hline DT & Determiner \\
\hline EX & Existential there \\
\hline FW & Foreign word \\
\hline IN & Preposition or subordinating conjunction \\
\hline $\mathrm{JJ}$ & Adjective \\
\hline JJR & Adjective, comparative \\
\hline JJS & Adjective, superlative \\
\hline LS & List item marker \\
\hline MD & Modal \\
\hline $\mathrm{NN}$ & Noun, singular or mass \\
\hline NNS & Noun, plural \\
\hline NP & Proper noun, singular \\
\hline NPS & Porper noun, plural \\
\hline PDT & Predeterminer \\
\hline POS & Possessive ending \\
\hline PP & Personal pronoun \\
\hline PP\$ & Possessive pronoun \\
\hline $\mathrm{RB}$ & Adverb \\
\hline RBR & Adverb, comparative \\
\hline RBS & Adverb, superlative \\
\hline $\mathrm{RP}$ & Particle \\
\hline SYM & Symbol \\
\hline TO & To \\
\hline $\mathrm{UH}$ & Interjection \\
\hline VB & Verb, base form \\
\hline VBD & Verb, past tense \\
\hline VBG & Verb, gerund or present participle \\
\hline VBN & Verb, past participle \\
\hline VBP & Verb, non-3rd person singular present \\
\hline VBZ & Verb, 3rd person singular present \\
\hline WDT & Wh-determiner \\
\hline WP & Wh-pronoun \\
\hline WP\$ & Possessive pronoun \\
\hline WRB & Wh-adverb \\
\hline
\end{tabular}

Quadro 1 - Etiquetas do Tree-Tagger (inglês). 
Etiquetas para o idioma português:

\begin{tabular}{|l|l|}
\hline \multicolumn{1}{|c|}{ Etiqueta } & \multicolumn{1}{c|}{ Descrição } \\
\hline ADJ & Adjetivo \\
\hline ADV & Advérbio \\
\hline DET & Determinante \\
\hline CARD & Número Cardinal / Ordinal \\
\hline NON & Nome Comum / Próprio \\
\hline P & Pronome \\
\hline PREP & Preposição \\
\hline V & Verbo \\
\hline I & Interjeição \\
\hline VIRG & Separadores dentro da oração \\
\hline
\end{tabular}

Quadro 2 - Etiquetas do Tree-Tagger (português).

As expressões de busca nada mais são do que a combinação de uma ou mais etiquetas e a palavra sendo pesquisada. Vejamos um exemplo de busca, utilizando a ferramenta Concord (vide 3.2.1) do WordSmith Tools (Scott, 2007, versão 5). Para investigar os adjetivos seguidos do substantivo apartamento(s), a expressão utilizada foi "NOM apartamento * ADJ", que significa: substantivo singular ou plural (NOM) apartamento mais qualquer $(*)$ adjetivo (ADJ). Os resultados estão ordenados pelos colocados à direita (destacados em verde) da expressão de busca:

\begin{tabular}{|c|c|c|c|}
\hline \multicolumn{3}{|c|}{ C Concord } & \multirow[t]{2}{*}{$-\theta x$} \\
\hline Edit & View Compute Settings Window Help & & \\
\hline \multicolumn{2}{|r|}{ N Concordance } & Set $\mid$ Tag $\mid$ Word \#|t. \#| os.|| & $\#$ os.| \\
\hline 1 & ADJ diferenciado como CONJ como os DET o apartamento NOM apartamento 17 ADJ @card@e CONJ e 18 ADV & $32,5925811 \%$ & $05 \%$ \\
\hline 2 & Quarto $\vee$ triplo CARD triplo solteiro ADJ solteiro Apartamento NOM apartamento aconchegante ADJ aconchegante e CONJ e & $36,720|038| 6 \% \mid$ & $08 \% \mathbf{l}$ \\
\hline 3 & \multirow{2}{*}{$\begin{array}{l}\text { NOM luz e CONJ e ar-condicionado } \vee \text {. SENT - apartamentos NOM apartamento aconchegantes ADJ aconchegante com } \\
\text { ter à PRP+DET a disposicẫo NOM disposiçẫo apartamentos NOM apartamento aconchegantes ADJ aconchegante e CON.J }\end{array}$} & $85,16405513 \%$ & $04 \% \mathbf{I}$ \\
\hline 4 & & $23,4622949 \%$ I & $06 \%$ \\
\hline 5 & acomodaçőes NOM acomodaçẫo em PRP em apartamentos NOM apartamento aconchegantes ADJ aconchegante, PUNCT & & $08 \% \mathbf{I}$ \\
\hline 6 & hotel conta $\vee$ contar com PRP com um DET um apartamento NOM apartamento adaptado ADJ adaptado para PRP para & & $04 \% \mathbf{l}$ \\
\hline 7 & năo ADV não fumante ADJ fumante - PUNCT - Apartamento NOM apartamento adaptado ADJ adaptado para PRP para & $02|292| 0 \% \mid$ & $00 \%$ \\
\hline 8 & - Wi $\vee$ Fi $\vee$ Contamos $\vee$ contar com PRP com apartamento NOM apartamento adaptado ADJ adaptado para PRP para & & $04 \% \mathbf{I}$ \\
\hline 9 & PRP+DET de manhã NOM manhã. SENT.$\cdot \vee$ Apartamento NOM apartamento adaptado ADJ adaptado para PRP para & & $04 \%$ \\
\hline 10 & e laminado $V$ laminar. SENT - Um DET um apartamento NOM apartamento adaptado ADJ adaptado para PRP para & 87|0\% & 09 \\
\hline 11 & de PRP de cabelo NOM cabelo; PUNCT - Apartamentos NOM apartamento adaptados ADJ adaptado para PRP para & $47|609| 6 \% \mathbf{I}$ & $06 \%$ \\
\hline 12 & \multirow{2}{*}{$\begin{array}{l}\text { ADV não fumantes ADJ fumante - PUNCT - Apartamentos NOM apartamento adaptados ADJ adaptado para PRP para } \\
\text { disso PRP+P de , PUNCT - possui } \vee \text { possuir apartamentos NOM apartamento adaptados ADJ adaptado para PRP para }\end{array}$} & ;80| $85618 \%$ I & 069 \\
\hline 13 & & $344426 \% \mathbf{l}$ & $06 \% \mathbf{l}$ \\
\hline 14 & hóspede NOM hóspede 7 PRP+DET @card@ apartamentos NOM apartamento adaptados ADJ adaptado para PRP para & & $08 \%$ \\
\hline 15 & V ? PUNCT . - PUNCT - 02 P+P @card@ apartamentos NOM apartamento adaptados ADJ adaptado para PRP para & $\mid 7 \%$ & $00 \%$ \\
\hline 16 & NOM serviço wi-fi $\vee$. SENT - Possuimos $V$ apartamentos NOM apartamento adaptados ADJ adaptado para PRP para & $\%$ & 09 \\
\hline 17 & eletrônico Telefone NOM telefone Frigobar $\vee$ Apartamentos NOM apartamento adaptados ADJ adaptado para PRP para & & $07 \% \mathbf{I}$ \\
\hline 18 & SENT - Dispomos $\vee$ dispor de PRP de apartamentos NOM apartamento adaptados ADJ adaptado para PRP para & $\% \mathbf{l}$ & $04 \% \mathbf{l}$ \\
\hline 19 & NOM totalizando V totalizar 48 DET @card@ apartamentos NOM apartamento alugados ADJ alugado por PRP por & & 07 \\
\hline 20 & \multirow{2}{*}{$\begin{array}{l}\text { : PUNCT - Exclusive ADV exclusive : PUNCT - Apartamento NOM apartamento amplo ADJ amplo e CONJ e confortável ADJ } \\
\text { PUNCT - Suíte NOM suíte Júnior } V: \text { PUNCT - Apartamento NOM apartamento amplo AD.J amplo e CONJ e confortável ADJ }\end{array}$} & $09,264|748| 3 \% \mid$ & $04 \%$ \\
\hline 21 & & $09,721|759| 5 \% \mathbf{I}$ & $04 \% \mathbf{I}$ \\
\hline 22 & Super NOM Luxo NOM luxo é $\vee$ ser um DET um apartamento NOM apartamento amplo A.DJ amplo e CONJ e aconchegante & $36,895|040| 4 \% \mathbf{l}$ & $08 \% \mathbf{l}$ \\
\hline 23 & \multirow{2}{*}{ local. SENT - De PRP de Luxe V: PUNCT - Apartamento NOM apartamento amplo AD.J amplo e CONJ e confortável ADJ } & $09,504|754| 3 \% \mathbf{I}$ & $04 \% \mathbf{l}$ \\
\hline 24 & & $9691 \%$ & $06 \%$ \\
\hline 25 & $\begin{array}{l}\text { AD.J melhor sonho NOM sonho. SENT - Apartamentos NOM apartamento amplos ADJ amplo, PUNCT - completos } V \\
\text { Plaza } \vee \text { oferece } V \text { oferecer } 102 \text { DET @card@ apartamentos NOM apartamento amplos ADJ amplo e CONJ e confortáveis } V\end{array}$ & 9|924] & $09 \% \mathbf{I}$ \\
\hline 26 & NOM campino com PRP com96 DET@card@ apartamentos NOM apartamento amplos ADJ amplo e CONJ e confortáveis $V$ & 4 062/5\% & \\
\hline 27 & .SENT - Possui V possuir84 DET@card@ apartamentos NOM apartamento amplos ADJ amplo, PUNCT - equipados & & \\
\hline 28 & \multirow{2}{*}{$\begin{array}{l}\text { ADJ composto por PRP por } 84 \mathrm{DET} @ \text { @ard@ apartamentos NOM apartamento amplos ADJ amplo e CONJ e confortáveis } V \\
\text { serviço categorizado } V \text { categorizar PUNCT - apartamentos NOM apartamento amplos ADJ amplo e CONJ e confortáveis }\end{array}$} & $42,2984577 \% \mathbf{I}$ & 07 \\
\hline 29 & & $53,520|918| 9 \% \mid$ & $00 \% \mathbf{l}$ \\
\hline & 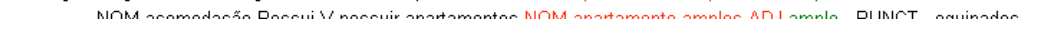 & & \\
\hline
\end{tabular}

Figura 22 - Linhas de concordância parciais de apartamento(s) + adjetivos no corpus etiquetado. 
A seção de discussão dos resultados apresenta as demais expressões de busca utilizadas na investigação do corpus.

\subsubsection{Critérios redefinidos}

A compilação de um corpus não é uma tarefa simples e livre de obstáculos. Pelo contrário, inúmeros são os desafios que surgem desde o momento do planejamento até a etapa final de exploração. Assim, os critérios de compilação e a metodologia seguida precisam ser constantemente revisitados e aperfeiçoados. A seguir, serão relatadas algumas dificuldades que exigiram a redefinição de determinados critérios da construção do corpus.

Ao iniciarmos nossa pesquisa, já tínhamos em mãos mais de 1000 textos descritivos de hotéis, em formato .txt, no idioma inglês, em decorrência de um projeto de tradução de que participamos. Esses textos integravam o conteúdo do site de buscas e reservas www.hotels.com. Ao realizar as primeiras pesquisas com esse corpus praticamente pronto, percebemos que a linguagem altamente padronizada representava as idiossincrasias daquele cliente. Optamos, assim, por descartar esse corpus. Passamos a utilizar o site www.hotels.com apenas como ponto de partida para identificar os hotéis das diferentes categorias, para então nos dirigirmos ao site do próprio estabelecimento, de onde coletávamos o texto. Assim, conseguimos garantir uma maior variedade linguística.

Um dos maiores problemas enfrentados foi no momento da definição da estrutura do corpus. Nosso intuito era representar todas as categorias de hotéis e, para isso, iniciamos uma pesquisa sobre as diferentes tipologias de hotéis. Nesse momento, identificamos diversas possibilidades de classificação. No Brasil, por exemplo, encontramos as seguintes possibilidades:

- Classificação do Ministério do Turismo: divide os estabelecimentos nas categorias superluxo (5 estrelas SL), luxo (5 estrelas), superior (4 estrelas), turístico (3 estrelas), econômico (2 estrelas) e simples (1 estrela) (Aldrigui, 2007:39). A questão envolvendo essa classificação é que, pelo fato de ser relativamente nova (entrou em vigor a partir de 2002), é necessário que todos os hotéis classificados pelo modo antigo solicitem e paguem pelo enquadramento na 
nova classificação. Assim, segundo dados disponíveis no site da Associação Brasileira da Indústria de Hotéis ${ }^{31}$, apenas 23 estabelecimentos estão classificados oficialmente, sendo 19 hotéis e 4 resorts. Outro problema com essa categorização é o fato de ser muito abrangente, ou seja, para incluir estabelecimentos além de "hotéis" (como resorts, hotéis-fazenda, pousadas, etc.), precisaríamos de uma classificação complementar. De qualquer forma, resolvemos manter a classificação por estrelas para a subcategoria de hotéis por ser bastante conhecida no mundo todo.

- Classificação comercial: é aquela cuja validação é feita pelos consumidores ou pelo mercado, como, por exemplo, a do Guia Michelin e Guia Brasil 4 Rodas. No caso da publicação brasileira, os estabelecimentos são identificados por “casinhas", sendo: 5 casinhas - luxo; 4 casinhas - muito confortável; 3 casinhas confortável; 2 casinhas - médio conforto; 1 casinha - simples ${ }^{32}$. Essa classificação parece ser bastante consistente, apesar de os critérios não serem divulgados (Aldrigui, 2007: 41). Optamos por não utilizá-la porque julgamos estar muito próxima à classificação por estrelas, que, por vez, é mais conhecida e amplamente divulgada. Além disso, não encontramos um sistema equivalente a esse para os estabelecimentos em inglês. No entanto, o site do Guia Brasil 4 Rodas foi utilizado como uma importante fonte de consulta.

Outras categorizações que integram a classificação comercial são as disponibilizadas pelos sites de busca de hotéis, como as que elegemos para esta pesquisa, e as dos mais variados guias de viagem.

- Classificação independente: bastante similar à comercial, mas restrita a determinadas empresas. É o caso dos hotéis que se autodenominam "seis estrelas" ou "o melhor". Outro exemplo são os grupos hoteleiros, especialmente os de presença internacional, que estabelecem diferentes marcas para as diferentes categorias de serviço. É o caso do grupo Accor Hotels, dono de marcas mais sofisticadas, como Sofitel, Novotel, Mercure, às mais simples, como Ibis, Formule 1 e Parthenon. Esse tipo de classificação é muito restrita, portanto, limitaria a representatividade de nosso corpus. Mas há estudos interessantes que comparam a

\footnotetext{
${ }^{31} \mathrm{http}: / /$ www.abih.com.br/UtilPub_Classificacao.php acesso em 15/07/2011.

$32 \mathrm{http}$ //viajeaqui.abril.com.br/guia4rodas/busca/hoteis/index_hosp.php casso em 15/07/2011.
} 
linguagem utilizada pelo mesmo grupo para descrever os hotéis destinados a públicos variados (Dias, 2006).

Um ponto em comum entre as classificações acima está no fato de se concentrarem no grau de conforto, na qualidade dos serviços e também nos preços dos estabelecimentos. É possível ainda definir os tipos de hotéis conforme a sua localização (hotel de cidade, de praia, de montanha, de aeroporto) ou destinação (hotel de turismo, negócios, lazer, cassino, convenções, etc.) (Andrade et al., 2007: 45).

Em relação às categorias de hotéis nos Estados Unidos, a dificuldade de encontrar uma classificação única foi ainda maior. Apenas na obra Hotel Design Planning and Development (Adams et al., 2001) são listados mais de 50 tipos de estabelecimentos. Duas citações dos autores do livro resumem bem essa realidade do mercado:

Apesar de as classificações de hotéis serem necessárias para organizar e servir como parâmetro, elas não são de maneira alguma perfeitas e não substituem o conhecimento específico do caráter individual e atributos detalhados do hotel. (Adams et al., 2001: 6) ${ }^{33}$

Com os novos tipos de hotéis e as possibilidades de combinações praticamente infinitas, é cada vez mais difícil para o hóspede escolher um hotel quando as denominações são inadequadas e equívocas. Hotéis no centro da cidade possuem o mesmo número de quadras de tênis, piscinas e saunas que os resorts. Os resorts hospedam a mesma quantidade de visitantes de conferências que os hotéis para esse fim localizados no centro da cidade ou próximos aos aeroportos. Os motor inns não são superiores aos motels. Os inns não são necessariamente antigos. Lodge, spa e guest ranch também são denominações pouco claras. O preço não é um indicador - hotéis caros podem ter apartamentos pequenos, ao passo que hotéis econômicos possuem apartamentos maiores e mais bem decorados. Comprar com base nos atributos parece ser a nova tendência. (Adams et al., 2001: 6) ${ }^{34}$

Diante desse cenário e das inúmeras possibilidades, optamos pela classificação oferecida pelos sites www.hotels.com (Hotels (1-5 estrelas), Resorts, Bed

\footnotetext{
33 While hotel classifications are necessary for the purpose of organizing and referencing information, they are by no means perfect and no substitute for specific knowledge of the individual character and detailed ingredients of the hotel.

34 Along with the new hotel types and almost infinite combination varieties, it is increasingly difficult for guests to select a hotel when labels are inadequate or misleading. Downtown hotels have as many tennis courts, pools and saunas as resorts. Resorts have as many convention or conference guests as downtown convention hotels or airport meeting centers. Motor inns are not necessarily superior to motels. And "inns" are not necessarily old. "Lodge", "spa", "guest ranch" are also unclear labels. Price is no indicator - expensive hotels may have small rooms, while budget hotels have larger, better appointed rooms. Buying on the basis of ingredients looks like the new wave.
} 
\& Breakfasts, Condos, Suites) e www.hoteis.com.br (Hotéis (1-5 estrelas), Resorts, Pousadas, Hotéis-fazenda, Flats), cientes de que estamos diante de uma categorização imperfeita e limitada. Entretanto, julgamos essa opção válida para atender os objetivos de nossa pesquisa por algumas razões.

Primeiramente, o foco de nossa pesquisa é a terminologia utilizada nas descrições dos hotéis e não as categorias de hotéis em si. Na realidade, percebemos que, independentemente do rigor da classificação, existe uma sobreposição das categorias e estabelecimentos. Assim, o mesmo hotel cinco estrelas pode ser um hotel superluxo, cinco casinhas ou um Sofitel. Em inglês, o mesmo hotel três estrelas também se identifica como inn. Considerando mais uma vez o enfoque deste trabalho, optamos por uma classificação oferecida diretamente ao público final, ao hóspede, e não ao profissional da hotelaria. Além disso, levamos em conta a semelhança entre os sites americano e brasileiro em termos de propósito: disponibilizar de maneira organizada informações sobre uma diversidade de estabelecimentos hoteleiros, permitir que o hóspede escolha um deles com base nos seus critérios de busca e, finalmente, realize uma reserva. Por fim, consideramos a facilidade de utilizar o próprio site como fonte para identificar estabelecimentos das respectivas categorias.

Tendo definido as categorias, passamos para a etapa de compilação propriamente dita. Nossa meta inicial era balancear o corpus por número de textos. $\mathrm{Na}$ primeira categoria em inglês, Hotels, alcançamos pouco mais de 100 mil palavras com 50 textos. Em português, 50 textos geraram cerca de 40 mil palavras. Um estudo piloto realizado com esse corpus mostrou que seria necessário incluir mais textos em português para obter mais opções de equivalentes. Além disso, como a oferta de textos na internet é farta, não haveria razão para ter um corpus com poucas palavras em português. Redefinimos assim o critério do balanceamento e passamos a realizá-lo por número de palavras.

Os três casos relatados acima - um anterior à construção do corpus, um na fase de estruturação das categorias e outro durante a compilação - ilustram como, na prática, a elaboração de um corpus não se dá de maneira linear, mas exige alguns, senão diversos, ajustes e mudanças de direção. Nossa experiência é corroborada pelos 
dizeres de Zanettin: "A criação de um corpus envolve uma série de ajustes entre o desejo ideal e o possível, dadas as limitações práticas e teóricas”35 (2002: 329).

\subsubsection{Aspectos culturais revelados pela compilação do corpus}

A despeito das dificuldades relatadas anteriormente, a construção do corpus também lançou luz sobre aspectos culturais da hotelaria que não esperávamos encontrar. Esta seção, embora não trate especificamente da metodologia, pretende discutir alguns desses aspectos.

Por aspectos culturais nos referimos a características do domínio da hotelaria típicas de cada um dos países representados - EUA e Brasil. Não pretendemos adentrar a complexa questão sobre a diversidade de enfoques e definições para o termo cultura (Katan, 2004). Neste ponto, nosso objetivo é simplesmente relatar alguns aspectos característicos do domínio da hotelaria que puderam ser observados no momento da compilação do corpus e que tiveram impacto sobre a sua construção. Pretendemos também mostrar que o processo de construção de um corpus é capaz de fornecer subsídios adicionais para a compreensão mais aprofundada da área de especialidade sob investigação.

Primeiramente, faremos algumas observações sobre a relação entre os nomes dos estabelecimentos e as categorias de hotéis. Em seguida, destacaremos aspectos específicos de cada categoria contemplada no corpus. Abordaremos também a linguagem empregada por hotéis de grandes redes internacionais. Por fim, comentaremos sobre a diferença observada no volume de informação veiculado nos sites de hotéis brasileiros e americanos.

Retomando a dificuldade de se estabelecer uma categorização uniforme para os hotéis, constatamos que alguns nomes de estabelecimentos corroboram essa problemática. Durante a etapa de seleção dos textos, procuramos privilegiar estabelecimentos cuja categoria estivesse explicitada no nome, por exemplo, $X X$ Bed and Breakfast ou Pousada XX. Entretanto, na prática, nos surpreendeu observar casos

\footnotetext{
${ }^{35}$ the creation of a corpus involves a series of compromises between what is ideally desirable and what is possible given practical and theoretical limitations.
} 
de sobreposição das categorias, desafiando nosso entendimento sobre elas, como uma pousada resort ou um resort inn. Vejamos alguns exemplos:

Pousada Hotel Fazenda Laranjal

Pousada Resort 7 Belo

Vale Suiço Resort Hotel

Hotel Cabreúva Resort

Búzios Flat Pousada

Pitangueiras Hotel Fazenda \& Resort

Em inglês, temos casos semelhantes:

Copa Cabana Resort Hotel \& Suites

Four Ambassadors Condo Suites Hotel

Ocean Resort Inn

Ao analisar os sites desses estabelecimentos, observamos realidades distintas. Há casos em que existe de fato uma mescla nos tipos de serviço, como o Four Ambassadors Condo Suites Hotel, que oferece serviços de Hotel e de Condo (explicaremos essa categoria mais adiante), até mesmo com sites diferentes para cada um deles. Em outros casos, apenas uma das categorias se sobressai, como o Hotel Cabreúva Resort, que destaca no seu site suas características de resort. Por vezes, agregar um título a mais ao nome do estabelecimento parece ser uma estratégia de marketing. Por exemplo, pelo seu site, a Pousada Resort 7 Belo é um resort, mas o slogan anuncia que o preço é de pousada; já o Pitangueiras Hotel Fazenda \& Resort é um hotel-fazenda com inúmeras opções de lazer, donde a referência a resort, mas oferecer opções de lazer é uma característica comum aos hotéis-fazenda. Constatamos também casos de total ausência de uma diferenciação no tipo de estabelecimento, como no Búzios Flat Pousada, em que os apartamentos são simplesmente denominados flats, mas serviços de flat não são oferecidos. E, por fim, observamos ainda inúmeros casos de divergência entre o nome anunciado nos sites de reserva de hotéis e o nome do site oficial do estabelecimento. Esse é o caso do Vale Suiço Resort Hotel, que aparece com a palavra hotel nos sites de reserva, mas sem ela no site oficial.

Em suma, observamos casos de falta de critérios objetivos para as denominações dos estabelecimentos. Nesse sentido, procuramos privilegiar aqueles cuja categoria estivesse bem definida no nome, mas não nos prendemos a esse critério de modo rígido. 
Por exemplo, muitos flats não contêm a palavra flat no nome, mas foram selecionados por terem sido indicados pelos sites de reservas. No caso dos estabelecimentos 'mistos', incluímos o texto sob a categoria mais representativa; por exemplo, um hotel resort foi considerado resort, por essa categoria ser mais específica do que hotel, um termo utilizado de modo mais genérico.

A compilação de cada categoria permitiu aprofundar o entendimento sobre elas. Mencionaremos apenas alguns dos inúmeros aspectos que nos chamaram a atenção por terem sido desconhecidos inicialmente.

Na categoria Hotéis, conforme mencionamos, adotamos a divisão clássica por estrelas. Chamou-nos a atenção, no entanto, a dificuldade de se encontrar estabelecimentos brasileiros identificados como uma e duas estrelas, o que não aconteceu na busca por estabelecimentos nos EUA. No lugar dessa denominação, notamos que hotéis mais simples no Brasil se intitulam econômicos ou até mesmo low cost. Nossa hipótese é que a classificação com poucas estrelas tem um valor negativo no Brasil; portanto, os estabelecimentos preferem evitá-la. Outra hipótese é que os hotéis muito simples não sejam privilegiados pelos sites de reservas ou simplesmente não estejam anunciados na internet. Assim, para conseguir preencher essa categoria, foi necessário buscar hotel econômico ou selecionar os hotéis marcadamente mais baratos.

A categoria Resort apresentou aspectos culturais bastante típicos dos dois países. Identificamos nos Estados Unidos diversos tipos de resorts que não encontram equivalentes diretos no Brasil, como, por exemplo, casino resorts, island resorts, hunting resorts e snow resorts. Em relação a esses últimos, verificamos tratar-se não apenas de um estabelecimento, mas de verdadeiras estâncias de esqui. Esse é o caso do Beaver Creek, no Colorado, que abriga vilarejos, restaurantes, lojas, spas e opções de vida noturna, conforme podemos observar na imagem a seguir. 


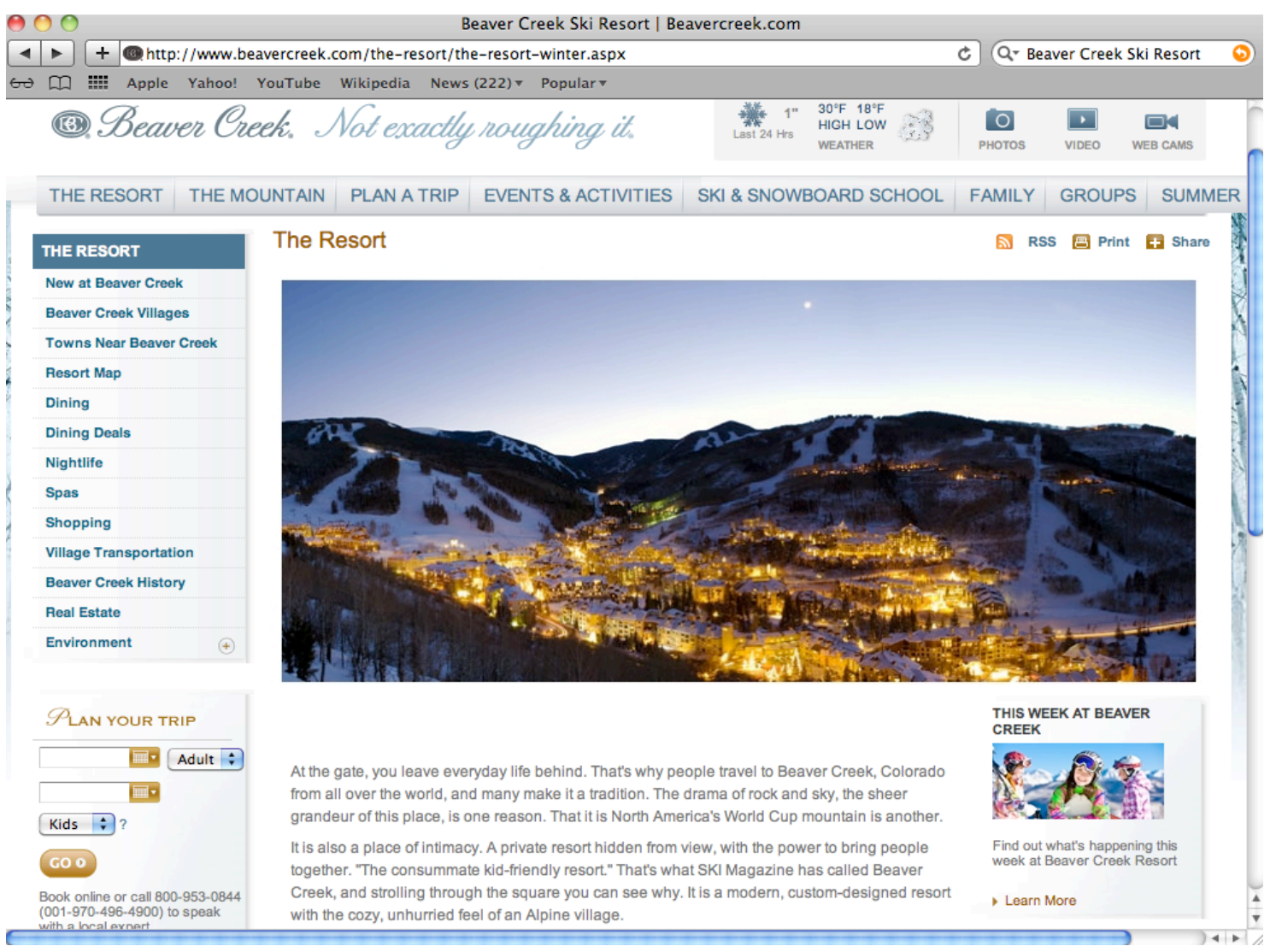

Figura 23 - Site do snow resort Beaver Creek, nos Estados Unidos.

Em relação à categoria de Pousadas, um dos aspectos que nos chamou a atenção foi a presença de empreendimentos de luxo, contrariando nossa visão sobre esse tipo de estabelecimento. A Pousada Maravilha em Fernando de Noronha, por exemplo, oferece luxuosos bangalôs à moda dos resorts no Taiti, com diárias na casa dos 2 mil reais.

Semelhantemente, a categoria de Bed and Breakfast também apresentou grande variação no tipo de estabelecimento. Como o nome faz supor, bed and breakfast é um estabelecimento que fornece acomodação e café da manhã. No entanto, encontramos desde estabelecimentos simples, como o Rosewind Farm B\&B, uma casa com dois quartos em uma fazenda, até grandes empreendimentos, como o Elk Forge Bed and Breakfast Inn and Retreat, que abriga um spa e amplas instalações para negócios e eventos.

Ao compilar a categoria de Hotéis-fazenda, observamos maior incidência desses empreendimentos na região Sudeste do Brasil, em especial, nos estados de São Paulo e Minas Gerais. Nesses hotéis, a culinária, a flora e a fauna recebem destaque, conferindo-lhes uma forte marca cultural. Nos Estados Unidos, encontramos 
estabelecimentos dedicados ao turismo rural, em geral identificados por termos como ranch, farm e country, mas pertencentes a categorias diversas (resorts, inns, hotel, etc.), ou seja, existem estabelecimentos semelhantes, mas não sob uma categoria bem definida e popular como no Brasil.

Também com maior concentração na região Sudeste, porém nas grandes cidades, temos os estabelecimentos da categoria Flat, que engloba empreendimentos hoteleiros destinados a hóspedes temporários e moradores permanentes. São, portanto, apartamentos que combinam características de uma residência com serviços de hotel. Incluímos também nesta categoria os estabelecimentos denominados apart-hotéis, por oferecerem serviço semelhante.

Por fim, gostaríamos de comentar duas categorias bastante comuns nos Estados Unidos - Condos e Suites.

A primeira representa um tipo de empreendimento que oferece unidades residenciais (denominadas condominiums ou condos) ou uma combinação de acomodações hoteleiras tradicionais e unidades residenciais que desfrutam dos serviços do hotel (os chamados condo hotels ou condo resorts). Essas unidades variam de apartamentos a casas de veraneio e podem ser alugadas ou adquiridas como forma de investimento. Como exemplos, podemos citar o Executive Keys Condos, no Texas, que oferece condos - neste caso, casas de veraneio - em frente ao mar; e o Victorian CondoHotel Resort \& Conference Center no Texas, que disponibiliza os condos apartamentos - na área do resort.

A categoria de Suites, como o nome indica, traz empreendimentos compostos por unidades na forma de suites - apartamentos com quarto e banheiro em uma área separada da sala de estar e que inclui geralmente uma cozinha. De modo geral, esses estabelecimentos visam atender a um público interessado em estadias prolongadas. $\mathrm{Na}$ prática, observamos que eles possuem características bastante semelhantes aos hotéis tradicionais. Constatamos ainda a frequente combinação da palavra suites e a outras categorias, como inn \& suites, suites \& resort e suites hotel, sem que isso diferencie o estabelecimento de modo claro.

Pelo que pudemos observar, essas duas categorias - Condos e Suites - não possuem equivalentes totais e diretos no Brasil - existem empreendimentos com características semelhantes, porém com denominações distintas. Por exemplo, um flat no Brasil assemelha-se em alguns aspectos a um condo hotel nos Estados Unidos, mas 
esse último pode incluir até mesmo luxuosas casas de veraneio, o que não verificamos no caso dos flats.

Também verificamos que questões geográficas e históricas influenciam as características de diversos estabelecimentos. Nos Estados Unidos, podemos citar o Isabelle Inn, em Los Angeles, Califórnia, construído para recriar o ambiente das tradicionais plantations no sul do país; o Cottages at Garden Gate Get-a-way, em Millesburg, Ohio, situado em meio a montanhas e à comunidade Amish; e o Legacies Bed \& Breakfast, com temática histórica dedicada à Route 66 e ao Grand Canyon National Park, onde está localizado. No Brasil, podemos citar a Pousada do Príncipe, em Paraty, no Rio de Janeiro, pertencente ao bisneto da Princesa Isabel, com temática que recria o período Imperial no Brasil. Outros exemplos são a Pousada Alto Xingu e a Pousada Mutum, ambas na região do Pantanal e dedicadas ao ecoturismo, com ampla referência à natureza da região.

Constatamos ainda diferenças nas especialidades dos serviços oferecidos. Por exemplo, nos Estados Unidos, encontramos hotéis dedicados exclusivamente ao público gay (gay friendly hotels) ou ao chamado turismo de nudismo (clothing optional hotels); no Brasil, essas especialidades não foram encontradas. Verificamos também ser bastante usual nos Estados Unidos a realização de casamentos nos estabelecimentos hoteleiros, desde os grandes resorts até os mais pitorescos bed and breakfasts. No Brasil, esse serviço existe, porém, é bem menos usual, o que pôde ser confirmado pelo corpus: wedding(s) ocorreu 735 vezes, ao passo que casamento(s), apareceu 136 vezes, mesmo com um número de estabelecimentos bem maior em português.

Outra questão relevante no momento da seleção dos textos foi a consideração dos hotéis de redes hoteleiras internacionais, como Marriott, Sheraton, Ocean Breezes, Hilton, Ceasar Park, Sofitel, dentre outras. Por serem de uma mesma rede, os estabelecimentos apresentam características semelhantes, como estrutura e serviços. Assim, a linguagem veiculada nos sites também apresenta padrões próprios da rede, mesmo em se tratando de estabelecimentos de categorias distintas e em cidades diferentes, como o Renaissance São Paulo Hotel, o JW Marriott Hotel Rio de Janeiro e o flat Apartamentos Executivos São Paulo, todos da rede Marriott. Nesse sentido, optamos por evitar sempre que possível compilar textos de uma mesma rede hoteleira, a fim de garantir uma maior variedade linguística para o corpus.

Ainda em relação à linguagem dos hotéis de grandes redes, foi curioso observar 
sites de estabelecimentos no Brasil que mostravam sinais evidentes de serem traduzidos para o português. Em alguns casos, como o do hotel Mercure São Paulo Alamedas, notamos até mesmo a variante do português de Portugal, observada em trechos como: secador de cabelo na casa de banho, cozinha equipada com micro-ondas e frigorífico. Os exemplos são diversos, mas a título de ilustração, gostaríamos de analisar apenas a seguinte página do site do Sheraton, um hotel cinco estrelas em Foz do Iguaçu.

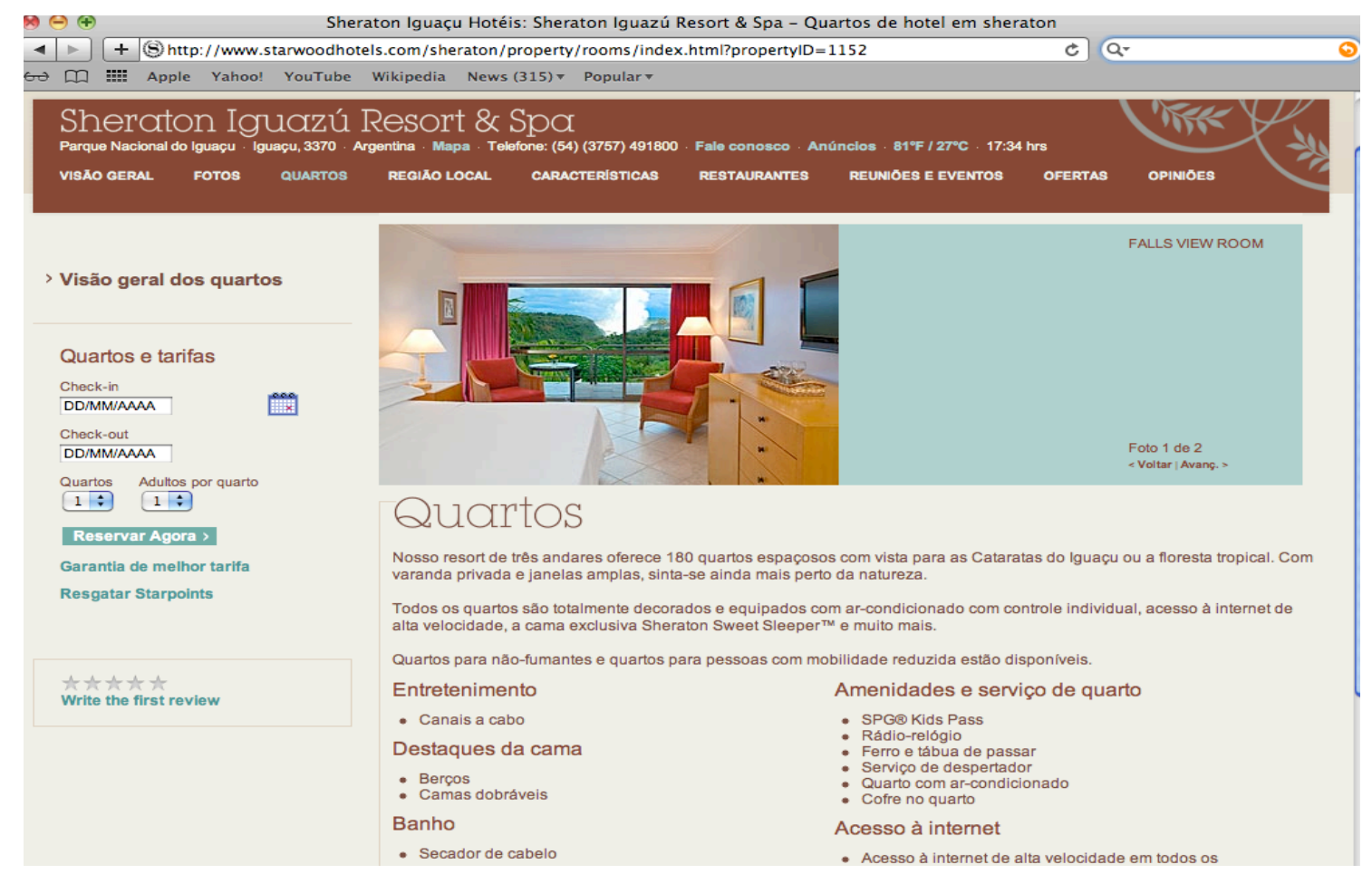

Figura 24 - Site do hotel Sheraton, em Foz do Iguaçu.

Chama inicialmente a atenção o fato de "Iguaçu" estar grafado com $z$, uma versão mais internacional do nome da cidade. Com uma leitura rápida, é possível observar trechos estranhos, como destaques da cama e, em seguida, berços. Notamos também palavras menos usuais em português que remetem diretamente a termos frequentes no inglês, segundo nossa pesquisa com o corpus. É o caso de quartos, tradução direta de rooms, quando o mais usual é apartamentos; ou amenidades, tradução literal de amenities, no sentido de instalações ou facilidades; ou ainda reservar agora, que remete a book now, quando em português usa-se frequentemente faça sua reserva. Não podemos afirmar com precisão em que condições esse texto foi produzido, mas fica evidente não se tratar de um texto escrito originalmente em português. Dessa forma, ao observarmos indícios de tradução no momento da compilação, optamos por 
descartar o estabelecimento, uma vez que nosso objetivo é trabalhar com textos escritos originalmente nos idiomas em questão.

Por fim, a partir da observação de centenas de sites de estabelecimentos no Brasil e nos Estados Unidos, gostaríamos de destacar um aspecto marcante entre eles a diferença no volume de texto.

Conforme mencionamos anteriormente, foi preciso balancear o corpus pelo número de palavras e não de textos, visto que em português as descrições se mostraram bem mais sucintas que em inglês. Esse fato ficou contundente nos números finais do corpus: para alcançar um pouco mais de 500 mil palavras em cada idioma, foram necessários 321 textos em inglês e 710 em português, mais que o dobro. Isso denota que os sites americanos trazem uma quantidade de informações maior que os sites brasileiros, descrevendo mais características e com maior riqueza de detalhes.

Essa diferença pode ser explicada por uma teoria antropológica que considera o grau de expectativa de cada cultura em relação ao volume de informação linguística (texto) que precisa ser explicitado para que a comunicação seja bem-sucedida. Em outras palavras, algumas culturas tendem a inferir mais pelo contexto, ao passo que outras tendem a explicitar mais os elementos contextuais.

Segundo esse conceito, elaborado por Edward Hall (1976), contexto refere-se às informações armazenadas na mente dos falantes ou "a quantidade de informação que se espera que a outra pessoa tenha sobre determinado assunto" (Hall, 1983: 61 apud Katan, 2004: 245$)^{36}$. Assim, existem culturas nas quais os integrantes partem do pressuposto que o interlocutor dispõe de um alto volume de informação, sendo denominadas de high context cultures. Privilegia-se, portanto, uma comunicação mais econômica, na medida em que muito pode ser inferido pelo contexto e há menos tolerância à sobrecarga de informação. No outro extremo, estão as low context cultures, culturas que tendem a uma comunicação baseada na informação transmitida de forma mais explicitada.

Os estudiosos dessa teoria chegaram a desenvolver uma escala que associa as diferentes culturas à preferência por uma forma de comunicação mais econômica (high context) ou mais explícita (low context). Nessa escala, as culturas suíça, alemã e norteamericana, por exemplo, são classificadas como low context, ao passo que a japonesa, a árabe e as latino-americanas são consideradas high context (Victor, 1992: 143 apud Katan, 2004: 253). Vale a ressalva de que nenhuma cultura encontra-se em apenas um

\footnotetext{
${ }^{36}$ the amount of information the other person can be expected to possess on a given subject.
} 
extremo dessa escala, mas apresenta tendências e que essa orientação pode variar de acordo com a situação (Katan, 2004: 247).

Com base nesses conceitos, os números apresentados pelo nosso corpus de estudo corroboram essa tendência no âmbito da hotelaria: a cultura brasileira tende a operar com base em uma comunicação high context, e a americana está mais orientada a uma comunicação low context. De maneira geral, todos os tópicos mencionados nos sites dos hotéis apresentam diferença no nível de informação entre as duas culturas, qual seja, um maior detalhamento nos sites americanos do que nos brasileiros.

O Four Seasons Resort Hualalai at Historic Ka'upulehu, no Havaí, ilustra bem um desses aspectos - as acomodações. O resort oferece seis apartamentos e 13 suítes e descreve cada uma das 19 unidades individualmente, ainda que apresentem características bastante semelhantes. São incluídas informações sobre vista, metragem, decoração, comodidades, tipo de cama, móveis na sala e características do banheiro; há ainda fotos e um quadro com um resumo dos detalhes de cada acomodação. Nos estabelecimentos brasileiros, encontramos em geral apenas uma descrição para todas as acomodações da mesma categoria ou uma breve descrição de cada uma delas, além de um nível de detalhamento menor; por exemplo, não são usuais descrições detalhadas dos banheiros ou das camas.

Para ilustrar esse contraste com um exemplo mais concreto, selecionamos um trecho da descrição das acomodações do Cobb Lane Bed and Breakfast, no Alabama, e do Hotel Fazenda Clube dos 200, em São Paulo, ambos com temática histórica.

Traçaremos alguns comentários na sequência de cada descrição. 
Southern Magnolia Suite - It features a golden Cupid Chandelier, and rare Scarlet O'Hara fainting couch, period clothes on display, an antique pedal sewing machine, tea service and is beautifully appointed in every detail. Perfect for private conversations and lingering sunset views. Delightful and relaxing, this room is usually the favorite of Antique lovers and Honeymooners.

* Academy Award winner Patricia Neal selected this room during her stay

* 1898 ornamental Fire Place

* Half Tester Queen Size High Bed with steps

* Private Bath with Athenian relief, Tub with Shower

* Persian Rug

* Antique wash-station in room

* Sterling silver tea service

* French Armoire with beveled glass mirrors

* Magnificent multi-faceted crystal chandelier in Bedroom

* Beautiful rose chandelier in bath room

* 12 Foot High Ceilings

* Large bay windows with deep rose luxurious custom draperies

* Rich Mahogany original paneling

* Beautifully appointed in every respect

Figura 25 - Descrição das acomodações do Cobb Lane Bed and Breakfast.

Observa-se a riqueza de detalhes da descrição, traduzida na preocupação em mencionar, por exemplo, o ano de construção da lareira (1898 ornamental Fire Place), a descrição da cama (Half Tester Queen Size High Bed with steps), o tipo de decoração nos azulejos do banheiro (Private Bath with Athenian relief), o formato do lustre no banheiro (Beautiful rose chandelier in bath room), as características das cortinas (deep rose luxurious custom draperies) e até mesmo a altura do pé-direito (12 Foot High Ceilings). A descrição detalhada é ainda complementada por uma foto. Constata-se, portanto, a tentativa de "contextualizar" a acomodação, trazendo o maior número de informações possíveis para que o futuro hóspede saiba exatamente o que esperar.

Vejamos a seguir um exemplo de descrição das acomodações de um hotelfazenda histórico no Brasil:

Temos dois tipos de acomodações aqui no Clube dos 200: Apartamentos e Chalés. Os apartamentos são quartos situados no interior do casarão principal e que conservam o charme e o mobiliário antigo e importado da época da construção do hotel. Mantendo as características originais da construção, todos os apartamentos foram restaurados e possuem banheiro privativo e ventiladores de teto.

Os Chalés são quartos externos ao casarão, situados bem próximo à sede (50 mts). Além da localização, os chalés diferenciam-se dos apartamentos por terem sido construídos em época diferente. Sendo assim, eles possuem a mesma estrutura, um pouco menores que os apartamentos, mas apresentam características um pouco mais modernas na decoração.

Figura 26 - Descrição das acomodações do Hotel Fazenda Clube dos 200. 
Nota-se inicialmente uma descrição geral para todos os apartamentos e suítes. Ao descrevê-los, muitos detalhes são omitidos. Por exemplo, em "os apartamentos (...) conservam o charme e o mobiliário antigo e importado da época da construção do hotel", não se sabe exatamente qual ou como é esse mobiliário ou de que período é a construção do hotel. Nessa mesma linha, ao descrever os chalés ("eles possuem a mesma estrutura, um pouco menores que os apartamentos, mas apresentam características um pouco mais modernas na decoração"), não se menciona novamente a estrutura do apartamento e não se sabe em que medida eles são menores ou mais modernos. Fica evidente, portanto, que a descrição é bem mais genérica e sucinta, deixando margem para uma interpretação mais livre.

Não se pode afirmar que essa ou aquela descrição é melhor ou pior. Entendemos que ambas são suficientes dentro da cultura em que estão inseridas.

Nesta seção, nosso objetivo foi demonstrar que a construção do corpus trouxe à tona uma série de questões que colaboraram para um entendimento mais aprofundado sobre o domínio da hotelaria. Por ser uma etapa eminentemente prática, ela levou a uma longa incursão pela realidade que nos aventuramos a estudar, ampliando, por vezes confundindo, nosso conhecimento prévio da área. Antes mesmo da análise linguística, essa etapa ampliou a dimensão do nosso estudo para o universo cultural representado pelo corpus, trazendo contribuições interessantes e relevantes para a pesquisa.

\subsection{Exploração do corpus e procedimentos de análise}

Nesta seção, apresentaremos as ferramentas e os procedimentos empregados para a identificação das colocações em inglês e seus equivalentes em português. Tratase de uma metodologia semiautomática: partimos dos dados fornecidos pelo software WordSmith Tools (Scott, 2007, versão 5) e, em seguida, realizamos uma análise qualitativa desses dados.

Inicialmente, será feita uma descrição das ferramentas do referido software utilizadas para a pesquisa. Em seguida, serão delineados os passos para a identificação das colocações. Por fim, ilustraremos por meio de exemplo como a metodologia foi empregada. 


\subsubsection{Ferramentas do WordSmith Tools e parâmetros adotados}

A pesquisa linguística em todo o material compilado depende da utilização de um software que permita examinar os dados contidos no corpus. Para essa etapa da pesquisa, utilizamos o software de análise lexical WordSmith Tools, versão 5, de autoria de Mike Scott (2007). Vale ressaltar que o programa não interpreta os dados, sendo essa a função do pesquisador. O programa apenas apresenta os dados de maneira organizada, os quais são então selecionados, avaliados e interpretados.

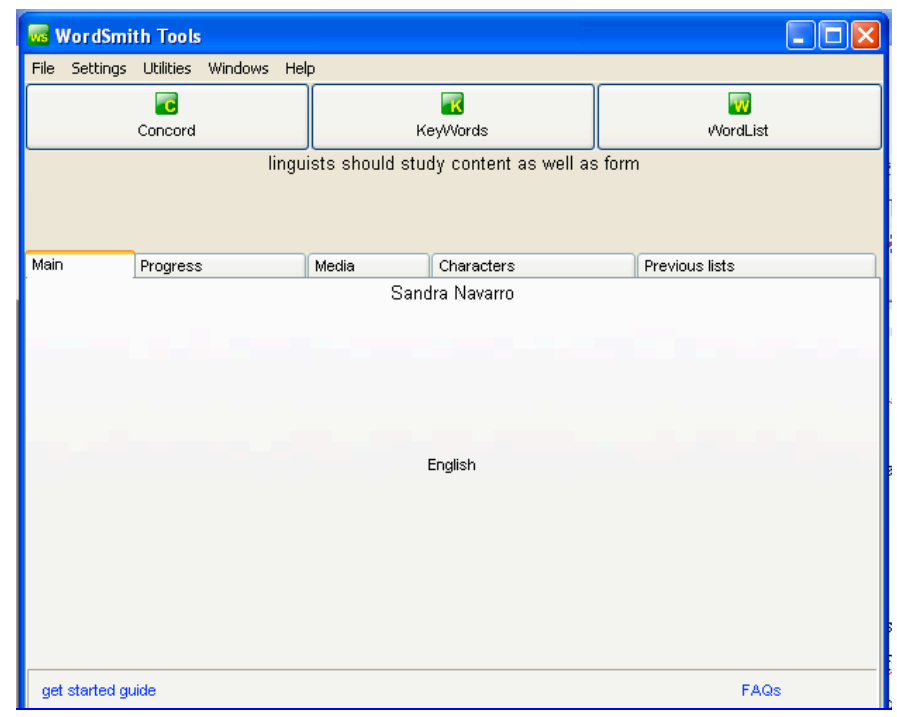

Figura 27 - Tela inicial do WordSmith Tools, versão 5 (Scott, 2007).

Esse software reúne ferramentas que foram essenciais para a identificação das colocações, são elas:

\section{a) Lista de palavras (Wordlist)}

Ferramenta que permite gerar uma lista de todas as palavras contidas no corpus. A apresentação dos dados pode ser por ordem de frequência ou alfabética. A ferramenta também resume diversos dados estatísticos do corpus, como o número total de palavras (tokens), o número de palavras distintas (types) e a razão entre elas (type/token ratio), que fornece uma indicação da variedade linguística do corpus. 


\begin{tabular}{|c|c|c|c|c|c|c|c|}
\hline \multicolumn{8}{|c|}{ W' wordlist_inglês. Ist } \\
\hline File Edit V & View Compute & e Setting & $s$ Window $\mathrm{He}$ & & & & \\
\hline $\mathrm{N}$ & $\mathrm{N}$ & & Word & Freq. & $\%$ & Texts & \begin{tabular}{l|l|l|}
$\%$ & emmas & Set \\
\end{tabular} \\
\hline 1 & 1 & & THE & 19,148 & 3.51 & 279 & 85.58 \\
\hline 2 & 2 & & AND & 18,264 & 3.34 & 278 & 85.28 \\
\hline 3 & 3 & & \# & 11,914 & 2.18 & 277 & 84.97 \\
\hline 4 & 4 & & A & 11,119 & 2.04 & 278 & 85.28 \\
\hline 5 & 5 & & OF & 9,830 & 1.80 & 277 & 84.97 \\
\hline 6 & 6. & & TO & 9,196 & 1.68 & 278 & 85.28 \\
\hline 7 & 7 & & $\mathbb{N}$ & 7,302 & 1.34 & 278 & 85.28 \\
\hline 8 & 8 & & WITH & 6,473 & 1.19 & 275 & 84.36 \\
\hline 9 & 9 & & FOR & 5,775 & 1.06 & 276 & 84.66 \\
\hline 10 & a & & OUR & 4,519 & 0.83 & 259 & 79.45 \\
\hline 11 & 1 & & YOUR & 4,415 & 0.81 & 270 & 82.82 \\
\hline 12 & 2 & & is & 4,293 & 0.79 & 274 & 84.05 \\
\hline 13 & 3 & & ROOM & 3,653 & 0.67 & 270 & 82.82 \\
\hline 14 & 4 & & $\mathrm{OR}$ & 3,371 & 0.62 & 269 & 82.52 \\
\hline 15 & 5 & & YOU & 3,334 & 0.61 & 261 & 80.06 \\
\hline 16 & 6 & & AT & 3,144 & 0.58 & 264 & 80.98 \\
\hline 17 & & & ARE & 2,906 & 0.53 & 270 & 82.82 \\
\hline 18 & 8 & & ON & 2,584 & 0.47 & 271 & 83.13 \\
\hline 19 & 9] & & HOTEL & 2,529 & 0.46 & 231 & 70.86 \\
\hline 20 & & & FROM & 2,204 & 0.40 & 254 & 77.91 \\
\hline 21 & & & ALL & 1,926 & 0.35 & 267 & 81.90 \\
\hline 22 & & & AN & 1,909 & 0.35 & 235 & 72.09 \\
\hline 23 & 3 & & ROOMS & 1,882 & 0.34 & 249 & 76.38 \\
\hline 24 & & & SUITES & 1,760 & 0.32 & 203 & 62.27 \\
\hline 25 & 5 & & WILL & 1,702 & 0.31 & 244 & 74.85 \\
\hline 26 & 6. & & AS & 1,692 & 0.31 & 213 & 65.34 \\
\hline 27 & & & $\mathrm{BE}$ & 1,677 & 0.31 & 240 & 73.62 \\
\hline 28 & 8 & & ONE & 1,675 & 0.31 & 241 & 73.93 \\
\hline 29 & 9 & & THIS & 1,632 & 0.30 & 242 & 74.23 \\
\hline 30 & ] & & THAT & 1,485 & 0.27 & 233 & 71.47 \\
\hline 31 & 1| & & WE & 1,480 & 0.27 & 238 & 73.01 \\
\hline frequency & alphabetical & statistics & filenames no & tes & & & \\
\hline
\end{tabular}

Figura 28 - lista de palavras parcial do corpus em inglês em ordem decrescente de frequência.

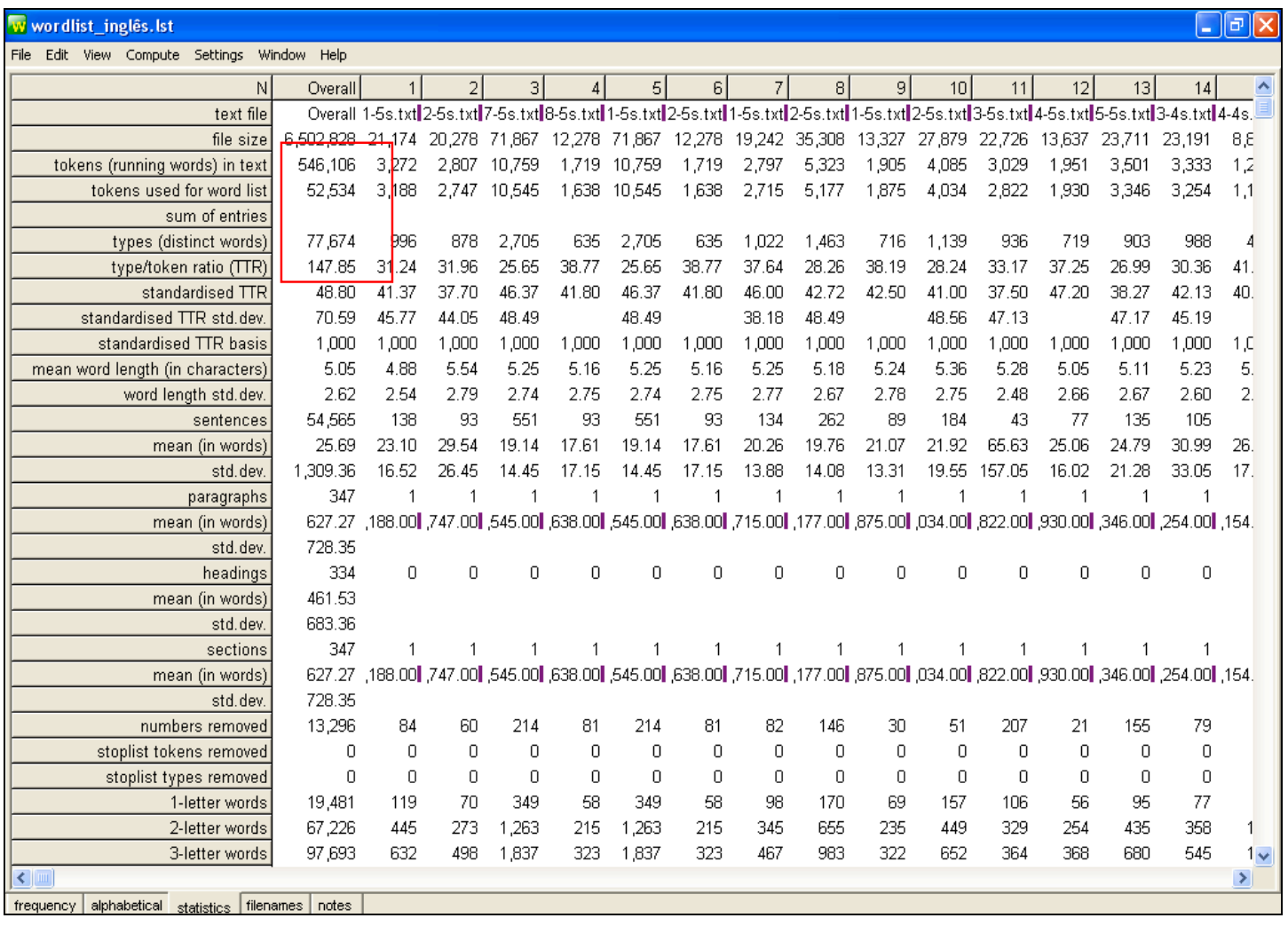

Figura 29 - Estatísticas do corpus em inglês. 


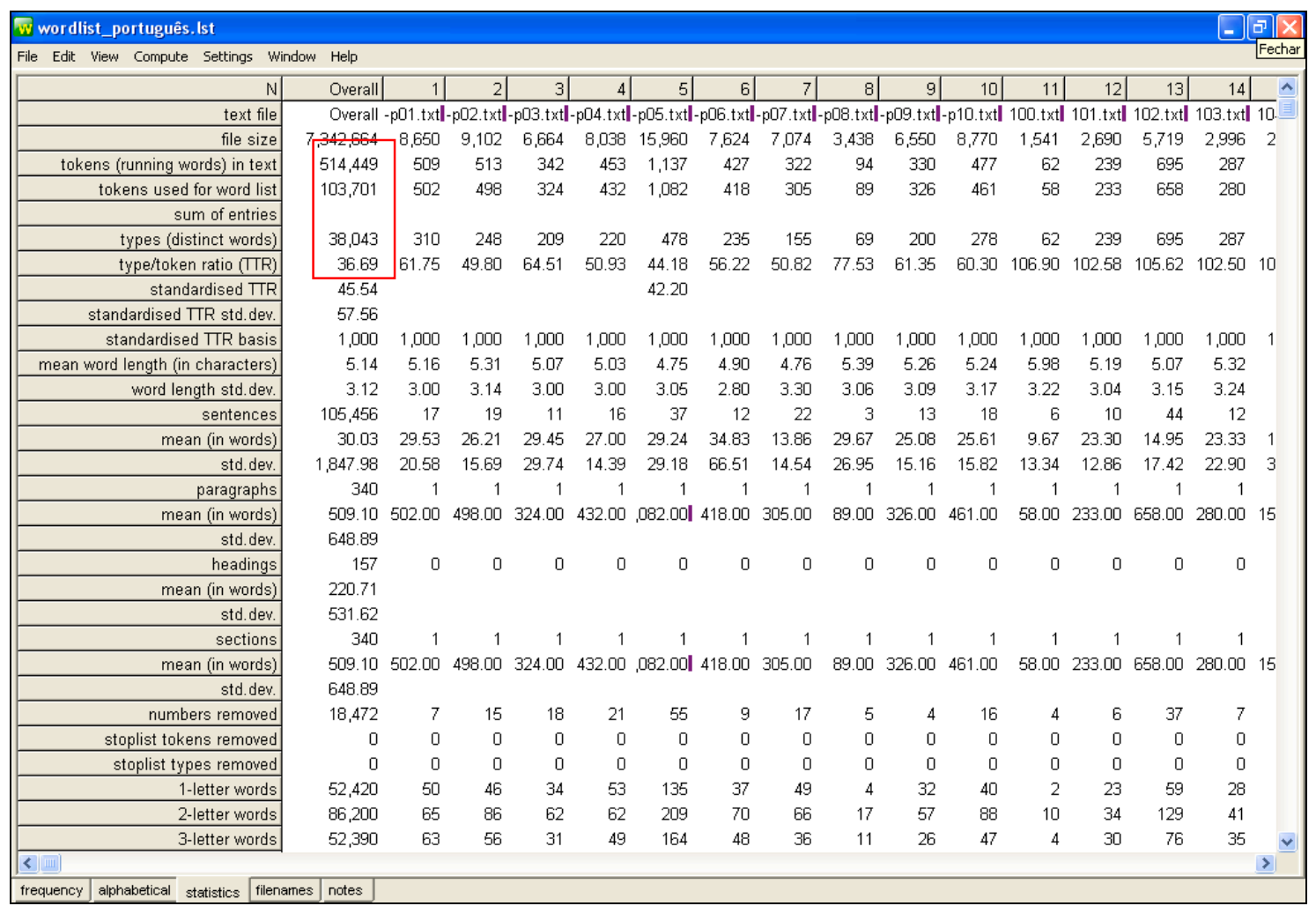

Figura 30 - Estatísticas do corpus em português.

\section{b) Palavras-chave (Keywords)}

Como o nome indica, esta ferramenta mostra as palavras mais representativas do corpus em termos estatísticos. Essa representatividade é calculada levando-se em consideração a frequência da palavra no corpus de estudo em relação a outro corpus, denominado de referência, isto é, se uma palavra possui um número de ocorrências relativo significativamente maior no corpus de estudo do que no de referência, ela é considerada uma palavra-chave. Para isso, o programa compara a lista de palavras do corpus de estudo com a lista de palavras do corpus de referência.

Em nossa pesquisa, utilizamos como referência a lista de palavras do BNC (British National Corpus), um corpus fechado (1990-1994), com cerca de 100 milhões de palavras de língua geral das variantes escrita e falada do inglês britânico. Para representar a variante do português do Brasil, escolhemos o corpus de referência Banco do Português, com 247 milhões de palavras. 


\begin{tabular}{|c|c|c|c|c|c|c|c|c|}
\hline \multicolumn{9}{|c|}{ K KeyWords } \\
\hline File Edit & View & Compute Settings Window & Help & & & & & \\
\hline $\mathrm{N}$ & & Key word & Freq. & $\%$ & Freq.ll & RC. \% & Keyness & $\mathrm{P}$ |mmasi| Set \\
\hline 1 & & SUITES & 1,760 & 0.32 & 249 & & $16,842.79$ & 00000 \\
\hline 2 & & ROOM & 3,653 & 0.67 & 28,821 & 0.03 & $15,562.27$ & 000000 \\
\hline 3 & & HOTEL & 2,529 & 0.46 & 10,911 & 0.01 & $13,485.89$ & 000000 \\
\hline 4 & & OUR & 4,519 & 0.83 & 93,455 & 0.09 & $11,511.87$ & 000000 \\
\hline 5 & & ROOMS & 1,882 & 0.34 & 5,347 & & $11,385.71$ & $00000 \mid$ \\
\hline 6 & & AMENITIES & 1,140 & 0.21 & 510 & & $9,846.63$ & $00000 \mid$ \\
\hline 7 & & INTERNET & 1,004 & 0.18 & 97 & & $9,808.56$ & 000000 \\
\hline 8 & & SPA & 1,128 & 0.21 & 514 & & $9,721.18$ & 00000l \\
\hline 9 & & SUITE & 1,287 & 0.24 & 1,460 & & $9,632.84$ & 00000l \\
\hline 10 & & COMPLIMENTARY & 958 & 0.18 & 318 & & $8,555.06$ & 000000 \\
\hline 11 & & CENTER & 989 & 0.18 & 503 & & $8,405.99$ & 00000l \\
\hline 12 & & YOUR & 4,415 & 0.81 & $34,393 \mathbf{I}$ & 0.14 & $8,368.08$ & 00000l \\
\hline 13 & & GUESTS & 1,305 & 0.24 & 3,285 & & $8,157.39$ & 00000l \\
\hline 14 & & DINING & 1,151 & 0.21 & 1,717 & & $8,151.66$ & 00000l \\
\hline 15 & & RESORT & 1,091 & 0.20 & 2,101 & & $7,293.93$ & 000000 \\
\hline 16 & & GUEST & 1,005 & 0.18 & 2,233 & & $6,487,56$ & 000000 \\
\hline 17 & & ACCOMMODATIONS & 594 & 0.11 & 43 & & $5,876.01$ & 000000 \\
\hline 18 & & BEDROOM & 1,008 & 0.18 & 4,031 & & $5,506.12$ & 000000 \\
\hline 19 & & RESERVATION & 667 & 0.12 & 643 & & $5,142.68$ & 000000 \\
\hline 20 & & OFFERS & 1,029 & 0.19 & 5,844 & & $4,984.66$ & 00000l \\
\hline 21 & & CHECK & 1,049 & 0.19 & 7,129 & & $4,745.22$ & 00000l \\
\hline 22 & & LOCATED & 759 & 0.14 & 2,500 & & $4,399.87$ & 000000 \\
\hline 23 & & ENJOY & 964 & 0.18 & 6,439 & & $4,390.44$ & 00000l \\
\hline 24 & & RESERVATIONS & 623 & 0.11 & 976 & & $4,365.22$ & 000000 \\
\hline 25 & & BREAKFAST & 853 & 0.16 & 4,247 & & $4,331.04$ & 00000l \\
\hline 26 & & VEGAS & 482 & 0.09 & 216 & & $4,161,79$ & 00000l \\
\hline 27 & & POOL & 836 & 0.15 & 4,455 & & $4,144.08$ & 00000l \\
\hline 28 & & MASSAGE & 539 & 0.10 & 634 & & $4,005.67$ & 00000l \\
\hline 29 & & SPACIOUS & 524 & 0.10 & 641 & & $3,864.57$ & 00000l \\
\hline 30 & & SERVICE & 1,461 & 0.27 & 30,252 & 0.03 & $3,712.22$ & 00000l \\
\hline 31 & & WIRELESS & 483 & 0.09 & 513 & & $3,659.27$ & 00000l \\
\hline
\end{tabular}

Figura 31 - Lista de palavras-chave do corpus em inglês.

Antes de gerar a lista de palavras-chave, é necessário ajustar as medidas estatísticas da ferramenta. Em Settings, utilizamos as seguintes configurações: log likelihood $^{35 a}$; $p$-value $e^{36}=0.00001$; frequência acima de 3 ; número máximo de palavras na lista 500 .

\footnotetext{
${ }^{35 a}$ A medida estatística log likelihood é indicada para a comparação de listas de grandes dimensões entre si (Gerber, 2007).

${ }^{36}$ Teste de significância estatística atingido pelo resultado da chavicidade, ou seja, a probabilidade de a palavra ter sido erroneamente identificada como chave pelo cálculo estatístico. (Teixeira, 2008: 173). Um $\mathrm{p}$-value $=0,000001$ significa dizer que a cada 100.000 palavras, 1 pode não ser chave.
} 


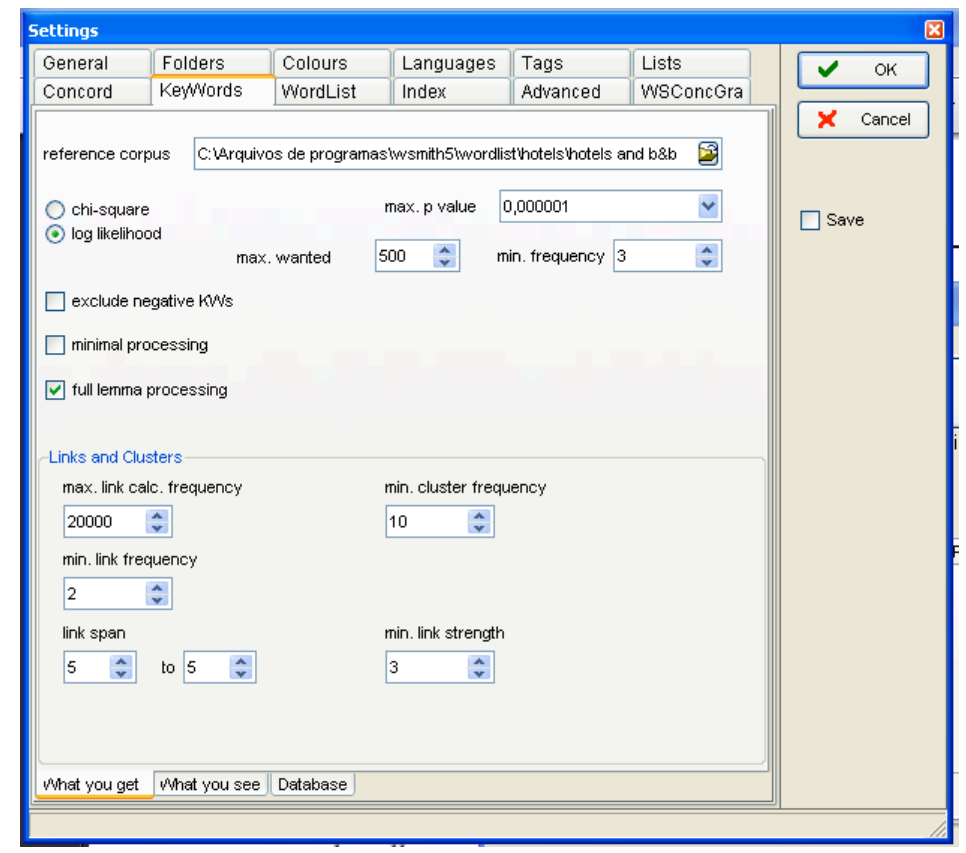

Figura 32 - Ajustes da ferramenta Keywords.

\section{c) Concord}

\section{Esta ferramenta permite:}

- gerar uma lista dos colocados (Collocates) da palavra de busca, por ordem de frequência ou alfabética.

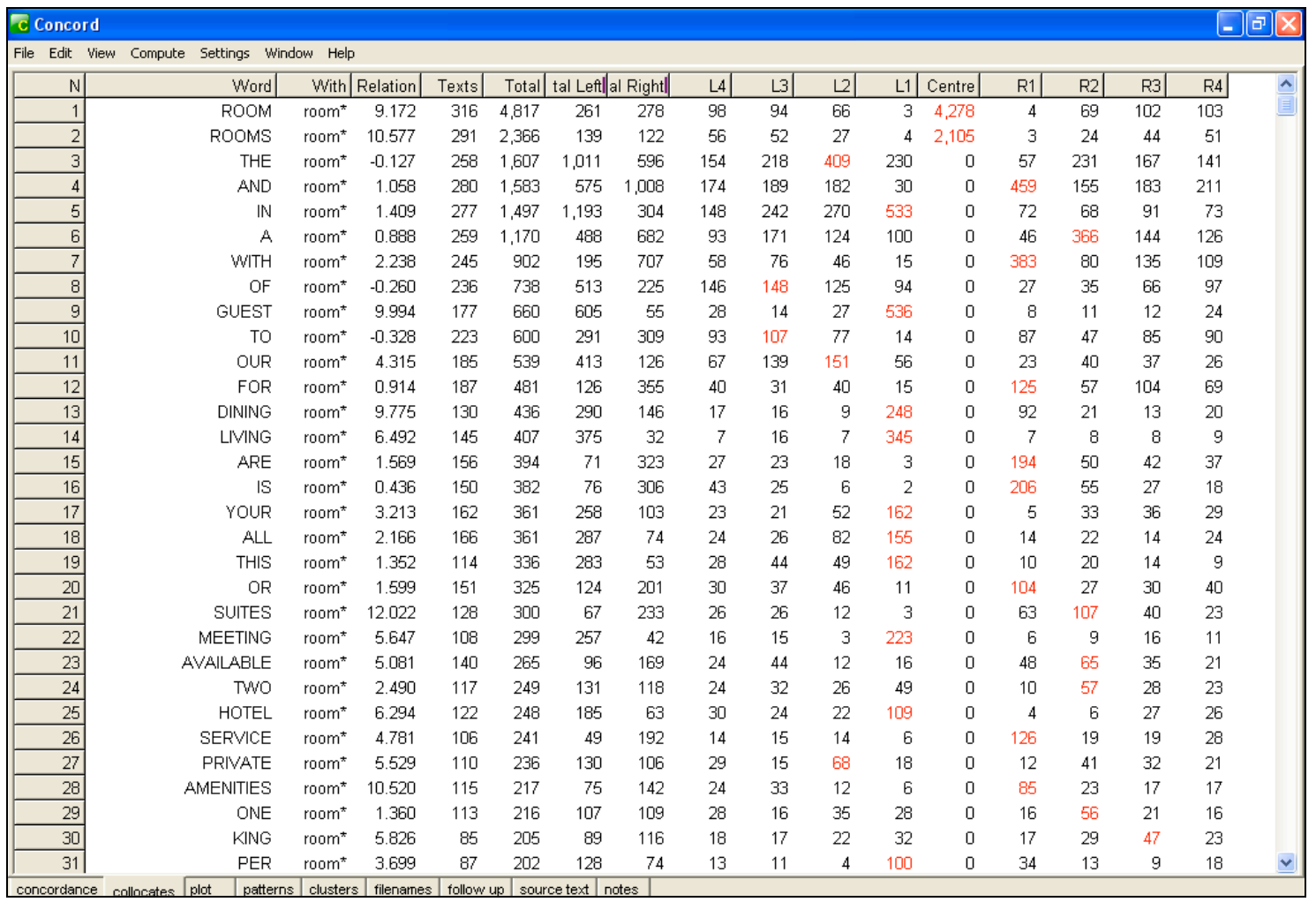

Figura 33 - Lista de colocados de $\operatorname{room}(s)$, por ordem de frequência, na ferramenta Concord. 
Ajustamos as medidas estatísticas da ferramenta da seguinte maneira: MI score (Mutual Information) maior ou igual a 3. Essa opção estatística proposta por Church and Hanks (1990) fornece uma medida da força de atração entre dois itens lexicais. Quanto maior o MI score, menor a chance de a co-ocorrência entre o nódulo e o colocado ser aleatória, ou seja, quanto maior o MI score, mais forte a colocação. Os autores sugerem que qualquer número acima de 3 (indicado na coluna "Relation" na figura acima) indica um padrão com recorrência significativa.

Também ajustamos a ferramenta para considerar os colocados em uma janela de $4 \times 4$, ou seja, o contexto de quatro palavras à direita e quatro palavras à esquerda do nódulo. As palavras de busca podem ser lematizadas por meio da inclusão do símbolo (*), como mostra a figura acima. Esse tipo de busca permite incluir as variações quanto às desinências (verbos) e derivações (substantivos e adjetivos).

A figura acima mostra as colunas exibidas pela ferramenta Collocate. Além da coluna Relation, temos a coluna Text, que indica o número de textos em que a palavra aparece. As colunas Total, Total Left e Total Right exibem respectivamente o número total de ocorrências da palavra no corpus, as ocorrências à esquerda e à direita do nódulo. As colunas $L 4, L 3, L 2, L 1$, Centre, $R 1, R 2, R 3$ e $R 4$ também trazem essas informações $-L$ indica o número de ocorrências das palavras à esquerda $(l e f t)$ do nódulo, em um intervalo de até 4 palavras, e $R$ exibe as ocorrências das palavras à direita (right), com o mesmo intervalo. Em vermelho, estão destacados os números mais significativos.

- gerar uma lista de agrupamentos lexicais (Clusters) da palavra de busca, por ordem de frequência. Essa funcionalidade é especialmente útil para a identificação de unidades colocacionais maiores, contento a partir de três palavras. 


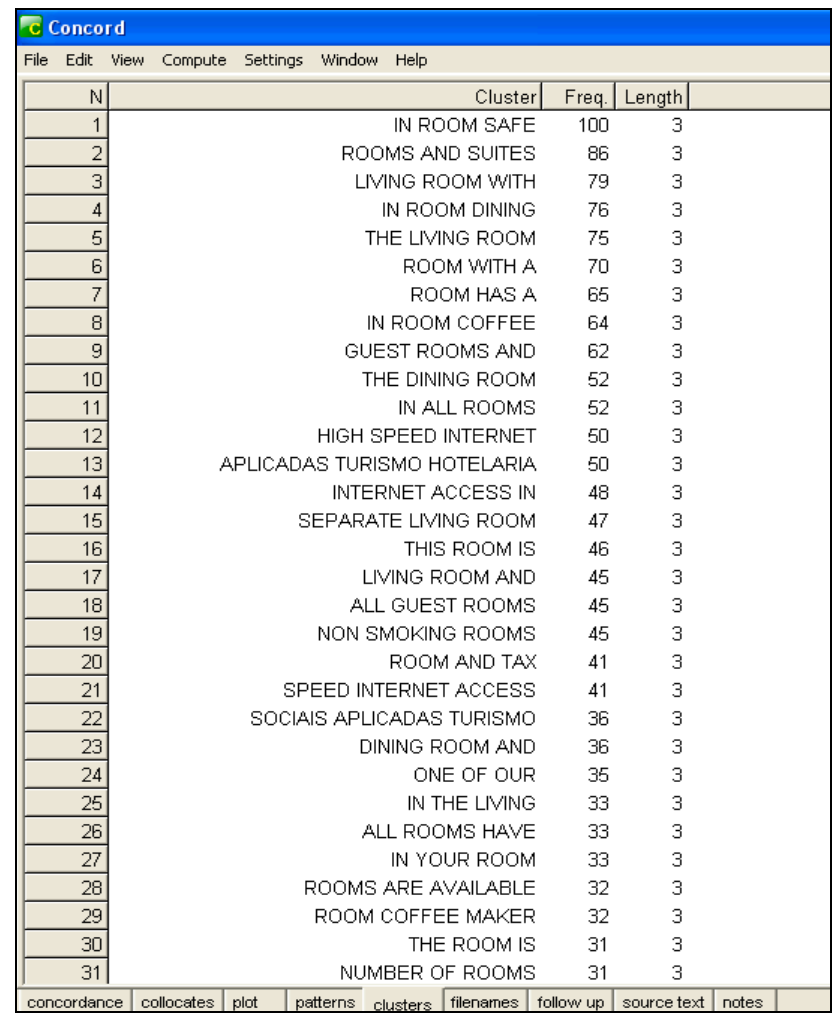

Figura 34 - Lista de clusters de room(s), por ordem de frequência, na ferramenta Concord.

Como é possível observar, o fato de ser indicada como cluster não significa que a sequência de palavras forme uma unidade de sentido, ou seja, um possível padrão colocacional. Assim, é preciso filtrar a lista, eliminando e agrupando clusters.

- gerar uma lista de concordâncias (Concordance), isto é, trechos contendo a palavra de busca, que é mostrada em destaque. Assim, é possível contemplar o contexto da palavra e seus colocados, realizando uma análise qualitativa dos dados. A ferramenta permite também a visualização da palavra de busca no seu texto-fonte, clicando duas vezes sobre a linha de concordância. 


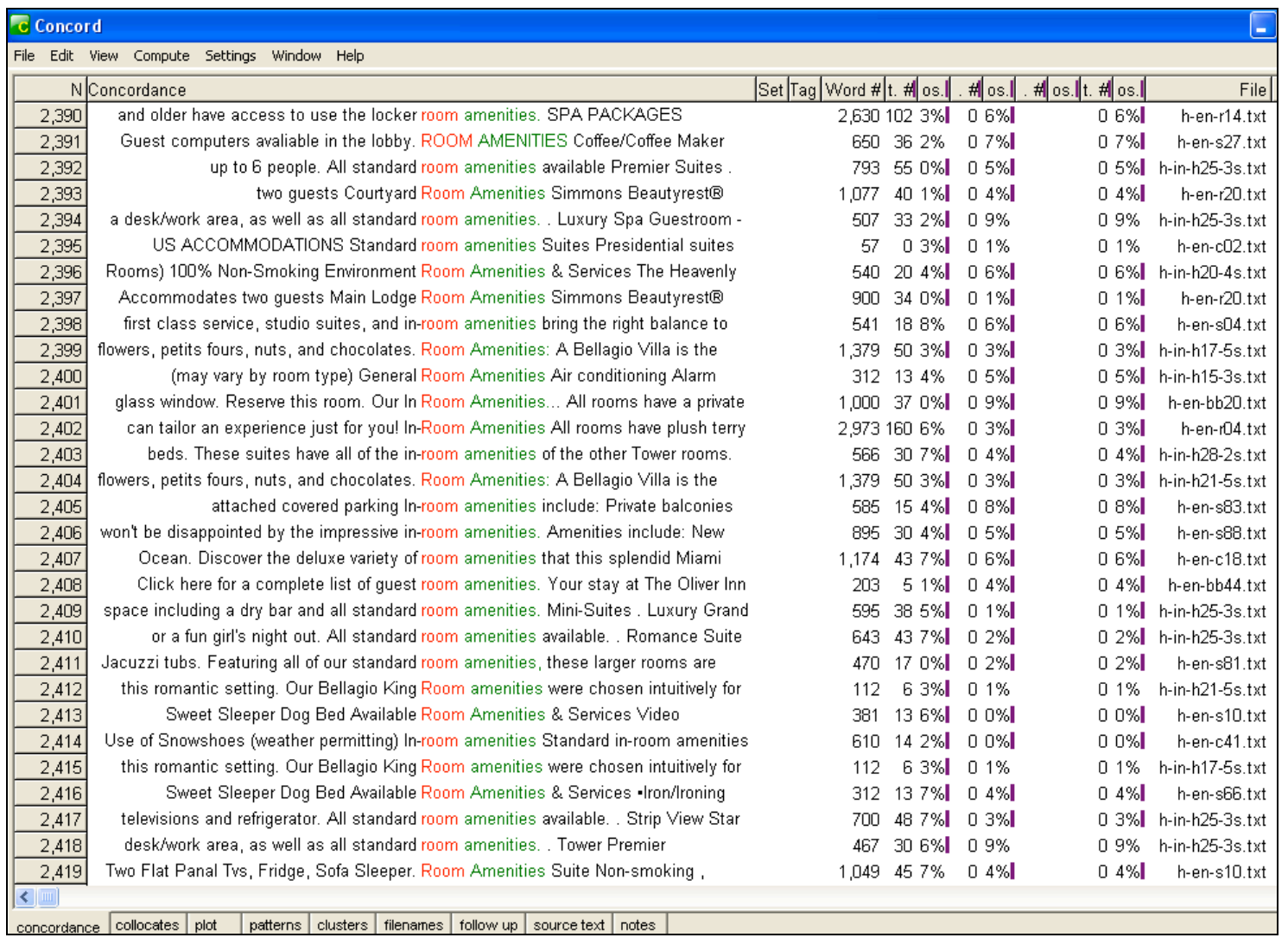

Figura 35 - Lista de concordâncias de room, ordenadas pelos colocados à direta, na ferramenta Concord.

As ferramentas descritas acima foram essenciais para a extração das colocações e levantamento dos equivalentes. Os procedimentos adotados para a etapa de análise dos dados estão detalhados a seguir.

\subsubsection{Procedimentos de identificação das colocações e seus equivalentes}

Os procedimentos para identificar as colocações em inglês e estabelecer seus equivalentes em português podem ser resumidos da seguinte maneira:

\section{Colocações em inglês:}

- gerar uma lista de palavras do corpus;

- gerar uma lista de palavras-chave;

- identificar as palavras-chave mais recorrentes, que serão as palavras de busca para identificar as colocações;

- gerar uma lista de colocados da palavra-chave selecionada; 
- gerar uma lista de clusters da palavra;

- gerar e analisar as linhas de concordância da palavra;

- gerar e analisar linhas de concordância utilizando o corpus etiquetado;

- fazer um levantamento dos candidatos a colocações e validá-los segundo os critérios estabelecidos (frequência, estatísticas, análise dos contextos).

Para aferir o status de colocações das palavras, foram adotados alguns critérios:

- a colocação deve apresentar uma palavra-chave;

- estabelecida essa palavra-chave, o candidato a colocado deve figurar entre os 200 primeiros itens na lista de colocados da palavra-chave;

- a lista de colocados considera uma janela de $4 \times 4$;

- base e colocado devem ter índice de associação MI score acima de 3;

- a colocação deve ocorrer ao menos 10 vezes;

- o cluster deve ocorrer ao menos 10 vezes;

- a análise qualitativa das linhas de concordância deve confirmar que se trata de uma colocação.

\section{Equivalentes em português:}

- gerar uma lista de palavras do corpus;

- gerar uma lista de palavras-chave;

- analisar a lista de palavras-chave e identificar um equivalente prima facie; ou

- na ausência de um equivalente prima facie, gerar linhas de concordância a partir dos padrões imediatos à colocação investigada (palavras que remetem ao mesmo contexto);

- gerar uma lista de colocados do candidato a equivalente;

- gerar uma lista de clusters do candidato;

- gerar e analisar as linhas de concordância do candidato;

- gerar e analisar linhas de concordância utilizando o corpus etiquetado;

- $\quad$ utilizar a $W e b$ como fonte adicional para validar o candidato;

- estabelecer o(s) equivalente(s) com base nas informações levantadas. 
Elaboração da entrada para o glossário:

- incluir todas as informações coletadas na ficha terminológica;

- ordenar os equivalentes em ordem de frequência;

- selecionar exemplos;

- quando cabível, elaborar as informações complementares;

- montar o verbete.

Vale ressaltar que nem todos os procedimentos previstos acima são empregados para todos os verbetes. Existem colocações mais facilmente identificáveis, ao passo que outras requerem mais etapas para serem validadas. Da mesma forma, um equivalente pode ser validado sem a necessidade de se recorrer ao corpus etiquetado ou à internet. Esse julgamento fica inevitavelmente a cargo do pesquisador.

\subsection{Metodologia exemplificada}

Nesta seção, o objetivo é demonstrar por meio de um exemplo como as ferramentas e os procedimentos descritos acima são empregados na investigação linguística.

\section{Extração da colocação em inglês}

Como ponto de partida para a extração das colocações em inglês, geramos uma lista de palavras do corpus (vide Figura 28). Em seguida, geramos uma lista das palavras-chave (vide Figura 31) utilizando o BNC como corpus de referência. Essa lista traz a palavra suites em primeiro lugar. Entretanto, somando as ocorrências no singular e plural, a palavra room mostra-se a mais frequente, conforme se observa nas contagens a seguir, realizadas com a ferramenta Concord:

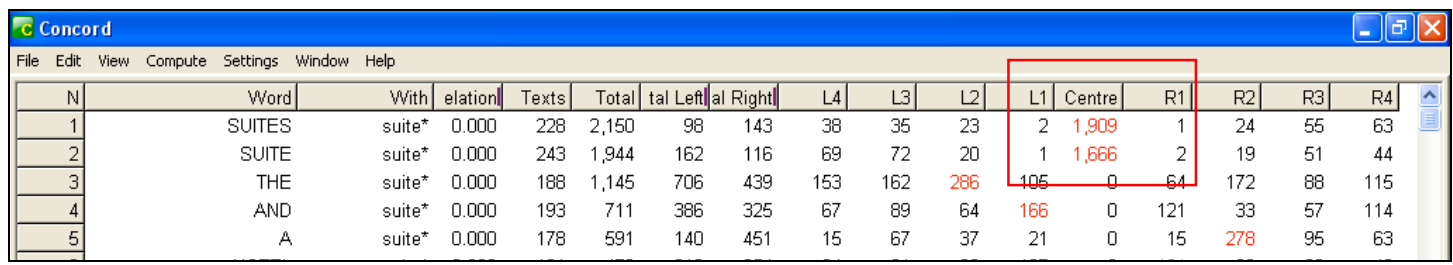

Figura 36 - Número de ocorrências da palavra suite(s) no corpus. 


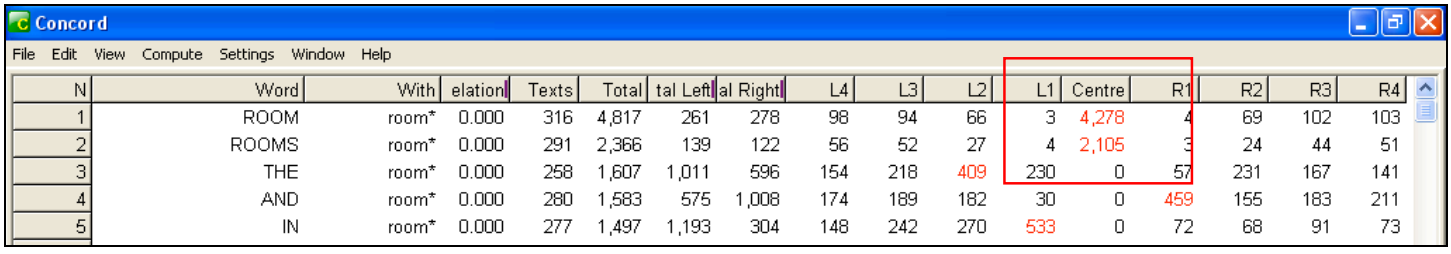

Figura 37 - Número de ocorrências da palavra room(s) no corpus.

A palavra suite ocorre 1.909 vezes no plural e 1.666 no singular, somando 3.575 ocorrências. Por sua vez, room apresenta 4.278 ocorrências no plural e 2.105 ocorrências no singular, somando 6.383. Decidimos, portanto, investigar as colocações dessa palavra.

O próximo passo foi gerar uma lista dos colocados de room* (vide Figura 33), que forneceu 1.140 colocados. Esta pesquisa contempla os 200 primeiros. Por se tratar ainda de um grande volume de dados, analisamos a lista dos clusters (vide Figura 34), que retornou mais de 1.000 itens com extensão de 3 palavras. Nossa linha de corte é considerar somente os que possuem frequência acima de 10.

Fazendo um cotejo dos dados da lista de colocados e da lista de clusters, chegamos ao candidato a colocação in-room safe, com 100 ocorrências. Verificamos que safe se encontra na posição 58 da lista de colocados de room, com frequência maior na posição R1, ou seja, imediatamente à direita de room. Geramos, portanto, uma lista de concordâncias de room safe e, analisando as 84 linhas oferecidas, confirmamos que o padrão colocacional é de fato in-room safe.

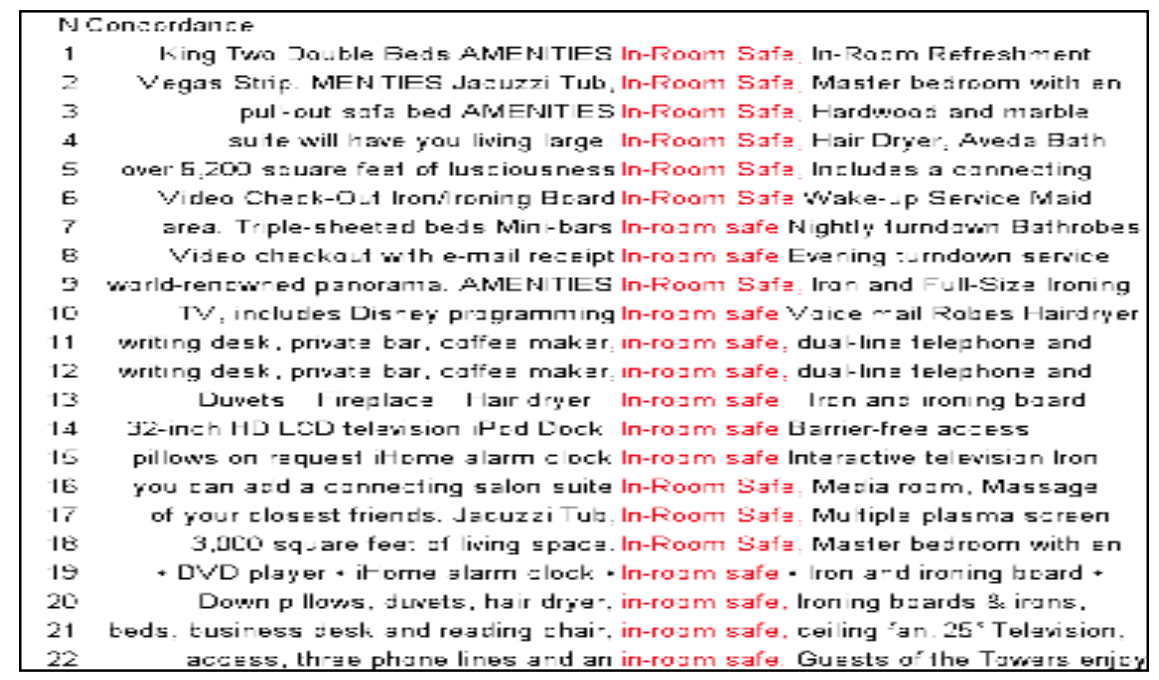

Figura 38 - Parte das linhas de concordância de in-room safe. 
A análise das linhas de concordância revelou ainda que in-room safe geralmente integra uma listagem dos itens oferecidos no apartamento, como por exemplo, writing desk, private bar, coffee maker, in-room safe, dual line telephone (...). Chamou-nos a atenção a linha de concordância 1, em que in-room safe antecede in-room refreshment center. Pareceu-nos uma redundância a repetição de in-room. Investigando os contextos expandidos, observamos que praticamente todas as ocorrências de in-room eram de certa forma redundantes, pois o contexto já esclarecia que o objeto estava no apartamento. No entanto, em inglês essa aparente redundância é considerada adequada, como na sentença:

Services/amenities in all rooms: cable/satellite TV, flat screen/plasma TV, free high speed internet, free local calls, hair dryer, in-room coffee maker, in-room desk, inroom safe, individual a/c \& heat.

Additionally, all hotel rooms are equipped with comprehensive facilities including high speed Internet access, three phone lines and an in-room safe.

Mostraremos mais adiante como esse dado adicional pode integrar uma nota ao tradutor.

A próxima etapa é identificar o equivalente em português.

\section{Identificação dos equivalentes em português}

Por equivalente entendemos os correspondentes que funcionam da mesma forma em inglês e em português. Trata-se da equivalência pelo contexto, ou equivalence in context, proposta por Chesterman (1998: 31$)^{37}$.

Vale destacar que nem sempre uma colocação em inglês terá como equivalente uma colocação em português - o equivalente pode ser um item lexical isolado ou uma outra sugestão de tradução.

O primeiro passo para identificar o correspondente de in-room safe em português foi analisar a lista de palavras-chave do corpus. Identificamos cofre, com 444 ocorrências, como uma tradução prima facie de safe. Geramos, então, uma lista de colocados para cofre:

\footnotetext{
${ }^{37}$ A noção de equivalência adotada nesta pesquisa está detalhada na seção 2.3.
} 


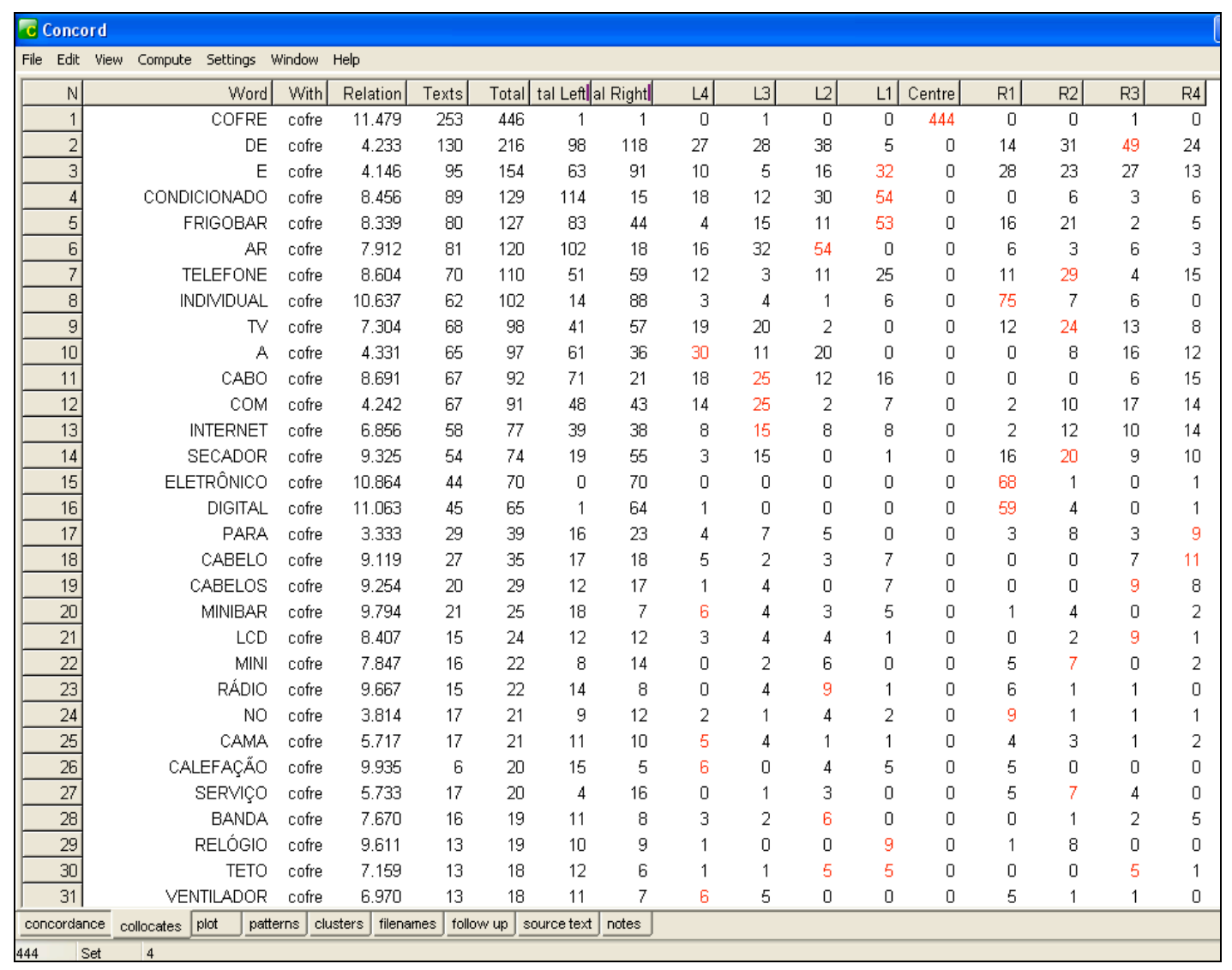

Figura 39 - Lista parcial de colocados de cofre.

A partir da análise da lista de colocados acima, podemos identificar alguns adjetivos utilizados para descrever cofre: individual (linha 8), eletrônico (linha 15), digital (linha 16). Os colocados também indicam que estamos diante de um contexto semelhante ao de in-room safe (um cofre no apartamento): frigobar, telefone, TV a cabo, secador de cabelos, são todos itens que normalmente integram as acomodações dos hotéis. Por fim, fazendo um cruzamento entre a lista de colocados, a lista de clusters e as linhas de concordância, identificamos os seguintes candidatos a equivalentes de inroom safe: 


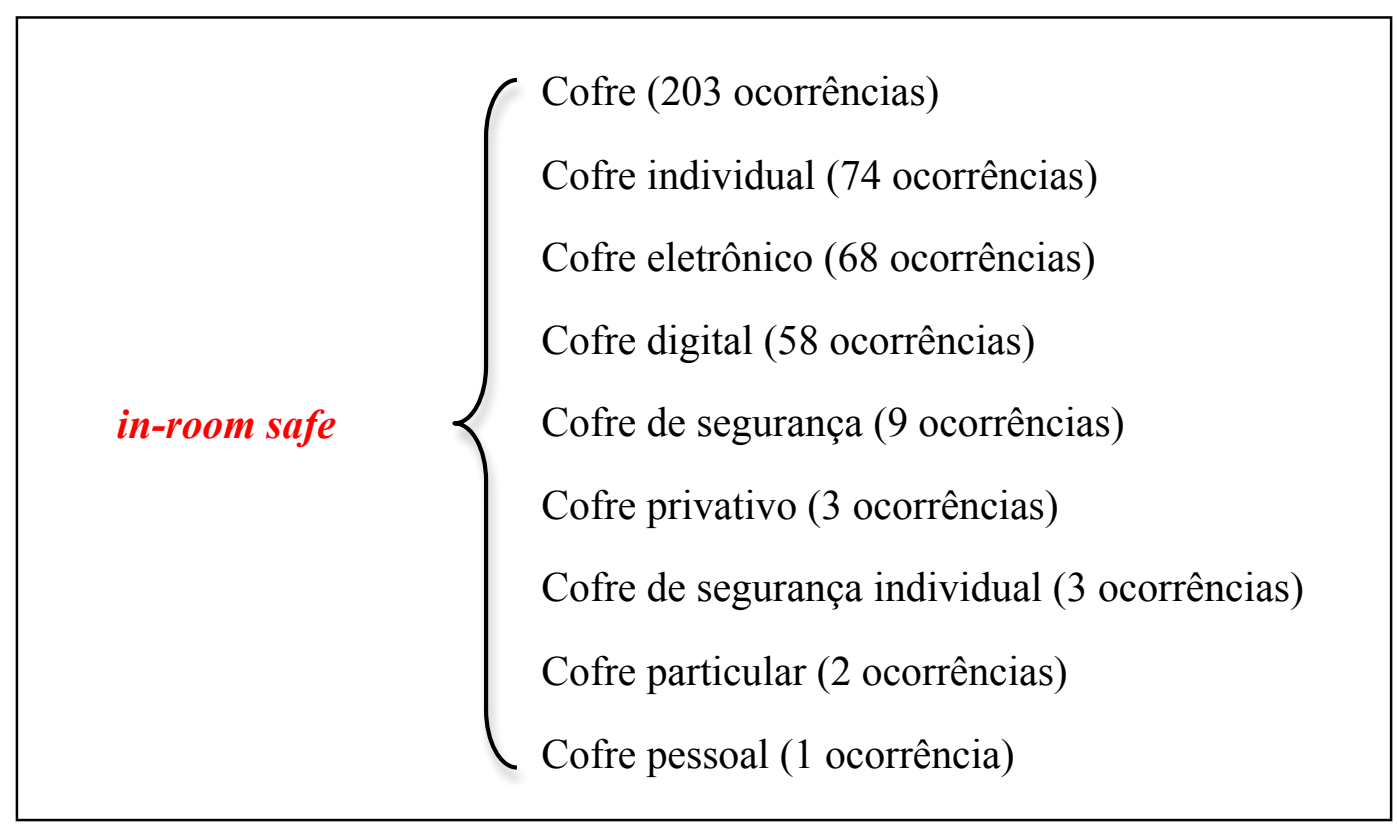

Figura 40 - Candidatos a equivalentes de in-room safe.

Chama a atenção o fato de o equivalente mais frequente para in-room safe ser apenas cofre, sem nenhum outro adjetivo. Essa constatação só foi possível mediante a análise das linhas de concordância, que confirmou se tratar do mesmo contexto do inglês (por ex., na linha 13: calefação, TV LCD, aparelho de DVD, frigobar, cofre, telefone, acesso gratuito a internet/wireless, cama box). Assim, contabilizamos apenas as ocorrências de cofre no apartamento do hóspede, excluindo os casos de cofre na recepção, por exemplo. Observamos também pelas linhas de concordância que, diferentemente do inglês, não há referência direta a apartamento (in-room), pois essa referência está clara pelo contexto, como mostram os exemplos na figura a seguir. 


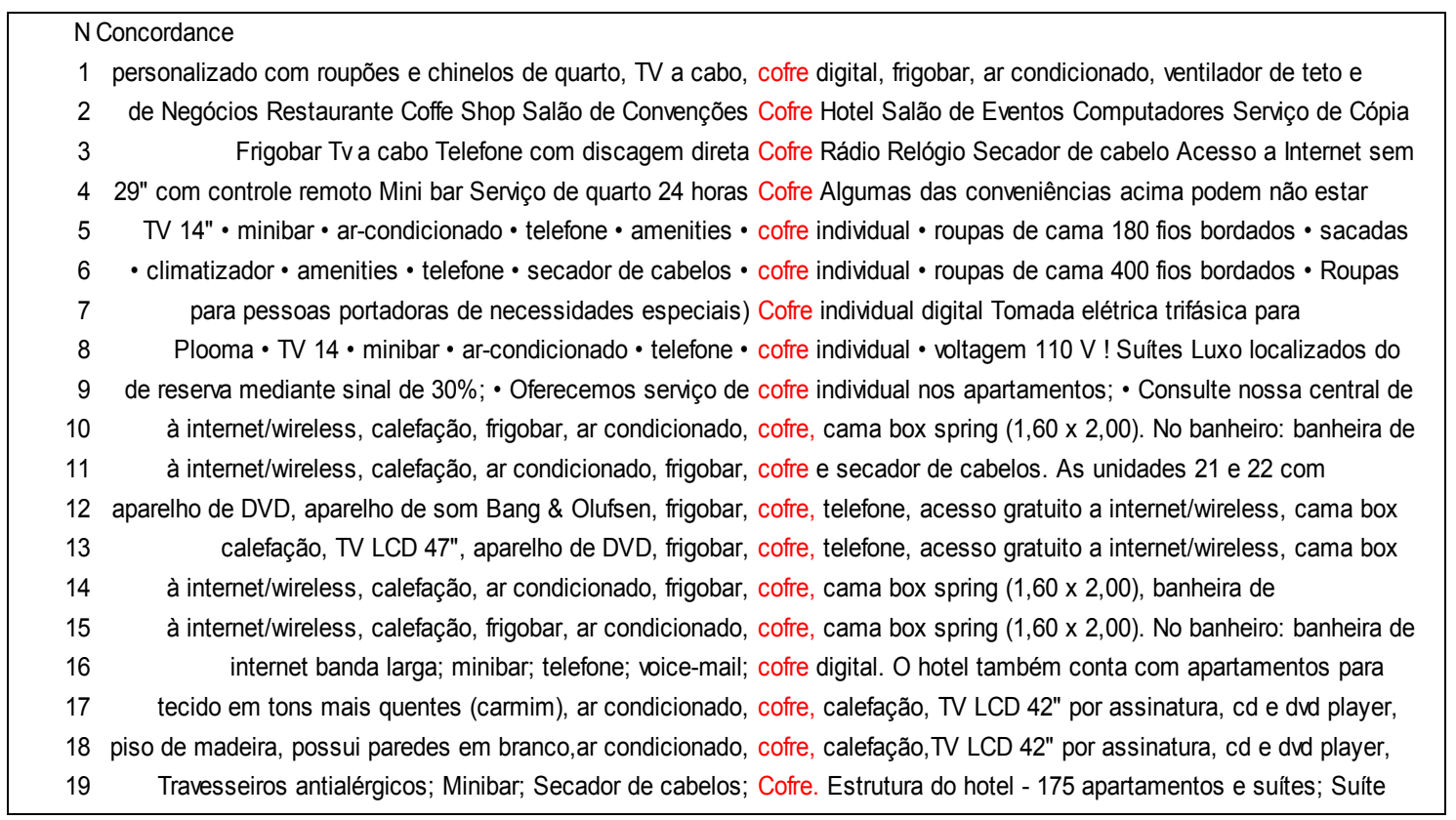

Figura 41 - Parte das linhas de concordância de cofre. Total de 297 ocorrências.

Selecionamos para inclusão no verbete os quatro primeiros correspondentes, por serem bem mais frequentes que os demais. Assim, temos:

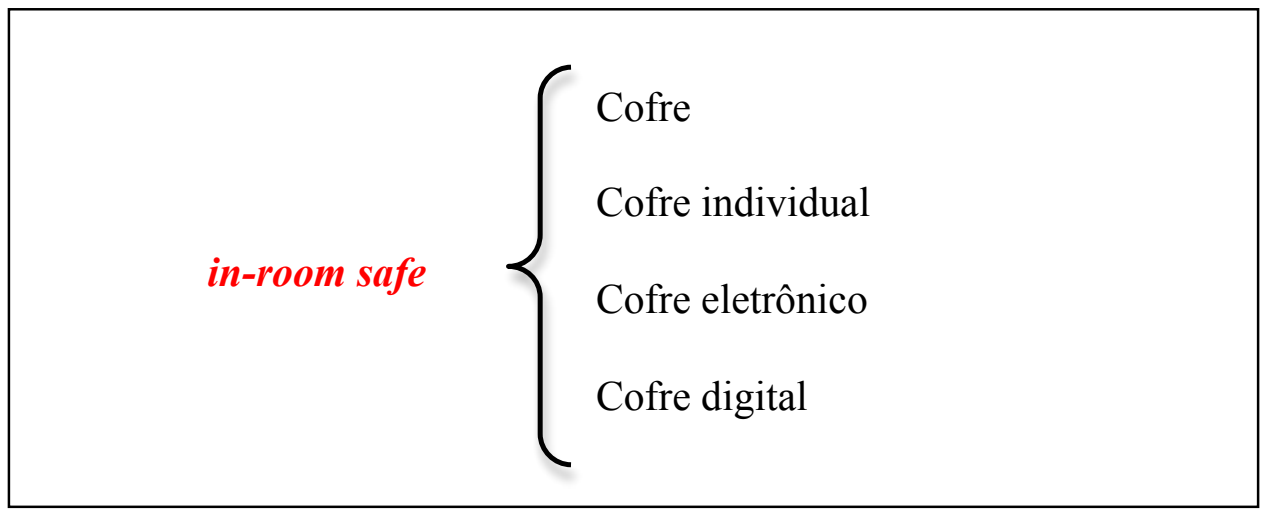

Figura 42- Equivalentes validados para in-room safe.

Nesse caso, julgamos relevante incluir no verbete uma nota ao tradutor informando que o contexto em português permite a omissão da referência a apartamento ou quarto.

Todas essas informações são, por fim, registradas na ficha terminológica, que apresentamos a seguir. 


\subsubsection{Ficha terminológica}

A ficha terminológica tem como objetivo registrar e organizar o conjunto de informações a respeito da colocação. Para os fins de nossa pesquisa, elaboramos uma ficha simples, com os seguintes campos:

\begin{tabular}{|c|c|}
\hline Colocação inglês & Ocorrências \\
\hline \multicolumn{2}{|l|}{ Base da colocação } \\
\hline \multicolumn{2}{|l|}{$\begin{array}{l}\text { Exemplo 1 } \\
\text { [texto-fonte] }\end{array}$} \\
\hline \multicolumn{2}{|l|}{$\begin{array}{l}\text { Exemplo } 2 \\
\text { [texto-fonte] }\end{array}$} \\
\hline \multicolumn{2}{|l|}{ Variação } \\
\hline \multicolumn{2}{|l|}{ Remissiva } \\
\hline \multicolumn{2}{|l|}{ Você Sabia? } \\
\hline \multicolumn{2}{|l|}{ Nota ao Tradutor } \\
\hline \multicolumn{2}{|l|}{ Observações } \\
\hline Equivalente 1 & ocorrências \\
\hline \multicolumn{2}{|l|}{$\begin{array}{l}\text { Exemplo 1 } \\
\text { [texto-fonte] }\end{array}$} \\
\hline \multicolumn{2}{|l|}{$\begin{array}{l}\text { Exemplo } 2 \\
\text { [texto-fonte] }\end{array}$} \\
\hline Equivalente 2 & ocorrências \\
\hline \multicolumn{2}{|l|}{$\begin{array}{l}\text { Exemplo 1 } \\
\text { [texto-fonte] }\end{array}$} \\
\hline \multicolumn{2}{|l|}{$\begin{array}{l}\text { Exemplo } 2 \\
\text { [texto-fonte] }\end{array}$} \\
\hline Equivalente 3 & ocorrências \\
\hline \multicolumn{2}{|l|}{$\begin{array}{l}\text { Exemplo } 1 \\
\text { [texto-fonte] }\end{array}$} \\
\hline \multicolumn{2}{|l|}{$\begin{array}{l}\text { Exemplo } 2 \\
\text { [texto-fonte] }\end{array}$} \\
\hline \multicolumn{2}{|l|}{ Nota ao Tradutor } \\
\hline \multicolumn{2}{|l|}{ Você Sabia? } \\
\hline Observações & \\
\hline
\end{tabular}

Figura 43 - Modelo de ficha terminológica.

1) Colocação inglês: indica a colocação validada em inglês;

2) Ocorrências: número de ocorrências da colocação no corpus;

3) Base da colocação: apresenta a palavra-chave a partir da qual a colocação foi extraída. É sob essa palavra que a colocação é apresentada no glossário; 
4) Exemplo 1 / 2 [texto-fonte]: transcrição do contexto da colocação seguido do respectivo nome do arquivo;

5) Variação: indica diferentes grafias ou expressões sinôminas da colocação;

6) Remissiva: o usuário é convidado a consultar uma entrada relacionada (como, por exemplo, o outro termo que compõe a colocação, se esse também for uma palavra-chave);

7) Você Sabia?: seção que relaciona palavras e colocações de sentido semelhante em inglês, explicando as diferenças entre elas e fornecendo exemplos; traz também notas culturais.

8) Nota ao Tradutor: traz informações úteis ao tradutor em relação à colocação em inglês;

9) Observações: espaço reservado para qualquer particularidade linguística acerca da colocação em inglês;

10) Equivalente 1/2/3: correspondentes em ordem de frequência;

11) Ocorrências: número de ocorrências do equivalente no corpus;

12) Exemplo 1 / 2 [texto-fonte]: transcrição do contexto do equivalente seguido do respectivo nome do arquivo/fonte;

13) Você Sabia?: seção que relaciona palavras e colocações de sentido semelhante em português, explicando as diferenças entre elas e fornecendo exemplos; traz também notas culturais.

14) Nota ao Tradutor: traz informações úteis ao tradutor em relação aos equivalentes em português, tais como possíveis problemas de tradução, erros comuns, sugestões adicionais de tradução, etc.;

15) Observações: espaço reservado para qualquer particularidade linguística acerca do equivalente em português.

Vejamos a seguir um exemplo da ficha preenchida: 


\begin{tabular}{|c|c|c|}
\hline Colocação inglês & IN-ROOM SAFE & 100 \\
\hline Base da colocação & \multicolumn{2}{|l|}{ ROOM } \\
\hline $\begin{array}{l}\text { Exemplo } 1 \\
\text { [texto-fonte] }\end{array}$ & \multicolumn{2}{|c|}{$\begin{array}{l}\text { One king or two queen beds, business desk and reading chair, in- } \\
\text { room safe, ceiling fan, } 25 \text { " Television, High-speed internet, large } \\
\text { dormer window or standard windows. [H-EN-R08] }\end{array}$} \\
\hline $\begin{array}{l}\text { Exemplo } 2 \\
\text { [texto-fonte] }\end{array}$ & \multicolumn{2}{|c|}{$\begin{array}{l}\text { Additionally, all hotel rooms are equipped with comprehensive } \\
\text { facilities including high speed Internet access, three phone lines } \\
\text { and an in-room safe. [H-EN-BF40] }\end{array}$} \\
\hline \multicolumn{3}{|c|}{ ( } \\
\hline \multicolumn{3}{|l|}{ Remissiva } \\
\hline \multicolumn{3}{|l|}{ Você Sabia? } \\
\hline \multicolumn{3}{|l|}{ Nota ao Tradutor } \\
\hline \multicolumn{3}{|l|}{ Observações } \\
\hline Equivalente 1 & ocorrências & 203 \\
\hline $\begin{array}{l}\text { Exemplo } 1 \\
\text { [texto-fonte] }\end{array}$ & \multicolumn{2}{|c|}{$\begin{array}{l}\text { Suites de } 48 \mathrm{~m}^{2} \text {, com } 1 \text { quarto, saleta com sofá-cama, mini copa, } \\
\text { frigobar, forno microondas, TV a cabo, ar condicionado, cofre, } \\
\text { secador de cabelos, varanda e serviços de room service e } \\
\text { lavanderia. [H-PT-P88] }\end{array}$} \\
\hline $\begin{array}{l}\text { Exemplo } 2 \\
\text { [texto-fonte] }\end{array}$ & \multicolumn{2}{|c|}{$\begin{array}{l}\text { Outros [chalés] dispõem de um jardim interno ou de uma varanda, } \\
\text { onde você pode apreciar a vista. O ambiente acolhedor é formado } \\
\text { ainda por lareira, banheira de hidromassagem, cofre, telefone, TV, } \\
\text { DVD, Internet Wireless sistema de calefaçâo e minibar.[H-PT-R15] }\end{array}$} \\
\hline Equivalente 2 & \begin{tabular}{|l||l} 
COFRE INDIVIDUAL & ocorrências
\end{tabular} & 74 \\
\hline $\begin{array}{l}\text { Exemplo } 1 \\
\text { [texto-fonte] }\end{array}$ & \multicolumn{2}{|c|}{$\begin{array}{l}\text { Nos apartamentos do Hotel Beira Mar, você conta com ar- } \\
\text { condicionado, minibar, TV a cabo, cofre individual, serviço de } \\
\text { quarto e acesso à internet sem fio (wi-fi) em todo o hotel.[H-PT-F15] }\end{array}$} \\
\hline $\begin{array}{l}\text { Exemplo } 2 \\
\text { [texto-fonte] }\end{array}$ & \multicolumn{2}{|c|}{$\begin{array}{l}\text { A Pousada das Araras conta com } 6 \text { confortáveis apartamentos, } \\
\text { todos com TV, DVD, Internet Wireless sistema de calefação, } \\
\text { minibar, telefone e cofre individual. }\end{array}$} \\
\hline Equivalente 3 & \begin{tabular}{l||l} 
COFRE ELETRÔNICO & ocorrências \\
\end{tabular} & 68 \\
\hline $\begin{array}{l}\text { Exemplo } 1 \\
\text { [texto-fonte] }\end{array}$ & \multicolumn{2}{|c|}{$\begin{array}{l}\text { Espaçosa área com duas confortáveis camas de solteiro, poltronas, } \\
\text { banheiro exclusivo e varanda privativa para desfrutar da belíssima } \\
\text { paisagem segundo sua localização. A unidade possui também, TV a } \\
\text { cabo, internet, ar quente e frio, cofre eletrônico, frigobar e } \\
\text { telefone. [H-PT-P55] }\end{array}$} \\
\hline $\begin{array}{l}\text { Exemplo } 2 \\
\text { [texto-fonte] }\end{array}$ & \multicolumn{2}{|c|}{$\begin{array}{l}\text { Apartamento Superior Double Bed: todos com vista para o Seringal } \\
\text { e Palmital; TV a cabo; ar condicionado individual; cofre } \\
\text { eletrônico; Internet banda larga cortesia; frigobar; rádio relógio. } \\
\text { [H-PT-HF40] }\end{array}$} \\
\hline Nota ao Tradutor & \multicolumn{2}{|c|}{$\begin{array}{l}\text { Não é necessário traduzir in-room. Em geral, a referência a } \\
\text { apartamento está implícita no contexto. [H-PT-HF7] }\end{array}$} \\
\hline \multicolumn{3}{|c|}{ T } \\
\hline Observações & & \\
\hline
\end{tabular}

Figura 44 - Modelo de ficha terminológica preenchida parcialmente com a colocação in-room safe. 
A etapa final é a elaboração do verbete. Os quatro equivalentes são exibidos ao lado da colocação original, em ordem de frequência, que também é indicada pelas estrelas (quanto mais estrelas, mais frequente). Há também um exemplo para todas as colocações.

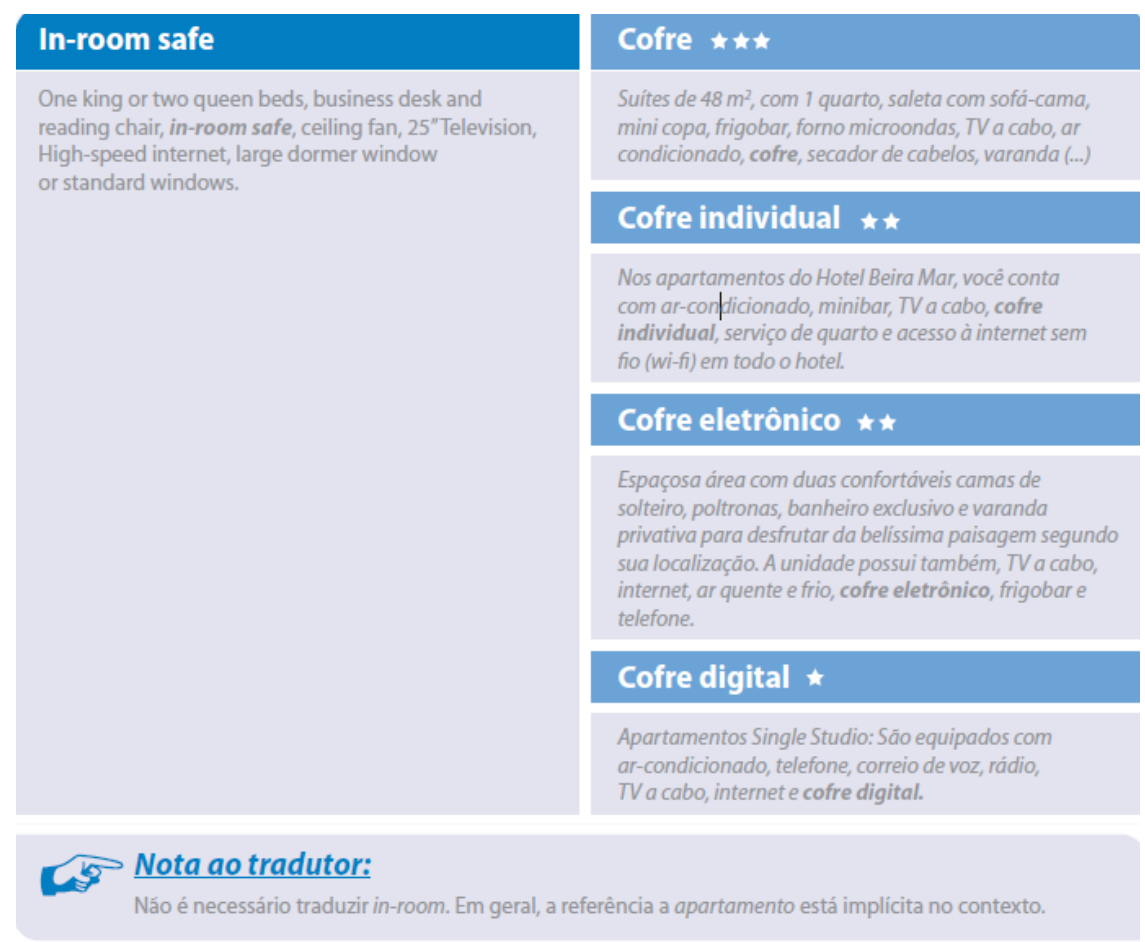

Figura 45 - Modelo de verbete de in-room safe.

No capítulo a seguir, apresentaremos as demais colocações que compõem nossa proposta de glossário. Discutiremos os procedimentos para a identificação de cada uma delas, bem como de seus equivalentes. Por fim, apresentaremos o modelo de verbete do glossário. 


\section{Capítulo 4 - Apresentação dos resultados e modelo de verbete}

Este capítulo apresenta a análise e discussão dos dados levantados a partir da exploração do corpus de estudo, bem como nossa proposta de glossário de colocações da hotelaria, na direção inglês-português, para tradutores.

Trata-se de um estudo aprofundado de uma palavra-chave: room. As colocações dessa palavra serão apresentadas uma a uma, incluindo informações sobre o número de ocorrências, variações, contextos de uso, dentre outras. Na sequência, detalharemos o percurso para o estabelecimento dos equivalentes, bem como as informações adicionais selecionadas para compor o verbete.

Ao final das discussões, apresentaremos os dados na forma de verbete, precedido por uma explicação sobre sua estrutura e os símbolos utilizados.

\subsection{Os colocados de room}

Room foi a palavra escolhida para ilustrar nossa proposta de glossário pelos seguintes motivos: a) trata-se da palavra-chave mais frequente no corpus, com 6.383 ocorrências, numa amostra de pouco mais de 500 mil palavras (vide Figura 37). É, portanto, inegavelmente, representativa do domínio investigado; b) em um estudo-piloto realizado por nós, essa palavra mostrou-se muito rica em conteúdo, possibilitando o levantamento de diversos colocados e suscitando discussões sobre as mais variadas áreas da hotelaria, como mostraremos a seguir; c) julgamos ser essa palavra um bom exemplo para ilustrar a proposta que pretendemos seguir para as demais palavras-chave do corpus na construção do glossário completo.

Todas as colocações partiram da análise inicial da lista de colocados de room (anexo C). Chegamos a 33 colocações principais, 72 equivalentes, 13 Notas ao tradutor, 13 informações adicionais incluídas na seção Você sabia?. São esses dados que passamos a apresentar a seguir, em ordem alfabética. 


\subsubsection{Acessible room}

Accessible room ocorre 43 vezes no corpus. Além dessa forma, com 26 ocorrências, a colocação apresenta variações menos frequentes, identificadas pelas linhas de concordância ordenadas pelos colocados à esquerda:

Accessible room (26) - ou -

Handicap(ped) accessible room (9)

Wheelchair accessible room (3)

Disability accessible room (3)

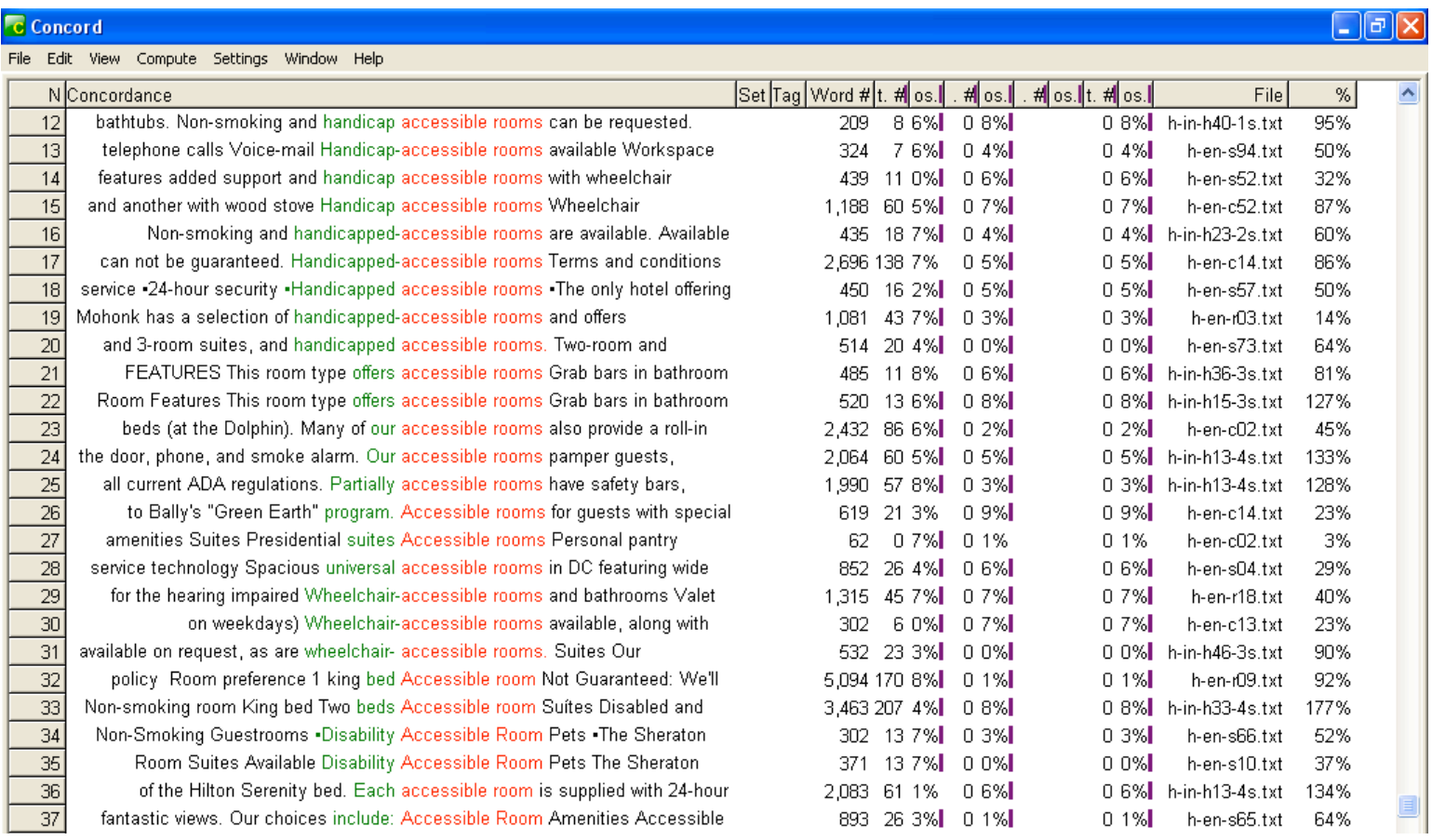

Figura 46 - Parte das linhas de concordância de accessible room(s) ordenadas pela primeira palavra à esquerda.

Para chegar ao equivalente, iniciamos a busca por "portadores", tendo em mente portadores de necessidades especiais ou portadores de deficiência (física), pois essas palavras remetem ao mesmo contexto de accessible room. Geramos linhas de concordância para "portadores" e encontramos 61 ocorrências de portadores de necessidades especiais e 13 de portadores de deficiência (física). Estendemos a busca com a palavra "deficiente" e contabilizamos 28 ocorrências de deficientes físicos e 11 de deficientes (singular e plural). Por fim, encontramos ainda 10 ocorrências de pessoas com deficiência. Esses dados em si já são interessantes, pois demonstram a preferência 
de uso por portadores de necessidades especiais, sendo a forma mais politicamente correta de referir-se a pessoas nessa condição. Incluímos esse dado na Nota ao tradutor.

O passo seguinte foi pesquisar cada uma das opções acima individualmente, ordenando as linhas de concordância pelos colocados à esquerda. Assim, identificamos os seguintes equivalentes:

Apartamento para portadores de necessidades especiais (16)

Apartamento adaptado para portadores de necessidades especiais (8)

Apartamento para deficientes físicos (7)

Vejamos alguns exemplos:

Preocupado em atender melhor o seu público, o hotel disponibiliza ainda apartamentos para portadores de necessidades especiais.

Dispomos de apartamentos adaptados para portadores de necessidades especiais. Dispomos de um apartamento para deficientes físicos, com porta mais larga e barras de apoio no banheiro.

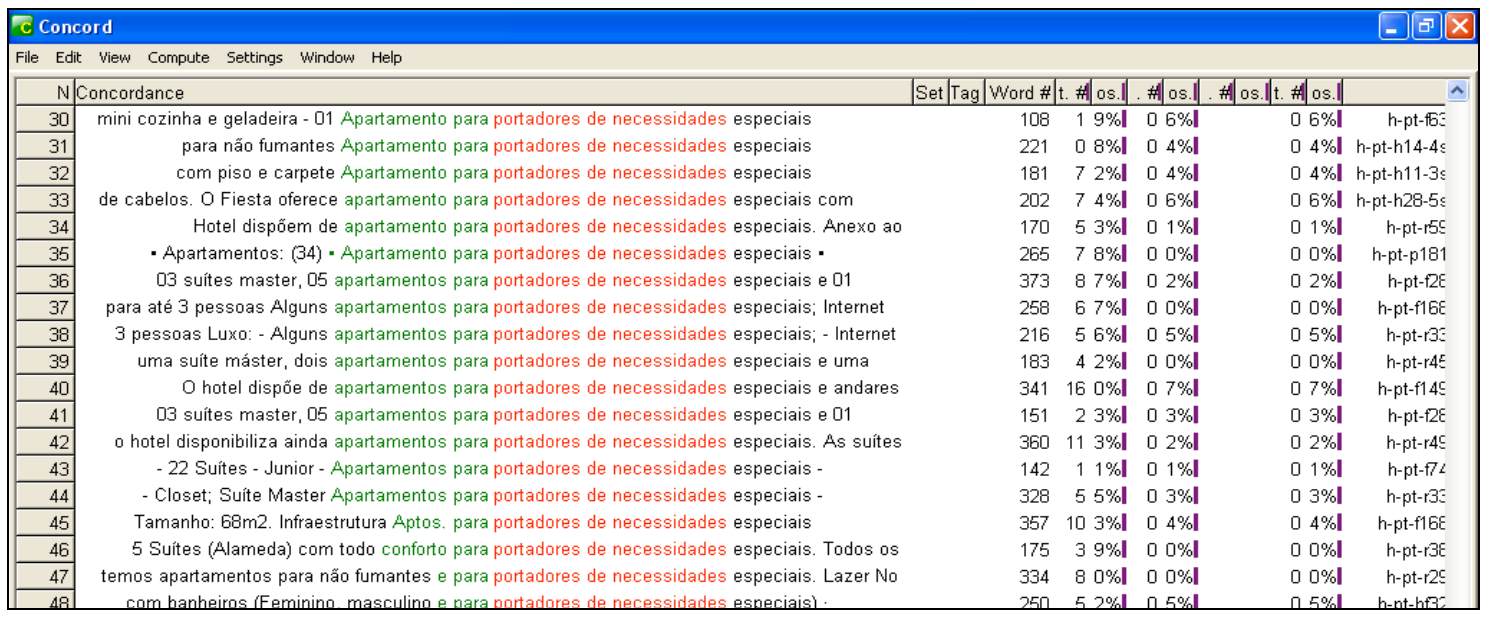

Figura 47 - Parte das linhas de concordância de portadores de necessidades especiais, ordenadas pelas palavras à esquerda.

\subsubsection{Banquet room}

Encontramos 19 ocorrências de banquet room(s) no corpus. Pela análise dos contextos, nota-se que banquet room se refere tanto a um espaço dedicado a banquetes 
propriamente dito, como para eventos em geral, como mostra a parte sublinhada dos exemplos abaixo:

We feature a banquet room and foyer that can accommodate up to 150 guests. Perfect for a variety of occasions, these versatile rooms are the ideal location for your next social event and will provide you and your guests with a truly memorable evening.

The Atheneum features flexible and dynamic multi-service banquet rooms including our spectacular Grand Ballroom.

Iniciamos a busca do equivalente pelo cognato "banquete*", que apresentou 67 ocorrências.

\begin{tabular}{|c|c|c|c|c|c|c|c|c|c|c|c|c|c|c|c|c|}
\hline \\
\hline File Edit & View & Compute Settings & Window Help & \multicolumn{13}{|c|}{$\begin{array}{l}\text { c Concord } \\
\text { File Edit View Compute Settings Window Help }\end{array}$} \\
\hline$N$ & & Word & With & | elation| & Texts & Total & tal Left|la & | Right|| & $\llcorner 4$ & $\mathrm{L3}$ & L2 & L1 & Centre & R1 & $\mathrm{R} 2$ & R3 \\
\hline 1 & & BANQUETES & banquete* & 15.885 & 26 & 34 & 0 & 0 & 0 & 0 & 0 & 0 & 34 & 0 & 0 & 0 \\
\hline 2 & & BANQUETE & banquete* & 15.837 & 31 & 37 & 2 & 2 & 0 & 1 & 1 & 0 & 33 & 0 & 1 & 1 \\
\hline 3 & & ATE & banquete ${ }^{*}$ & 7.652 & 7 & 7 & 1 & 6 & 1 & 0 & 0 & 0 & 0 & 0 & 3 & 0 \\
\hline 4 & & AUDITÓRIO & banquete* & 11.371 & 12 & 12 & 8 & 4 & 1 & 0 & 5 & 2 & 0 & 1 & 3 & 0 \\
\hline 5 & & $\mathrm{COM}$ & banquete* & 4.879 & 7 & 9 & 0 & 9 & 0 & 0 & 0 & 0 & 0 & 4 & 2 & 1 \\
\hline 6 & & CONVENÇỐES & banquete* & 8.592 & 4 & 5 & 5 & 0 & 3 & 0 & 2 & 0 & 0 & 0 & 0 & 0 \\
\hline 7 & & COQUETÉIS & banquete* & 11.395 & 7 & 7 & 6 & 1 & 0 & 1 & 2 & 3 & 0 & 1 & 0 & 0 \\
\hline 8 & & COQUETEL & banquete* & 13.449 & 11 & 11 & 6 & 5 & 0 & 3 & 1 & 2 & 0 & 4 & 1 & 0 \\
\hline 9 & & $\mathrm{DE}$ & banquete* & 5.311 & 25 & 29 & 13 & 16 & 3 & 1 & 2 & 7 & 0 & 0 & 3 & 11 \\
\hline 10 & & E & banquete* & 5.102 & 16 & 19 & 13 & 6 & 1 & 4 & 0 & 8 & 0 & 4 & 1 & 0 \\
\hline 11 & & EM & banquete* & 6.906 & 13 & 15 & 9 & 6 & 2 & 0 & 2 & 5 & 0 & 2 & 1 & 1 \\
\hline 12 & & ESCOLAR & banquete* & 14.435 & 14 & 14 & 11 & 3 & 2 & 1 & 3 & 5 & 0 & 0 & 2 & 1 \\
\hline 13 & & ESPINHA & banquete* & 12.843 & 8 & 8 & 4 & 4 & 2 & 2 & 0 & 0 & 0 & 1 & 2 & 1 \\
\hline 14 & & 0 & banquete* & 5.068 & 9 & 9 & 1 & 8 & 0 & 0 & 0 & 1 & 0 & 5 & 0 & 1 \\
\hline 15 & & PARA & banquete* & 6.193 & 15 & 18 & 11 & 7 & 1 & 5 & 2 & 3 & 0 & 4 & 1 & 2 \\
\hline 16 & & PEIXE & banquete* & $=11.843$ & 8 & 8 & 5 & 3 & 0 & 2 & 1 & 2 & 0 & 0 & 0 & 1 \\
\hline 17 & & PESSOAS & banquete* & 8.421 & 7 & 11 & 7 & 4 & 2 & 2 & 1 & 2 & 0 & 0 & 2 & 0 \\
\hline 18 & & REUNIỖES & banquete* & 9.468 & 5 & 5 & 4 & 1 & 1 & 0 & 1 & 2 & 0 & 0 & 1 & 0 \\
\hline 19 & & SALA & banquete* & 7.753 & 4 & 8 & 6 & 2 & 1 & 4 & 0 & 1 & 0 & 1 & 0 & 1 \\
\hline 20 & & U & banquete* & 12.125 & 7 & 8 & 4 & 4 & 1 & 1 & 0 & 2 & 0 & 1 & 1 & 1 \\
\hline
\end{tabular}

Figura 48 - Lista de colocados de banquete(s).

Pela lista de colocados, identificamos sala (linha 19) como candidato a equivalente. Entretanto, a análise das linhas de concordância revelou não se tratar do mesmo contexto de banquete room, mas do tipo de disposição dos espaços para eventos dos hotéis, como mostra o exemplo:

Estrutura da sala: data show, coffee break, equipamento de som e de iluminação (...) sala escolar, sala banquete, sala auditório, sala em $U$.

Esses tipos de disposição dos espaços para eventos são abordados em detalhes no item 4.1.21. 
Considerando cada linha de concordância de "banquete*", verificamos dois exemplos de salões sendo utilizados para eventos gerais com menção a banquetes. Assim, apesar de os exemplos não mencionarem exatamente salão para banquetes, consideramos esse o equivalente mais adequado.

Salões para convenções e banquetes com capacidade de acomodar até 300 pessoas simultaneamente.

Estrutura do hotel: [...] business room; piscina aquecida; 4 salões para coquetéis e banquetes.

\subsubsection{Book [a, your, this] room}

Essa colocação ocorre 46 vezes no corpus. Trata-se de uma estrutura sinônima de reserve a room, mais recorrente (56). Por esse motivo, apresentaremos as discussões no item 4.1.23, juntamente com reserve a room e, no verbete, incluímos uma remissiva a essa colocação.

\subsubsection{Comfortable room}

Constatamos 12 ocorrências de comfortable room(s) no corpus. Além dessas colocações, o adjetivo, bastante recorrente no corpus (409), integra o contexto de room de diversas maneiras: comfortable hotel rooms / accommodations / suites / bedrooms. É, portanto, uma colocação representativa de room.

Identificamos uma colocação de uso semelhante, cozy room, com 8 ocorrências, que integra a seção de variação da presente colocação.

Partimos de confortável como a tradução prima facie de comfortable. No entanto, como nosso objetivo é disponibilizar um amplo leque de opções de tradução para o tradutor, elaboramos uma lista com todos os adjetivos mais recorrentes com apartamento e quarto (discussão desses equivalentes em 4.1.13). Para tanto, nos valemos de três fontes:
a) a lista de colocados de apartamento(s);
b) a lista dos adjetivos mais recorrentes no corpus, fornecida pelo corpus etiquetado; 
c) as linhas de concordância de apartamento(s) antecedido ou sucedido por adjetivos, no corpus etiquetado (expressões utilizadas: "apartamentos NOM apartamento * ADJ" e “ADJ * apartamentos NOM apartamento").

Assim, foi possível elaborar a seguinte relação de adjetivos (em ordem de frequência):

\begin{tabular}{|c|c|c|c|}
\hline \multicolumn{4}{|c|}{ Adjetivos mais frequentes no corpus em português } \\
\hline $\begin{array}{l}\text { especial (892) } \\
\text { melhor (792) } \\
\text { completo (689) } \\
\text { equipado (578) } \\
\text { grande (511) } \\
\text { amplo (524) } \\
\text { bom (450) } \\
\text { internacional (408) } \\
\text { ideal (386) } \\
\text { natural (367) } \\
\text { maior (343) } \\
\text { delicioso (339) } \\
\text { novo (334) } \\
\text { privativo (327) } \\
\text { confortável (323) } \\
\text { exclusivo (314) } \\
\text { aconchegante (297) } \\
\text { agradável (272) } \\
\text { moderno (267) }\end{array}$ & $\begin{array}{l}\text { disponivel (266) } \\
\text { perfeito (250) } \\
\text { pequeno (250) } \\
\text { excelente (250) } \\
\text { standard (241) } \\
\text { ecológico (249) } \\
\text { superior (231) } \\
\text { diferenciado (227) } \\
\text { panorâmico (217) } \\
\text { privilegiado (211) } \\
\text { simples (207) } \\
\text { aquecido (191) } \\
\text { personalizado (186) } \\
\text { decorado (179) } \\
\text { tradicional (177) } \\
\text { livre (171) } \\
\text { belo (171) } \\
\text { esportivo (165) } \\
\text { diferente (162) }\end{array}$ & $\begin{array}{l}\text { especializado (157) } \\
\text { gratuito (157) } \\
\text { relaxante (145) } \\
\text { histórico (125) } \\
\text { importante (118) } \\
\text { lindo (117) } \\
\text { charmoso (112) } \\
\text { forte (109) } \\
\text { maravilhoso (104) } \\
\text { exuberante (101) } \\
\text { romântico (100) } \\
\text { espaçoso (99) } \\
\text { saboroso (93) } \\
\text { bonito (89) } \\
\text { sofisticado (89) } \\
\text { independente (87) } \\
\text { acolhedor (82) } \\
\text { comum (80) } \\
\text { atrativo (72) }\end{array}$ & $\begin{array}{l}\text { tranquilo (72) } \\
\text { rústico (68) } \\
\text { elegante (66) } \\
\text { descontraído (66) } \\
\text { nobre (64) } \\
\text { contemporâneo (57) } \\
\text { saudável (57) } \\
\text { clássico (54) } \\
\text { requintado (50) } \\
\text { deslumbrante (45) } \\
\text { particular (43) } \\
\text { grátis (41) } \\
\text { suave (38) } \\
\text { luxuoso (37) } \\
\text { encantador (31) } \\
\text { impecável (30) } \\
\text { espetacular (23) } \\
\text { excepcional (23) } \\
\text { inigualável (21) }\end{array}$ \\
\hline
\end{tabular}

Figura 49 - Lista dos adjetivos em português mais frequentes no corpus. 


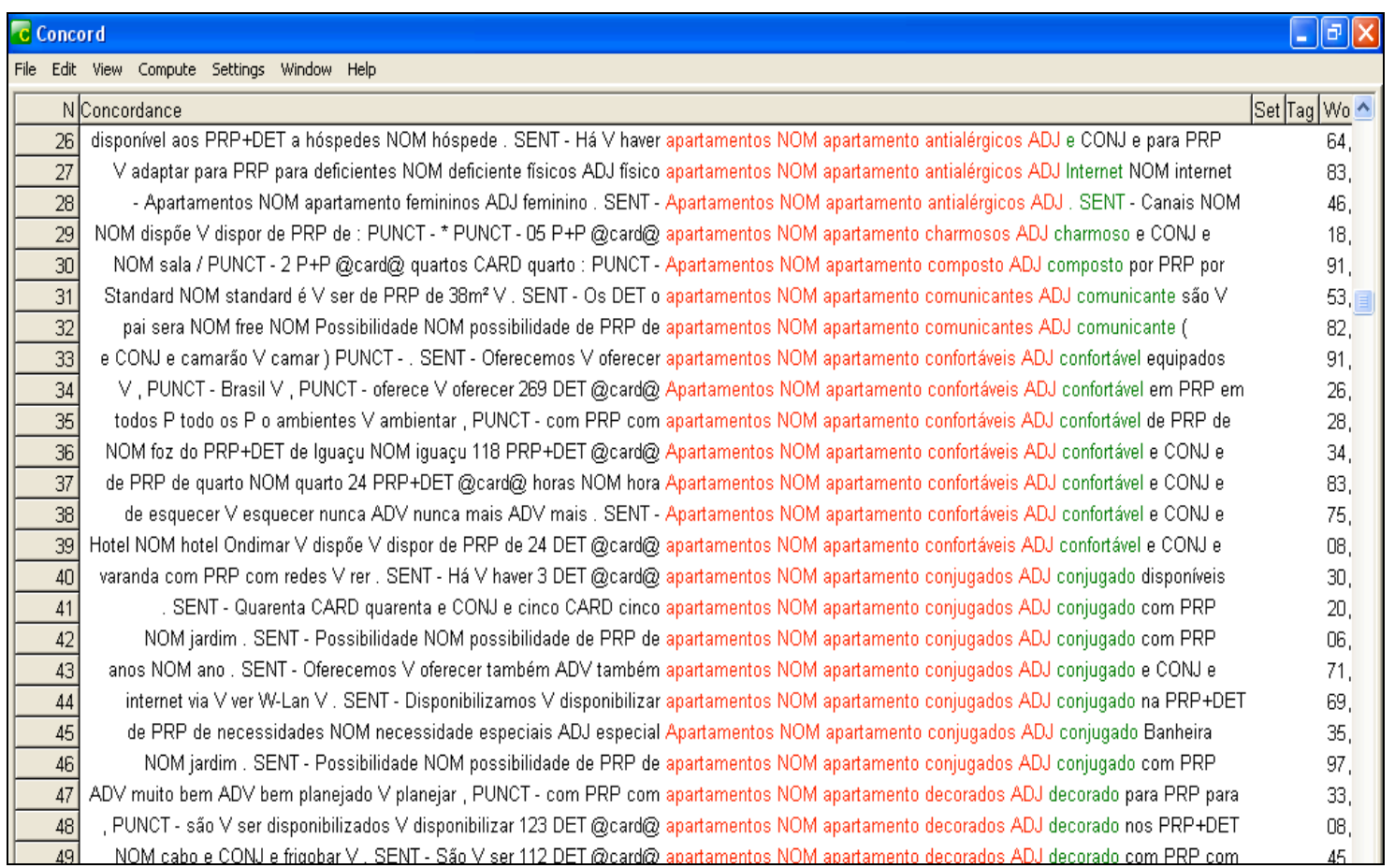

Figura 50 - Linhas parciais das concordâncias de apartamento(s) seguido de adjetivos, no corpus etiquetado.

Esse procedimento, apesar de mais trabalhoso, forneceu resultados que serviram de ponto de partida para a identificação de equivalentes de outras colocações adjetivas de room, como luxurious room, discutida no item 4.1.20. Além disso, a relação acima pode ser útil na pesquisa de colocações adjetivas com diferentes bases, como hotel, suite, acomodações, ambiente, decoração, etc.

Dentre esses adjetivos, selecionamos quatro que julgamos equivalentes prima facie de comfortable: confortável, aconchegante, relaxante, acolhedor. Analisando as linhas de concordância de cada um deles, no singular e no plural, verificamos que, de fato, confortável é a opção mais recorrente, com 42 ocorrências com apartamento; seguida de aconchegante, com 16; e acolhedor, com 2. Vale ressaltar que, no caso de acolhedor, consideramos os contextos em que o adjetivo qualifica apartamento, não necessariamente a colocação exata apartamento acolhedor. Não incluímos relaxante, pois o adjetivo não foi empregado para qualificar um apartamento, mas tratamentos de spa, dentre outros.

\section{O Praia Mansa Suite Hotel possui 110 confortáveis apartamentos de 1 e 2} dormitórios equipados com ar condicionado, cofre, frigobar, TV a cabo, acesso a internet, sala de estar e copa. 
Descanse em nossos aconchegantes apartamentos com vista para a cidade do Rio de Janeiro, sentindo o primor de cada detalhe e vivendo nossa decoração clássica, requintada e acolhedora.

Espaçosos e acolhedores, nossos apartamentos oferecem 1, 2 e 3 quartos.

\subsubsection{Conference room}

Conference room(s) aparece 46 vezes no corpus. Para chegar ao equivalente, iniciamos a busca pela tradução prima facie: sala de conferência, o que retornou 4 ocorrências. Poderíamos considerar esse o equivalente válido, uma vez que os contextos se assemelhavam:

Business travelers will appreciate our in-suite high-speed Internet access and three exquisite conference rooms - ideal for board meetings, planning sessions, seminars, and working luncheons.

As salas de conferência são ideais para desde pequenas reuniões executivas até grandes congressos.

No entanto, em função do baixo número de ocorrências (4) para designar um item que julgamos comum nos hotéis, resolvemos prosseguir a busca por mais equivalentes.

Passamos então a analisar a palavra conferência(s) isoladamente, com 58 ocorrências. Analisando a lista de colocados e as linhas de concordância, não identificamos a presença de outro candidato a equivalente. Descartamos a possibilidade de centro de conferências por ser o equivalente mais direto de conference center e não conference room. Nesse ponto, consideramos a hipótese de conferência em português não ser usado da mesma forma que conference em inglês.

Passamos então a pesquisar palavras que remetiam ao mesmo contexto de conferência, como eventos, reuniões. Assim, identificamos uma alta incidência de convenções, com 455 ocorrências. A lista de colocados de convenções apontou candidatos a equivalentes que buscávamos: salão de convenções, com 46 ocorrências, 
sala de convenções, com 23. Para confirmar se estávamos diante de um equivalente válido, analisamos as linhas de concordância:

Além de toda a infra-estrutura e opções de lazer, ele oferece um equipado salão de convenções, onde é possível falar de negócios e realizar seu evento em meio à natureza.

Ou seja, o equivalente mais recorrente de "conference" room é sala de "convenções" e não de "conferências", como se supõe inicialmente. Nesse ponto, nos perguntamos: seriam convenção, conferência, convention e conference utilizados da mesma forma no contexto da hotelaria?

Em português, constamos que convenção(es) é oito vezes mais recorrente do que conferência(s), 484 ocorrências contra 58, respectivamente. Além disso, convenção está associada a: eventos, reuniões, congressos, seminários, treinamentos, festas, palestras, workshops, feiras, casamentos, coquetéis e encontros. Por sua vez, conferência apresentou como principais colocados vídeo (16, o principal colocado), tele (4) e áudio (1), formando vídeo conferência ou tele conferência (36\% das ocorrências).

\begin{tabular}{|c|c|c|c|c|c|c|c|}
\hline \multicolumn{2}{|c|}{ C Concord } & & & & & \multicolumn{2}{|c|}{0 - $x$} \\
\hline File Edit & - View Compute Settings Window Help & & & & & & \\
\hline \multicolumn{2}{|c|}{ N Concordance } & Set $\mid$ Tag $\mid$ Word \# $\#$ t. \# & $H \mid$ os.l| & \#| os.||t. \# os.|| & File & $\%$ & 스 \\
\hline 214 & 4 para executivos com sala de convençốes, conexăo Internet banda & $\begin{array}{lll}111 & 15 \%\end{array}$ & $07 \%$ & $07 \%$ & $\mathrm{~h}-\mathrm{pt}-\mathrm{fD} 7 \mathrm{txt}$ & $41 \%$ & \\
\hline 215 & Lazer Restaurante Sala de convençốes Reservas Conheça Riviera O & $06 \%$ & $02 \%$ & $02 \%$ & h-pt-f162.txt & $29 \%$ & \\
\hline 216 & natureza preservada! sala de convençốes para 200 participantes sala & $96 \%$ & $05 \% \mathbf{l}$ & $05 \% \mathbf{I}$ & h-pt-hf11.txt & $68 \%$ & \\
\hline 217 & \multirow{2}{*}{$\begin{array}{l}\text { Barqueiro Ar condicionado Sala de convençốes Sala de massagem Bar da } \\
\text { quadras de esportes, saunas, sala de convençốes, Restaurante Porto das }\end{array}$} & $852299 \% \mathbf{I}$ & $04 \%$ & $04 \%$ & h-pt-p125.txt & $76 \%$ & \\
\hline 218 & & $478 \quad 123 \% \mathbf{I}$ & $09 \%$ & $09 \%$ & h-pt-r02.txt & $34 \%$ & \\
\hline 219 & \multirow{2}{*}{$\begin{array}{l}\text { você encontrará sauna a vapor, sala de convençôes, sala de massagem, sala de } \\
\text { familiares e empresariais. Sala de convençôes, serviços de Buffet e }\end{array}$} & $13734 \% \mathbf{I}$ & $00 \% \mid$ & $00 \%$ & h-pt-p55.txt & $31 \%$ & \\
\hline 220 & & $500185 \%$ & $03 \%$ & $03 \%$ & h-pt-hf54.txt & $84 \%$ & \\
\hline 221 & - Completo salẫo de jogos - Sala de convençốes - Estacionamento Coberto - & $360113 \% \mathbf{I}$ & $01 \% \mathbf{I}$ & $01 \%$ & h-pt-f45.txt & $90 \%$ & \\
\hline 222 & \multirow{2}{*}{$\begin{array}{l}\text { ao alvo; Arco e flecha; Ampla sala de convençốes para aliar lazer a eventos; } \\
\text { no bar do saguâo, piscina e sala de convençôes Agência de viagens }\end{array}$} & $37179 \% \mathbf{l}$ & $03 \% \mathbf{l}$ & $03 \% \mathbf{I}$ & h-pt-hf87.txt & $76 \%$ & \\
\hline 223 & & $884417 \%$ & $09 \%$ & $09 \% \mathbf{l}$ & h-pt-h29-5s.txt & $103 \%$ & \\
\hline 224 & \multirow{2}{*}{$\begin{array}{l}\text { Quadra de vôlei de praia. Sala de convençốes, capacidade } 80 \text { pessoas em } \\
\text { para } 200 \text { participantes sala de convençôes com sala de apoio }\end{array}$} & $620249 \% \mathbf{I}$ & $09 \% \mathbf{I}$ & $09 \%$ & h-pt-p140.txt & $53 \%$ & \\
\hline 225 & & $18694 \% \mathbf{I}$ & $07 \%$ & $07 \%$ & h-pt-hf11.txt & $69 \%$ & \\
\hline 226 & única Sauna a vapor Sala de convençôes com capacidade para 150 & $92 \% \mathbf{I}$ & $08 \% \mathbf{I}$ & $08 \%$ & h-pt- & $47 \%$ & \\
\hline 227 & de babás; para as empresas, sala de convençôes equipada. babás; para as & $563188 \% \mathbf{I}$ & $09 \% \mathbf{I}$ & $09 \% \mathbf{I}$ & h-pt-hf38.txt & $97 \%$ & \\
\hline 228 & infantil, internet-station, w-lan, sala de convençốes, sala de convivência e TV, & $326 \quad 120 \% \mathbf{I}$ & $09 \% \mathbf{I}$ & $09 \% \mathbf{I}$ & h-pt-p175.txt & $48 \%$ & \\
\hline 229 & muita saude na area da piscina Sala de convençốes - Dispomos de uma sala de & $1,9361161 \% \mathbf{I}$ & $01 \%$ & $01 \%$ & $h-p t-h$ & $71 \%$ & \\
\hline 230 & \multirow{2}{*}{$\begin{array}{l}\text { tipos de apresentaçẫo. Nossa sala de convençổes está preparada para receber } \\
\text { audiovisuais, entre outros). Salẫo de convençôes para até } 200 \text { pessoas, copa, }\end{array}$} & $462 \quad 142 \%$ & $01 \% \mathbf{I}$ & $01 \%$ & h-pt-hf38.txt & $83 \%$ & \\
\hline 231 & & $2,7951123 \% \mathbf{I}$ & $00 \% \mathbf{l}$ & $00 \% \mathbf{I}$ & & $62 \%$ & \\
\hline 232 & e comporta até 70 pessoas. 0 salăo de convençổes do hotel também conta com & $493139 \%$ l & $00 \% \mathbf{I}$ & $00 \% \mathbf{I}$ & & $81 \%$ & \\
\hline 233 & \multirow{2}{*}{$\begin{array}{l}\text { beira da piscina: a sauna, o salăo de convençổes com capacidade para } 120 \\
\text { mini horse e cavalos de cela. Salăo de convençốes / tatersal: Com área para }\end{array}$} & $446 \quad 185 \% \mathbf{I}$ & $07 \%$ & $07 \%$ & h-pt-hf49.txt & $94 \%$ & \\
\hline 234 & & $914206 \%$ & $08 \% \mathbf{l}$ & $08 \% \mathbf{I}$ & h-pt-h+97.txt & $69 \%$ & \\
\hline 235 & Prêmios Tardes Dançantes Salẫo De Convençốes: Capacidade: 120 pessoas & $382116 \% \mathbf{I}$ & $00 \% \mid$ & $00 \% \mathbf{I}$ & h-pt-hf113.txt & $76 \%$ & \\
\hline 236 & \multirow{2}{*}{$\begin{array}{l}\text { e livros de arte e culinária. Salâo de Convençốes - com capacidade para até } \\
\text { na cidade. Trata-se de um Salăo de Convençốes (perto do Palácio do }\end{array}$} & $458 \quad 153 \%$ & $09 \% \mid$ & $09 \% \mathbf{I}$ & h-pt-p141.txt & $80 \%$ & \\
\hline 237 & & $1,02536 \quad 1 \% \mathbf{I}$ & $03 \% \mid$ & $03 \%$ & h-pt-p92.txt & $57 \%$ & \\
\hline 238 & simpósios e reuniốes. No salấo de convençốes do hotel, o usuário tem à & $62426 \quad 6 \% \mathbf{I}$ & $08 \% \mid$ & $08 \% \mathbf{I}$ & h-pt-hf1 47.txt & $80 \%$ & \\
\hline 239 & \multirow{2}{*}{$\begin{array}{l}\text { Shop Restaurante Cofre Hotel Salâo de Convençốes DDD / DDI Salão de } \\
\text { restaurante, american-bar, salâo de convençốes, entre outros atrativos. É }\end{array}$} & $1,554770 \% \mathbf{l}$ & $05 \% \mathbf{l}$ & $05 \%$ & h-pt-h04-4s.txt & $171 \%$ & \\
\hline 240 & & $17239 \% \mathbf{I}$ & $08 \%$ & $08 \%$ & h-pt-hf34.txt & $41 \%$ & \\
\hline 241 & \multirow{2}{*}{$\begin{array}{l}\text { a } 35 \text { campos de futebol. Salẫo de convençôes- } 2 \text { salas p/ } 30 \text { e } 40 \text { pessoas, } \\
\text { oferece um amplo e moderno salẫo de convençôes, gue bem equipado e }\end{array}$} & $561219 \% \mathbf{I}$ & $09 \%$ & $09 \% \mathbf{I}$ & $h-p t-h+99 . t x t$ & $71 \%$ & \\
\hline 242 & & $24182 \% \mathbf{l}$ & $0.5 \% \mathbf{l}$ & $05 \% \mathbf{I}$ & h-pt-f08.txt & $55 \%$ & \\
\hline כ12 & 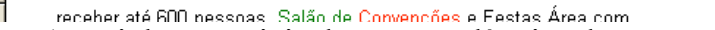 & $59 A \quad 377 \%$ & $n \pi \% 1$ & $n$ ก\% & h_nt_nfo twt & $35 \%$ & \\
\hline
\end{tabular}

Figura 51 - Linhas parciais das concordâncias de convenções, ordenadas pelo colocado à esquerda. 


\begin{tabular}{|c|c|c|c|c|c|c|c|c|}
\hline \multicolumn{2}{|c|}{ c Concord } & & & & & & \multicolumn{2}{|c|}{0 - $x$} \\
\hline File Edit & View Compute Settings Window Help & & & & & & & \\
\hline \multicolumn{2}{|r|}{ N/Concordance } & \begin{tabular}{|l|l|l|l} 
Set & Tag & Word \# \\
\end{tabular} & t. $\# \mid$ os. $\mid$ | & \#| os.l|| & $\#$ |os.||t. $\# \mid$ os.l|| & File & $\%$ & A \\
\hline 1 & e tipo Madonna), sistema de áudio conferencia, retro projetores, projetores & 861 & $367 \%$ & $03 \%$ & $03 \%$ & h-pt-h30-3s.txt & $150 \%$ & \\
\hline 2 & novas geraçốes de equipamentos de conferência, Internet Wi-Fi, telas de & 285 & $99 \% \mathbf{I}$ & $04 \%$ & $04 \%$ & h-pt-f24.txt & $86 \%$ & \\
\hline 3 & da transferência online para fins de conferência, devidamente identificado & 428 & $86 \%$ & $02 \%$ & $02 \%$ & h-pt-h18-3s.txt & $117 \%$ & \\
\hline 4 & para o seu grupo. Possuímos salas de conferência ideais para reuniốes & 1,722 & $512 \%$ I & $07 \%$ & $07 \%$ & h-pt-h05-5s.txt & $177 \%$ & \\
\hline 5 & o Tropical da Bahia oferece salas de conferência que podem ser adaptadas a & 1,030 & $455 \% \mathbf{I}$ & $07 \%$ & $07 \%$ & h-pt-h29-5s.txt & $119 \%$ & \\
\hline 6 & à internet de banda larga. As salas de conferência sâo ideais desde peguenas & 1,033 & $246 \% \mathbf{I}$ & $02 \%$ & $02 \%$ & h-pt-h05-5s.txt & $110 \%$ & \\
\hline 7 & para a realizaçẫo de evento ou conferência, por favor envie um e-mail & 1,471 & $516 \% \mathbf{I}$ & $02 \%$ & $02 \% \mathbf{I}$ & h-pt-h31-5s.txt & $149 \%$ & \\
\hline 8 & às $21 \mathrm{h00}$ ) Seu próximo evento ou conferência será, certamente, um & 937 & $411 \% \mathbf{I}$ & $02 \%$ & $02 \%$ & h-pt-h29-5s.txt & $109 \%$ & \\
\hline 9 & um extrato de sua conta para conferência e assinatura; uma via de & 229 & $40 \% \mathbf{I}$ & $03 \% \mathbf{I}$ & $03 \% \mathbf{l}$ & h-pt-770.txt & $42 \%$ & \\
\hline 10 & em seu apartamento um extrato para conferência de seus débitos, evitando & 393 & $74 \%$ & $04 \%$ & $04 \%$ & h-pt-h22-3s.txt & $137 \%$ & \\
\hline 11 & para apresentaçấo audiovisual, Tele Conferência, e acesso 24 horas à & 692 & $293 \% \mathbf{I}$ & $01 \% \mathbf{I}$ & $01 \%$ & h-pt-f178.txt & $46 \%$ & \\
\hline 12 & e Wireless Video Conferência, Tele conferência e Vataç̆̈̆o Eletrônica Áudio & 600 & $270 \% \mathbf{I}$ & $08 \% \mathbf{I}$ & $08 \%$ & h-pt-h01-4s.txt & $122 \%$ & \\
\hline 13 & para apresentaçẫo audiquisual e tele conferência; Acesso à internet Wi-Fi; & 765 & $320 \% \mathbf{I}$ & $06 \%$ & $06 \% \mathbf{I}$ & h-pt-f178.txt & $50 \%$ & \\
\hline 14 & de alta velocidade, sentiço de video conferência, secreta lia geral, central de & 400 & $97 \%$ & $00 \% \mathbf{l}$ & $00 \% \mathbf{l}$ & h-pt-h19-5s.txt & $91 \%$ & \\
\hline 15 & à internet a cabo e Wileless Video Conferência, Tele cofferência e Votaçẫo & 598 & $279 \% \mathbf{I}$ & $08 \% \mathbf{I}$ & $08 \%$ & h-pt-h01-4s.txt & $121 \%$ & \\
\hline 16 & player, som, equipamento de vídeo-conferência, câmera作 e microfones. ¿- & 1,768 & $670 \% \mathbf{I}$ & $00 \%$ & $00 \% \mathbf{I}$ & h-pt-120.txt & $71 \%$ & \\
\hline 17 & VIP, de Leitura, de Apolio, de Vídeo Conferência e o Esc jitório Virtual, para & 879 & $323 \% \mathbf{I}$ & $08 \%$ & $08 \%$ & h-pt-h28-5s.txt & $140 \%$ & \\
\hline 18 & data shows e acesso a tele e vídeo conferência. O Tulip nn Paulista & 299 & $90 \% \mathbf{I}$ & $08 \% \mathbf{I}$ & $08 \%$ & h-pt-f24.txt & $88 \%$ & \\
\hline 19 & Wireless Internet (M|FI) e Vídeo Conferência. Busine & 948 & $320 \% \mathbf{I}$ & $03 \% \mathbf{I}$ & $03 \% \mathbf{I}$ & h-pt-h09-5s.txt & $71 \%$ & \\
\hline 20 & show, projetores, gravalốes a vídeo conferência $\cdot \gg$ Total nente independente & 783 & $173 \% \mathbf{I}$ & 0 1\% & $01 \%$ & h-pt-r16.txt & $64 \%$ & \\
\hline 21 & e tecnológicos, incluindo audio e vídeo-conferência, para rełlizaçấo de eventos, & 542 & $134 \% \mathbf{I}$ & $07 \%$ & $07 \%$ & h-pt-106.txt & $80 \%$ & \\
\hline 22 & ou coffee-break, sala para vídeo-conferência ou reunipes menores, sala & 310 & $121 \% \mathbf{I}$ & $06 \% \mathbf{I}$ & $06 \%$ & h-pt-f83.txt & $73 \%$ & \\
\hline 23 & exclusiva e todo suporte para vídeo conferência, equipado com TV de 41 & 271 & $121 \% \mathbf{I}$ & $03 \% \mathbf{I}$ & $03 \%$ & h-pt-f27.txt & $79 \%$ & \\
\hline 24 & à Internet e habilitaçấ para Vídeo Conferência. Busine \$s Cells Center - Um & 1,194 & $410 \% \mathbf{I}$ & $01 \% \mathbf{I}$ & $01 \%$ & h-pt-h09-5s.txt & $88 \%$ & \\
\hline 25 & e também com habilitaçă para Vídeo Conferência. A área te eventos inclui & 1,159 & $390 \% \mathbf{I}$ & $00 \% \mathbf{I}$ & $00 \% \mathbf{I}$ & h-pt-h09-5s.txt & $86 \%$ & \\
\hline 26 & e săo habilitado \& para Vídeo Conferência. Seviç̧oß de Secretaria e de & 1,729 & $640 \% \mathbf{I}$ & $00 \% \mathbf{I}$ & $00 \%$ & h-pt-h09-5s.txt & $122 \%$ & \\
\hline 27 & dez pessoas, com recursos para vídeo conferência Equipe de profissionais & 1,687 & $596 \% \mathbf{I}$ & $06 \%$ & $06 \%$ & h-pt-124.txt & $48 \%$ & \\
\hline 28 & necessários: estruturla para vídeo conferência, isolamento acústico, tela de & 2,407 & $861 \% \mathbf{I}$ & $09 \%$ & $09 \%$ & h-pt-h08-5s.txt & $140 \%$ & \\
\hline 29 & Simpósio, Convençăo, Workshop, Conferência e/ou Reuniẫo, & 456 & $197 \% \mathbf{I}$ & $00 \% \mathbf{I}$ & $00 \% \mathbf{I}$ & h-pt-h25-5s.txt & $112 \%$ & \\
\hline 30 & de 10 a 1000 convidados atendendo a conferências, convençốes, festas de & 2,391 & $768 \% \mathbf{I}$ & $05 \% \mathbf{I}$ & $05 \% \mathbf{I}$ & $\mathrm{h}-\mathrm{pt}-\mathrm{r} 24 . \mathrm{t} \times \mathrm{t}$ & $67 \%$ & \\
\hline 31| & de 10 a 700 convidados atendendo a conferências, convençő́es, festas, & 815 & $313 \%$ I & $06 \%$ & $0.6 \%$ & h-pt-h20-5s.txt & $137 \%$ & $\underline{v}$ \\
\hline
\end{tabular}

Figura 52 - Linhas parciais das concordâncias de conferência, ordenadas pelo colocado à esquerda.

Em inglês, contabilizamos 321 ocorrências de conference e 147 de convention. Ou seja, uma diferença considerável (mais que o dobro) entre um e outro, apesar de não tão acentuada como no português (oito vezes). Analisamos as palavras nas listas de colocados e verificamos que conference aparece relacionado a palavras como meetings, banquet, catering, events, wedding, balls, reception. Não encontramos a presença de video na lista de mais de 100 colocados. Semelhantemente, convention está relacionado a meetings, catering e events.

Neste ponto, podemos afirmar, portanto, que existe uma preferência em português por convenção(es), que se inverte no inglês - usa-se mais conference(s), apesar de em inglês os dois termos em questão serem mais próximos. Em outras palavras, pode-se dizer que conference e convention são mais sinônimos em inglês do que conferência e convenção em português, sempre considerando o contexto da hotelaria. Essa informação fica registrada no glossário em uma Nota ao tradutor, alertando-o a preferir convenções em lugar de conferências em suas traduções para o português.

Foi possível identificar ainda outra questão relevante para o tradutor. 
Por meio da análise das concordâncias de salão de convenções (o equivalente mais recorrente), verificamos a alta incidência da referência ao número de pessoas que o salão pode comportar. Como no exemplo abaixo:

Dispomos de restaurante internacional, american bar, salão de convenções com capacidade para 40 pessoas em forma de auditório com equipamentos de áudio/vídeo e serviço de coffee break.

Analisando a forma como essa informação é transmitida, verificamos que, dos 31 contextos com referência ao número de pessoas, mais da metade empregou a expressão com capacidade para:

Para grupos e empresas o Hotel oferece amplo salão de convenções, $150 \mathrm{~m} 2$, com capacidade para 130 pessoas ou mais.

Aqui você encontra a infra-estrutura ideal para a realização do seu evento. Dispomos de salão de convenções confortável, climatizado, equipado com suporte audiovisual e com capacidade para acomodar 200 pessoas.

Essa constatação pode ser atestada com a lista de colocados de pessoas (1221 ocorrências), que traz capacidade como um de seus principais colocados (299 à esquerda).

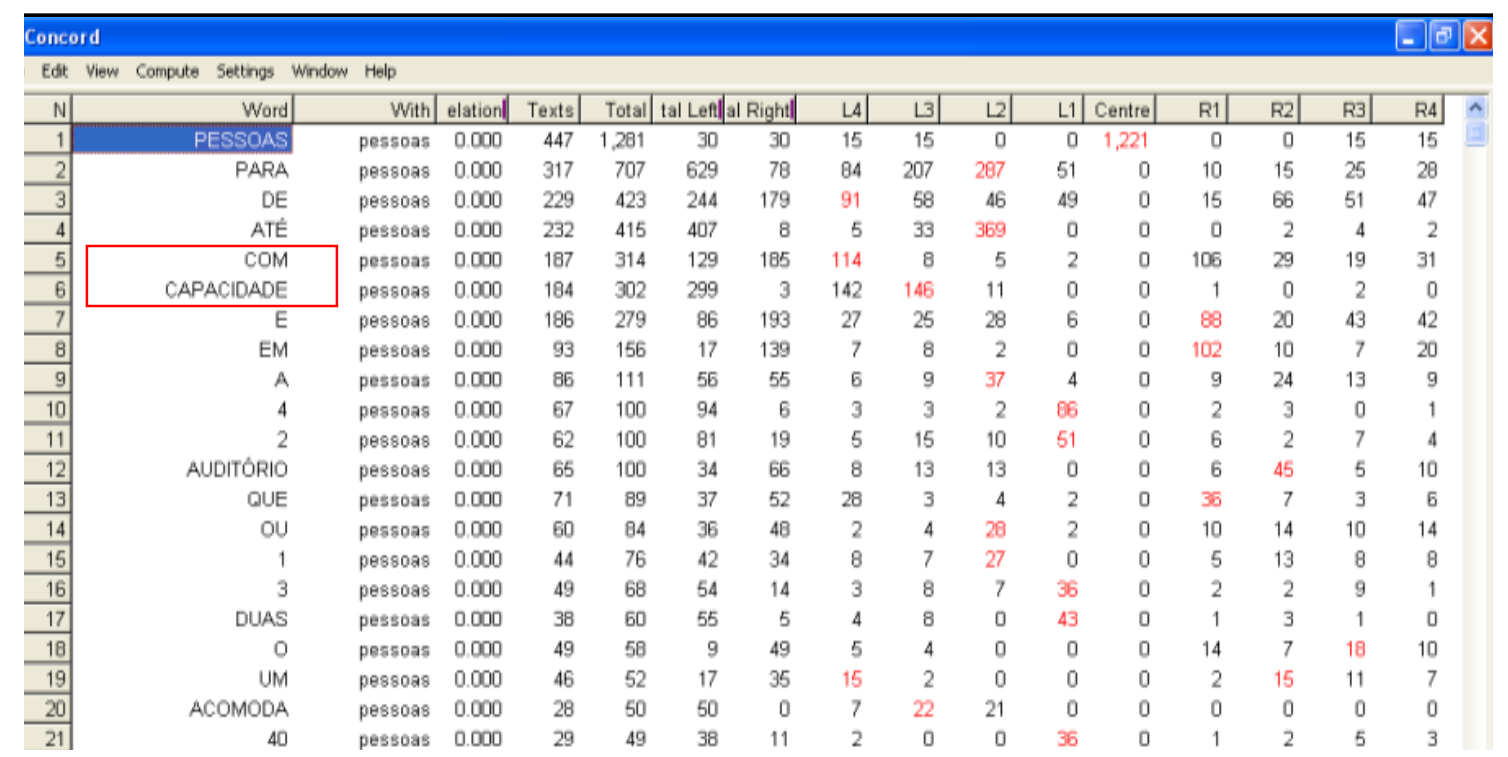

Figura 53 - Lista parcial dos colocados de pessoas. 
O relevante dessa constatação é observar que, em inglês, há preferência pelos verbos accommodate, seat:

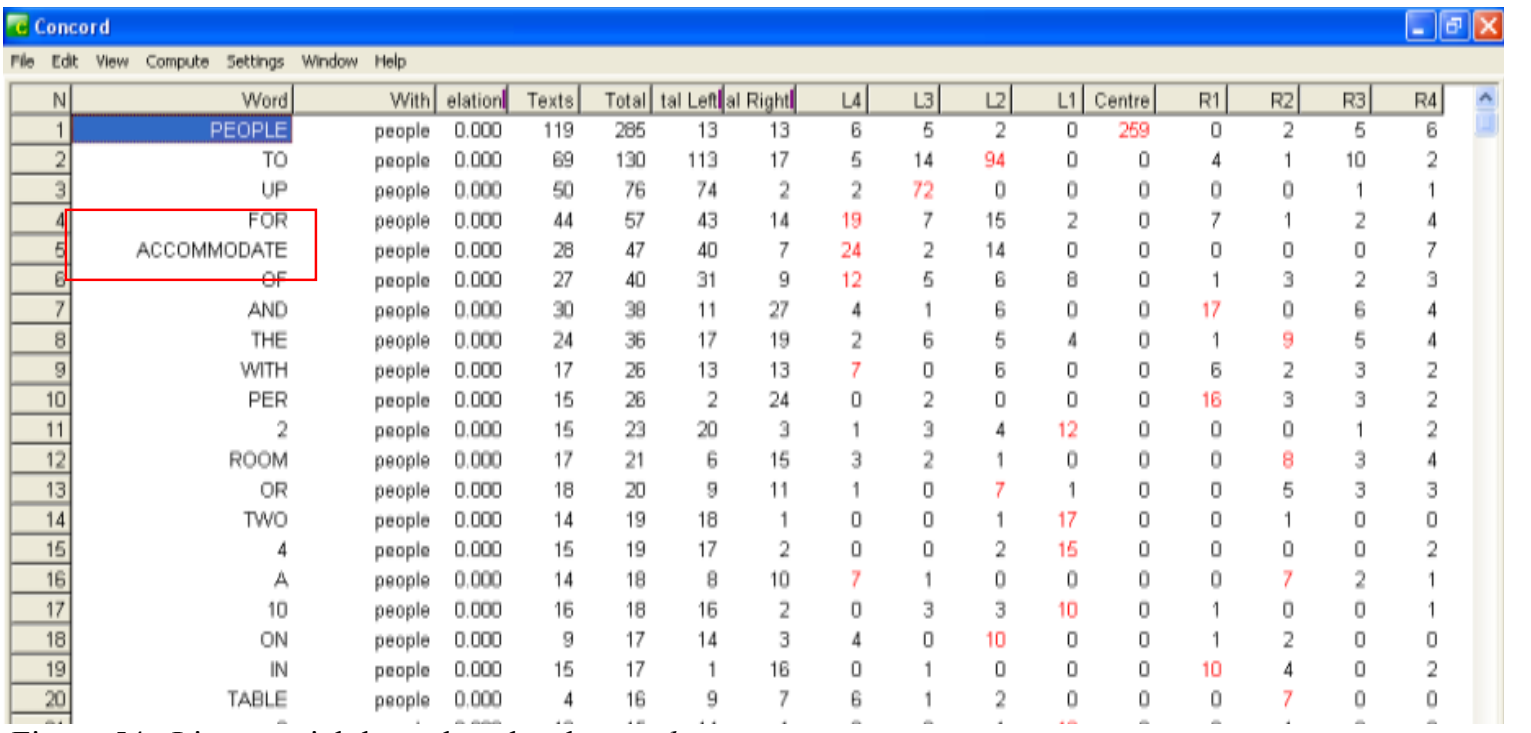

Figura 54- Lista parcial dos colocados de people.

Small meetings receive all the advantages of larger gatherings at The Waldorf Astoria, including the hotel's cutting-edge technology and distinctively appointed conference rooms accommodating meetings of up to 100.

Our largest meeting space measures 1500 square feet, it accommodates up to 80 people theater style, 64 people classroom style, or 70 people in banquet rounds.

Esse dado também foi incluído na seção Nota ao tradutor.

\subsubsection{Connecting room}

Foram encontradas 22 ocorrências de connecting room(s) no corpus. A colocação é utilizada para se referir a acomodações com uma porta de ligação entre elas.

A identificação do primeiro candidato a equivalente partiu da lista de colocados de apartamento (esse equivalente de room está detalhado no item 4.1.13), na qual encontramos conjugados na posição 152. Geramos as linhas de concordância para essa palavra e encontramos 18 ocorrências de apartamentos conjugados, no contexto almejado: 


\begin{tabular}{|c|c|c|c|c|c|c|c|c|}
\hline \multicolumn{2}{|c|}{ C Concord } & & & & & & \multicolumn{2}{|c|}{ 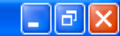 } \\
\hline File Edit & View Compute Settings Window Help & & & & & & & \\
\hline \multicolumn{2}{|r|}{$\mathrm{N}$ Concordance } & \begin{tabular}{|l|l|l|} 
Set & Tag & Word \# \\
\end{tabular} & t. $\# \mid$ os. $\mid$ & \#| os.l| & $\# \mid$ os.||t. $\# \mid$ os.|| & File & $\%$ & 슨 \\
\hline 18 & com quarto de casal e quarto anexo. 2 conjugados com 2 quartos & 337 & $145 \%$ & $05 \%$ & $05 \%$ & h-pt-hf33.txt & $30 \%$ & \\
\hline 19 & \multirow{2}{*}{$\begin{array}{l}2 \text { unidades. Salăo com três ambientes conjugados: suíte c/ closet, sala de } \\
\text { com redes. Há } 3 \text { apartamentos conjugados disponiveis: de um lado uma }\end{array}$} & 282 & $148 \% \mid$ & $09 \%$ & $09 \%$ & h-pt-f127.txt & $47 \%$ & \\
\hline 20 & & 158 & $44 \%$ I & $02 \%$ & $02 \%$ & h-pt-p160.txt & $55 \%$ & \\
\hline 21 & suítes, diversos chalés e apartamentos conjugados, todos decorados com & 137 & $16 \% \mid$ & $02 \%$ & $02 \%$ & h-pt-hf126.txt & $39 \%$ & \\
\hline 22 & \multirow{2}{*}{$\begin{array}{l}\text { W-Lan. Disponibilizamos apartamentos conjugados na categoria Premium } \\
\text { triplos, dois apartamentos conjugados, e um apartamento para }\end{array}$} & 109 & $10 \% \mathbf{I}$ & $03 \%$ & $03 \%$ & h-pt-p175.txt & $25 \%$ & \\
\hline 23 & & 505 & $170 \% \mathbf{l}$ & $09 \% \mathbf{I}$ & $09 \%$ & h-pt-f68.txt & $55 \%$ & \\
\hline 24 & jardins. Possibilidade de apartamentos conjugados com porta de comunicação. & 417 & $196 \% \mathbf{I}$ & $03 \% \mathbf{I}$ & $03 \%$ & h-pt-f159.txt & $66 \%$ & \\
\hline 25 & necessidades especiais Apartamentos conjugados Banheira de hidromassagem & 186 & $70 \% \mathbf{l}$ & $05 \% \mathbf{l}$ & $05 \% \mathbf{l}$ & h-pt-h11-3s.txt & $67 \%$ & \\
\hline 26 & \multirow{2}{*}{$\begin{array}{l}\text { Quarenta e cinco apartamentos conjugados com dois quartos e um } \\
\text { especiais - Apartamentos conjugados - Aceitamos animais de }\end{array}$} & 142 & $22 \% \mathbf{I}$ & $01 \%$ & $01 \%$ & h-pt-r12.txt & $33 \%$ & \\
\hline 27 & & 234 & $23 \% \mid$ & $03 \% \mathbf{I}$ & $03 \%$ & h-pt-136.txt & $44 \%$ & \\
\hline 28 & O hotel oferece ainda apartamentos conjugados, hipoalergênicos e para năo & 145 & $63 \% \mathbf{I}$ & $04 \%$ & $04 \%$ & h-pt-h18-5s.txt & $70 \%$ & \\
\hline 29 & Oferecemos também apartamentos conjugados e adaptados para portadores & 344 & $112 \% \mathbf{I}$ & $02 \%$ & $02 \%$ & h-pt-p21.txt & $15 \%$ & \\
\hline 30 & jardins. Possibilidade de apartamentos conjugados com porta de comunicaçẫo. & 391 & $166 \% \mathbf{I}$ & $04 \%$ & $04 \%$ & h-pt-r46.txt & $40 \%$ & \\
\hline 31 & \multirow{2}{*}{$\begin{array}{l}\text { canto dos passarinhos. Os dois chalés conjugados localizados a } \\
\text { de casal ou solteiro, sala e cozinha conjugados, banheiro, sacada. }\end{array}$} & 508 & $192 \% \mathbf{I}$ & $05 \%$ & $05 \%$ & $\mathrm{~h}-\mathrm{pt}-\mathrm{r} 41 . \mathrm{txt}$ & $29 \%$ & \\
\hline 32 & & 411 & $195 \% \mathbf{I}$ & $04 \%$ & $04 \%$ & h-pt-f149.txt & $50 \%$ & \\
\hline 33 & \multirow{2}{*}{$\begin{array}{l}\text { Amarela (conjugada): Dois dormitórios conjugados equipados com: Cama King } \\
\text { entre o bloco principal, sul e conjugados; - } 20 \text { apartamentos chalés; }\end{array}$} & 311 & $72 \% \mathbf{I}$ & $06 \%$ & $06 \%$ & h-pt-p92.txt & $22 \%$ & \\
\hline 34 & & 261 & $26 \%$ & $07 \% \mathbf{l}$ & $07 \%$ & h-pt- $135 . t \times t$ & $38 \%$ & \\
\hline ज्ञ & 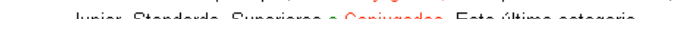 & An & . I I I I & n and & $\therefore$ anil & $1 . . .5 n+\ldots$ & ran & \\
\hline
\end{tabular}

Figura 55- Linhas parciais de concordância de conjugados, ordenadas pelos colocados à esquerda.

Vale lembrar que também contabilizamos ocorrências de conjugados e apartamentos mesmo quando não ligados diretamente, como em:

Desse total, 02 apartamentos são adaptados para pessoas portadoras de necessidades especiais e 07 apartamentos são conjugados.

Para verificar a possibilidade de outros candidatos a equivalente, analisamos as linhas de concordância de apartamento + adjetivos, no corpus etiquetado (expressão de busca: "NOM apartamento * ADJ"), onde verificamos outra possibilidade: comunicante.

\begin{tabular}{|c|c|c|c|c|}
\hline \multicolumn{4}{|c|}{ C Concord } & \multirow[t]{2}{*}{ - $0 \underline{x}$} \\
\hline File Edit & : View Compute Settings Window Help & & & \\
\hline & Concordance & Set $\mid$ Tag $\mid$ Word \#| $\mid$ t. \#| os.l| & \#| os.l| & \# os.l|t. $\#$ os. 슨 \\
\hline 36 & cama de PRP de solteiro AD.J solteiro Apartamento NOM apartamento anti-alérgico ADJ por PRP por andar & $15,568|022| 8 \% \mid$ & $00 \% \mathbf{I}$ & $00 \%$ \\
\hline 37 & NOM internet TV V a DET a Cabo ADJ Apartamentos NOM apartamento antialérgicos A.DJ Andares V năo & $43,671|856| 3 \% \mid$ & $01 \%$ & $01 \%$ \\
\hline 38 & e CONJ e conforto $\vee$ confortar. SENT - Apartamentos NOM apartamento antialérgicos ADJ com PRP com & $03,580|633| 3 \%$ & $00 \% \mathbf{l}$ & $00 \%$ \\
\hline 39 & NOM hóspede. SENT - Há $\vee$ haver apartamentos NOM apartamento antialérgicos ADJ e CONJ e para & $64,067|196| 6 \%$ & $07 \%$ & $07 \%$ \\
\hline 40 & NOM deficiente fisicos AD.J físico apartamentos NOM apartamento antialérgicos AD.J Internet NOM & $83,333|406| 2 \% \mid$ & $02 \% \mathbf{l}$ & $02 \%$ \\
\hline 41 & femininos ADJ feminino. SENT - Apartamentos NOM apartamento antialérgicos ADJ. SENT - Canais & $46,020|916| 6 \% \mid$ & $02 \%$ & $02 \%$ \\
\hline 42 & MeI V. SENT - E CONJ e que PR que apartamento NOM apartamento charmoso ADJ charmoso ! PUNCT - & $58,948|304| 3 \% \mid$ & $04 \%$ & $04 \%$ \\
\hline 43 & Mel V. SENT - E CONJ e que PR que apartamento NOM apartamento charmoso ADJ charmoso ! PUNCT - & $29,081|165| 3 \% \mid$ & $07 \%$ & $07 \%$ \\
\hline 44 & PUNCT - * PUNCT - 05 P+P@card@ apartamentos NOM apartamento charmosos ADJ charmoso e CONJ e & $18,9142612 \% \mathbf{I}$ & $06 \%$ & $06 \%$ \\
\hline 45 & na PRP+DET em Diária ADJ diário Apartamento NOM apartamento COMPLETO ADJ completo com & $68,0249221 \% \mathbf{l}$ & $00 \% \mathbf{I}$ & $00 \%$ \\
\hline 46 & quartos CARD quarto : PUNCT - Apartament厄S vUMM apartamento composto ADJ composto por PRP & $91,105|482| 0 \% \mathbf{I}$ & $05 \%$ & $05 \%$ \\
\hline 47 & de PRP de $38 \mathrm{~m}^{2} \mathrm{~V}$. SENT - Os DET o apartamentos NOM apartamento comunicantes ADJ comunicante são & $53,9457344 \% \mathbf{l}$ & $05 \%$ & $05 \%$ \\
\hline 48 & NOM possibilidade de PRP de apartamentos NOM apartamento comunicantes ADJ comunicante & $82,181|403| 3 \% \mathbf{I}$ & $06 \% \mathbf{l}$ & $06 \%$ \\
\hline 49 & 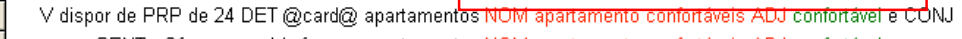 & $08,896|722| 5 \% \mathbf{I}$ & $00 \%$ & $00 \%$ \\
\hline 50 & - SENT - Oferecemos V oferecer apartamentos NOM apartamento confortáveis ADJ confortável & $91,219|709| 9 \%$ & $03 \% \mid$ & $03 \%$ \\
\hline 51 & - oferece $\vee$ oferecer 269 DET @card@ Apartamentos NOM apartamento confortáveis ADJ confortável em & $26,327|160| 15 \% \mathbf{I}$ & $03 \% \mathbf{I}$ & $03 \%$ \\
\hline 52 & NOM iguaçu 118 PRP+DET@card@ Apartamentos NOM apartamento confortáveis ADJ confortável e CONJ & $34,716|045| 6 \% \mid$ & $02 \%$ & $02 \%$ \\
\hline 53 & ADV nunca mais ADV mais. SENT - Apartamentos NOM apartamento confortáveis ADJ confortável e CONJ & $75,016|329| 4 \% \mathbf{I}$ & 0 1\% & $01 \%$ \\
\hline 54 & $\checkmark$ ambientar, PUNCT - com PRP com apartamentos NOM apartamento confortáveis ADJ confortável de PRP & $28,8203956 \%$ I & $08 \%$ & $08 \%$ \\
\hline
\end{tabular}

Figura 56 - Linhas parciais de concordância de apartamento + adjetivos, no corpus etiquetado." 
Geramos uma lista de concordância para "comunicantes", na qual verificamos três casos de apartamentos comunicantes um de quartos comunicantes. Validamos, pelo contexto, a equivalência da colocação.

A área total do apartamento standard é de $38 \mathrm{~m}^{2}$. Os apartamentos comunicantes são térreos.

Por fim, a leitura de uma linha de concordância nos levou a mais um candidato a equivalente.

Apartamentos comunicantes: dois apartamentos interligados por uma porta que pode ser fechada, permitindo a privacidade entre os quartos.

Verificamos a ocorrência de quatro apartamentos interligados no corpus e, apesar do baixo número, julgamos relevante acrescentá-lo a fim de enriquecer a entrada do verbete.

\subsubsection{Deluxe room}

Foram encontradas 40 ocorrências de deluxe room(s) no corpus e 12 da variação deluxe guest rooms. Além disso, observamos outras ocorrências de deluxe room intercalado por algum nome de categoria específica do hotel, como Deluxe King Room, Deluxe Alcove Room, Deluxe Noonmark Room, etc. Assim, constatamos, por meio da análise das linhas de concordância, que deluxe refere-se primordialmente à categoria do apartamento:

Both Deluxe and Premier Deluxe rooms are available, allowing you to discover the panoramic inlet and coastal views that surround the beachfront hotel.

Assim, uma das formas de chegar ao equivalente, foi por meio da busca pela palavra que remetia ao mesmo contexto, "categoria", que nos levou ao candidato a equivalente: luxo.

Todos os nossos apartamentos são categoria luxo e equipados com telefone, frigobar, TV a cabo, ar-condicionado e cofre individual. 
Efetuamos uma busca por "apartamento* luxo", que retornou 111 ocorrências. A totalidade dos contextos remete à categoria ou tipo do apartamento; assim como no inglês, alguns colocados incluíam um nome específico do hotel.

O Hotel Fazenda Fonte Colina Verde apresenta 155 apartamentos luxo que se destacam pelo conforto. Nossos apartamentos são classificados internamente como: Luxo Country e Luxo City.

Upgrade para Apartamento Luxo.

Tarifas: apartamentos Luxo com ar-condicionado (não fumante)

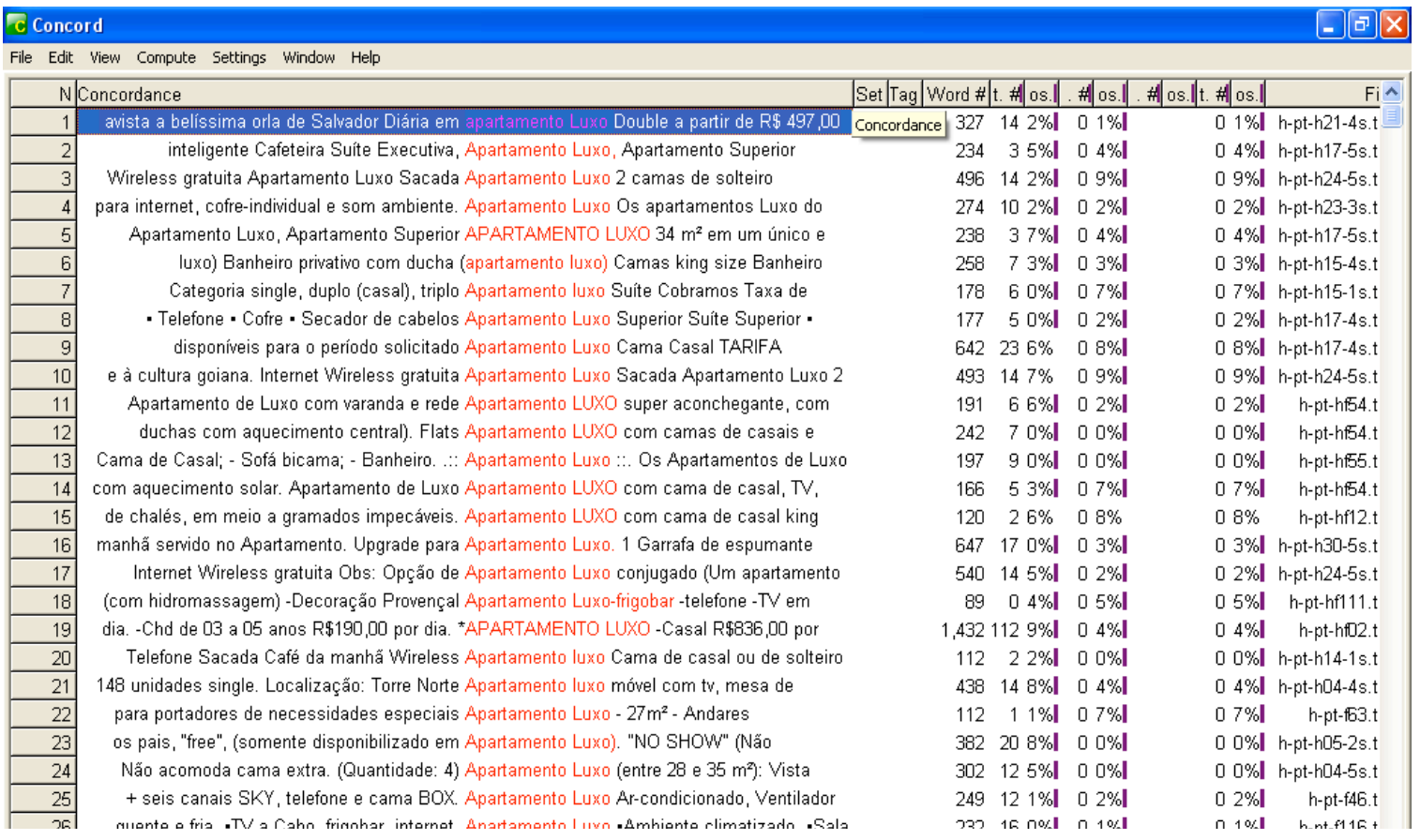

Figura 57 - Linhas parciais de concordância de apartamento luxo.

Outra categoria de apartamento investigada é standard room. Nessa entrada, discutida no item 4.1.27, elencamos os nomes de categorias de apartamentos mais comuns em inglês e português.

\subsubsection{Dining room}

Dining room é uma colocação frequente no corpus, com 247 ocorrências. Não representa um problema de compreensão, sendo a sala de jantar ou um espaço destinado à realização das refeições, tanto nas acomodações do hóspede como nas áreas comuns do hotel: 
The Suite includes a living room and dining room, fireplace, full kitchen, 1,100 square foot private outdoor terrace, oversize bedroom with private sitting area, spacious master bath with soaking tub and half bath for guests.

Of course, you will enjoy access to the inn's many amenities, including a fresh \& hearty breakfast served in the inn dining room (...)

Além dessa acepção mais usual, os exemplos demonstram que dining room também pode ser um espaço amplo, para a realização de eventos, especialmente jantares:

The Inn's graceful dining room, with a fireplace and dramatic floor-to-ceiling French doors overlooking immaculate grounds, can accommodate conference needs for up to 60 guests.

A ferramenta cluster apontou outros dois padrões recorrentes de dining room, que foram confirmados pela análise das linhas de concordância: private dining room (28 ocorrências) e formal dining room (18).

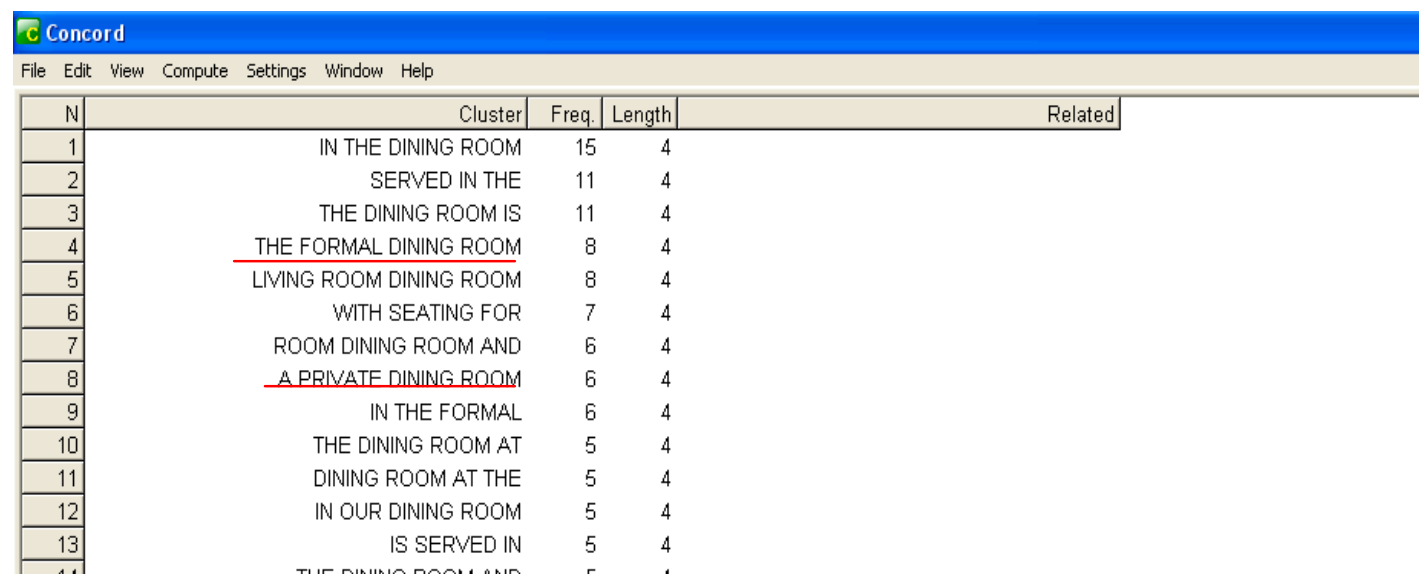

Figura 58 - Clusters parciais de dining room.

Os exemplos esclarecem que private dining room é um espaço separado em um restaurante ou no hotel, destinado a jantares particulares; ou seja, em nenhum dos exemplos do corpus essa sala se encontra na acomodação do hóspede: 
Seasons also features two private dining rooms, ideal for any occasion that calls for an intimate setting, exceptional cuisine and excellent service.

The elegantly draped private dining room at The Carlyle Restaurant accommodates up to 25 guests.

Apesar de formal dining room não representar aparentemente problema de entendimento, até mesmo pelos exemplos no corpus, pesquisamos uma definição na internet para nos certificarmos do sentido:

A formal dining room is a room separate from the kitchen, whose sole purpose is for eating in. It is the perfect place for special occasion meals, dinner parties and formal dinner events. A formal dining room will always have a dining table and dining chairs, often a more expensive or decorative suite than in a kitchen. Also common are a cabinet to display fine china and a sideboard for storing glass and tableware. A chandelier or two may be hung over the table, which is usually covered with a fine tablecloth and laid with silver cutlery, the best china and glassware. ${ }^{37}$

Assim, verificamos que se trata de uma sala de jantar completa, com mobiliário mais sofisticado. Os exemplos corroboraram a definição acima:

Wake up to an elegant breakfast in our formal dining room, served beneath the crystal chandelier on fine china in an atmosphere of Southern Hospitality.

Every morning breakfast is served in the formal dining room on period china (...).

A par dessas informações, passamos então para a identificação dos equivalentes. Partimos da tradução prima facie, sala de jantar. Apesar da menor frequência em relação à colocação em inglês, 30 ocorrências, pôde ser considerada o equivalente mais adequado:

As suites dispõem também de sala de jantar para 4 pessoas, sala de estar e hidromassagem.

A dificuldade maior foi identificar os equivalentes para as colocações relacionadas private dining room e formal dining room.

Para o primeiro caso, fizemos uma busca por jantar, jantares, almoços, a fim de verificar onde esse tipo de evento costuma ser realizado. Encontramos menção a nomes gerais, como restaurante, lounge, espaço, salão, ambiente reservado. Finalmente,

\footnotetext{
${ }^{37}$ http://www.ehow.com/info 8446854 qualifies-formal-dining-room.html Acesso em 15/09/2011.
} 
identificamos cinco ocorrências de sala privativa que se enquadravam no contexto de private dining room descrito acima:

$O$ (restaurante) Eau oferece 122 lugares, um terraço ao ar livre e uma sala privativa, que proporciona um ambiente exclusivo para qualquer tipo de evento, desde uma reunião informal até uma comemoração especial ou um importante jantar de negócios.

A sala privativa Monte Carlo, no Restaurante Mediterrâneo, foi concebida para que os executivos possam garantir o sigilo e a privacidade necessários em importantes almoços de negócios. O espaço comporta até 20 pessoas, assegurando total tranquilidade.

Definimos, assim, sala privativa como equivalente.

Para o segundo caso, formal dining room, analisamos individualmente cada ocorrência de sala de jantar, no intuito de verificar algum adjetivo que a qualificasse como formal. Encontramos casos que descreviam uma sala de jantar completa, mas sem um adjetivo ou uma colocação específica:

A charmosa e ampla sala de jantar, também com vista para o mar, possui mesa retangular em madeira nobre e 16 confortáveis cadeiras, além de uma mesa auxiliar, cadeira e um discreto lavabo.

Sala de jantar com mesa retangular de 14 lugares e 2 aparadores.

Sala de jantar com mesa de 8 lugares, aparador e espelho.

Antes de esgotar as possibilidades, realizamos uma pesquisa no Google por "sala de jantar formal”, em sites ". $b r$ ”. Identificamos ocorrências provenientes de sites de tradução, blogs, anúncios de venda de móveis e até mesmo de venda de casas nos Estados Unidos. A busca na web não foi exaustiva, mas o suficiente para percebermos que não estávamos diante do contexto almejado (hotel ou apartamento de hotel).

Assim, optamos por não apresentar uma colocação específica como equivalente de formal dining room e apenas incluir uma Nota ao tradutor explicando o significado. 


\subsubsection{Elegant room}

Elegant room(s) ocorre 10 vezes no corpus. A discussão dessa colocação encontra-se no item 4.1.20, que descreve luxurious room, colocação considerada sinônima e também mais frequente. No verbete, incluímos apenas uma remissiva.

\subsubsection{Fitness room}

Foram encontradas 26 ocorrências de fitness room. Também identificamos a colocação sinônima exercise room, com um número praticamente idêntico de ocorrências, 25. Optamos pela entrada fitness room e não exercise room por dois motivos: a) fitness é um colocado mais forte de room na lista de colocados (posição 150, enquanto exercise aparece na posição 214); b) fitness é uma palavra-chave no corpus em inglês (posição 40) e exercise não.

Our fitness room has treadmills, exercise bike, universal weight machine, stretching mats and TV to make your workout enjoyable.

Our exercise room for resort guests features cardiovascular equipment as well as a universal gym.

Para identificarmos o equivalente em português, fizemos uma busca por "sala de *". Obtivemos 888 ocorrências dessa estrutura. Analisando a lista de colocados, identificamos rapidamente ginástica. Assim, investigamos o uso de sala de ginástica como um candidato a equivalente. Constatamos 101 ocorrências, no mesmo contexto da colocação original. 


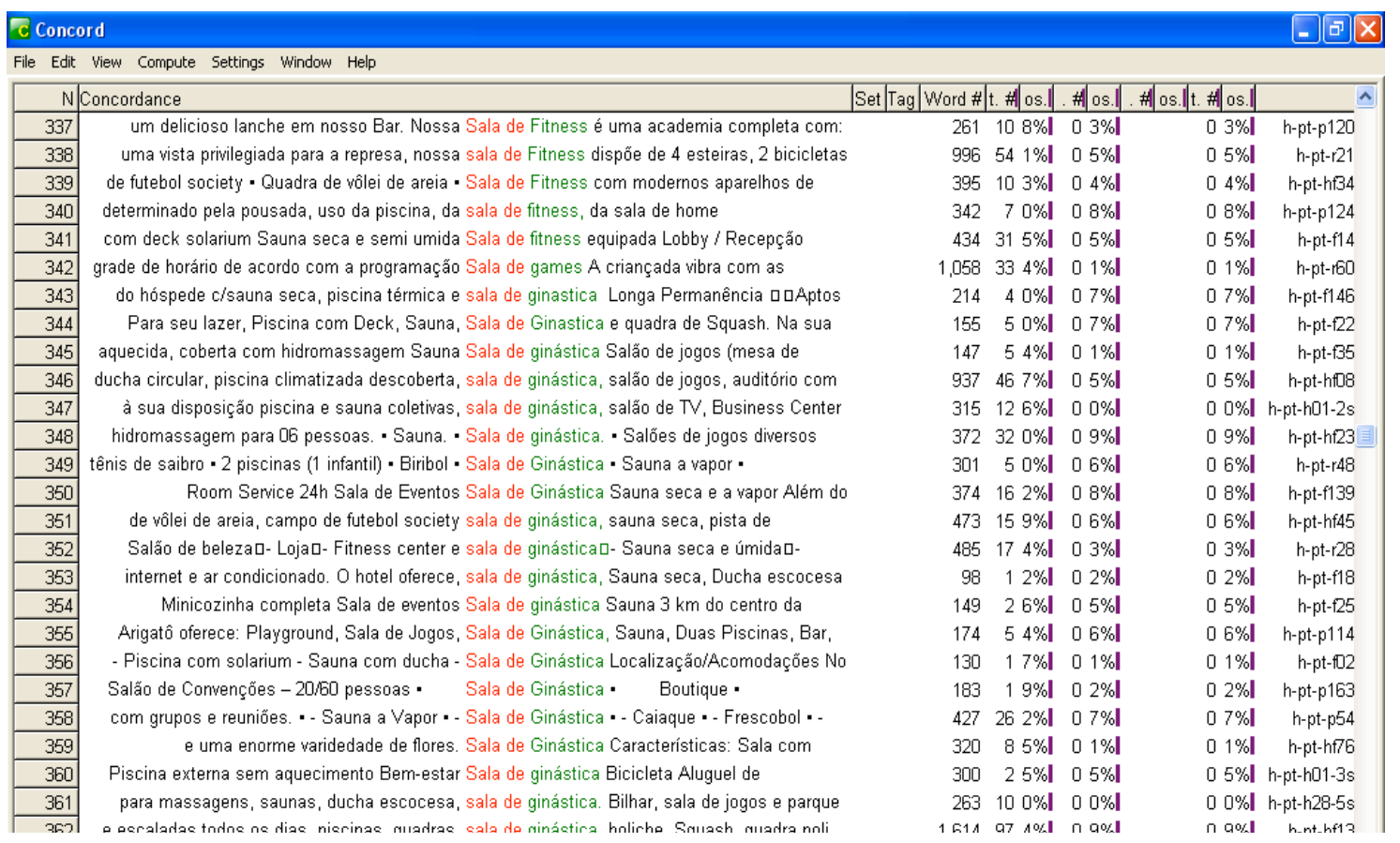

Figura 59 - Linhas parciais de concordância de "sala de *". No destaque, as ocorrências de sala de ginástica.

Analisamos também a palavra ginástica e, por meio das linhas de concordância, identificamos outra possibilidade de equivalente: academia de ginástica (24). Investigando somente academia, constatamos que também pode ser um equivalente para fitness room, com 64 ocorrências. Por fìm, encontramos ainda sala de musculação, com 7 ocorrências e sala de fitness, com 5, totalizando cinco equivalentes.

O hotel dispõe de sala de ginástica, com aparelho multifuncional para exercícios físicos, bicicleta horizontal, aparelho para abdominais e "saco de pancadas".

Exercite-se na nossa academia: infra-estrutura com aparelhos para musculação, bicicletas ergométricas, esteiras e step.

Há, ainda, uma piscina térmica, coberta, ideal para relaxamento, e uma academia de ginástica equipada com modernos aparelhos Technogym, referência no setor de fitness.

Sala de musculação cuidadosamente equipada, além da sauna seca, ducha circular e repouso.

Com uma vista privilegiada para a represa, nossa sala de fitness dispõe de 4 esteiras, 2 bicicletas horizontais, 2 bicicletas verticais e total aparelhagem de musculação. 
Conforme mencionamos inicialmente, fitness é uma palavra-chave no corpus em inglês (posição 40, 1571 ocorrências). Integra principalmente a colocação fitness center, expressão frequentemente utilizada como sinônima de fitness room:

Fitness center equipped with two treadmills, 1 elliptical, 1 stationary bike, free weights and a weight bench.

Our fitness room has treadmills, exercise bike, universal weight machine, stretching mats and TV to make your workout enjoyable.

Todavia, por meio da análise da lista de colocados e das linhas de concordância das duas colocações, observamos duas diferenças, a primeira mais contundente: a) fitness center é mais de dez vezes mais recorrente que fitness room - 293 ocorrências contra 26, respectivamente; b) fitness center tem spa como um de seus principais colocados. A análise das concordâncias também demonstrou essa ligação entre fitness center e spa.

Within Icon Brickell, the hotel stands steps from the 28,000-square-foot spa and fitness center, 300-foot infinity pool on Biscayne Bay, poolside bar and fireplace, and life-size chess set.

The spa also boasts its own high-tech fitness center featuring the newest gym equipment from Technogym ${ }^{\circledR}$, the Italian provider of the world's most advanced fitness and wellness equipment. 


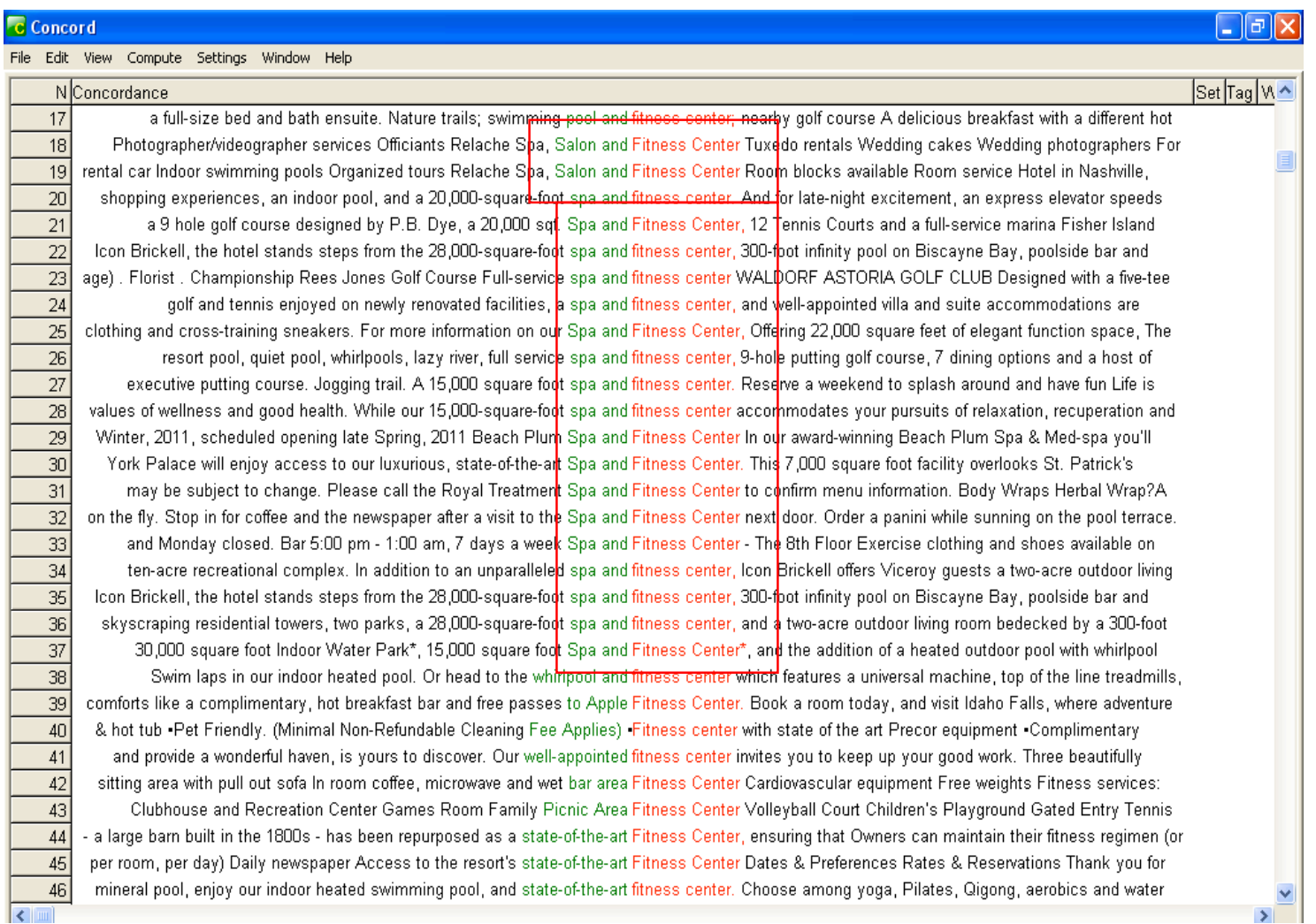

Figura 60 - Linhas parciais de concordância de fitness center. No destaque, a associação com spa.

Em português, fitness center também é recorrente, 176 ocorrências, e tem uso semelhante a sala de ginástica:

O fitness center conta com equipamentos de primeira linha: esteiras, bicicletas ergométricas, bolas de pilates, jumps, equipamento de musculação e muito mais.

O hotel dispõe de sala de ginástica, com aparelho multifuncional para exercícios físicos, bicicleta horizontal, aparelho para abdominais e "saco de pancadas".

Além disso, verificamos que a diferença de frequência entre as duas expressões (176 fitness center x 101 sala de ginástica) não é tão acentuada como no inglês (293 fitness center x 26 fitness room).

Apesar de semelhantes, observamos uma diferença de uso entre as colocações em português: fitness center é utilizado por alguns hotéis para designar uma estrutura mais ampla, que inclui outras instalações:

São ao todo 2 mil $m 2$ de área de lazer, que incluem ainda sala de ginástica, hidroginástica e fitness center, com sauna a vapor, salão de beleza e salas de massagem e relaxamento. O local é ideal para quem quer se divertir, mas sem deixar de lado os cuidados com a saúde. 
A infra-estrutura de lazer e entretenimento do Porto d'Aldeia Resort engloba ainda estádio com campo de futebol gramado, quadras de tênis, playground, salão de jogos, fitness center com sauna seca e sala de musculação, piscinas com toboáguas.

Em português, não observamos uma correlação entre fitness center e spa, como no inglês.

As semelhanças e diferenças de uso descritas acima são incluídas na seção Você Sabia?. Para completar esse estudo, incluímos outros três sinônimos de fitness room em inglês: exercise room, fitness facility e gym.

\subsubsection{Function room}

Foram encontradas 20 ocorrências de function room(s). Trata-se de um espaço destinado à realização de eventos, conforme mostram os exemplos:

With 32 adaptable meeting and function rooms of varying sizes and décor to accommodate groups from five to 1,000, Beaver Run Resort and Conference Center is sure to have the correct venue to fit the needs of your event.

From events of 10 to 400 guests, our wide selection of function rooms provide unique and impressive space for any conference or catered event.

Assim, para buscar o equivalente, partimos da palavra evento, pois remete ao mesmo contexto de function room. Ordenando os colocados à esquerda da palavra de busca, encontramos dois equivalentes para a colocação: sala(s) de eventos (54 ocorrências) e salão(ões) de eventos (38 ocorrências).

O Aquarius Hotel está preparado para sediar, em grande estilo, seus seminários e convenções, dispondo para isso de sala de eventos, totalmente equipada, salão de festas para até 250 pessoas e salas de reuniões capazes de acomodar de 40 a 250 participantes.

No salão de eventos, você poderá realizar encontros empresariais, reuniões, palestras, etc. O local possui excelente infra-estrutura com: internet wi-fi, sistemas de áudio e vídeo, computador e capacidade para até 90 pessoas. 


\begin{tabular}{|c|c|c|c|c|c|c|}
\hline C Concor & & & & & & $-\square \mathrm{a}$ \\
\hline File Edit V & View Compute Settings Window Help & & & & & \\
\hline & Concordance & Set $\operatorname{Tag}$ & Word \#|t. \#| os.|| & \#| os.|| & 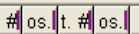 & $\hat{\Lambda}$ \\
\hline 291 & 2 Dorm. Piscina / Solarium Galeria Sala de Eventos Serviços -Camareira -Lavanderia -Portaria & seth & $15141 \%$ & $09 \%$ & $09 \%$ & $h-1$ \\
\hline 292 & bilíngue As belas e elegantes paredes da sala de eventos, com capacidade para até 100 pessoas, & & $389151 \% \mathbf{l}$ & $08 \% \mathbf{l}$ & $08 \% \mathbf{l}$ & h-pt-h1 \\
\hline 293 & Santa Mônica chegou para ser: uma sala de eventos de grande capacidade na Região & & $1,123923 \% \mathbf{I}$ & $01 \%$ & $01 \%$ & h-pt \\
\hline 294 & ANOS Café Extra Jantar (tarifa por pax) Sala de Eventos Bonito ( 30 pax) Sala de Eventos Marruá & & $1,07038 \quad 4 \% \mathbf{l}$ & $05 \%$ & $05 \%$ & $\mathrm{~h}-\mathrm{pt}-\mathrm{h} 1$ \\
\hline 295 & internet banda larga. Garagem Coberta Sala de Eventos Hidro-Massagem Pacote de Núpcias & & $137 \quad 29 \% \mathbf{I}$ & $03 \% \mathbf{I}$ & $03 \% \mathbf{l}$ & $\mathrm{h}-\mathrm{pt}$ \\
\hline 296 & exclusivo dos hóspedes. Home Hotel Sala de Eventos Sala de Eventos A sala de eventos tem & & $249107 \% \mathbf{I}$ & $08 \% \mathbf{I}$ & $08 \%$ & h-pt-t \\
\hline 297 & hóspedes. Home Hotel Sala de Eventos Sala de Eventos A sala de eventos tem $110 \mathrm{~m} 2$ e 2,70 m & & $252106 \% \mathbf{I}$ & $09 \%$ & $09 \% \mathbf{l}$ & h-pt-t \\
\hline 298 & pax) Sala de Eventos Bonito ( 30 pax ) Sala de Eventos Marruá ( 120 pax ) Regime de & & $1,078 \quad 383 \% \mathbf{I}$ & $06 \%$ & $06 \% \mathbf{l}$ & h-pt-h1 国 \\
\hline 299 & restaurante, elevador, bares, auditório, sala de eventos, salão de jogos, piscina, solário, área de & & $372121 \% \mathbf{l}$ & $01 \% \mathbf{l}$ & $01 \% \mathbf{l}$ & h-pt-he \\
\hline 300 & impressora e acesso à Internet. Sala de Eventos Demóstenes com $45 \mathrm{~m} 2$ e área de apoio & & $467 \quad 333 \% \mid$ & $09 \% \mathbf{I}$ & $09 \%$ & $h-k$ \\
\hline 301 & para realizar reuniőes oferecemos uma sala de eventos com capacidade para 60 pessoas e & & $23286 \% \mathbf{I}$ & $02 \% \mathbf{I}$ & $02 \%$ & $h-r$ \\
\hline 302 & -Home Theather -Bar e Chocolateria -Sala de Eventos e Convençốes para 80 Pessoas -Sala de & & $590 \quad 137 \% \mathbf{I}$ & $09 \% \mathbf{I}$ & $09 \% \mathbf{l}$ & $h-k$ \\
\hline 303 & homens de negócio como dos turistas: sala de eventos com capacidade para acomodar até 50 & & $177 \quad 66 \% \mathbf{I}$ & $02 \% \mid$ & $02 \%$ & $h-k$ \\
\hline 304 & com um Business Center, Restaurante e Sala de Eventos; toda infra-estrutura necessária para o & & $12 \%$ & $09 \% \mathbf{I}$ & $09 \%$ & $\mathrm{~h}-\mathrm{pt}-\mathrm{hC}$ \\
\hline 305 & e convençổes, dispondo para isso de sala de eventos, totalmente equipada, salâo de festas & & $19848 \% \mathbf{I}$ & $07 \% \mathbf{I}$ & $07 \%$ & h-pt \\
\hline 306 & Hotel Sala de Eventos Sala de Eventos A sala de eventos tem $110 \mathrm{~m} 2$ e $2,70 \mathrm{~m}$ de pé direito, & & $256107 \% \mathbf{I}$ & $09 \% \mathbf{I}$ & $09 \% \mathbf{l}$ & h-pt-t \\
\hline 307 & Alta proteção acústica. Uma sala de eventos para 150 pessoas. Almoços e jantares de & & $1,782703 \% \mathbf{I}$ & $00 \% \mathbf{I}$ & $00 \% \mathbf{l}$ & $h-\mathrm{k}$ \\
\hline 308 & com lareira. - Sala de vídeo/DVD. - Saläo de eventos (70 pessoas). - Salăo de Jogos com bar e & & $233131 \% \mathbf{l}$ & $00 \% \mathbf{I}$ & $00 \%$ & h-pt \\
\hline 309 & - Recreacionista (alta temporada) Saläo de eventos $•$ Quadro Branco $•$ Retropojetor $\cdot$ Telăo & & $35550 \% \mathbf{I}$ & $02 \% \mathbf{I}$ & $02 \%$ & $h-k$ \\
\hline 310 & a infra-estrutura de recepção, chalés, salão de eventos entre outros. Recentemente o hotel & & $467224 \% \mathbf{I}$ & $03 \% \mathbf{I}$ & $03 \% \mathbf{l}$ & $h-p t$ \\
\hline 311 & Hotel Salâo de Convençốes DDD / DDI Salẫo de Eventos Elevador Seviço de Cópia Espaço de & & $1,560775 \% \mathbf{I}$ & $06 \% \mathbf{I}$ & $06 \%$ & $\mathrm{~h}-\mathrm{pt}-\mathrm{hc}$ \\
\hline 312 & estar com lareira, sala de vídeo e DVD, salăo de eventos, salăo de jogos com bar e churrasqueira, & & $666561 \%$ & $07 \%$ & $07 \%$ & h-pt \\
\hline 313 & de grande vantagem competitiva: 01 salăo de eventos e convençổes com espaços moduláveis e & & $587 \quad 257 \% \mathbf{l}$ & $04 \% \mathrm{l}$ & $04 \%$ & $h-k$ \\
\hline 314 & Shop Salăo de Convençốes Cofre Hotel Salăo de Eventos Computadores Serviço de Cópia DDD / & & $487 \quad 103 \% \mid$ & $08 \% \mathbf{I}$ & $08 \%$ & h-pt-h1 \\
\hline 315 & o Hotel oferece sala de jogos, de TV, salăo de eventos e convençốes (com toda infra-estrutura e & & $326 \quad 157 \%$ & $05 \%$ & $05 \%$ & h-pt \\
\hline 316 & lazer tarifário a fazenda como chegar salăo de eventos tarifário Localizado a $3 \mathrm{Km}$ do Arraial do & & $6100 \% \mathbf{I}$ & $08 \%$ & $08 \%$ & h-pt-t \\
\hline 317 & Estrutura para negócios: O nosso salăo de eventos é perfeito para convençôes ou jantares & & $452154 \% \mathbf{I}$ & $05 \%$ & $05 \%$ & $\mathrm{~h}-\mathrm{pt}$ \\
\hline 318 & foi testada e aprovada pela ONG. No Saläo de Eventos, você poderá realizar encontros & & $506258 \% \mathbf{I}$ & $05 \%$ & $05 \%$ & h-pt \\
\hline 319 & molhado; $\cdot$ Restaurante; -Lavanderia. -Salăo de eventos para 150 pessoas. (Reuniôes, jantares e & & $337 \quad 257 \%$ l & $04 \%$ & $04 \%$ & h-pt \\
\hline 320 & e vista para o lago e montanhas. - Bar, Salăo de Eventos, Palestras, Jogos e Estar. - Piscina & & $80 \% \mathbf{l}$ & $00 \% \mathbf{l}$ & $00 \% \mathbf{l}$ & $h-p t-t_{2}$ \\
\hline 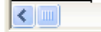 & & & & & & $\geq$ \\
\hline & nes $\mid$ follow up 1 sour & & & & & \\
\hline
\end{tabular}

Figura 61 - Linhas parciais de concordância de eventos, ordenadas pelos colocados à esquerda.

Nas linhas de concordância de function room, encontramos diversas referências às formas de disposição das mesas para atender a diferentes tipos de eventos, Como mostra o exemplo:

Function Room Setup: classroom with 2 people per table to accommodate 28 people; U-Shape to accommodate 20 people; classroom with 3 people per table to accommodate 42 people; Round tables or banquet with 5 to 6 people per table to accommodate 36 people; Hollow Square with 2 people per table to accommodate 28 people.

Essas configurações das salas foram analisadas em detalhe e encontram-se na entrada meeting room, discutida no item 4.1.21. 


\subsubsection{Game room}

Foram constatadas 36 ocorrências de game room(s) no corpus. Para a busca do equivalente, partimos de uma das palavras da tradução prima facie, "jogos". A lista de colocados mostra rapidamente os dois candidatos a equivalentes - sala de jogos, com 186 ocorrências, e salão de jogos, com 136.

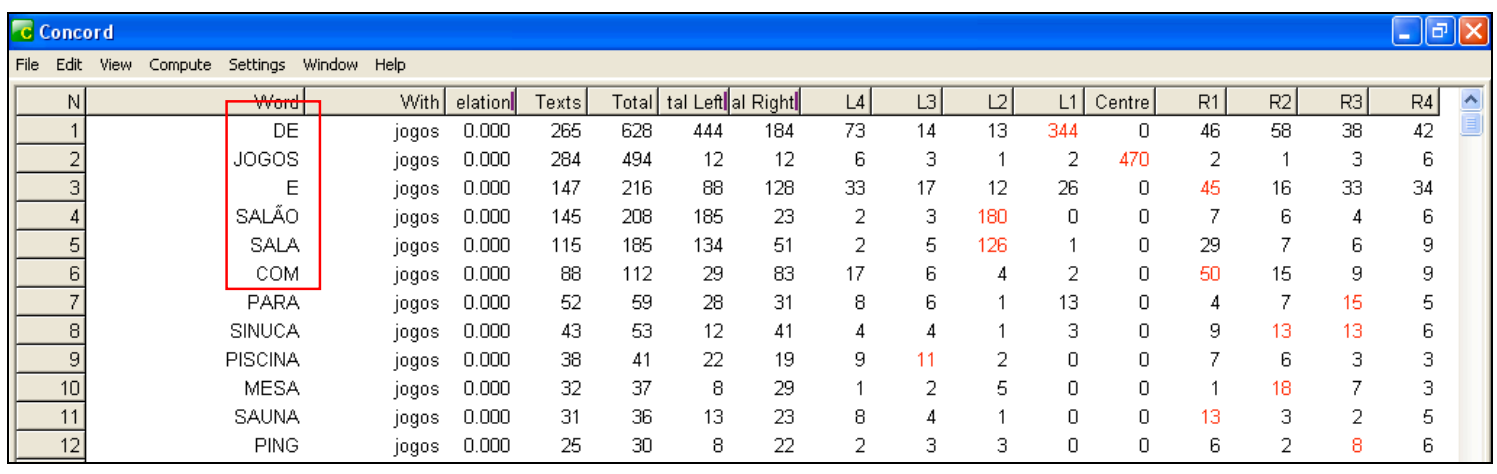

Figura 62 - Lista parcial de colocados de jogos.

Chamou-nos a atenção a diferença no número de ocorrências, 36 de game room e 322 de sala (salão) de jogos. Procuramos investigar o porquê dessa diferença. Analisamos cada uma das 36 concordâncias em inglês e entendemos se tratar de uma sala de jogos usual. Alguns casos incluíam jogos eletrônicos, algo mais próximo ao nosso fliperama, mas, ainda assim, uma sala de jogos. Em seguida, pesquisamos as palavras que remetem ao mesmo contexto de game room: billiards (7), pool table (13), ping pong (13), foosball (8), board games (11), a fim de verificar se esses jogos poderiam ser praticados em um espaço diferente de game room. Essa suspeita não se confirmou. Além de três billiards rooms, não encontramos menção recorrente a outro tipo de espaço para jogos em inglês. A única hipótese que podemos levantar é que esse tipo de opção de lazer é mais comum nos estabelecimentos brasileiros do que americanos.

Assim, apesar da diferença marcante no número de ocorrências, mantivemos os equivalentes sala de jogos e salão de jogos, pois encontramos contextos bastante semelhantes ao da colocação game room.

The Hershey Game Room has a great variety of classic and new arcade games, as does the Forest Game Room where you can also enjoy ping pong, foosball and billiards. 
A sala de jogos oferece diversão em amplo espaço: mesa de ping pong, mesa de sinuca, pebolim.

\subsubsection{Guest room}

Guest é a primeira palavra de conteúdo na lista de colocados de room, formando guest room(s), com 530 ocorrências. Somam-se a esse número 161 casos de guestroom, grafado como uma só palavra, indicado na entrada como uma variação de guest room. Além dessa variação, ressaltamos que room, isoladamente, também é usado como sinônimo de guest room. Os três casos (guest room, guestroom e room) designam as acomodações do hóspede no hotel.

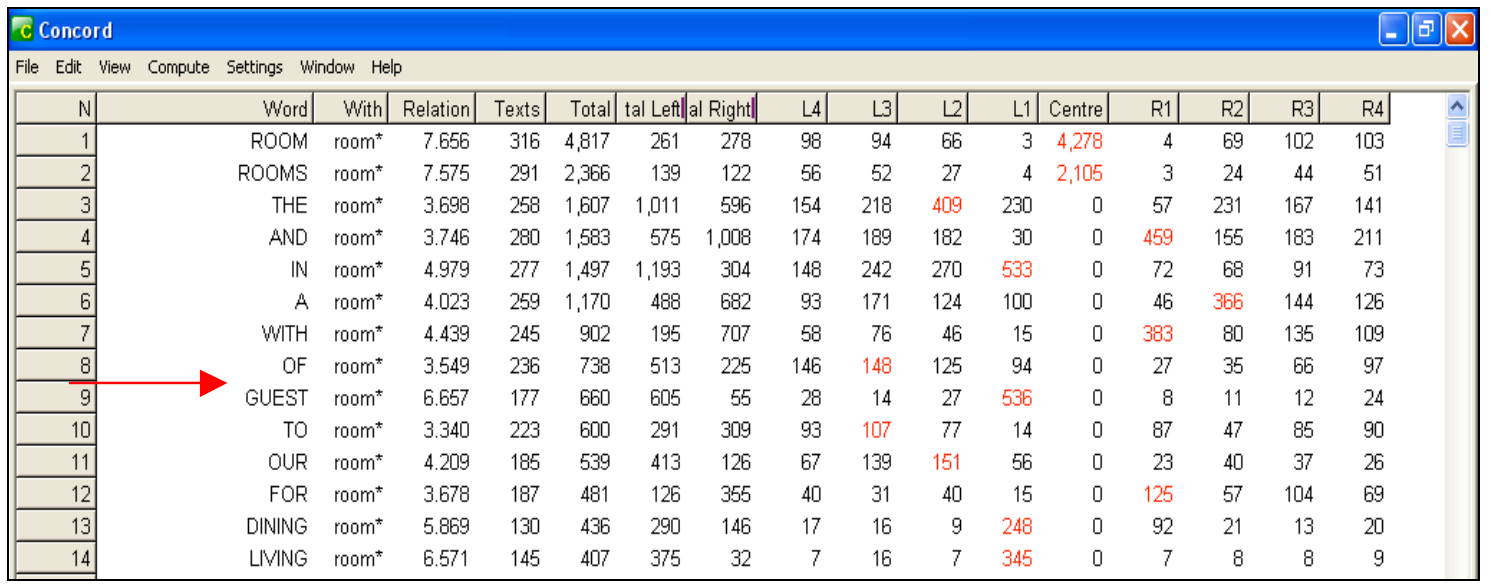

Figura 63 - Lista parcial dos colocados de room. No destaque, guest.

All guest rooms have a full kitchen, which includes a refrigerator, two-burner stove (...) and chairs. Each room also features a private bath with tub and shower (...).

These double guestrooms feature a balcony, two double Hilton Serenity beds, nonallergenic down pillows and comforter, and 250 thread-count triple sheets. Double rooms gaze over aquamarine Blue Lagoon or the piercing blue of the Miami city skyline.

Poder-se-ia criticar o status de colocação de guest room, uma vez que permite a grafia em uma única palavra. Em nosso estudo, consideramos guest uma colocação de room por cumprir os requisitos (vide seção 3.2.2) que estabelecemos para determinar uma colocação: a) estar presente na lista de colocados, entre as 200 primeiras palavras guest é o primeiro colocado na lista; b) atingir a frequência mínima de 10 - são 530 
ocorrências de guest room; c) apresentar valor maior ou igual a 3 para a medida estatística MI score em uma janela de 4 x 4 - o valor de guest indicado na coluna Relation (figura acima) é 6.

Atestada a colocação, passamos para uma análise mais detalhada de guest room. Geramos uma lista dos seus colocados, observamos as linhas de concordância bem como os agrupamentos na ferramenta cluster. Constatamos que guest room integra uma estrutura maior, guest room and suites (33 ocorrências).

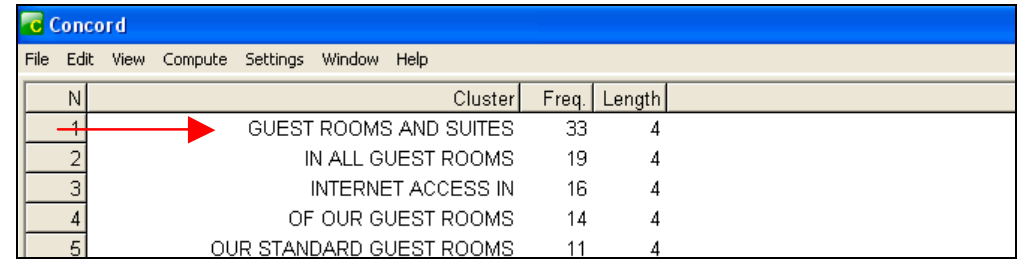

Figura 64 - Clusters parciais de guest room(s).

O passo seguinte foi estabelecer o equivalente da colocação. Iniciamos com a análise das palavras-chave do corpus em português e selecionamos os candidatos a equivalente: apartamento(s) (2621 ocorrências) e quarto(s) (1061).

Constatamos que apartamento é o equivalente mais direto, pois além da maior frequência, apresenta colocados e contextos semelhantes a guest room, como demonstram os exemplos e imagem abaixo:

No Le Premier Othon Suites, todos os apartamentos são amplos, confortáveis e equipados com: ar-condicionado; frigobar; TV a cabo; Internet rápida; cofre.

Os apartamentos Luxo do Royal Palm Plaza oferecem aos hóspedes tudo que se espera de um apartamento de padrão internacional: ar condicionado central; workstations com acesso à Internet (...).

Uma das estruturas mais frequentes com apartamento é de fato apartamentos e suites, assim como guest rooms and suites, mencionado anteriormente. Estabelecemos assim também o equivalente para essa colocação. 


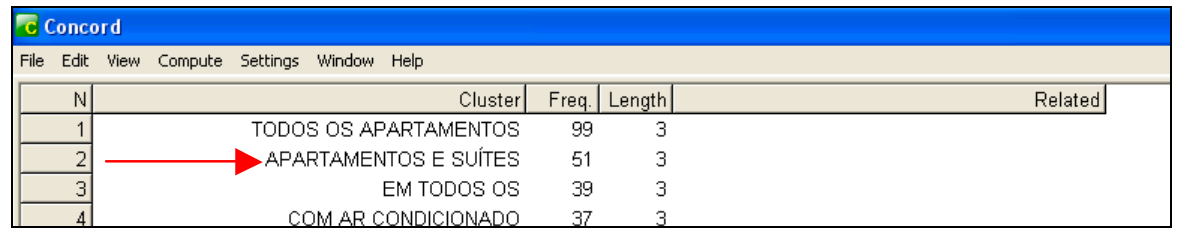

Figura 65 - Clusters parciais de apartamento(s).

Interessante notar que, em ambos os casos, a ordem dos elementos da fraseologia também é convencionalizada. Encontramos apenas seis ocorrências de suites e apartamentos e uma de suites and guest rooms.

O hotel possui 174 apartamentos e suítes com ar condicionado, música ambiente, cofre e fechadura eletrônicos, telefone com discagem direta, TV a cabo, internet gratuita, telefone no banheiro, secador de cabelo, espelho para maquiagem e banheira.

Analisamos os usos de quarto, o outro candidato a equivalente. Constatamos que se trata também de um equivalente de guest room, como no exemplo abaixo:

Four Seasons makes no additional charge for children 18 years old and under occupying the same guest room with parents or guardians (space permitting).

Diária família: uma criança com menos de 10 anos no mesmo quarto que os pais não paga.

No entanto, algumas linhas de concordância apontavam para uma diferença de uso em alguns casos. Assim, resolvemos investigar o contexto em mais de 1000 linhas de concordância de quarto. Muitas foram descartadas por não pertencer ao contexto almejado (85 casos de serviço de quarto, por exemplo) ou por serem repetições de um mesmo estabelecimento. Assim, foi possível categorizar o contexto de 540 das linhas. Observamos os seguintes padrões:

a) O quarto é um dos cômodos do apartamento, suíte, chalet (300 contextos):

O hotel possui 23 amplos apartamentos, 19 com um quarto com cama de casal (para 2 pessoas) e 4 apartamentos duplos, com dois quartos com cama de casal (para 4 pessoas).

b) quarto é usado no mesmo sentido de apartamento (240 contextos): 
São 24 apartamentos, todos claros arejados que acomodam confortavelmente de 2 a 5 pessoas. Os quartos contam todos com ventilador de teto, sanitário privativo com chuveiro elétrico e tudo isso complementado pelo silêncio e romantismo da natureza exuberante.

Desses 240 contextos acima:

b1) 105 são em pousadas:

A pousada possui 33 quartos com banheiro privativo, ventilador de teto, televisão, roupas de cama e frigobar.

c) Quarto como uma categoria diferente, mais simples, de apartamento:

Nossos apartamentos contam com confortáveis instalações, pois possuem arcondicionado, TV a cores e banheiro. Temos apartamentos duplos, triplos, quádruplos e nossa diária inclui café da manhã. Dispomos também de quartos duplos e triplos mais simples: com ventilador e TV.

Essas nuances de sentido são incluídas na nota Você sabia? no verbete.

Os dados até aqui nos levaram ao seguinte questionamento: se os equivalentes de guest room são apartamento e quarto; então, quais seriam os usos de apartment e bedroom, termos que remetem a apartamento e quarto respectivamente? Realizamos, portanto, um estudo das diferenças desses termos aparentemente sinônimos em inglês: bedroom, apartment e suite.

Bedroom aparece 1084 vezes no corpus. Seus principais colocados incluem one (221), two (211), suite(s) (234). Nas concordâncias, destacaram-se as palavras relacionadas à quantificação. A ferramenta cluster evidenciou ainda mais essa constatação. Também notamos que bedroom é utilizado para especificar o tipo de dormitório, como master bedroom. A figura abaixo mostra os colocados de bedroom: 


\begin{tabular}{|c|c|c|c|c|c|c|c|c|c|c|c|c|c|c|c|c|c|c|}
\hline \multicolumn{4}{|c|}{ c Concord } & & & & & & & & & & & & & & \multicolumn{2}{|c|}{ - $01 x$} \\
\hline File Edit & View & Compute Settings & Window Help & & & & & & & & & & & & & & & \\
\hline $\mathrm{N}$ & & Word & With & Relation & Texts & Total & tal Left|la & | Right| & $\llcorner 4$ & $\mathrm{L} 3$ & ㄴ.2 & L1 & Centre & R1 & $\mathrm{R} 2$ & R3 & $\mathrm{R} 4$ & $\bar{A}$ \\
\hline 1 & & BEDROOM & bedroom & 9.338 & 202 & 1,187 & 51 & 52 & 27 & 16 & 8 & 0 & 1,084 & 0 & 8 & 18 & 26 & \\
\hline 2 & & $\rightarrow \mathrm{ONE}$ & bedroom & 7.119 & 113 & 420 & 341 & 79 & 41 & 70 & 9 & 221 & 0 & 29 & 25 & 14 & 11 & \\
\hline 3 & & AND & bedroom" & 3.594 & 140 & 395 & 192 & 203 & 28 & 30 & 116 & 18 & 0 & 113 & 27 & 25 & 38 & \\
\hline 4 & & $\rightarrow$ TwO & bedroom" & 7.213 & 109 & 390 & 290 & 100 & 10 & 50 & 19 & 211 & 0 & 42 & 25 & 19 & 14 & \\
\hline 7 & & WITH & bedroom ${ }^{*}$ & 4.473 & 118 & 256 & 42 & 214 & 16 & 13 & 12 & 1 & 0 & 103 & 52 & 35 & 24 & \\
\hline 是 & & - SUITE & bedroom ${ }^{*}$ & 6.520 & 80 & 247 & 63 & 184 & 25 & 26 & 11 & 1 & 0 & 125 & 19 & 22 & 18 & \\
\hline 9 & & $\mathbb{N}$ & bedroom ${ }^{*}$ & 4.177 & 81 & 238 & 186 & 52 & 23 & 82 & 59 & 22 & 0 & $\theta$ & 4 & 11 & 29 & \\
\hline 10 & & $\rightarrow$ SUITES & bedroom ${ }^{*}$ & 5.780 & 70 & 187 & 32 & 155 & 17 & 12 & 3 & 0 & 0 & 109 & 14 & 20 & 12 & \\
\hline 11 & & KING & bedroom ${ }^{*}$ & 6.912 & 74 & 148 & 46 & 102 & 13 & 16 & 5 & 12 & 0 & 8 & 26 & 46 & 22 & \\
\hline 12 & & BED & bedroom & 6.230 & 58 & 147 & 62 & 85 & 32 & 17 & 12 & 1 & 0 & 0 & 3 & 20 & 62 & \\
\hline 17 & & ROOM & bedroom ${ }^{*}$ & 3.988 & 56 & 105 & 63 & 42 & 22 & 15 & 17 & 9 & 0 & 0 & 15 & 17 & 10 & \\
\hline 10 & & LIVING & bedroom ${ }^{*}$ & 6.276 & 55 & 92 & 37 & 55 & 5 & 22 & 10 & 0 & 0 & 11 & 17 & 17 & 10 & \\
\hline 19 & & $\rightarrow 1$ & bedroom ${ }^{*}$ & 0.000 & 39 & 91 & 47 & 44 & 8 & 8 & 8 & 23 & 0 & 14 & 13 & 9 & 8 & \\
\hline
\end{tabular}

Figura 66 - Lista parcial dos colocados de bedroom.

\begin{tabular}{|r|r|r|}
\hline \multicolumn{1}{|c|}{ Cluster } & Freq. & Length \\
\hline ONE BEDROOM SUITE & 64 & 3 \\
\hline THE MASTER BEDROOM & 57 & 3 \\
\hline TWO BEDROOM SUITE & 51 & 3 \\
\hline ONE BEDROOM SUITES & 50 & 3 \\
\hline TWO BEDROOM SUITES & 45 & 3 \\
\hline AND TWO BEDROOM & 45 & 3 \\
\hline IN THE MASTER & 36 & 3 \\
\hline BEDROOM HAS A & 36 & 3 \\
\hline MASTER BEDROOM AND & 35 & 3 \\
\hline THE SECOND BEDROOM & 34 & 3 \\
\hline ONE AND TWO & 34 & 3 \\
\hline KING SIZE BED & 32 & 3 \\
\hline
\end{tabular}

Figura 67 -Clusters parciais de bedroom. 


\section{N Concordance}

1 pool - each for a per night surcharge. * 1 Bedroom/2 Bath King size Heavenly Bed and Jacuzzi tub. Available as a 1-bedroom, $1 \frac{1}{2}$ bath or with a connecting order, is not to be missed! Luxurious 1 Bedroom $11 / 2$ Bathroom Suite Marble seat Shower, roll-in (some rooms) 1 Bedroom Executive Suite, $1 \mathrm{King}$, This newly remodeled third floor, 2 bedroom suite features queen beds, an bed The Apartment We have one 2 bedroom suite, The Renaissance Suite, a pull out sofa in the living room. The 2 bedroom and 2 bath unit has a kitchen Club Level with Concierge Service - 2-Bedroom Ambassador Suite Club Level based on two.) KatieÕs Kottage - 2 Bedroom Town Home (2 Bedrooms bed and breakfast inn ... one with a 2-bedroom option ... all with custom decor, balcony overlooking the rose garden. 2 Bedroom/Bath, King and Queen Bed, Reunions etc.. 2-4 Occupants - 2 Bedroom 2 Bath • Living Area with Cable Maximum occupancy 2. Hydrangea 2 bedroom Suite Newly decorated large Club Level with Concierge Service - 2-Bedroom Princess Suite View of private castle. Also available as a 2-bedroom suite when booked together Master Bedroom/Queen Size in 2nd Bedroom. 2 Baths - Sophisticated Master Bedroom/Queen Size in 2nd Bedroom. 2 Baths - Sophisticated in 1 st and one queen bed in the 2 nd bedroom. All two bedroom suites have a connecting guestroom that adds a 2 nd bedroom and additional full marble bath. feet (98 square meters) Dynasty 3-Bedroom Family Suite Rice paper sliding

21 family. 3 and 4 Bedroom Suites 3 and 4 bedroom suites are a two bedroom

Figura 68 - Linhas parciais de concordância de bedroom.

Assim, concluímos que bedroom é utilizado para indicar o dormitório, quantidade e tipo, dentro da suíte ou apartamento.

A palavra apartment apareceu 57 vezes no corpus. Esse dado em si já é revelador: apartment é bem menos usado que guest room (mais de 6 mil ocorrências) e bedroom (mais de mil). Além da acentuada diferença de frequência, também foi possível constatar usos distintos. Os exemplos abaixo mostram que apartment é usado para designar uma unidade independente, de autosserviço, podendo ser até mesmo uma casa, com diversos cômodos, destinada a estadias mais prolongadas.

Just opened for extended stay, this apartment features one bedroom with queen sized poster bed and a full separate office equipped with full size desk. It includes a living room and a fully equiped and functional kitchen with large side by side refrigerator, gas stove, double sinks, dishwasher, etc. This unit features a separate entry for privacy. 
The apartment features gourmet kitchen with custom cabinets, granite countertops, stainless steel appliances. Additional features include: mirror armoires in bedroom, large living area, French doors, brand new carpet, fireplace, laundry and a large courtyard.

Assim, conclui-se que apartamento em português e apartment em inglês apresentam usos distintos. Apartmento é o termo mais frequente para designar as acomodações em português; em inglês, é o menos recorrente, uma vez que guest room é o mais utilizado. Assim, na versão para o inglês, traduzir apartamento por apartment não seria o mais indicado, a menos que se tivesse certeza de estar diante do contexto indicado acima (uma unidade habitacional mais próxima a uma casa). Como esse ponto pode representar um problema de tradução, incluímos essa informação na Nota ao tradutor.

Por fim, analisamos o termo suite, o segundo mais frequente no corpus, depois de room, com 3.559 ocorrências. Em função do elevado número de ocorrências, não pudemos realizar um estudo aprofundado. No entanto, nos valemos das listas de colocados e clusters e aproveitamos os dados da pesquisa de bedroom descrita acima.

Segundo a definição que encontramos, uma suíte caracteriza-se por possuir dormitório e banheiro em uma área separada da sala de estar, além de uma cozinha ${ }^{38}$. Entendemos ser, portanto, uma categoria superior a guest room.

We offer private, spacious suites, beautifully appointed and meticulously maintained, with living rooms, kitchens, bathrooms, bedrooms, TVs and private lanais.

Our suites are 50\% larger than traditional hotel rooms with separate spaces for living, dining, sleeping and working. There are studio, one and two bedroom floor plans to maximize efficiency and ease. A fully equipped kitchen enables our guests to enjoy relaxing meals within the privacy of their own suite.

Todas essas informações são organizadas na seção Você sabia? do verbete.

\footnotetext{
${ }^{38}$ A Suite is a hotel room in which the bedroom and bathroom are separate from the living area and a kitchenette is often included. Disponível em: http://www.cvent.com/en/resources/suite-hotel.shtml. Acesso em 19/09/2011.
} 


\subsubsection{Hotel room}

Contabilizamos 94 ocorrências de hotel room(s) no corpus. Esse é um exemplo de colocação que não traz problema de entendimento, de decodificação, mas pode representar dificuldade no momento da produção textual.

Antes da busca pelo equivalente, analisamos as concordâncias para entender melhor os contextos de uso dessa colocação.

Identificamos os seguintes padrões e contextos principais:

a) sentido de apartamento / quarto (71 contextos)

To make a hotel room reservation, simply use the form at the right or call us directly at the numbers above.

The hotel rooms in the Beaver Village Lodge sleep between one and six people, offering two distinct room categories.

Nos exemplos acima e nos outros analisados, hotel room é usado no mesmo sentido de room. Ou seja, entendemos hotel como uma palavra de ênfase.

b) sentido de um quarto regular, com prosódia semântica negativa, precedido de adjetivos como average, typical, boxy, bland, cookie-cutter, traditional (20 contextos). Our suites are 50\% larger than traditional hotel rooms with separate spaces for living, dining, sleeping and working.

Free yourself from the confines of your average hotel room.

Gone are the days of cramped little hotel rooms. Welcome to the spacious Ft. Myers Beach condo rentals.

A busca pelo equivalente de hotel room no primeiro contexto revelou o mesmo que para guest room: apartamento (2621 ocorrências) e quarto (1061), uma vez que, conforme mencionamos, a palavra hotel é usada apenas para ênfase. Assim, consideramos os equivalentes de hotel room os mesmos de guest room (vide item 4.1.13). Vale aqui uma Nota ao tradutor, indicando o fato de não ser necessário incluir a palavra hotel na tradução.

Para o sentido com prosódia semântica negativa, não encontramos no corpus um candidato a equivalente. Optamos por não incluir um equivalente para essa acepção, pois ela depende exclusivamente do adjetivo que antecede hotel room. 


\subsubsection{In-room coffee maker}

Dentre os colocados de room, destaca-se na lista de clusters o agrupamento inroom coffee, com 59 ocorrências. Dessas, 27 integram uma colocação maior, in-room coffee maker.

\begin{tabular}{|crrr|}
\hline N & Cluster & Freq. & Length \\
1 & IN ROOM SAFE & 95 & 3 \\
2 & LIVING ROOM WITH & 79 & 3 \\
3 & THE LIVING ROOM & 75 & 3 \\
4 & IN ROOM DINING & 75 & 3 \\
5 & ROOM WITH A & 70 & 3 \\
6 & ROOM HAS A & 65 & 3 \\
7 & IN ROOM COFFEE & 59 & 3 \\
8 & THE DINING ROOM & 51 & 3 \\
9 & SEPARATE LIVING ROOM & 47 & 3 \\
10 & THIS ROOM IS & 46 & 3 \\
11 & LIVING ROOM AND & 45 & 3 \\
12 & ROOM AND TAX & 41 & 3 \\
13 & DINING ROOM AND & 36 & 3 \\
14 & IN YOUR ROOM & 33 & 3 \\
15 & TIGH SPEED INTERNET & 33 & 3 \\
16 & THE ROOM IS & 31 & 3 \\
17 & IN THE LIVING & 31 & 3 \\
18 & TO YOUR ROOM & 30 & 3 \\
19 & IN EACH ROOM & 29 & 3 \\
20 & IN ROOM MOVIES & 28 & 3 \\
21 & ROOM FEATURES A & 27 & 3 \\
22 & ROOM COFFEE MAKER & 27 & 3 \\
\hline
\end{tabular}

Figura 69 - Clusters parciais de room(s), destaque para in-room coffee maker.

Além dos clusters acima, consideramos as linhas de concordância de coffee, um termo frequente no corpus, com 650 ocorrências. Concentrando-nos apenas nas colocações com room ordenadas à esquerda de coffee, identificamos variações possivelmente sinônimas de in-room coffe maker, como in-room coffee isoladamente (com 10 ocorrências), in-room coffee service (4) e in-room coffee station (2). Pelas linhas de concordância, não foi possível determinar se eram todas realmente sinônimas. Uma pesquisa na internet, consultando também as imagens, apontou que in room coffee 
não necessariamente inclui uma cafeteira, podendo ser apenas água quente e café solúvel. Resolvemos, portanto, não incluir essas colocações como variações sinônimas.

Para identificar o equivalente em português, iniciamos com a pesquisa de cafeteira, tradução prima facie. Constatamos 17 ocorrências, todas no contexto de inroom coffee maker, ou seja, uma cafeteira localizada na acomodação do hóspede:

Apartamento com $285 \mathrm{~m}^{2}$, decorado em estilo europeu. Possui agradáveis e espaçosas salas de estar e jantar com copa privativa, o que permite o preparo de refeições no local. A copa guarda geladeira, cafeteira e microondas.

Características padrão a todas a categorias de nosso hotel:

TV 29', TV a cabo, rádio-relógio, cafeteira, tábua de passar, ferro de passar, espelho de maquiagem, balança, secador de cabelo, ar condicionado, banheiro privativo com chuveiro / banheira, frigobar e cofre individual privativo.

Realizamos uma busca por café para verificar se poderia haver alguma outra alternativa de equivalente. A busca retornou 1.332 ocorrências, a maior parte delas integrando café da manhã. Ordenando as concordâncias pelos dois colocados à esquerda, identificamos apenas 4 casos no contexto almejado, ou seja, do café para preparo no apartamento. Cada um deles com apenas uma ocorrência:

Equipamento para café e chá

Kit café chá

Café e chá no apartamento

Máquina de café Nespresso

Por apresentarem apenas uma ocorrência cada, sendo que três incluíam chá e a outra uma marca, optamos por manter apenas cafeteira como equivalente.

Por fim, gostaríamos de comentar que, assim como em in-room safe, dentre outros, nos chama a atenção a expressão in-room por ser até certo ponto redundante. Isso porque, pelo contexto, está claro que estamos nos referindo a itens dentro do apartamento, como mostra o exemplo: 
Services/amenities in all rooms: At\& T long distance; cable/satellite TV; free newspaper mon-fri; hair dryer; in-room air conditioning; in-room coffee maker; in-room desk.

De fato, em nenhuma das ocorrências de cafeteira havia referência explícita ao apartamento, quarto ou suíte, informação sempre implícita no contexto. Assim, no verbete, incluímos uma Nota ao tradutor recomendando a omissão da expressão quarto ou apartamento, se essa informação estiver clara no contexto, para evitar uma interferência do inglês.

\subsubsection{In-room dining}

Essa colocação, com 64 ocorrências no corpus, é considerada sinônima de room service (125), portanto, será discutida na entrada dessa colocação, no item 4.1.25. No verbete, também haverá uma nota remissiva.

\subsubsection{In-room safe}

O percurso seguido para a identificação dessa colocação e de seus equivalentes serviu de ilustração da metodologia adotada para esta pesquisa no capítulo Metodologia (vide seção 3.3).

\subsubsection{Laundry room}

Foram constatadas 10 ocorrências de laundry room(s) no corpus. Interessante notar que oito das dez ocorrências advêm de estabelecimentos da categoria Condo, em geral, destinados a estadias prolongadas, incluindo casas. Os outros dois exemplos vieram de Bed and Breakfasts. Ou seja, trata-se de uma lavanderia na dependência do hóspede:

The suite features a one bedroom with a king size bed, master bathroom, living room and a fully equipped kitchen with full size appliances. There is also a guest powder room, a butler's half bath and a laundry room off the living area.

These condominiums also come standard with a laundry room, dining room, living room and kitchen. 
Essa colocação não representa um problema de entendimento, nem de tradução trata-se de uma lavanderia.

Uma das excelentes opções oferecidas pelo Pietra Flat é uma casa totalmente equipada, com ampla sala, três suites, churrasqueira, jardim, e dependência com minisuite e lavanderia.

No entanto, vale mencionar que procuramos entre as linhas de concordância de lavanderia uma forma de expressar que a lavanderia era de uso do próprio hóspede. Encontramos o seguinte exemplo, provenientes de um flat:

O staff está sempre disposto a ajudar e dar informações sobre a cidade e sobre os serviços que oferecemos, que são: internet wi-fi ou em computadores disponíveis na sala de estar, lavanderia de auto-serviço, guarda-bagagens, aluguel de automóveis, reservas de passeios e passagens.

Assim, além de lavanderia, incluímos lavanderia de autosserviço (dentro da nova ortografia) entre os equivalentes.

\subsubsection{Living room}

Living room é bastante recorrente no corpus, com 344 ocorrências. Para identificar o equivalente, partimos da tradução prima facie e confirmamos a equivalência de sala de estar, com 205 ocorrências, em contextos semelhantes.

Private comfortable living room features fireplace, leather sofas \& sofa sleeper, private balcony or patio, high ceilings (...).

A charmosa sala de estar possui decoração sóbria e dispõe de sofá, poltronas e uma mesa de reunião ou jantar para até 06 pessoas, serviço de café Brasileiro instantâneo e diversas opções de chás. 
Uma análise de sala isoladamente, com 1386 ocorrências, apontou o uso como sinônimo de sala de estar. Foi preciso analisar as linhas individualmente para identificar os contextos almejados e não considerar outros tipos de sala. Chegamos ao número de 158 ocorrências.

\begin{tabular}{|c|c|c|c|}
\hline \multicolumn{4}{|c|}{ C Concord } \\
\hline \multirow[t]{2}{*}{ File Edit } & View Compute Settings Window Help & & \\
\hline & Concordance & Set $|\mathrm{Tag}|$ Word \#| $\mid$. \# & Hos.|. \\
\hline 1 & dependências 1 Cozinha 1 Área de Serviço 1 Sala 1 Quarto de Casal 1 Banheiro 1 Varanda & $\begin{array}{lll}143 & 27 \%\end{array}$ & $05 \%$ \\
\hline 2 & das pessoas à exposiçẫo do seu produto na Sala 2; Gastronomia Aqui no Maredomus, você & $987 \quad 677 \%$ & $07 \% \mathbf{I}$ \\
\hline 3 & ampla varanda com rede. ${ }^{*}$ Chalé (com $80 \mathrm{~m}^{2}$ ) - sala 2 qtos, com ventilador de teto e $\mathrm{Ar}$ & $270 \quad 73 \% \mathbf{I}$ & $05 \%$ \\
\hline 4 & piso antialérgico e fechadura eletrônica. Sala / 2 quartos: Apartamentos composto por & $438217 \%$ & $07 \%$ \\
\hline 5 & pesquisa fica oculto do outro lado do vidro na Sala 4, obsenvando a reaçẫo das pessoas à & $974670 \% \mathbf{I}$ & $07 \%$ \\
\hline 6 & Break; A Sala Exitus II juntamente com a Sala 4 (vide esquema abaixo) pode ser utilizada & $941660 \% \mathbf{I}$ & $04 \%$ \\
\hline 7 & tipo studio, 40 apartamentos com um quarto e sala, 5 apartamentos com dois quartos e sala e & $14227 \% \mathbf{I}$ & $04 \%$ \\
\hline 8 & Tem TV com parabólica nos dois quartos e na sala, a cozinha é equipada com fogâo e & $564218 \% \mathbf{I}$ & $06 \%$ \\
\hline 9 & Tem TV com parabólica nos dois quartos e na sala, a cozinha é equipada com fogấo e & $514198 \% \mathbf{l}$ & $03 \% \mathbf{I}$ \\
\hline 10 & para período até 4 horas de uso da sala. A ligaçăo do Hotel Paraná Suíte com as & $372130 \%$ & $08 \%$ \\
\hline 11 & distribuída em vários locais estratégicos na sala, aceitando a conexẫo simultânea de & $1,031 \quad 498 \% \mathbf{I}$ & $08 \%$ \\
\hline 12 & $45 \mathrm{~m}^{2}$ (01 cama casal + 01 sofá-cama na ante sala; acomoda até 05 pax) - com varanda e vista & $25132 \% \mathbf{I}$ & $05 \%$ \\
\hline 13 & de apoio, serviços de "coffee break" e de sala (água e café), além de uma equipe & $81 \%$ & $00 \% \mathbf{I}$ \\
\hline 14 & size, banheiras, cozinha estilo americano e sala ambiente. Você merece se hospedar neste & $27 \%$ & $03 \%$ \\
\hline 15 & com $55 \mathrm{~m} 2$, em uma suíte com banheira, sala ampla com 3 ambientes, cozinha equipada, & $41 \%$ & $01 \% \mathbf{I}$ \\
\hline 16 & Cada suíte é composta por um dormitório, uma sala ampla, copa/cozinha e banheiro com & $277 \quad 133 \% \mathbf{I}$ & $06 \%$ \\
\hline 17 & hotel -Luxuosos quartos; $\cdot$ Cobertura duplex; -Sala ampla e confortável; $\cdot$ Cozinha equipada; & $19976 \% \mathbf{I}$ & $01 \%$ \\
\hline 18 & oferece luxuosos quartos, cobertura duplex, sala ampla e confortável e área para & $88 \%$ & $06 \% \mathbf{I}$ \\
\hline 19 & para atendê-lo. TV Lcd Internet wi-fi Ante-sala Amplo terraço Amenities personalizados & $13259 \% \mathbf{I}$ & $05 \% \mathbf{I}$ \\
\hline 20 & com pista de dança e 120 pessoas utilizando a Sala Antúrius como anexo. Agora o Restaurante & $1,102346 \% \mathbf{I}$ & $04 \%$ \\
\hline 21 & TV de plasma $26 "$ no quarto TV de LCD 42 " na sala Aparelho de DVDTV a cabo com canais & $278 \quad 61 \%$ & $06 \%$ \\
\hline 22 & com controle, cama king size e uma bela anti-sala Apartamento double casal standard com tv & $428166 \%$ & $04 \%$ I \\
\hline 23 & regular. - Os quartos sẫo separados por uma sala; - Apropriado para famílias Bangalô Master & $683253 \% \mathbf{I}$ & $05 \% \mathbf{I}$ \\
\hline 24 & pessoas, conforme a configuração adotada. - Sala Aquidaban - 20 Lugares em formato & $563186 \% \mathbf{I}$ & $04 \%$ \\
\hline 25 & pessoas. Todas as suites possuem: varanda, sala, ar-condicionado, cama king size, sofá & $14466 \%$ & $04 \%$ \\
\hline 26 & chalés com três quartos, duas suítes, varanda, sala, área gourmet, churrasqueira e & $50 \%$ & $07 \%$ \\
\hline 27 & » Microondas » Frigobar » Mesa para refeiçã̃o Sala » Armários » Mesa de trabalho » Telefone & $24351 \% \mathbf{I}$ & $03 \%$ \\
\hline 28 & nara arrumacẫo de mesas e cadeiras na sala Arrumacẩn Escolar 24 Pessoas & $465 \quad 114 \%$ & ـ $4 \%$ \\
\hline
\end{tabular}

Figura 70 - Linhas de concordâncias parciais de sala.

Identificamos, também por meio das linhas de concordância, a colocação separate living room (42 ocorrências).

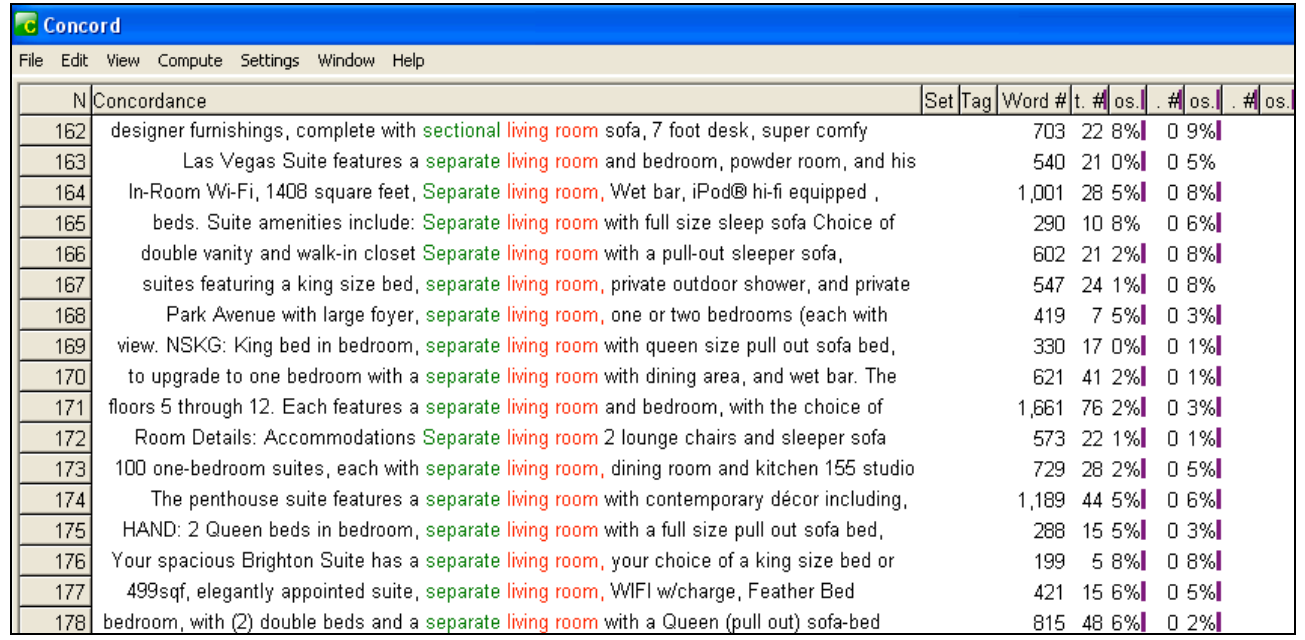

Figura 71 - Linhas de concordâncias parciais de living room, ordenadas pelo colocado à esquerda. 
Para chegar ao equivalente, analisamos inicialmente todos os colocados à direita de sala de estar. Encontramos apenas três ocorrências (duas do mesmo hotel) de sala de estar separada. Além do baixo número, esses dois resorts, Sheraton e SuperClubs Breezes, são de redes americanas, o que nos faz supor se tratar de textos traduzidos ou influenciados pela terminologia em inglês ${ }^{39}$.

\begin{tabular}{|c|c|c|c|c|c|}
\hline \multicolumn{5}{|c|}{ C Concord } & \multirow[t]{2}{*}{ 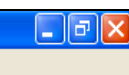 } \\
\hline & Edit Wiew Compute Settings Window Help & & & & \\
\hline \multicolumn{2}{|r|}{$\mathrm{N} \mid$ Concordance } & Set Tag | Word \#|t. \#n os.|| & . $\#$ os.l| & \# os.l|t. \#| os.|| & File \\
\hline 1 & I mar do $19^{\circ}$ andar e possui uma espaçosa sala de estar separada com mesa de jantar de & $919298 \%]$ & $05 \%$ & $05 \%$ & h-pt-124.txt \\
\hline 2 & tropicais. Elas também incluem closet e sala de estar separada. As Sútes Júnior & $834240 \% \mathbf{l}$ & $03 \%$ & $03 \%$ & h-pt-24.txt \\
\hline 3 & de 3 adultos) Suite Deluxe - 6 Suites Com sala de estar separada (mesmo tamanho que & $544236 \%$ & $07 \%$ & $07 \%$ & h-pt-23.txt \\
\hline
\end{tabular}

Figura 72 - Linhas de concordâncias de sala de estar separada.

Na pesquisa anterior, para identificar os contextos de sala no sentido de sala de estar, deparamos com diversas ocorrências de ante-sala, o que nos chamou a atenção. Analisamos as 51 ocorrências e concluímos que, como o nome indica, se trata de uma sala que antecede o dormitório, sendo, consequentemente, "separada" dele, assim como a separate living room no exemplo abaixo:

Acclaimed Four Seasons Executive Suites, with partial valley views, include the privacy of a separate living room from the sleeping room.

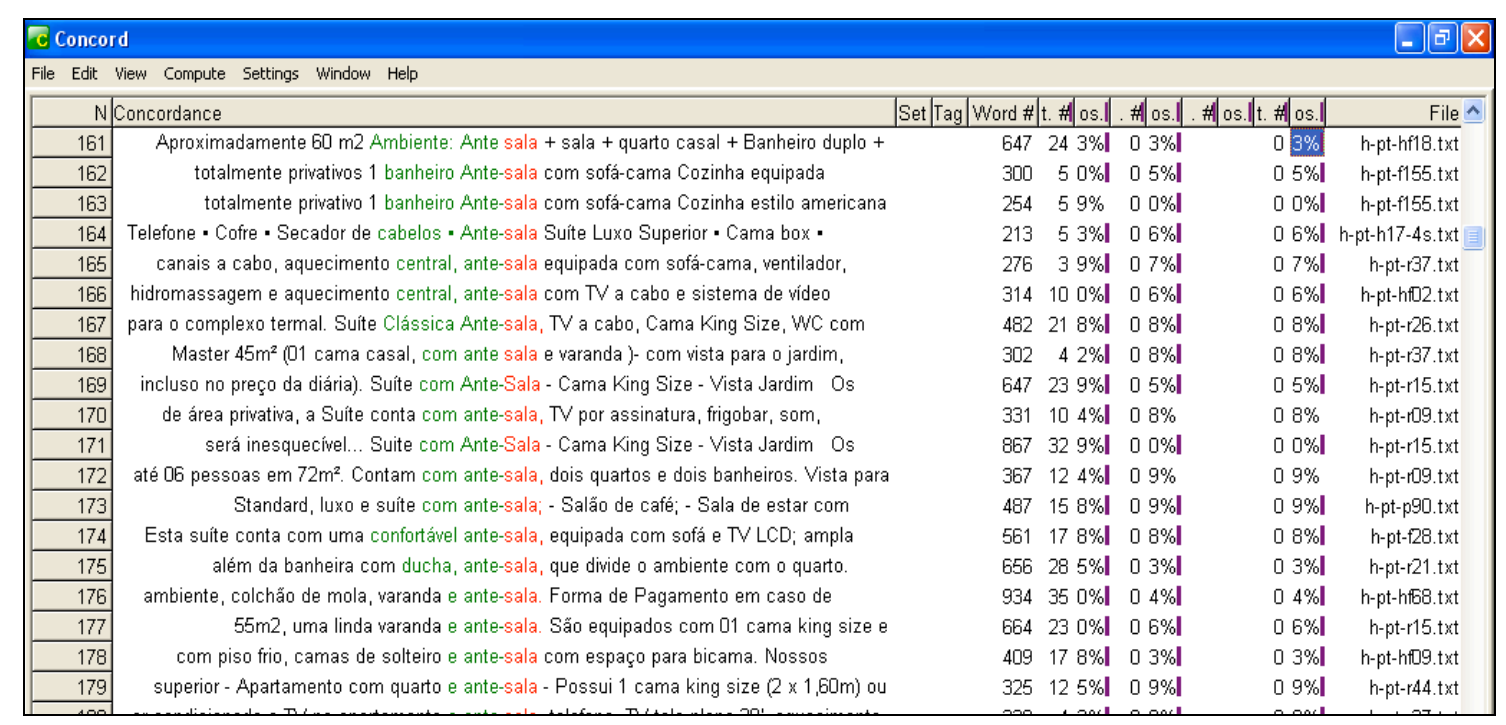

Figura 73 - Linhas de concordâncias parciais de sala, ordenadas pelos colocados à esquerda.

Optamos, portanto, por validar ante-sala como equivalente de separate living room, descartando sala de estar separada.

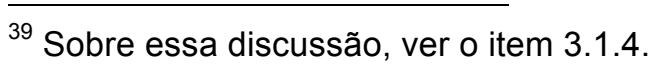


Além dessa colocação, pesquisamos o uso de outras duas de uso semelhante a living room, uma delas é sitting room (47):

The suite features a sitting room with gas fireplace (seasonal) and antiques.

Entendemos nesse caso tratar-se de uma sala ou sala estar comum.

A segunda colocação de uso semelhante a living room, porém com uma diferença sutil de sentido é sitting area (153). Trata-se de um espaço com jogo de sofá e poltronas, sem configurar em uma sala propriamente dita. Em português, essa variação não é usual, mas encontramos seis ocorrências de área de estar e uma de living.

The living room boasts a marble foyer, comfortable sitting area, a wet bar, an entertainment system with stereo (...).

[A suite] possui dois quartos com banheiros, uma grande sala com área de estar, leitura e sala de jantar.

Na sala de estar, um living de 8 metros de pé direito e uma bela lareira são um convite para o descanso.

Pelos exemplos acima, pode-se verificar que sitting area, assim como área de estar e living, estão sendo usados para designar o espaço com jogo de sofá, como parte de outra sala.

No verbete, essas informações adicionais estão registradas nas seções Você sabia? e Nota ao tradutor.

\subsubsection{Luxurious room}

Luxurious room(s) ocorre 10 vezes no corpus. Somando as 6 ocorrências da variação luxurious guest $\operatorname{room}(s)$, são 16. A colocação sinônima, porém menos frequente, elegant room (10), aparece em nota remissiva.

Para estabelecer o equivalente, seguimos o mesmo caminho descrito para comfortable room (item 4.1.4). Ou seja, levantamos candidatos a equivalente a partir da lista de colocados de apartamento, das linhas de concordância de apartamento mais adjetivos (corpus etiquetado) e da relação de adjetivos mais recorrentes no corpus, transcrita abaixo: 


\begin{tabular}{|l|l|l|l|}
\hline \multicolumn{5}{|c|}{ Adjetivos mais frequentes no corpus em português } \\
\hline especial (892) & disponivel (266) & especializado (157) & tranquilo (72) \\
melhor (792) & perfeito (250) & gratuito (157) & rúso (68) \\
completo (689) & pequeno (250) & relaxante (145) & el66) \\
equipado (578) & excelente (250) & histórico (125) & descontraído (66) \\
grande (511) & standard (241) & importante (118) & nobre (64) \\
amplo (524) & ecológico (249) & lindo (117) & contemporâneo (57) \\
bom (450) & superior (231) & charmoso (112) & saudável (57) \\
internacional (408) & diferenciado (227) & forte (109) & clássico (54) \\
ideal (386) & panorâmico (217) & maravilhoso (104) & requintado (50) \\
natural (367) & privilegiado (211) & exuberante (101) & deslumbrante (45) \\
maior (343) & simples (207) & romântico (100) & particular (43) \\
delicioso (339) & aquecido (191) & espaçoso (99) & grátis (41) \\
novo (334) & personalizado (186) & saboroso (93) & suave (38) \\
privativo (327) & decorado (179) & bonito (89) & luxuoso (37) \\
confortável (323) & tradicional (177) & sofisticado (89) & encantador (31) \\
exclusivo (314) & iivre (171) & independente (87) & impecável (30) \\
aconchegante (297) & belo(171) & acolhedor (82) & espetacular (23) \\
agradável (272) & exportivo (165) & comum (80) & incenal (23) \\
moderno (267) & diferente (162) & atrativo (72) & \\
\hline
\end{tabular}

Figura 74 - Listas dos adjetivos mais frequentes no corpus em português.

Destacamos, na lista acima, os candidatos que julgamos possíveis equivalentes de luxurious: belo (171), charmoso (112), sofisticado (89), elegante (66), requintado (50) e luxuoso (37). Prosseguimos com a análise das linhas de concordância de cada um deles. As colocações não foram identificadas sempre diretamente, ou seja, base e colocado na sequência. Contabilizamos também os adjetivos encontrados na descrição do apartamento pela leitura do contexto estendido. Além disso, consideramos as ocorrências de quarto mais o adjetivo, uma vez que quarto também é um equivalente de room. Isso possibilitou aumentar o leque de equivalentes. Os exemplos abaixo ilustram esses casos:

Os 06 apartamentos luxo são elegantes e aconchegantes.

O Le Soleil - Residence Hotel oferece luxuosos quartos, cobertura duplex, sala ampla e confortável é área para relaxamento.

Assim, validamos os seguintes equivalentes de luxurious room: apartamento elegante (7), luxuoso (6), charmoso (5), belo (2), requintado (2), sofisticado (2). 


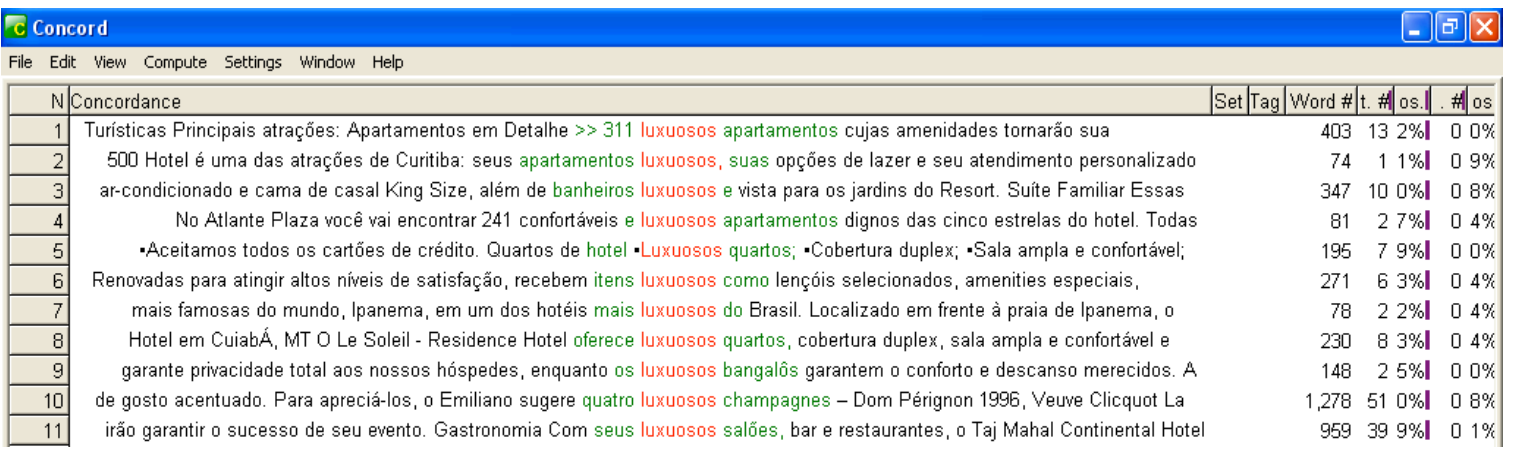

Figura 75 - Linhas de concordância de luxuoso, ordenadas pelos colocados à esquerda e à direita.

O Blue Tree Premium Paulista oferece 236 elegantes apartamentos com: arcondicionado, TV a cabo, conexão para computador, secador de cabelo, cofre, frigobar.

No Atlante Plaza você vai encontrar 241 confortáveis e luxuosos apartamentos dignos das cinco estrelas do hotel.

São 15 charmosos apartamentos confortáveis, totalmente reformados com: TV (Sistema TV Aberta e 2 Canais de Vídeo) Frigobar, Telefone; ventilador.

Belos apartamentos, com assoalho de Ipê e equipados com:

uma clássica e estilizada cama king size, vestida com roupas $100 \%$ algodão da Trussardi, travesseiros de látex e de plumas de ganso (...).

Entre seus atrativos estão os requintados apartamentos de $35 \mathrm{~m}^{2}$ de design sofisticado e discreto com um dormitório, banheiro, sala e mini-cozinha, acesso à internet banda larga, além de TV a cabo, ar condicionado e cofre digital.

Apartamento Luxo Twin: sofisticado apartamento de 42 metros quadrados com 2 camas. 


\subsubsection{Meeting room}

A colocação meeting room(s) ocorreu 218 vezes no corpus. A busca pelo equivalente seguiu os mesmos procedimentos descritos anteriormente. Partimos da palavra cuja tradução prima facie é mais conhecida: reunião e reuniões. Encontramos assim 92 ocorrências de sala(s) de reunião(es), em contextos que permitiam definir essa colocação como equivalente.

Three state-of-the-art meeting rooms with dedicated plasma screens and wireless Internet.

Em nosso Business Center 24 horas, nossos hóspedes têm acesso gratuito à internet nas workstations e contam ainda com uma sala de reuniões privativa.

No entanto, uma análise mais detalhada das linhas de concordância mostrou que em inglês existem diferentes acepções de meeting room, podendo ser:

a) uma sala de reuniões de negócios, propriamente dita, no centro empresarial ou na suíte do hotel:

Our contemporary meeting room boasts 350 square feet of affordable space that can accommodate up to 12 guests, boardroom style.

Our hotel offers two convenient suites that each feature a business meeting room connected to a guest bedroom.

b) um espaço para reuniões em sentido geral, ou eventos, como mostram os exemplos abaixo:

Choose from 14 distinct meeting rooms to suit the size and style of your next business or social function.

From an intimate five-course dinner in a meeting room to an elaborate ballroom gala, we specialize in creating events your guests will remember for a lifetime.

Our fully appointed, private meeting rooms feature: accommodations and meeting space for groups of 10 to a 1,000 people.

Para determinar o equivalente do segundo sentido de meeting room descrito acima (b), geramos as linhas de concordância de "evento", uma palavra que remete ao contexto almejado, e encontramos três referências a salão, como no exemplo a seguir:

O Hotel Plaza Praia Suites possui 3 salóes com o conforto e o espaço perfeito para realizar o seu evento. 
Julgamos relevante incluir essas diferentes acepções na nota Você sabia?.

No intuito de enriquecer ainda mais os resultados, optamos por acrescentar os tipos de arranjo especificados para as salas de reunião ou espaço de eventos. Essa iniciativa justifica-se por constatar esse contexto frequentemente relacionado à presente colocação:

The meeting room can accommodate 110 guests for theater settings, 70 guests for banquet settings and 60 guests for classroom seating. U-shape and conference settings are also available.

Salão Rio Preto da Eva Com área total de 81,62 $\mathrm{m}^{2}$ e pé direito de 2,80m. Capacidade para 110 pessoas no formato de auditório, para 60 pessoas nos formatos escola ou espinha de peixe e para 28 pessoas em $\underline{U}$.

Em inglês, essas disposições do espaço recebem o nome de: setup, layout, seating, setting, style. Em português: estilo, montagem, layout, configuração, formato.

Realizamos um levantamento por meio das linhas de concordância de meeting room e sala de reuniões. Em geral, em uma única linha de concordância era possível identificar alguns tipos de disposição das salas. Traçamos um paralelo entre eles e confirmamos os candidatos a equivalente na internet, por meio de imagens, especialmente nos casos com menor número de ocorrências. No caso de espinha de peixe encontramos o equivalente herringbone também por meio de pesquisa na web.

Chegamos aos seguintes tipos mais comuns de disposições das salas de eventos e seus equivalentes.

classroom $(10)=$ escolar (29)

u-shape (3) = formato $U(14)$

reception (5) = coquetel (13)

hollow square (3) = quadrado (2)

banquet (3) = banquete (24)

boardroom (2) / conference (3) = mesa única (1)

theater (6) = auditório (55)

herringbone (0) = espinha de peixe (29) 


\subsubsection{Powder room}

O corpus apresentou 29 ocorrências de powder room. Trata-se de um lavatório, ou banheiro pequeno, encontrado na acomodação, além do banheiro principal.

Pelas linhas de concordância e lista de colocados, identificamos uma estruturapadrão maior, guest powder room, com 11 ocorrências. Pelos exemplos, não identificamos uma diferença de sentido entre powder room e guest powder room.

Features include a dining room, two living rooms with two sofas, large wet bar with seating, kitchen staging area with refrigerator, and full bath and powder room with marble floors.

Each suite offers an expansive living room, a king master bedroom, a spacious marble bathroom and guest powder room.

Iniciamos a busca pelo equivalente a partir da palavra que remete ao mesmo contexto de powder room: banheiro. Não encontramos na lista de colocados nenhum candidato a equivalente prima facie e passamos para a análise das concordâncias, nas quais foi possível identificar lavabo.

\begin{tabular}{|c|c|c|c|c|c|c|}
\hline \multicolumn{6}{|c|}{ C Concord } & \multirow[t]{2}{*}{$D \underline{x}$} \\
\hline File Edit & View Compute Settings Window Help & & & & & \\
\hline \multicolumn{2}{|c|}{ N Concordance } & Set $\mathrm{Tag}$ Word \# & t. 制os. & H| os. $\mid$ & $H|0 s$.$| t. H| 0$ os. $\mid$ & \\
\hline 1 & dispốem de: 2 televisores home theater e DVD banheiro com hidromassagem vertical de 8 jatos & 393 & $169 \%$ & $02 \%$ & $02 \%$ & $\overline{h-p t-r t}$ \\
\hline 2 & com ar condicionado, frigobar, Tv 20', cofre, banheiro privativo, piso cerâmico, telefone & 271 & $117 \% \mathbf{I}$ & $03 \% \mathbf{I}$ & $03 \%$ & h-pt-r? \\
\hline 3 & de hidromassagem. Suíte: 02 ambientes, banheiro com banheira e sacada. Conjugado: & 316 & $146 \% \mathbf{I}$ & $08 \%$ & $08 \%$ & h-pt-res \\
\hline 4 & \multirow{2}{*}{$\begin{array}{l}\text { família de } 04 \text { ou mais pessoas, sendo com } 01 \text { banheiro somente Comunicados Superior:02 } \\
\text { (frente para a piscina) hidromassagem no banheiro sauna seca no banheiro Lazer Piscina }\end{array}$} & 336 & $151 \% \mathbf{l}$ & $01 \% \mathbf{l}$ & $01 \% \mathbf{l}$ & h-pt-re \\
\hline 5 & & 456 & $163 \% \mathbf{I}$ & $03 \% \mathbf{l}$ & $03 \% \mathbf{I}$ & h-pt-ret \\
\hline 6 & hidromassagem no banheiro sauna seca no banheiro Lazer Piscina Piscina Térmica / Coberta & 460 & $168 \% \mathbf{I}$ & $03 \%$ & $03 \% \mathbf{l}$ & h-pt-ret \\
\hline 7 & \multirow{3}{*}{$\begin{array}{l}\text { Apartamento luxo TV, telefone, mini geladeira, banheiro privativo, som ambiente e sacada (vista } \\
\text { suíte máster } 2 \text { TVs, telefone, mini geladeira, banheiro privativo, sacada de frente para o lago, } \\
\text { suíte luxo TV, telefone, mini geladeira, banheiro privativo, sacada de frente para o lago, }\end{array}$} & 138 & $41 \% \mathbf{I}$ & $04 \%$ & $04 \%$ & h-pt-r! \\
\hline 8 & & 159 & $45 \% \mathbf{I}$ & $07 \% \mathbf{I}$ & $07 \% \mathbf{I}$ & h-pt-res \\
\hline 9 & & 180 & $49 \%$ & $01 \% \mathbf{I}$ & $01 \% \mathbf{I}$ & h-pt-r! \\
\hline 10 & tanque e varal $\cdot$ Ampla varanda com rede $\cdot$ Banheiro Suítes $\cdot$ Ventilador de teto $\cdot \mathrm{Ar}$ & 190 & $39 \%$ & $02 \% \mid$ & $02 \%$ & h-pt- $\mathrm{r}_{\mathrm{s}}$ \\
\hline 11 & Sútes $\cdot$ Ventilador de teto $\cdot$ Ar condicionado $\cdot$ Banheiro $\cdot$ TV a cabo $\cdot$ Telefone $\cdot$ Forno de & 200 & $37 \%$ & $04 \%$ & $04 \% \mathbf{l}$ & h-pt- $\mathrm{r}_{\mathrm{s}}$ \\
\hline 12 & \multirow{2}{*}{$\begin{array}{l}\text { para deficientes físicos. Apartamentos com banheiro privativo com e sem varanda. Vista para } \\
\text { Suite B - Composta por um dormitório, um banheiro, um living, duas varandas. Acomoda } 2\end{array}$} & 376 & $144 \% \mathbf{I}$ & $02 \%$ & $02 \%$ & h-pt-ps \\
\hline 13 & & 438 & $191 \% \mathbf{I}$ & $08 \%$ & $08 \% \mathbf{I}$ & h-pt-rs. \\
\hline 14 & extra) Suite D - Duplex, com um dormitório, um banheiro, um lavabo, um living, duas varandas. & 489 & $227 \% \mathbf{l}$ & $02 \% \mid$ & $02 \% \mathbf{l}$ & h-pt- $r_{+}$ \\
\hline 15 & \multirow{2}{*}{$\begin{array}{l}\text { super king size, TV, som e um sofá para leitura. Banheiro amplo com hidromassagem Suíte } \\
\text { super king size, TV, som e um sofá para leitura. Banheiro amplo com hidromassagem. - Vista em }\end{array}$} & 481 & $206 \%$ & $08 \%$ & $08 \%$ & h-pt- $r_{s}$ \\
\hline 16 & & 527 & $220 \% \mathbf{I}$ & $01 \% \mathbf{I}$ & $01 \%$ & $h-p t-r_{.}$ \\
\hline
\end{tabular}

Figura 76 - Linhas de concordância parciais de banheiro; no destaque, a referência a lavabo.

Gerando concordâncias para lavabo, confirmamos tratar-se do mesmo contexto, portanto, um equivalente adequado.

A unidade tem como diferencial o fato de dispor de vários ambientes distribuídos em dois pisos com sofás, um sofá-cama, uma cama king size, mini-cozinha, DVD, copa, sala de estar e lavabo. 
Suite E - Suite Master, duplex, com dois dormitórios, um lavabo, dois banheiros, um grande living, amplo dormitório e closet, quatro varandas.

Nosso conhecimento prévio da terminologia da área nos levou a atestar o uso de half bath(s) (23) / half bathroom (2) como sinônimo de powder room.

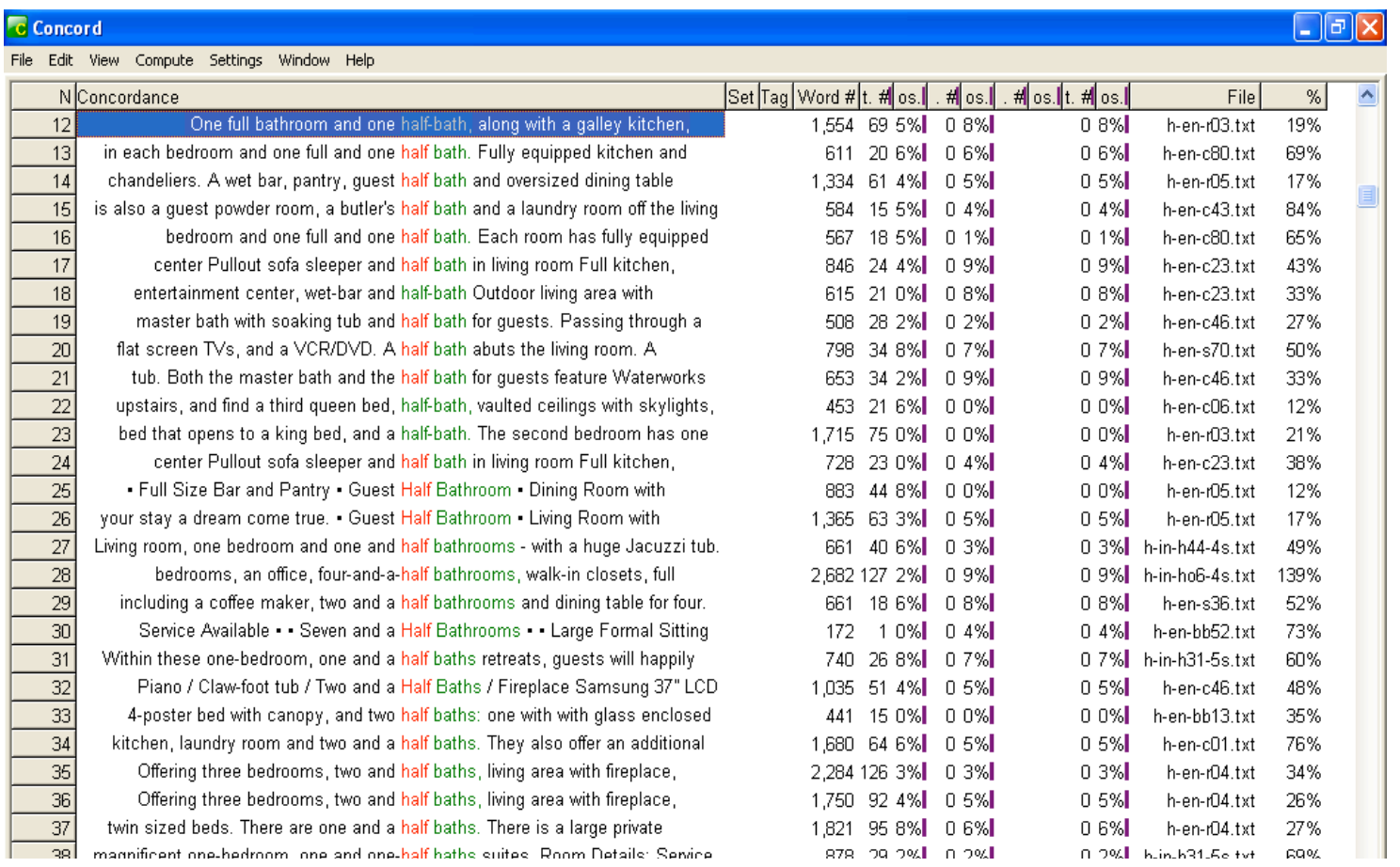

Figura 77 - Linhas de concordância parciais de half; ordenadas pelos colocados à direita. Destaque para as colocações half bath(s) e half bathroom(s).

É possível ainda observar expressões como one and a half baths ou two and a half baths, significando um banheiro e um lavabo ou dois banheiros e um lavabo, respectivamente.

A wet bar, pantry, guest half bath and oversized dining table make entertaining a dream.

A grand foyer welcomes guests into the distinguished atmosphere, which pervades throughout every square inch of these magnificent one-bedroom, one and one-half baths suites. 
Optamos por incluir essa informação na nota Você sabia?, juntamente com a variação guest powder room, mencionada inicialmente.

\subsubsection{Reserve [a, your, this] room}

Das 167 ocorrências do verbo reserve, 56 integram a colocação to reserve a/your/one room:

Our online booking service is the most convenient way to reserve a room.

In order to reserve your room a vaild credit card number will be required.

\begin{tabular}{|c|c|c|c|c|c|}
\hline \multicolumn{2}{|c|}{ c Concord } & \multicolumn{4}{|r|}{ 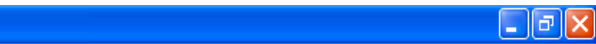 } \\
\hline File Edit & Niew Compute Settings Window Help & & & & \\
\hline \multicolumn{2}{|r|}{ N Concordance } & \begin{tabular}{|l|l|l|l|} 
Set & Tag & Word \# & t. \# \\
os.
\end{tabular} & \#| os.|| & An os.l| & File $\hat{\text { A }}$ \\
\hline 1. & Booking Made Easy - click here to reserve $10-25$ rooms at the Fairfield Inn and & $113 \quad 25 \%$ & $08 \%$ & $08 \%$ & h-en-s21.txt \\
\hline 2 & Discounted rates are available when you reserve 10 or more rooms per evening. To plan & $3,3771907 \% \mathbf{l}$ & $01 \%$ & $01 \% \mathbf{l}$ & h-en-c06.txt \\
\hline 3 & rooms. Group Bookings at This Hotel Need to reserve 10 or more guest rooms, meeting or & $439 \quad 118 \% \mathbf{l}$ & $06 \%$ & $06 \% \mathbf{l}$ & h-en-c35.txt \\
\hline 4 & together for a Winter Midweek getaway. Reserve 5 or more rooms and enjoy a special & $4,5682179 \%$ & $01 \%$ & $01 \%$ & h-en-r15.txt \\
\hline 5 & \multirow{2}{*}{$\begin{array}{l}\text { time with the Father's Day Spa Escape. Reserve a } 50 \text {-minute massage and receive an } \\
\text { amount is due by credit card payment, to reserve a booking. } 72 \text { hour cancellation notice }\end{array}$} & $6,5592870 \% \mathbf{l}$ & $04 \%$ & $04 \%$ & h-en-r12.txt \\
\hline 6 & & $792508 \%$ I & $03 \%$ & $03 \% \mid$ & h-en-bb27.txt \\
\hline 7 & enjoy your vacation your way. You can even reserve a childcare specialist to accompany & $1,088339 \% \mathbf{l}$ & $01 \%$ & $01 \% \mathbf{l}$ & h-en-r18.txt \\
\hline 8 & safe - Windows that partially open - Option to resenve a connecting Harbor View guestroom & $1,62131 \%$ I & $03 \%$ & $03 \%$ & h-in-ho3-5s.txt \\
\hline 9 & from the resort. Contact the Front Desk to reserve a court. Menu highlights A local's & $815338 \% \mathbf{l}$ & $04 \%$ & $04 \%$ & h-en-c11.txt \\
\hline 10 & and convention facilities. Minimum age to reserve a guestroom is 21 years old. Our & $11835 \%$ & $00 \%$ & $00 \% \mathbf{I}$ & h-en-s56.txt \\
\hline 11 & plenty of water. Hugs and piggyback rides. Reserve a little time Happy starts, happy & $32 \% \mathbf{l}$ & $02 \%$ & $02 \%$ & $h$-in-h33-4s.txt \\
\hline 12 & Available Meeting Rooms Meetings Home Reserve a Meeting Room Meeting Room & $73 \%$ & $03 \%$ & $03 \% \mathbf{I}$ & h-en-s31.txt \\
\hline 13 & personalized service for your next event. Reserve a meeting room at our Washington DC & $1,381 \quad 480 \% \mathbf{I}$ & $04 \%$ & $04 \%$ & h-en-c34.txt \\
\hline 14 & personalized service for your next event. Reserve a meeting room at our Washington $D C$ & $1,526570 \% \mathbf{l}$ & $02 \%$ & $02 \% \mid$ & h-en-c49.txt \\
\hline 15 & in the inviting social lounge. You can even resene a private dining room for special & 3,991 $1522 \%$ l & $07 \%$ & $07 \%$ & h-en-r01.txt \\
\hline 16 & getaway to your Cape Cod "home". Or reserve a residence in advance for out of & $343115 \%$ & $04 \%$ & $04 \%$ & h-en-c30.txt \\
\hline 17 & cook-top range, microwave, refrigerator, etc.) Reserve a room now Arrival and Departure & $884 \quad 458 \%$ l & $09 \%$ & $09 \%$ & h-en-c40.txt \\
\hline 18 & Online: Now, you can check our availability \& reserve a room online Check availability heck & $1,257 \quad 725 \% \mathbf{l}$ & $09 \%$ & $09 \%$ & h-en-bb53.txt \\
\hline 19 & Reservations Please use the form below to reserve a room. Doug will contact you to & $868565 \% \mathbf{l}$ & $09 \%$ & $09 \% \mathbf{I}$ & h-en-bb51.txt \\
\hline 20 & booking service is the most convenient way to reserve a room. If you prefer you can call toll & $2,7411405 \% \mid$ & $05 \%$ & $05 \%$ & h-en-c28.txt \\
\hline 21 & harbor. For a truly indulgent experience, reserve a room in our private Fairmont Gold & $472161 \%$ & $03 \%$ & $03 \%$ & h-en-c42.txt \\
\hline 22 & indulgent Boston waterfont hotel experience, reserve a room in our private Fairmont Gold & $779307 \%$ & $01 \%$ & $01 \%$ & h-en-c42.txt \\
\hline 23 & Reserve a Room by Phone, Fax or On-Line Reserve a room by phtne, fax or on-line - & $1,311646 \% \mathbf{l}$ & $06 \%$ & $06 \%$ & h-en-c52.txt \\
\hline 24 & the senses. For a truly indulgent experience, reserve a room in our private Fairmont Gold & $165 \quad 51 \%$ l & $05 \%$ & $05 \%$ & h-en-c42.txt \\
\hline 25 & terms, please visit our Reservations page. Reserve a Room Now Check-In MM/DD $/ Y Y$ & $667305 \%$ & $08 \%$ & $08 \%$ & h-en-s61.txt \\
\hline 26 & a group booking - $A$ credit card is required to reserve a room; can change method of & $400 \quad 150 \%$ & $06 \%$ & $06 \%$ & h-en-s34.txt \\
\hline 27 & card will not be charged until you check-out Reserve a room Book this reservation Th & $533202 \%$ I & $00 \%$ & $00 \% \mid$ & $h$-in-h38-2s.txt \\
\hline 28 & Inn's own chef creates meals to remember. Reserve a Room by Phone, Fax or On-Line & $1,303645 \% \mathbf{l}$ & $05 \%$ & $05 \%$ & h-en-c52.txt \\
\hline 29 & you may reach us by calling You may also reserve a room through our on-line reservations & $710331 \%$ l & $07 \%$ & $07 \%$ & h-en-s14.txt \\
\hline
\end{tabular}

Figura 78 - Linhas de concordância parciais de reserve; no destaque, reserve a room.

Além de colocar-se com room, identificamos outros 32 padrões do verbo reserve, a maioria com apenas 1 ocorrência, como por exemplo:

To reserve [a suite (7), a meeting room (4), accommodations (3), a stay (3), tee times (2), seating (2), a package (1), bycicles (1), tickets (1), a spot (1), a date (1), a table (1)]

Reserve a meeting room at our Washington DC conference venue, 
You must be at least 21 years or older to reserve any accommodations at Eagle Ridge Resort \& Spa.

O verbo também é bastante usado na forma intransitiva (31 ocorrências): reserve now (10), reserve online (8), reserve by phone (5), reserve early (1).

Reserve now! We look forward to having you as our guest!

Podemos afirmar, portanto, que reserve ocorre primordialmente com room, mas também é empregado de maneira mais genérica.

Essa pesquisa preliminar forneceu dados para a comparação com outro verbo sinônimo, to book, também presente na lista de colocados de room.

Constatamos 300 ocorrências do verbo book, ou seja, quase o dobro que reserve (167). O colocado mais frequente também é room, com 46 ocorrências.

Click here to check availability and book your room online.

Ready to book your room! Click here to take advantage of great rates!

Aqui já é possível traçar um paralelo importante. Book é mais recorrente no corpus do que reserve, e ambos são colocados de room. No entanto, a colocação reserve a room (56 das 167 ocorrências) é mais forte do que book a room (46 das 300 ocorrências).

Book também ocorre com diversos outros substantivos, contabilizamos mais de 40. Os principais estão relacionados a acomodações. Dentre eles, destacamos:

To book [a reservation (28), a suite (10), a stay (9), nights (9), accommodations (5), a package (4), an appointment (4), a hotel (3), an event (2), a massage (2), a vacation (1)] A two night deposit is required to book a reservation.

Book two nights and get $50 \%$ off the third night.

Um dos principais usos de book, no entanto, é na forma intransitiva (78 ocorrências). É o caso de book online (35), book now (29), book early (3).

Save up to $30 \%$ on your reservation at the Bay Inn \& Suites SeaWorld San Diego when you book online! Book Now! 
Aqui também identificamos um padrão de uso semelhante, mas com diferença relevante na frequência - reserve now (10), reserve online (8) / book online (35), book now (29).

Em resumo, essa análise comparativa nos permite afirmar que:

- ambos os verbos são sinônimos, pois compartilham o mesmo sentido e diversos colocados;

- ambos os verbos têm room como principal colocado, mas reserve a room é mais frequente e mais forte do que book a room;

- book é mais usado na form a intransitiva, especialmente em book now e book online.

Todas as informações são resumidas e incluídas na seção Você sabia? da entrada.

Partimos então para a identificação dos equivalentes em português.

Iniciamos pela análise das formas verbais - reserve e reservar; seguida dos substantivos reserva e reservas.

A forma reserve consta 46 vezes no corpus. Apresenta diversos colocados nominais e adverbiais. Por exemplo:

Reserve (um/uma, sua/seu(s), o/a(s)) [estadia (4), apartamento (1), suite (1), quarto (1), pacote (1), horário (1), café da manhã (1), espaço (1), férias (1)]

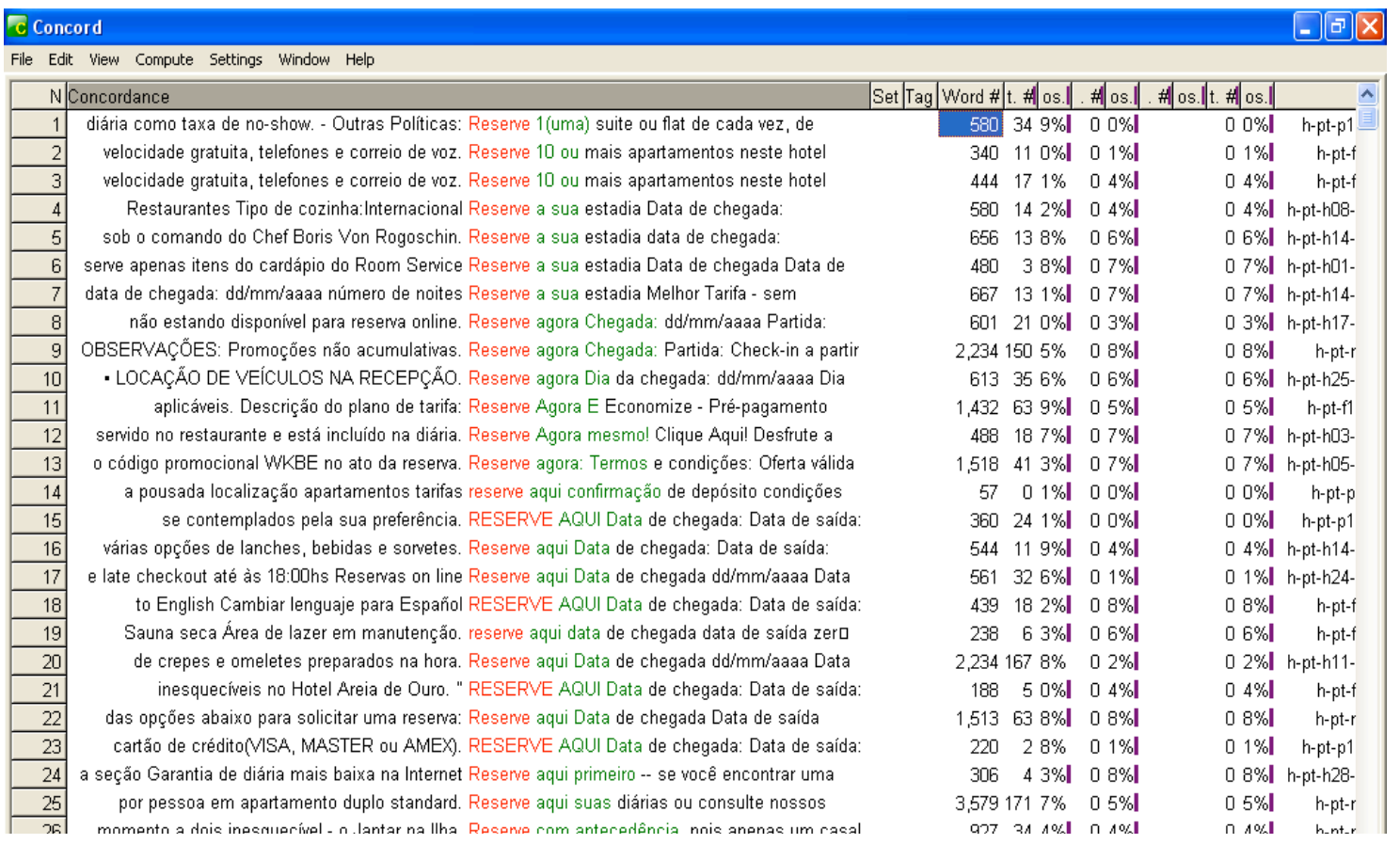

Figura 79 - Linhas de concordância parciais de reserve (em português). 
Como é possível observar na figura acima, o verbo também ocorre com alguns advérbios, como aqui (12), agora (7) e já (6).

A forma verbal no infinitivo - reservar - é menos frequente. São 34 ocorrências: 4 com apartamento e 1 com quarto, geralmente precedido da expressão mais de um.

Se você desejar reservar mais de um apartamento repita o processo incluindo diferentes nomes de hóspedes para cada apto

Para reservar mais de um quarto, basta fazer outra reserva.

Até este ponto, identificamos apenas 7 ocorrências de verbos (reserve/reservar) seguidos de apartamento/quarto, que seria a tradução prima facie de reserve a room.

Decidimos, portanto, investigar o substantivo reserva(s), bem mais frequente, somando 1939 ocorrências.

Em função do elevado número de ocorrências, desconsideramos da análise colocações que, apesar de representativas, fugiam do contexto almejado, tais como confirmar a reserva, cancelar a reserva, formulário de reserva, dentre outras. Ou seja, concentramos a análise de reserva(s) relacionada às acomodações.

Nesse ponto, valemo-nos da pesquisa com o corpus etiquetado. As seguintes expressões de busca foram utilizadas:

"V* reserva NOM": verbo + reserva

"V* reservas NOM": verbo + reservas

"V* sua ADJ sua reserva NOM": verbo + sua reserva

"V* suas ADJ sua reservas NOM": verbo + suas reservas

"V* a DET a reserva NOM": verbo + a reserva

"V* uma DET uma reserva NOM": verbo + uma reserva

"NOM reserva * ADV": reserva + advérbios

"reserva NOM reserva de PRP de * NOM": reserva de + substantivos

"reservas NOM reserva de PRP de * NOM": reservas de + substantivos

Apesar de as etiquetas ajudarem a filtrar a grande quantidade de dados, elas não dispensaram a consideração das listas de colocados e das linhas de concordância sem etiquetas.

Finalmente, chegamos aos seguintes colocados:

faça sua reserva (56) / faça [agora, já] sua reserva (26) / fazer [uma, sua] reserva (27)

Faça sua reserva on-line e ganhe $10 \%$ de desconto.

Para fazer a sua reserva no Victory Suites, efetue o cadastro em nosso sistema. 
Aproveite e faça já sua reserva. Não perca tempo. Venha desfrutar do paraíso na Pousada Ancoradouro.

efetuar [a, sua, uma] reserva (19)

Para efetuar sua reserva ou solicitar informações adicionais, favor entrar em contato conosco pelo email.

Solicitamos efetuar sua reserva com um dia de antecedência.

solicitar [a, sua, uma] reserva (18)

Preencha esse formulário para solicitar uma reserva.

Para solicitar sua reserva, por favor informe abaixo os dados de sua estadia conosco, bem como seus dados pessoais.

realizar [a, sua, uma] reserva (6)

Para realizar uma reserva, o cliente deverá fazer um depósito bancário de 25\% do valor total das diárias.

Para realizar a sua reserva, preencha o formulário abaixo.

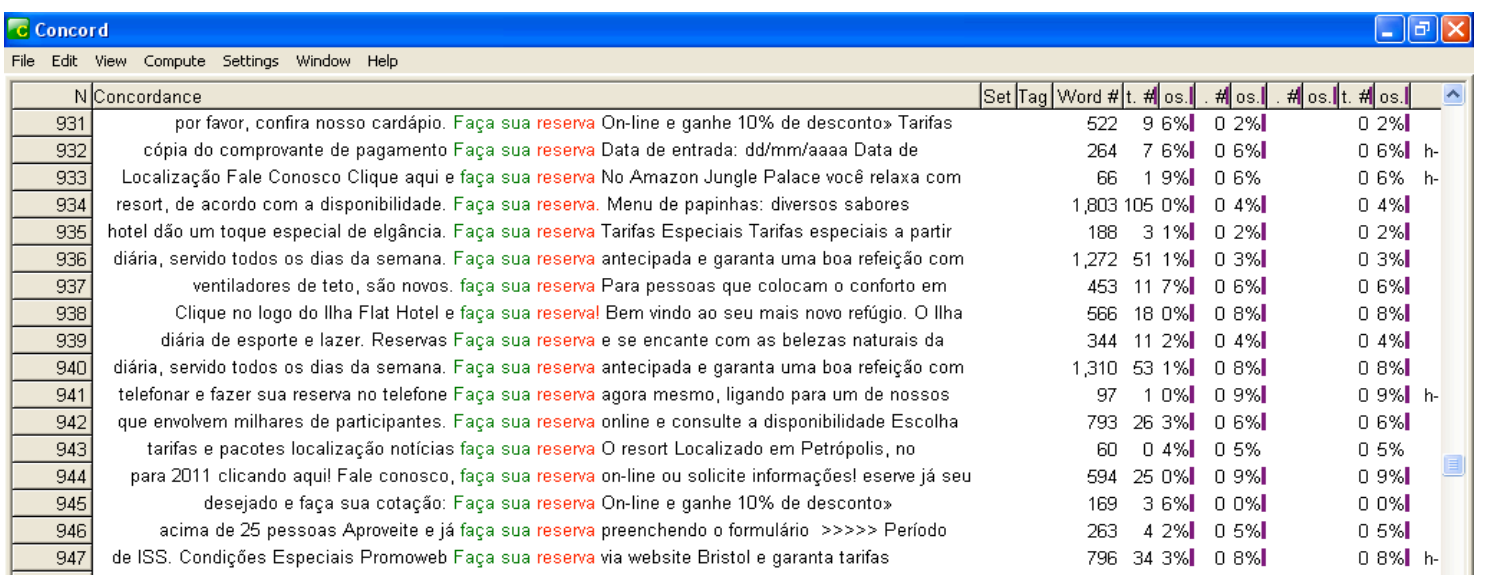

Figura 80 - Linhas de concordância parciais de reserva, ordenadas pelos dois colocados à esquerda.

Chamou-nos a atenção o fato de apartamento e quarto não estarem entre os colocados (reserva(s) de apartamento(s) / quarto(s) ocorreram apenas 3 vezes). Assim, podemos afirmar que apartamento fica subentendido no contexto em português, uma vez que todos os colocados relacionados acima se referem às reservas de acomodações no hotel.

Os dados demonstraram que em português existe a preferência pela estrutura "verbo + reserva" em lugar do verbo reservar. Por esse motivo, não incluímos entre os 
equivalentes a opção Reserve já, por exemplo, dando preferência para Faça já sua reserva.

Essas informações adicionais são acrescentadas na Nota ao tradutor.

\subsubsection{Room amenities}

Room amenities consta 74 vezes no corpus. Encontramos ainda a variante sinônima guest room amenities (16) e in-room amenities (14). Essa colocação é utilizada para referir-se às mais variadas comodidades encontradas nas acomodações, tais como cofre, cafeteira, internet, TV a cabo, DVD, secador de cabelos, roupões, etc.

Figura 81 - Linhas de concordância parciais de room amenities.

Pelas linhas de concordância, observamos que, em 52 das 74 ocorrências, a colocação antecede a relação dos itens contidos no apartamento, como nos seguintes exemplos:

Room amenities include a king-size bed, private bath, and a flat-screen cable TV.

Room amenities: cable television with multi channels, microwave, refrigerator, writing table with chairs, telephone for room to room and local calls, air conditioner, in-room safe, hair dryer, wireless internet access.

Em português, nossa intuição nos levou a buscar o equivalente pela tradução prima facie comodidades. Foram encontradas 19 ocorrências, das quais somente cinco destacavam os itens no apartamento: 
São 396 acomodações distribuidas entre apartamentos e suites, com todas as comodidades: wireless, workstation no quarto, TV a cabo, cofres individuais, telefone com discagem direta, frigobar, room-service 24 horas por dia (...).

Os outros casos foram usados em sentido mais amplo de conforto:

Respeitando à risca o conceito de resort, o Summerville conta com comodidades $e$ mordomias especiais fazendo com que os hóspedes aproveitem ao máximo a sua estada.

Em pleno coração de Itaipava, região serrana do Rio de Janeiro, a Pousada Arcádia enquadra-se no conceito de "pousada urbana", unindo todo conforto, charme e requinte de uma típica pousada no campo, com as comodidades e facilidades encontradas nos centros urbanos.

Consideramos comodidades um equivalente de room amenities. Entretanto, em função do baixo número de ocorrências (5) para um contexto bastante recorrente no corpus, continuamos a busca para identificar outras possibilidades. Lançamos mão da estratégia de realizar buscas pelas palavras que remetem ao contexto da colocação original, ou seja, os colocados de room amenities. Analisamos as concordâncias de palavras como cofre, cafeteira, frigobar, etc., para observar como esses itens eram introduzidos no texto. Assim, chegamos aos seguintes equivalentes em português:

\section{Facilidades}

180 ocorrências, das quais 27 remetiam aos atributos dos apartamentos e 95, aos do hotel:

Facilidades: acesso à internet banda larga, aquecimento central, ar condicionado com controle individual, TV a cabo.

Apartamentos de decoração aconchegante e personalizada com todas as facilidades do apartamento superior, porém mais espaçosos e alguns possuem terraço.

\section{Características}

110 ocorrências, das quais 19 remetiam aos atributos dos apartamentos e 19, aos do hotel: 
Características: armário, minibar, telefone com secretária eletrônica, mesa com 8 cadeiras, ar condicionado central, sofás, poltronas e chaise longues, TVs a cabo.

Disponibilizamos 80 confortáveis apartamentos (...), todos com decoração em tons suaves e possuindo as seguintes características: TV a cabo: mais de 40 canais; telefone; cofre, senha eletrônica (...).

Além dos equivalentes atestados acima, a pesquisa acima evidenciou que: em português, as "facilidades", ou os itens que compõem os apartamentos, na maioria das vezes não são introduzidos por uma palavra específica (como amenities no inglês). Em geral, essa relação é precedida por expressões como: equipado com, possui, conta com, (apartamento) com:

E para o seu total conforto, o Costa dos Coqueiros oferece 52 apartamentos equipados com frigobar, internet wireless, ar condicionado, varanda e um delicioso café da manhã, incluso na diária.

As acomodações do Mabu possuem ar condicionado, TV LCD, TV a cabo, WC com ducha, secador de cabelos, telefone, frigobar, amenities, internet wireless, tomadas identificadas para $110 \mathrm{~V}$ e $220 \mathrm{~V}$.

O Blue Tree Premium Paulista oferece 236 elegantes apartamentos com: arcondicionado, TV a cabo, conexão para computador, secador de cabelo, cofre, frigobar, vista para as Avenidas Paulista, Nove de Julho, Peixoto Gomide e para o MASP.

Nos apartamentos do Hotel Beira Mar, você conta com ar-condicionado, minibar, TV a cabo, cofre individual, serviço de quarto e acesso à internet sem fio (wi-fi) em todo o hotel. 


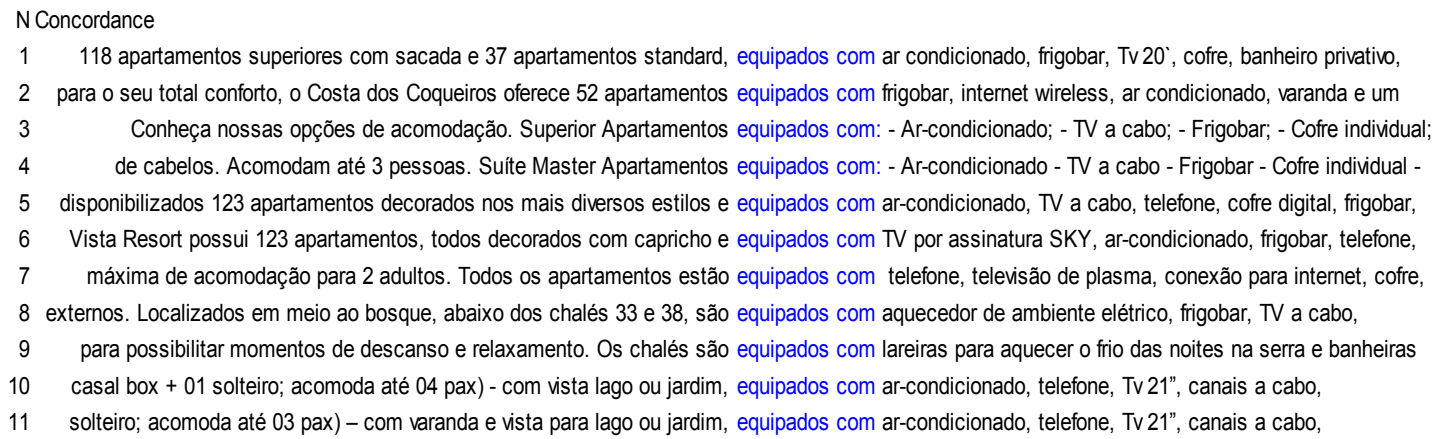

Figura 82 - Linhas de concordância parciais de equipados com.

Em resumo, podemos concluir que em inglês é mais usual a estrutura:

Room amenities include a king-size bed, private bath, and a flat-screen cable TV.

Ao passo que, em português, temos:

Apartamentos equipados com ar condicionado split, ventilador de teto, frigobar, TV 32 polegadas LCD, TV a cabo com 60 canais, cofre.

Portanto, estamos diante de convenções linguísticas distintas, ou de um "jeito que a gente diz" diferente.

Por fim, outra curiosidade foi constatar que a palavra amenities também é utilizada em português, com 64 ocorrências. Contudo, para designar os artigos de toalete encontrados nos banheiros, como shampoo, condicionador, touca de banho, etc.

Estes últimos possuem chave para segurança de seus pertences, amenities L'occitane, chinelo, roupão e toalha, sem contar os itens dispostos nas pias como secador de cabelos, creme hidratante, desodorante, cotonetes, algodão e espuma de barbear.

Roupão de banho, toalha de banho, chinelo, amenities (shampoo, condicionador).

Banheiro: secador, espelho de maquiagem, telefone, ducha e amenities.

Em inglês, usa-se toiletries (38) para referir-se aos itens disponibilizados no banheiro:

Bathroom toiletries include shampoos, hair conditioners, body gels and lotions, facial cotton towels, and shower caps.

Além dos correspondentes encontrados (facilidades, características, comodidades), as demais informações sobre os padrões linguísticos (está equipado com) e o falso cognato amenities são organizadas na forma de Notas ao tradutor no verbete. 


\subsubsection{5 [one/first night's] room and tax}

O binômio room and tax aparece 41 vezes no corpus. Dessas, 34 são precedidas de [one/first] night ou night's. Assim, consideramos a colocação estendida para entrada do verbete.

Encontramos ainda variações menos frequentes:

[one/first night] room and tax (15)

[your/one night] room charge plus tax (5)

[one/first night's] room rate and tax (4)

Antes de iniciar a busca pelo equivalente, analisamos os contextos de uso da expressão, por meio das linhas de concordância.

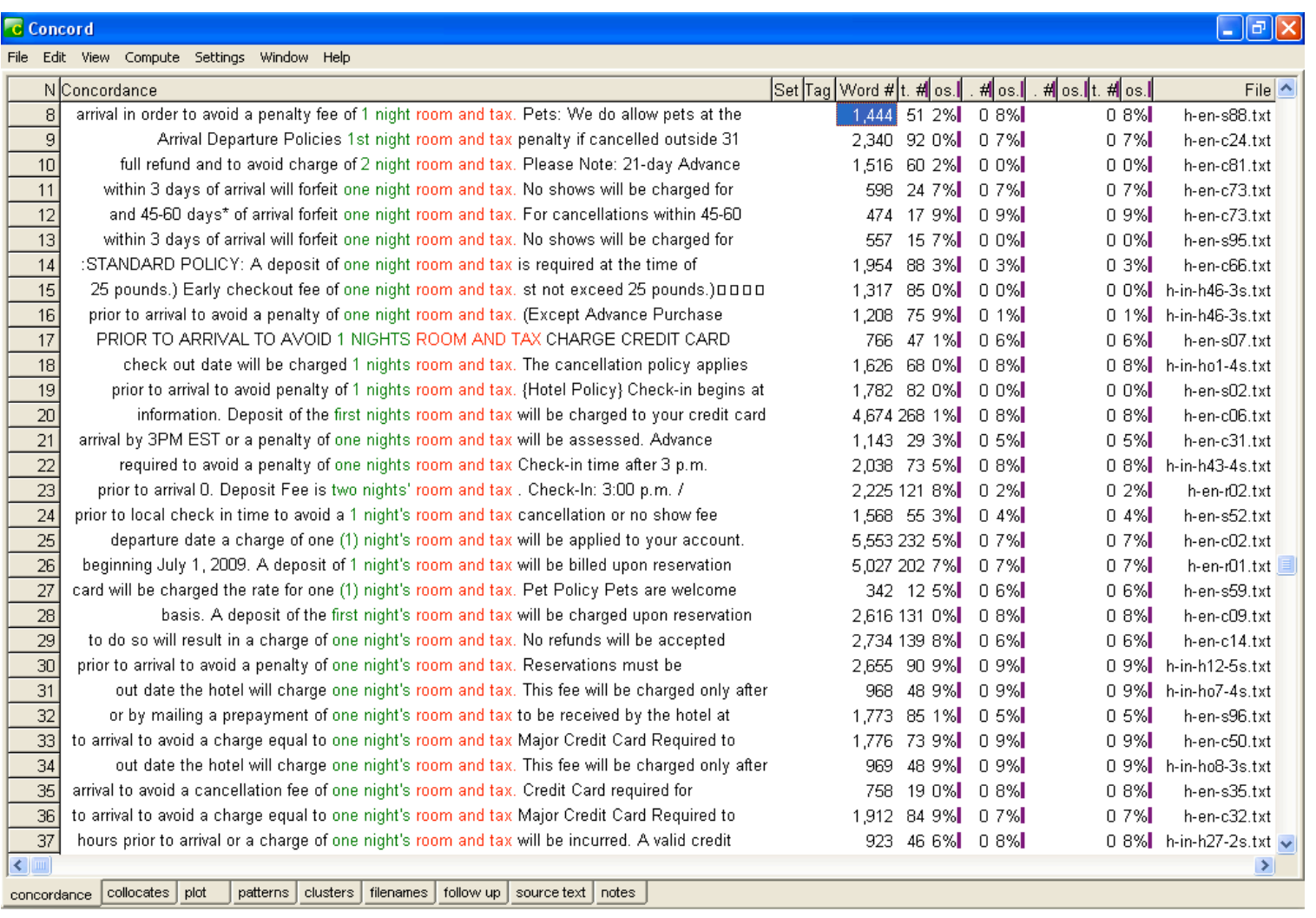

Figura 83 - Linhas de concordância parciais de room and tax, ordenados pelos colocados à esquerda.

Identificamos três contextos de uso da expressão:

a) cobrança estabelecida na política de cancelamento ( $70 \%$ dos contextos):

Must cancel 72 hours prior to local check in time to avoid a 1 night's room and tax cancellation or no show fee.

Cancellations received within 3 days of arrival will forfeit one night room and tax.

b) cobrança como garantia de reserva: 
A deposit of 1 night's room and tax will be billed upon reservation confirmation.

Prepayment of one night's room and tax to be received by the hotel at least 10 days prior to arrival.

c) cobrança por saída antecipada do hotel:

Early checkout fee of one night room and tax.

Any guests departing prior to their originally scheduled check out date will be charged

\section{1 night's room and tax.}

Por saber que os hotéis no Brasil também estabelecem cobrança nas situações descritas acima, acreditamos que seria simples encontrar um equivalente direto. No entanto, a busca revelou-se mais complexa.

Iniciamos a pesquisa pelo contexto mais recorrente, com a palavra cancelamento, presente 339 vezes no corpus. Analisando a lista de colocados, selecionamos algumas palavras que remetiam ao contexto buscado: valor, cobrança, multa, ônus, sinal. Pela ausência da palavra imposto, entendemos que o tipo de cobrança no caso de cancelamento poderia ser diferente entre os dois países. De fato, uma rápida busca por "* e impostos" retornou apenas 3 ocorrências de taxas e impostos em contextos diferentes do almejado. A busca "* mais impostos" não retornou ocorrências.

A fim de estreitar e otimizar a pesquisa, geramos as linhas de concordância para política de cancelamento e obtivemos 58 ocorrências. Analisando cada uma delas, verificamos que, nos exemplos do nosso corpus, os principais tipos de política em caso de cancelamento da reserva são:

a) cobrança de uma porcentagem sobre o valor da reserva (26 contextos):

Política de cancelamento: até quinze dias antes da entrada devolvemos o sinal ou remarcamos a data; cancelamentos fora destes prazos implicarão na cobrança de $50 \%$ do valor da estada.

Política de cancelamento: caso precise fazer o cancelamento de sua reserva, este será cobrado, observando as condições abaixo descritas: de 7 até a data do check in - será cobrado $50 \%$ do valor total da reserva.

b) devolução do valor em forma de crédito para futura hospedagem (10 contextos):

Política de cancelamento das reservas: não há devolução de valores pagos. Os depósitos efetuados permanecerão como crédito para utilização em 12 meses. 
Em caso de cancelamento, o valor depositado na confirmação da reserva não será devolvido em dinheiro, mas sim em crédito para hospedagem.

c) cobrança do valor de uma ou mais diárias (3 contextos):

Cancelamento com até 45 dias de antecedência: devolução do crédito com multa no valor de 1 (uma) diária.

Multa para cancelamento fora do prazo: cobraremos o valor de 3 diárias.

Verificamos, portanto, que a maior parte dos estabelecimentos de nossa amostra cobra uma porcentagem sobre o valor da estada como multa pelo cancelamento. Outra política é creditar o valor do depósito para futura hospedagem e, menos frequentemente, cobra-se o valor de uma ou mais diárias. Essa última opção, apesar de menos frequente, é a que parece se aproximar mais do contexto da colocação original.

Por fim, resolvemos analisar os tipos de cobranças adicionais sobre o valor das diárias. Realizamos uma busca por "diárias e *", "diária e *", "diárias mais *" e "diária mais *". Encontramos os seguintes exemplos, em contextos equivalentes ao da colocação original:

As diárias e respectivas taxas deverão ser pré-pagas para garantia da reserva, através de depósito bancário ou débito em cartão de crédito.

As reservas devem ser canceladas em até $72 \mathrm{~h}$ antes da data de chegada caso contrário será cobrado o valor de uma diária e taxas.

Reservas devem ser canceladas com no mínimo 24 horas antes da chegada para evitar cobranças da primeira diária e taxas.

Assim, adotamos diária e taxas como equivalente de one night's room and tax. Apesar de apenas três ocorrências, é a forma encontrada no corpus para referir-se ao tipo de cobrança realizado mais frequentemente nos Estados Unidos.

Nosso objetivo em relatar todo esse percurso foi demonstrar como o corpus, além das informações linguísticas, é capaz de trazer à tona aspectos culturais que enriquecem nosso entendimento das realidades sendo representadas e, 
consequentemente, os resultados da pesquisa terminológica. Assim, no verbete, decidimos incluir esse dado cultural, de forma simplificada, em uma Nota ao tradutor:

\subsubsection{Room features}

Constatamos 115 ocorrências da colocação verbal room features. Esse verbo é também bastante recorrente (1100 ocorrências), sendo a forma na terceira pessoa do singular uma das palavras-chave do corpus (posição 59).

A colocação é empregada para introduzir os itens encontrados nas acomodações: This room features a queen bed and private bath, gas fireplace, mini wet-bar with microwave oven and refrigerator, desk, paddle fan, air-conditioning (...).

Our spacious guest room features contemporary decor with stylish furnishings including one king Hyatt Grand Bed ${ }^{\mathrm{TM}}$, state-of-the-art media and work center with a 42 "flat-panel high-definition television (...).

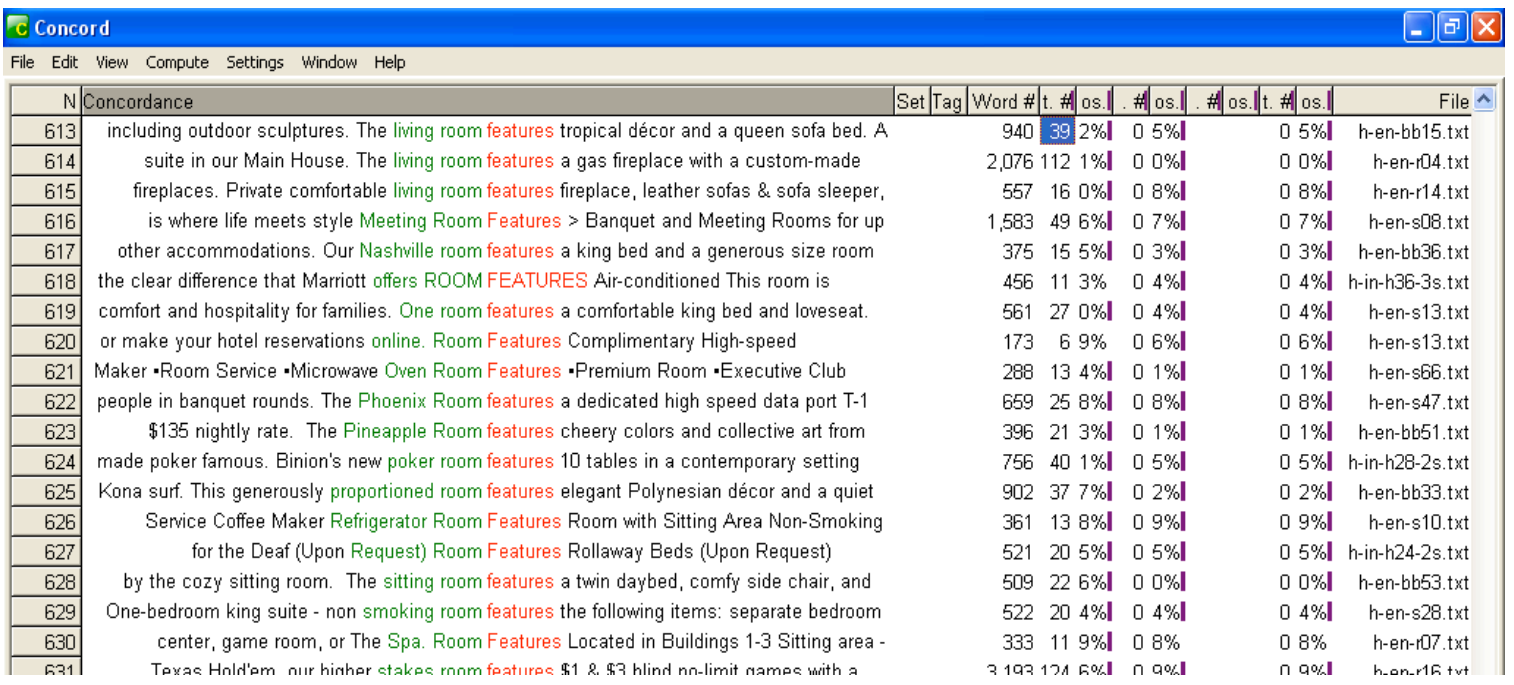

Figura 84 - Linhas de concordância parciais de features, ordenadas pelos dois colocados à esquerda.

Antes de identificar os equivalentes, realizamos uma busca por outros verbos em inglês que pudessem ser usados no mesmo sentido. Para isso, utilizamos o corpus etiquetado, com a seguinte expressão de busca: "NN room * VVZ", ordenando os colocados à direita. 


\begin{tabular}{|c|c|c|c|c|c|}
\hline C Conce & & & & & 0 - $x$ \\
\hline File Edit & View Compute Settings Window Help & & & & \\
\hline$N$ & Concordance & Set Tag & Word \#|t. \#| os.| & \#n os.l| & H os.||t. $\#$ os.|| \\
\hline 73 & SENT . Our PP\$ our Double NP Double room NN room features $W Z$ feature two $C D$ two full & & $82,956259 \mid 6 \%$ & $07 \%$ & $07 \%$ againinteiro.tạ \\
\hline 74 & NP Harbor NP Harbor guest NN guest room NN room features $W Z$ feature two $C D$ two beds & & $75,288|517| 4 \% \mathbf{I}$ & $05 \%$ & $05 \%$ Itagaininteiro tạ \\
\hline 75 & and inviting $W G$ invite guest NN guest room NN room features $W Z$ feature two $C D$ two beds & & $74,643|505| 9 \% \mathbf{I}$ & $04 \%$ & $04 \%$ Itagaininteiro ta! \\
\hline 76 & suites NNS suite , , , each DT each room NN room highlights WZ highlight a DT a & & $17,158|363| 5 \% \mathbf{|}$ & $01 \% \mathbf{l}$ & $01 \%$ resortinteiro.tal \\
\hline 77 & guests NNS guest. SENT. This DT this room NN room includes $W Z$ include a DT a beautiful & & $07,4991345 \mid 7 \%$ & $03 \% \mathbf{I}$ & $03 \%$ Itagaininteiro tą \\
\hline 78 & the rate NN rate of IN of your PP\$ your room NN room includes WZ include a DT a full JJ full & & $29,497|476| 8 \% \mid$ & $01 \% \mathbf{l}$ & 0 1\% Itagaininteiro.tas \\
\hline 79 & NP Vegas Strip. NP Each DT each room NN room includes WZ include a DT a King NP & & $90,484|185| 9 \% \mathbf{I}$ & $02 \% \mathbf{I}$ & $02 \%$ Ishotelinteiro.ta! \\
\hline 80 & guest NN guest. SENT. Each DT each room NN room includes WZ include a DT a sleeping & & $54,711685 \mid 4 \%$ & $02 \% \mathbf{I}$ & 0 2\%lh-en-c01_40.ta! \\
\hline 81 & guest rooms NNS room , , this DT this room NN room includes $W Z$ include all DT all of IN of & & $7,7412522 \% \mathbf{I}$ & $02 \%$ & $02 \%$ tagaininteiro.tạ \\
\hline 82 & DT the formal JJ formal dining NN dining room NN room includes WZ include an DT an & & $26,5956980 \% \mathbf{I}$ & $09 \% \mathbf{l}$ & $09 \%$ teste_um.tạ \\
\hline 83 & SENT. Each DT each guest NN guest room NN room includes WZ include free JJ free & & $32,743|427| 3 \% \mid$ & $05 \%$ & $05 \%$ l againinteiro ta! \\
\hline 84 & CC and shower W shower. SENT. Room NN room includes WZ include free JJ free WiFi & & $73,343|910| 4 \%$ & $05 \% \mathbf{I}$ & $05 \%$ Itagaininteiro tą \\
\hline 85 & SENT. Each DT each guest NN guest room NN room includes WZ include : : : Refrigerator & & $81,406|998| 1 \% \mid$ & $08 \% \mathbf{l}$ & $08 \% \mathrm{l} \mathrm{ag}$ \\
\hline 86 & DT each Gold NP Gold Club NP Club room NN room includes WZ include the DT the & & $87,595485 \mid 4 \%$ & $08 \% \mathbf{l}$ & $08 \%$ Ishotelinteiro.tac \\
\hline 87 & elegant, , , this DT this lovely JJ lovely room NN room invites $W Z$ invite you $P P$ you to TO to & & $29,1198657 \%$ & $09 \%$ & $09 \%$ tagaininteiro.tạ \\
\hline 88 & himself $\mathrm{PP}$ himself , , this $\mathrm{DT}$ this room NN room lives $\mathrm{WZ}$ live up $\mathrm{RP}$ up to TO to it $\mathrm{PP}$ & & $16,538|016| 7 \% \mathbf{I}$ & $07 \%$ & $07 \% \mathrm{Ita}$ \\
\hline 89 & NN treat , , , as IN as each DT each room NN room looks $W Z$ look onto IN onto the DT & & $84,428|990| 6 \% \mid$ & $09 \%$ & $09 \%$ resortinteiro ta! \\
\hline 90 & NN firmness. SENT. This DT this room NN room looks WZ look over IN over the DT & & $40,794|398| 9 \% \mid$ & $04 \% \mathbf{I}$ & $04 \%$ Itagaininteiro tạ \\
\hline 91 & the adjoining $J J$ adjoining sitting $W G$ sit room NN room makes $W Z$ make this $D T$ this our & & $15,153|352| 9 \% \mid$ & $08 \% \mathbf{I}$ & $08 \%$ Itagaininteiro.ta! \\
\hline 92 & SENT. Our PP\$ our superior JJ superior room NN room mixes $W Z$ mix modern JJ modern & & $76,047|694| 4 \% \mid$ & $07 \%$ & $07 \%$ Ishotelinteiro.ta! \\
\hline 93 & this well RB well appointed WN appoint room NN room offers WZ offer a DT a kitchen NN & & $72,391|872| 1 \% \mid$ & $05 \% \mathbf{l}$ & $0.5 \%$ Itagaininteiro.tac \\
\hline 94 & This DT this style NN style of IN of room NN room offers WZ offer a DT a studio NN & & $61,204,700|0 \%|$ & $01 \% \mathbf{I}$ & 0 1\% resortinteiro.tą \\
\hline 95 & SENT. Each DT each guest NN guest room NN room offers $W Z$ offer a DT a variety NN & & $06,021|978| 0 \% \mid$ & $05 \% \mathbf{I}$ & $05 \%$ I shotelinteiro.ta! \\
\hline 96 & lake. SENT. The DT the living NN living room NN room offers $W Z$ offer a DT a nice JJ nice & & $61,589720 \mid 4 \% \mathbf{l}$ & $01 \% \mathbf{l}$ & $01 \%$ resortinteiro tal \\
\hline 97 & NN second-floor Concord NP Concord room NN room offers WZ offer a DT a foldout NN & & $13,6603887 \%$ & $04 \%$ & $04 \%$ tagaininteiro ta! \\
\hline 98 & NP Street NP Street ; : ; the DT the room NN room offers WZ offer a DT a deluxe JJ & & $78,810477 \mid 1 \% \mathbf{I}$ & $05 \%$ & 0 5\% Itagaininteiro.ta! \\
\hline 99 & This DT this Building NP Building $4 \mathrm{CD} 4$ room NN room offers $W Z$ offer a DT a queen NN & & $17,899|383| 3 \% \mathbf{I}$ & $01 \% \mathbf{I}$ & $01 \% \mathbf{l}$ resortinteiro.ta! \\
\hline 100 & of four CD four. SENT. Each DT each room NN room offers $W Z$ offer a DT a Queen NP & & $37,153160|2 \%|$ & $02 \% \mathbf{I}$ & $02 \%$ Itagaininteiro.ta! \\
\hline 101 & family. SENT. The DT the main JJ main room NN room offers $W Z$ offer a DT a kina NN kina & & $58.85561019 \%$ & $00 \% \mathbf{l}$ & $00 \%$ resortinteiro.tac \\
\hline
\end{tabular}

Figura 85 - Linhas de concordância parciais de offers, ordenadas pelos dois colocados à esquerda.

Assim, levantamos outras colocações verbais com uso semelhante a room features:

Room has (100), offers (73), includes (44), is equipped with (21), boasts (10)

The main room has two queen-size beds, a table and two chairs plus a work desk.

This large room offers two beautiful queen-sized beds, antique furnishings, bright morning sun - private bath right outside your door, $A / C$, refrigerator, cable $T V$, wireless internet.

Each guest room includes free high-speed Internet and cable satellite television with $H B O \circledR$.

The room is equipped with wall mounted flat screen television and DVD capabilities.

This expansive 362 square foot room boasts a private, full size bath with shower and for the clothes-horse a large walk in closet!

Destacamos essas informações adicionais no verbete.

A busca dos equivalentes em português iniciou-se pela análise de "apartamentos + verbos" no corpus etiquetado (expressão de busca: "apartamento NOM apartamento * 
V”). No entanto, encontramos diversos erros de classificação morfossintática e, por isso, optamos pelo corpus sem etiquetas.

Assim, o procedimento para identificar os colocados foi: a) análise da lista de colocados de apartamento(s); b) análise das linhas de concordância de apartamento ordenadas pelos colocados à direita; c) análise das linhas de concordância de cada verbo selecionado como candidato para verificação do contexto almejado e seleção de exemplos; d) contagem das frequências para compor a entrada.

Assim, chegamos aos seguintes equivalentes:

\section{apartamento [ser/estar] equipado com (133)}

Todos os apartamentos estão equipados com telefone, televisão de plasma, conexão para internet, cofre, mini bar, serviço de quarto 24 horas, vista mar, varanda (...).

Apartamento equipado com cama box, ar-condicionado, cofre, frigobar, telefone e TV a cabo e banheiro com ducha higiênica e secador de cabelo.

\section{possuir (74)}

Nossos apartamentos possuem ar-condicionado, frigobar, cofre, TV via satélite e a cabo, canais de som, controles de cabeceira, camas box-spring, ducha, secador, PABX inteligente e varanda com rede.

Os apartamentos possuem ar condicionado ou ventilador teto, frigobar, colchão de mola.

ter (31)

Todos os 315 apartamentos têm decoração moderna e funcional com: som ambiente, vinte e três canais de programação, ar condicionado central, TV em cores, frigobar, secador de cabelos e banheira.

Cada apartamento tem: 1 beliche e uma cama de casal, ventilador, TV (...). 


\section{Oferecer (23)}

O apartamento oferece uma deliciosa cama queen size, ar condicionado, secador de cabelo, TV a cabo com diversos canais nacionais e internacionais, cofre e conexão de internet $100 \%$ Wi-FI.

Os apartamentos oferecem todos os itens necessários ao seu maior conforto, $W C$, camas box, ar condicionado, frigobar, TV com canal de filmes, telefone, cofre, ventilador de teto, varandas com rede e vista para o mar.

\section{dispor de (20)}

Todos os nossos apartamentos dispõem de ar-condicionado, ventilador de teto, banheiro privativo, banho quente, frigobar, serviço telefônico e telas de proteção contra insetos.

Cada apartamento dispõe de: ar condicionado, banheiro, mini bar, cofre pessoal, televisão a cabo, telefone (...).

\subsubsection{Room rate}

Room rate consta 98 vezes no corpus. Além dessa colocação, identificamos variações menos recorrentes:

Nightly rate (23)

Daily rate (13)

Night's room rate (7)

Nightly room rate (4)

Analisando os contextos de ocorrência da colocação, por meio das concordâncias, constatamos naturalmente a referência aos preços das acomodações, bem como aos itens inclusos nesse valor e também advertências de valores sujeitos a alteração, dentre outras, como mostram os exemplos:

Room rates for 2011 are $\$ 194.00$ plus tax for one person and $\$ 199.00$ plus tax for two people per night.

Room rates are subject to availability and can change without prior notice. 
Our nightly room rates include expanded continental breakfast, all amenities, and WiFi access.

Para chegar ao equivalente, partimos de uma tradução prima facie que conhecíamos - diária. Obtivemos um alto número de ocorrências, 1088, somando singular e plural. Utilizamos o corpus etiquetado em português para contabilizar apenas os casos de diária como substantivo, excluindo adjetivos, como em limpeza diária. Todavia, ele apresentou diversos erros de classificação, considerando adjetivos diversos substantivos. Assim, resolvemos realizar essa pesquisa apenas com o corpus sem etiquetas.

Pelas concordâncias, identificamos contextos bastante semelhantes ao do inglês, o que atestou nossa hipótese e definimos diária como equivalente para room rate. Vale lembrar que encontramos apenas 2 ocorrências de diária do quarto e apenas 6 de diária do apartamento; portanto, essas opções não foram incluídas na relação de equivalentes.

Valor da diária: $R \$ 169,00$ (suite solteiro ou casal).

A diária inclui café da manhã servido no restaurante e 01 vaga na garagem por apartamento.

Os produtos oferecidos no frigobar não estão inclusos no valor da diária e o seu consumo deverá ser pago à parte.

Com base também no nosso conhecimento prévio bem como por meio das leituras das linhas de concordância do contexto de diária, identificamos tarifa como outro candidato a equivalente de room rate. A busca no singular e plural retornou um elevado número de ocorrências, 501. Esse número compreende variados tipos de tarifa, mas o contexto de room rate foi ampla e facilmente identificado nas linhas de concordância. Assim, tarifa também figura entre os equivalentes:

Nossas tarifas estão sujeitas a alteração sem aviso prévio.

As tarifas promocionais dependem de disponibilidade e são exclusivas da reserva online do site.

Tarifas válidas para permanência mínima de 03 noites. 
A pesquisa até aqui suscitou outras questões que julgamos interessante investigar, tendo em vista o tradutor como usuário deste glossário. Consideremos os seguintes exemplos:

Room rates are based on double occupancy, charges for additional adults and for children will be applied to the rate.

Nos feriados, será cobrado o mínimo de 03 diárias com tarifa de alta temporada.

Esses trechos poderiam apresentar problema de tradução em relação ao uso mais adequado, mais natural, de termos com sentido próximo, como tarifa, diária, em português; rate, charges, em inglês, dentre outros.

Assim, ampliamos a questão e resolvemos investigar mais detalhadamente a diferença de usos entre rate, charge, fee, cost, em inglês; diária, tarifa, taxa, custo e tarifário, em português.

\section{Rate, charge, fee, cost}

Fizemos inicialmente uma lista dos principais colocados de cada um dos termos. Também realizamos buscas dos adjetivos e substantivos que ocorrem com essas palavras por meio do corpus etiquetado.

Chegamos aos seguintes colocados principais (contabilizando singular e plural):

Rate (930): room (98), nightly (34), best available (32), special (30), group (30), corporate (15), daily (15), [off, peak] season (10), affordable (9), monthly (9), discounted (8), rack (7), online (6), extended stay (5).

Fee (536): resort (41), cancellation (36), additional (33), service (26), nominal (19), processing (19), cleaning (18), [resort] amenity (17), pet (11), parking (9), handling (8), access (5), administrative (5).

Charge (308): additional (61), full (14), room (12), service (12).

Vale mencionar que o corpus etiquetado foi bastante útil para analisar charge e charges, diferenciando os substantivos do verbo. As seguintes expressões foram utilizadas: "charge NN charge" (charge singular); "charges NNS charge" (charges 
plural); "NN * charge NN charge" (colocados nominais de charge singular); "JJ * charge NN charge" (colocados adjetivos de charge singular).

Para entender melhor o uso de charge, foi preciso investigar cada contexto mais detalhadamente, uma vez que additional, o colocado mais frequente, não esclarece a que tipo de cobrança charge se refere. Verificamos que se tratam especialmente de cobranças por pessoas extras nas acomodações, crianças nos quartos dos pais, bem como pelo uso de serviços e comodidades diversas.

Também constatamos que charge é o termo mais usado na expressão negativa no additional charge(s), com 5 ocorrências, contra apenas 1 de no additional fee. Em virtude do baixo número de ocorrências, fizemos uma busca no Google por no additional charge e no additional fee juntamente com a palavra hotel para aproximarmos o contexto. O resultado foi 23.900 .000 ocorrências com a palavra charge e 6.180.000 com fee. Ou seja, uma proporção muito aproximada ao nosso corpus charge é cerca de 4 vezes mais utilizado que fee nessa expressão.

Analisando os colocados, chegamos às seguintes conclusões:

Rate é o termo mais recorrente, usado primordialmente para referir-se ao valor cobrado pelo uso das acomodações. Além de room ser o colocado mais frequente, os outros também remetem ao uso das acomodações.

Book your room at The Virginian Suites hotel at least 14 days in advance and save at least $15 \%$ off the best available rate.

At check-in, guests paying the nightly rate will be charged for their entire stay. All rooms at this special rate include breakfast \& happy hour for up to 2 guests.

Fee é um termo mais específico, refere-se principalmente ao valor cobrado para usar determinado serviço, instalação, comodidade, ou como multa ou penalidade.

Your resort fee includes the following amenities: USA Today delivered every weekday morning, in-room high-speed Internet access, fitness center access, 2 bottles of water per day in guest room (...).

If you smoke, you will be charged a substantial cleaning fee to return the room to its proper condition.

Cancellation is $6 \mathrm{pm}$ day of arrival to avoid a cancellation fee of one night's room and $\operatorname{tax}$. 
Charge é um termo mais genérico, empregado frequentemente para se referir à cobrança adicional, em especial, por pessoa extra, serviços, comodidades. É o termo preferencial na expressão for/at no additional charges.

The sitting room has a comfortable sofa bed that may accommodate a third person for an additional charge.

All rooms with microwave and fridge for no additional charge.

These services and amenities are subject to availability. Additional charges may apply. Age limits for children occupying parents' or guardians' guest rooms at no additional charge may vary at some properties.

\section{diária, tarifa, taxa, custo, tarifário}

Identificar os diferentes padrões de uso entre os termos acima se mostrou mais trabalhoso em português do que inglês.

A etapa inicial foi procurar relacionar os principais colocados de cada termo. Em seguida, analisamos os contextos, por fim, traçamos as generalizações de uso.

\section{Diária}

Apresentamos os colocados das palavras no singular e plural separadamente, em virtude do grande número de ocorrências e diferentes padrões:

Diária (586): incluso [na diária] (90), valor [da diária] (60), incluído [na diária] (29), [diária, de/para] casal (18), primeira [diária] (27), [a diária] inclui (14), [diária por/do/em] apartamento (12), meia [diária] (11).

Diárias (503): [diárias] incluem (42), mínimo [de/número diárias] (33), total [das/de diárias] (26), valor [das/de diárias] (25), a partir de [número diárias] (9), número de [diárias] (11), [diárias] começam (12), [diárias] iniciam (10), [diárias] com café da manhã (9), inclusos [nas diárias] (9), [diárias] a partir de [preço] (8), incluídos [nas diárias] (7), [diárias] promocionais (6). 
A análise dos colocados acima e das linhas de concordância nos permitiu identificar três acepções diferentes de diária(s):

a) valor pago pelo uso da acomodação: $81 \%$ das ocorrências de diária (476) e $58 \%$ de diárias (294)

Para o periodo de baixa estação, o hotel solicita o pré-pagamento de 1 diária para garantir a reserva.

Forma de pagamento: pagamento antecipado de 100\% do valor total das diárias no ato da confirmação.

b) dias / estada no hotel: 5\% das ocorrências de diária (35) e 25\% de diárias (129) 6 diárias em confortáveis apartamentos com TV a cores, ar condicionado, chuveiro elétrico, fribogar e varanda com mesinha frente à piscina.

Diárias românticas, com direito ao delicioso "Festival de Inverno" e suite especial! Comentários valem diárias no Bavária Sport Hotel.

c) horário de check-in e check-out: 4,5\% das ocorrências de diária (27) e 10\% de diárias (52)

As diárias começam e terminam ao meio-dia.

As diárias se encerram às 12:00 (check-out) e se iniciam às 14:00 (check-in).

Podemos concluir que diária refere-se primordialmente ao preço pago para uso das acomodações, mas também ao período de estadia no hotel (cada 24 horas) e ao horário de início e encerramento desse período (check-in e check-out).

Ao consultar a definição de diária no glossário especializado "Vocabulário para Turismo" (Garcia, 2004: 35), nos surpreendemos ao notar as três acepções destacadas acima presentes na definição:

"Entende-se por diária o preço de hospedagem correspondente à utilização da unidade habitacional e dos serviços incluídos [acepção a], por um período básico de 24 horas [acepção b], observados os horários fixados para entrada (check-in) e saída (check-out) [acepção c]."

No entanto, o dicionário traz apenas uma sugestão de tradução para o inglês: daily rate, justamente a opção menos frequente no corpus.

As diferentes acepções têm naturalmente implicações para a tradução. Consideremos o exemplo a seguir: 
Caso deseje hospedar-se por um maior número de dias, basta multiplicar o valor da diária normal acima pelo número de diárias.

A diária tem término às 14:00h do dia seguinte, quando o hóspede deve desocupar o quarto, podendo permanecer no hotel até às 17:00h sem custo adicional. Caso deseje continuar no quarto será cobrada outra diária.

Com base nas constatações acima, podemos afirmar que cada diária no período tem uma tradução diferente no inglês, pois guardam acepções distintas. Assim:

Caso deseje hospedar-se por um maior número de dias, basta multiplicar o valor diária normal [regular room rate] acima pelo número de diárias [nights].

*A diária tem término [check-out is at] às 14:00h do dia seguinte, quando o hóspede deve desocupar o quarto, podendo permanecer no hotel até às 17:00h sem custo adicional. Caso deseje continuar no quarto será cobrada outra diária [room rate].

\section{Tarifa}

Os principais colocados são:

tarifa (158): [tarifa] balcão (18), [tarifa] válida (9), promocional (6), [tarifa] especial (6), [tarifa] inclui (7).

tarifas (501): especiais (26), [tarifas] sujeitas a [alteração(ões)] (22), válidas (21), promocionais (11), [tarifas] e reservas (12), [tarifas] e pacotes (10), [tarifas] diferenciadas (7), [tarifas] incluem (7), [tarifas] balcão (5).

clusters: tarifas, reservas, localização / tarifas, promoções, reservas / tarifas, reservas, contatos

Chamaram-nos a atenção os padrões tarifas e reservas e tarifas e pacotes, juntamente com tarifas, reservas, localização / tarifas, promoções, reservas / tarifas, reservas, contatos. Todas essas ocorrências são provenientes de uma mesma parte do texto, a qual denominamos site e que traz as abas (seções) de cada site. Ou seja, além das colocações acima, podemos afirmar que tarifas também é usado nos sites para destacar os preços das acomodações.

Conclui-se que tarifa(s) está relacionado ao preço cobrado pelo uso das acomodações, assim como diária, porém com destaque a alguma especificidade - tarifa 
balcão, tarifa promocional, tarifas especiais. No plural, é a forma mais utilizada nas abas dos sites de hotéis.

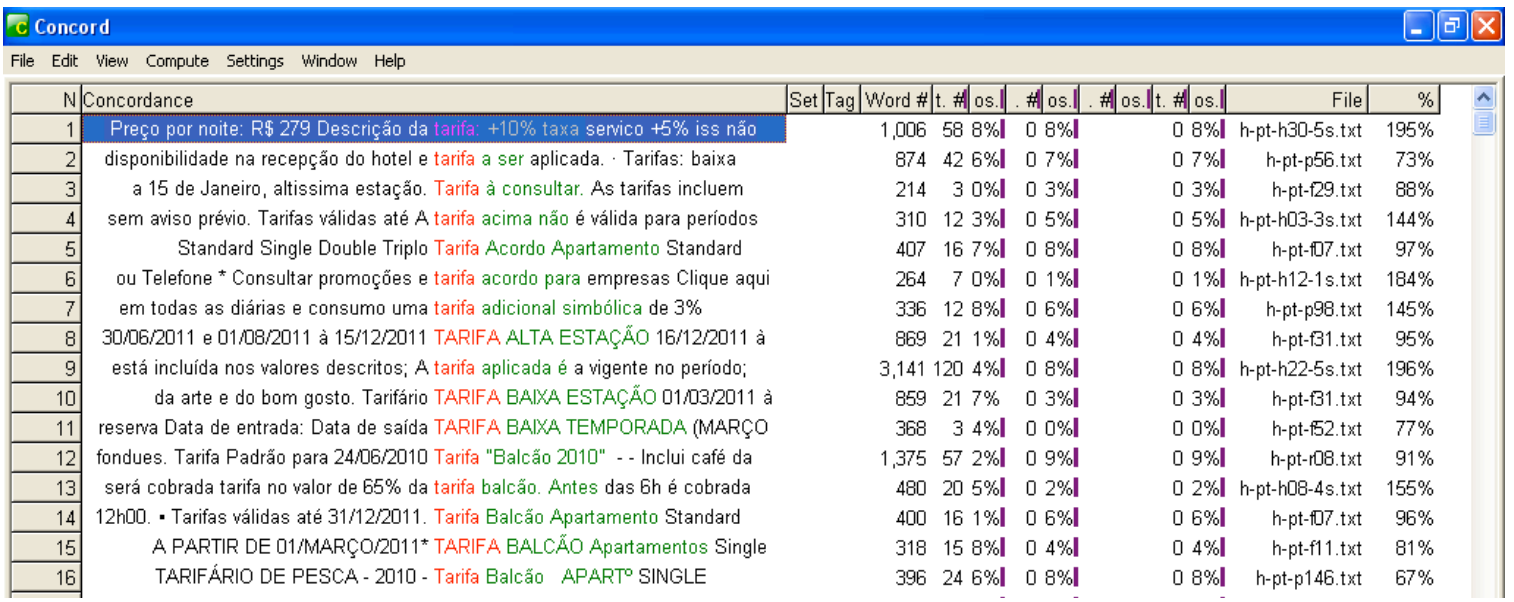

Figura 86 - Linhas de concordância parciais de tarifa, ordenadas pelos dois colocados à direita.

\section{Taxa}

Principais colocados:

Taxa (450): de serviço (169), de turismo (39), adicional (25), de ISS (9), administrativa (8), de higienização (4), de cancelamento (4), de no show (3).

Cobramos taxa de serviço de 10\% sobre os extras. Além disso, é cobrada uma taxa de turismo no valor de $R \$ 1,50$, que será repassada ao Convention Bureau da cidade.

Nos preços serão acrescidos $10 \%$ de taxa de serviços e 5\% de ISS.

É cobrada taxa de turismo (room tax) de $R \$ 2,30$ (opcional).

Analisando os colocados bem como suas concordâncias, concluímos que:

Taxa é um termo mais específico, relacionado principalmente a encargos e impostos, como taxa de serviço e taxa de turismo. 


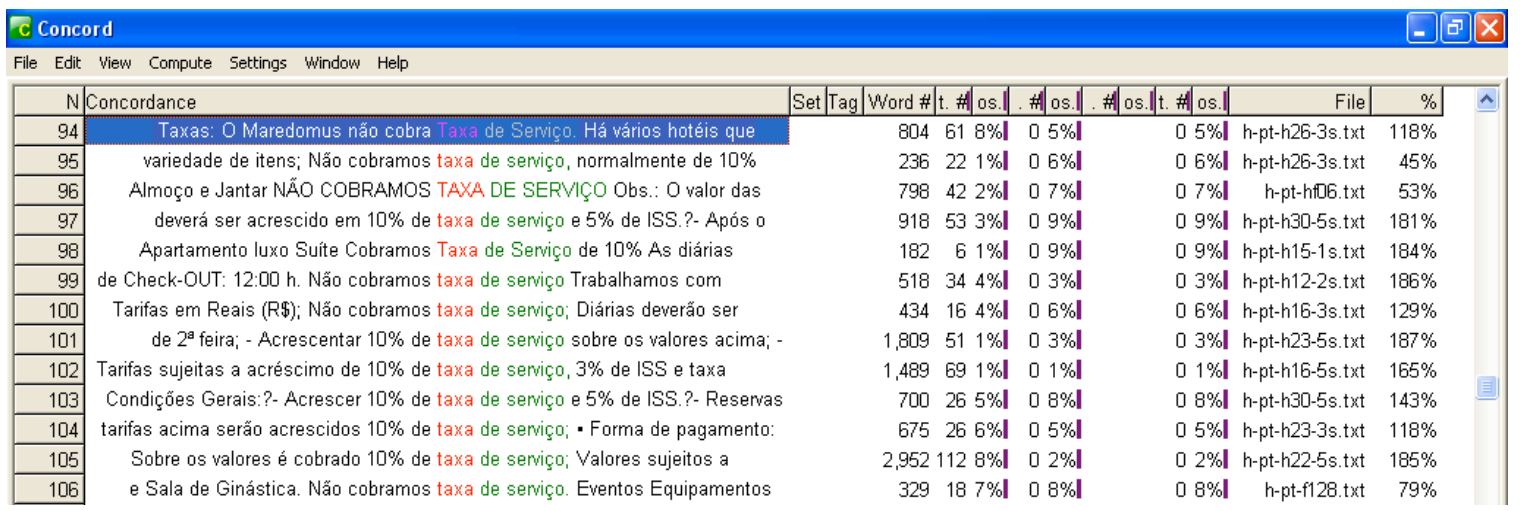

Figura 87 - Linhas de concordância parciais de taxa, ordenadas pelos dois colocados à direita.

\section{Custo}

Principais colocados (singular e plural):

Custo (130): adicional (49), sem [custo] (41), extra (19)

Constatamos que mais da metade das ocorrências de custo refere-se a custo adicional e custo extra (68 de 130). Aprofundamos a pesquisa dos contextos para identificar que tipo de cobrança adicional é essa. Vejamos alguns exemplos:

Política para crianças: máximo 2 crianças menores de 12 anos de idade no mesmo apartamento dos pais sem custo adicional.

As atividades listadas abaixo não têm custo adicional e podem ser realizadas a qualquer momento de sua estadia conosco: pesca, tênis, caminhada, cinema, fitness centre (...)

Alguns serviços possuem custo adicional. Informe-se na recepção durante o check-in.

Assim:

Custo é um termo mais genérico, utilizado sobretudo para referir-se a uma cobrança extra estabelecida pelo hotel por serviços e atividades em geral. Destaque para a expressão sem custo adicional.

\section{Tarifário}

Principais itens na lista de colocados:

Tarifário (136): localização (30), contato (21), fotos (21), reservas (19), tarifário ano (9), sujeito a [alteração] (5)

Os colocados mais recorrentes de tarifário parecem não estar relacionados semanticamente. Isso se explica pelo fato de serem provenientes da seção < site> do 
texto, que indica as abas dos sites. Assim como tarifas, o termo é preferencialmente empregado das divisões ou abas dos sites, como mostra a imagem a seguir:

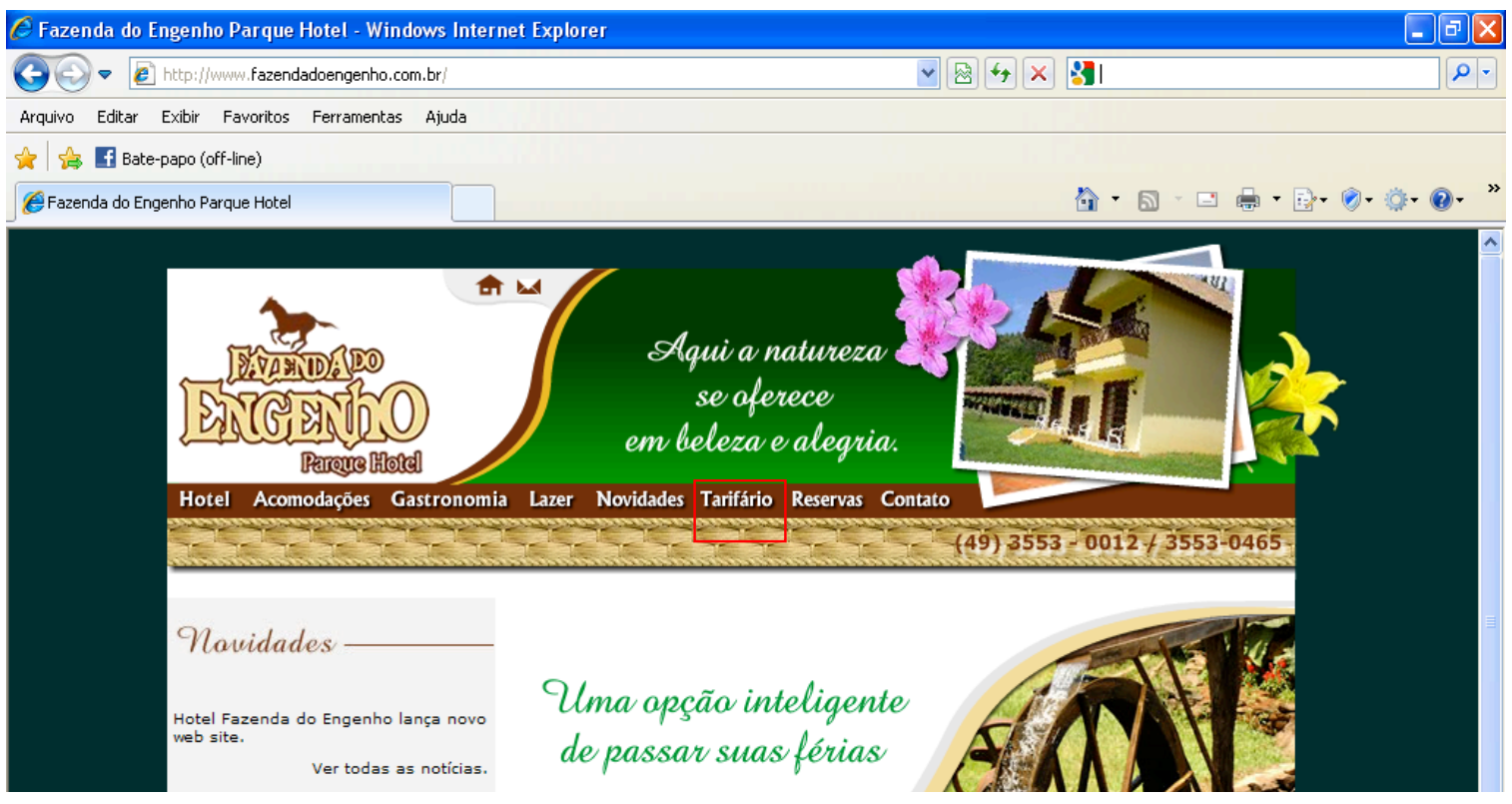

Figura 88 - Site de estabelecimento hoteleiro no Brasil. No destaque, o uso de tarifário.

Tarifário refere-se ao conjunto ou tabela de preços pelo uso das acomodações do hotel. É principalmente utilizado nas abas dos sites para que o interessado consulte o valor das diárias.

Todas as informações levantadas acima, tanto no inglês - rate, fee, charge, costcomo no português - diária, tarifa, taxa, custo, tarifário -, são organizadas na forma de Você sabia? no verbete, com exemplos, fornecendo ao tradutor uma listagem de fácil visualização dos termos relacionados ao que ele buscou inicialmente.

\subsubsection{Room service}

A colocação room service é encontrada 125 vezes no corpus. Na lista de clusters de room, identificamos outra colocação sinônima - in-room dining -, com 64 ocorrências. Ambas designam o serviço de oferecer refeições no apartamento do hóspede: 
If you're not interested in sampling one of New York's many restaurants, stay in and order room service from 6am-11am for breakfast and 5pm-12 midnight for dinner at The Roosevelt Hotel.

Room service is open for: breakfast, lunch, dinner.

Four Seasons In-Room Dining is a fine-dining experience within the comfort and convenience of your guest room or suite. It is ideal for time-zone-hopping travellers, impromptu meetings or simply for quiet, private dining. Choose from an extensive menu, day or night.

In-room dining is open for breakfast, lunch and dinner.

Em português, investigamos os usos de serviço de quarto, bem como da própria colocação em inglês, room service. Interessante constatar que o número de ocorrências de room service - 178 - é mais que o dobro de serviço de quarto - 78. Ou seja, os estabelecimentos no Brasil utilizam preferencialmente room service. Os exemplos abaixo ilustram o contexto:

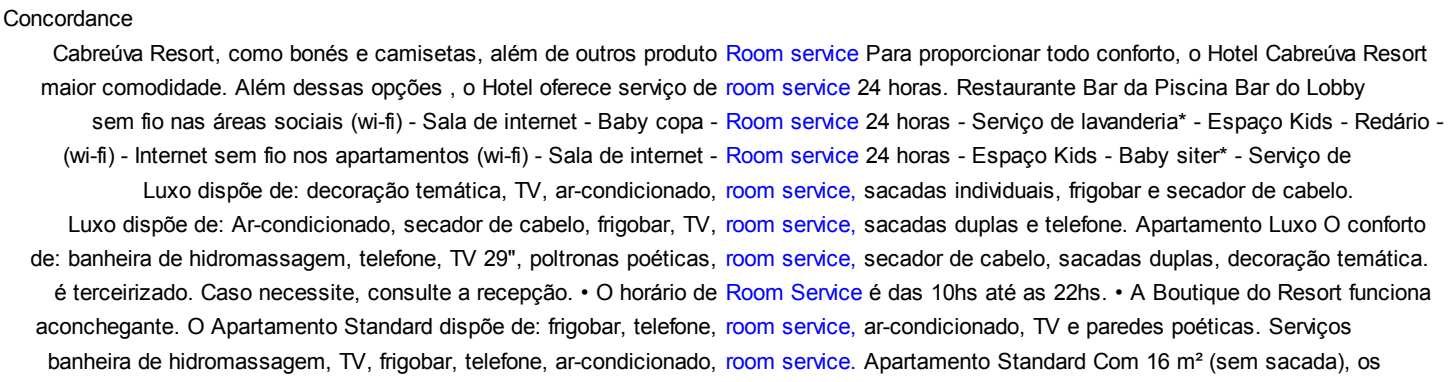

Figura 89 - Linhas de concordâncias parciais de room service, em português.

As duas colocações, room service e in-room dining, integram ainda uma colocação maior: 24-hour room service (20) e 24-hour in-room dining (9). Em português, as linhas de concordância ordenadas pela esquerda apontaram os equivalentes room service 24 horas (94) e serviço de quarto 24 horas (24), respectivamente.

\subsubsection{Spacious room}

Spacious é um dos adjetivos mais frequentes no corpus, com 573 ocorrências. A colocação spacious room(s) aparece 35 vezes, além de 18 casos de spacious guest room. 
A fim de verificar a ocorrência significativa de outros adjetivos com sentido semelhante, analisamos a lista de colocados de room e identificamos large room, com 7 ocorrências, e oversized room, com 6. Interessante notar a ausência de big na lista. Incluímos essas opções na seção de Variações no verbete.

These spacious rooms delight guests with their antique furnishings and warm wood tones.

This large room offers two beautiful queen-sized beds, antique furnishings, bright morning sun -- private bath right outside your door.

This comfortable, oversized room offers two queen beds with a separate sitting area.

Para chegar ao equivalente, consultamos inicialmente a lista de adjetivos mais comuns no corpus em português elaborada para a entrada comfortable room (item 4.1.4). A partir dessa lista, selecionamos os seguintes candidatos a equivalentes: amplo (524), grande (511), espaçoso (99).

Gerando listas de concordância para cada um dos adjetivos, constatamos que apartamento se coloca mais frequentemente com amplo (57), seguido de espaçoso (11) e, por fim, grande (1). Em função do baixo número, descartamos grande como equivalente.

\subsubsection{Standard room}

O corpus apresentou 42 ocorrências de standard room, além de 25 de standard guest rooms. Assim como deluxe room, trata-se de uma categorização do tipo de apartamento, em geral a categoria mais básica ou padrão do hotel.

Para encontrar o equivalente, partimos de uma tradução prima facie, “apartamento standard”, obtendo 77 ocorrências: 


\begin{tabular}{|c|c|c|c|c|c|c|}
\hline \multicolumn{6}{|c|}{ c Concord } & \multirow[t]{2}{*}{$\theta \underline{x}$} \\
\hline File Edi & Edit View Compute Settings Window Help & & & & & \\
\hline \multicolumn{2}{|r|}{ N Concordance } & \multirow[t]{2}{*}{ Set Taqly } & Word \#|t. \# os. $\mid$ & \multicolumn{2}{|c|}{ 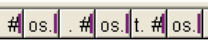 } & $\hat{=}$ \\
\hline 1 & 1 *1 (um) Apartamento Master, na Sede; *1 (um) Anartamento Standard na Sede; 2 (dois) & & $43 \%$ & $02 \%$ & $02 \%$ & h-pt-hf1 \\
\hline 2 & de voz, rádio, TV a cabo, internet e cofre digital. Apartamento Standard Podem ser single ou twin e & 216 & $88 \%$ & $01 \%$ & $01 \%$ & h-pt-h01-2 \\
\hline 3 & aceitamos animais domésticos. - Somente o Apartamento Standard Villa do Jardim, Loft Villa & 873 & $519 \% \mathbf{I}$ & $08 \%$ & $08 \% \mathbf{I}$ & h-pt-h04-5 \\
\hline 4 & e ampla varanda com $37 \mathrm{~m}^{2}$. (Quantidade: 1) Apartamento Standard (30 m²): Localizados na & 483 & $266 \%$ & $09 \%$ & $09 \% \mathbf{I}$ & h-pt-h04-5 \\
\hline 5 & varanda (acomoda ate 6 pessoas com conforto) Apartamento Standard Acomodaçẫo para casal & 382 & $99 \% \mathbf{I}$ & $01 \%$ & $01 \% \mathbf{I}$ & h-pt-hf14 \\
\hline 6 & que chegar o turista, já escolhe o que fazer. Apartamento Standard :.. Os Apartamentos & 164 & $77 \%$ & $06 \%$ & $06 \% \mathbf{I}$ & $h-p t-h+5$ \\
\hline 7 & - Apartamento standard duplo ou triplo; - Apartamento standard triplo ou quádruplo; - & 399 & $280 \%$ & $02 \%$ & $02 \% \mathbf{l}$ & h-pt-hf7 \\
\hline 8 & e chuveiros com aquecimento solarlenha. - Apartamento standard duplo ou triplo; & 393 & $283 \%$ & $01 \%$ & $01 \% \mathbf{I}$ & h-pt-hf7 \\
\hline 9 & NOITE DE NÚPCIAS STANDARD - Apartamento standard - Champagne - Bombons - & 621 & $137 \% \mathbf{I}$ & $05 \%$ & $05 \% \mathbf{I}$ & h-pt-f3 \\
\hline 10 & que sẫo prioridades do Apart Hotel. Tarifas Apartamento Standard Ar-condicionado, TV aberta & 236 & $117 \%$ & $08 \%$ & $08 \%$ & h-pt-f4 \\
\hline 11 & Estacionamento fechado (segurança 24 horas) Apartamento Standard Casal ou Duplo Amplo & 168 & $56 \% \mathbf{I}$ & $07 \%$ & $07 \% \mathbf{I}$ & $h-p t-f 3$ \\
\hline 12 & A parte superior possui a mesma estrura do apartamento Standard. Varanda Banheiro Todos & 93 & $21 \%$ & $06 \%$ & $06 \%$ & h-pt-hf13 \\
\hline 13 & Apartamentos Standard, Superior e Luxo Apartamento Standard Localizado no 10, 20 e 30 & 197 & $78 \%$ & $06 \%$ & $06 \%$ & h-pt-h11-3 \\
\hline 14 & privilégio de hospedá-lo, estamos à sua espera. Apartamento standard Conforto e bem estar, & 441 & $138 \% \mathbf{I}$ & $03 \%$ & $03 \% \mathbf{I}$ & h-pt-h23-5 \\
\hline 15 & para internet, cofre-individual e som ambiente. Apartamento Standard São ótimos apartamentos & 313 & $126 \%$ & $06 \%$ & $06 \%$ & h-pt-h23-3 \\
\hline 16 & superior, suite superior e suíte luxo superior. Apartamento Standard · Tv a cabo • Frigobar • & 132 & $51 \%$ & $06 \%$ & $06 \% \mathbf{I}$ & h-pt-h17-4 \\
\hline 17 & apartamentos: 1 suite, 8 apartamentos Luxo e 1 apartamento Standard. Nossos apartamentos săo & 111 & $35 \%$ & $04 \%$ & $04 \%$ & h-pt-h15-1 \\
\hline 18 & aliados a bom gosto e praticidade, é o que o Apartamento Standard oferece. Numa área de & 457 & $131 \% \mathbf{l}$ & $04 \%$ & $04 \%$ & h-pt-h23-5 \\
\hline
\end{tabular}

Figura 90 - Linhas de concordâncias parciais de apartamento standard.

Nas imediações das colocações, tanto em inglês como em português, observamos frequentemente menção a outras categorias de acomodações (linha 13 na figura acima), como luxo, superior, single, ou deluxe, master, executive. Seriam essas categorias semelhantes entre os dois idiomas? Quais seriam as mais frequentes? Acreditamos que essa é uma questão com a qual o tradutor pode deparar, dada a alta frequência dessas estruturas no corpus. Assim, prosseguimos com uma pesquisa sobre as categorias de apartamento, cujos resultados são incluídos na seção Você sabia?. Vale ressaltar que o intuito não foi estabelecer equivalentes tradutórios entre as categorias, mas levantar as mais recorrentes nos dois idiomas.

Essa pesquisa foi trabalhosa, em função da dificuldade de se estreitar as buscas, uma vez que os nomes das categorias poderiam ser qualquer adjetivo (como presidencial ou nupcial) ou substantivo (solteiro ou casal). Além disso, foi preciso analisar dois termos dos mais frequentes no corpus em ambos os idiomas apartamentos e suites, rooms e suites.

Assim, optamos por analisar na íntegra as listas de colocados de cada palavra, selecionando nomes que julgamos representativos das categorias. Em seguida, geramos linhas de concordância de cada candidato. Ao ler essas linhas, frequentemente deparávamos com outros nomes de categorias, para os quais foram geradas novas linhas de concordância. Outro fator de dificuldade foi a sobreposição de categorias, por exemplo, em Deluxe Double Queen room. Decidimos contabilizar apenas as categorias mais gerais, mais "padrão". Assim, realizamos um grande levantamento, mantendo 
apenas os nomes recorrentes e descartando as especificidades de cada estabelecimento, o que tornaria a lista extensa demais.

A seguir, os resultados em ordem decrescente de frequência:

\begin{tabular}{|c|c|}
\hline \multicolumn{2}{|c|}{ Principais categorias de apartamentos e suítes } \\
\hline Português & Inglês \\
\hline Apartamento luxo (120) & Standard room (42) \\
Apartamento standard (78) & Deluxe room (40) \\
Apartamento superior (68) & King room (39) \\
& Queen room (27) \\
Apartamento casal (53) & Double room (16) \\
Apartamento duplo (47) / double (20) & \\
Apartamento single (49) / solteiro (23) / & \\
individual (11) & \\
Apartamento triplo (67) & \\
Apartamento quádruplo (20) & Executive suite (62) \\
\hline Suíte máster (85) & Deluxe suite (38) \\
Suíte luxo (69) & Luxury suite (36) \\
Suíte presidencial (41) & Presidential suite (36) \\
Suíte junior (23) & Junior suite (31) \\
Suíte executiva (18) & Penthouse suite (30) \\
Suíte standard (15) & Master suite (27)) \\
Suíte nupcial (15) & Family suite (20) \\
Suíte casal (14) & Grand suite (17) \\
& (14) \\
\hline
\end{tabular}

Figura 91 - Principais categorias de apartamentos e suítes, em inglês e português.

Como pode ser observado na tabela, as categorias apresentam algumas semelhanças (por ex.: apartamento standard - standard room / suite executiva executive suite / suite máster - master suite / suite presidencial - presidential suite) e muitas diferenças, tanto nas denominações como nas frequências.

Interessante observar que, em português, apartamento single é mais utilizado que apartamento solteiro ou individual, mas apartamento duplo é mais comum que double. Frequentemente, encontramos a sequência: apartamento single e duplo ou single, double e triplo.

Entretanto, o que nos chamou mais a atenção foi a ausência de single room na tabela em inglês, colocação encontrada apenas 3 vezes no corpus em inglês, mas bastante frequente em português (83). 


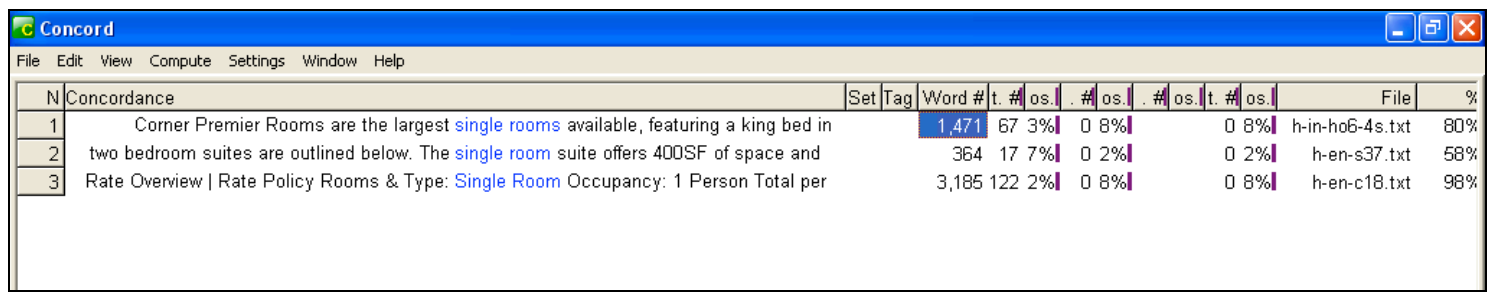

Figura 92 - Linhas de concordância de single room.

Os dados que analisamos não explicam claramente essa diferença. De qualquer forma, podemos afirmar que estamos diante de um aspecto cultural: em português, o nome da categoria dá ênfase ao número de pessoas no apartamento; ao passo que, em inglês, a preocupação maior é especificar o tipo de cama, uma vez que king room faz referência à cama king size e queen room à cama queen size.

Our bright and spacious queen rooms are an oasis of comfort. Decorated in a traditional Italian style decor, these rooms include two comfortable queen size beds, a 27" television with premium cable channels.

Tipos de acomodações: apartamento single, apartamento duplo, apartamento, triplo, apartamento quádruplo. Todas as acomodações possuem ar condicionado, cofre, cozinha, frigobar, sala, telefone, TV a cabo.

Conforme mencionamos, esses dados vão compor a seção Você sabia? do verbete.

\subsubsection{Steam room}

Steam room(s) consta 53 vezes no corpus. Para identificar o equivalente, partimos da tradução prima facie - sauna.

Contabilizamos um alto número de ocorrências de sauna(s), 427; dentre elas, 115 de sauna seca, 59 de sauna a vapor e 29 de sauna úmida. Portanto, nota-se que na grande maioria das vezes sauna aparece isoladamente. Nesses casos, não fica claro pelo contexto se estamos falando de sauna seca ou a vapor, diferentemente do inglês, em que steam room é claramente sauna a vapor. Por esse motivo, optamos pelos equivalentes sauna a vapor (59) e sauna úmida (29). 


\begin{tabular}{|c|c|c|c|c|c|c|c|}
\hline c Conco & & & & & & - & \\
\hline File Edit & View Compute Settings Window Help & & & & & & \\
\hline$N$ & Concordance & \begin{tabular}{|l|l|l|} 
Set & Tag & Word \# \\
\end{tabular} & t. \#| os. $\mid$ & H. os.l| & H| os.l|t. $\# \mid$ os. || & File & \\
\hline 1 & térmica coberta, terraço para tomar sol, sauna, 2 salas de massagem, sala de hidro & 1,383 & $533 \%$ & $03 \%$ & $03 \%$ & h-pt-h22-5s.txt & \\
\hline 2 & completa Sala de eventos Sala de ginástica Sauna $3 \mathrm{~km}$ do centro da cidade $5 \mathrm{~km}$ do & 152 & $29 \%$ & $06 \%$ & $06 \%$ & h-pt-25.txt & \\
\hline 3 & de bocha, 3 lagos para pesca e pedalinhos, sauna, 3 piscinas externas, mais uma coberta & 411 & $243 \%$ & $08 \%$ & $08 \%$ & h-pt-hf80.txt & \\
\hline 4 & TRYP Naçoes Unidas Piscina Fitness center Sauna 6 Salas de Reuniôes com capacidade & 352 & $86 \%$ & $08 \% \mid$ & $08 \%$ & h-pt- $-966 . t x t$ & \\
\hline 5 & Sẫo duas piscinas, ambas com sauna a lenha e sala de repouso; salẫo de & 372 & $113 \% \mid$ & $09 \%$ & $09 \%$ & h-pt-hf71.txt & \\
\hline 6 & de jogos Trilhas ecológicas Redário Bosques Sauna a lenha É um verdadeiro encontro com & 407 & $158 \%$ & $05 \%$ & $05 \% \mathbf{l}$ & h-pt-hf142.txt & \\
\hline 7 & e ainda podendo nadar e tomar aquela sauna a todo vapor! Lagos p/ Pesca Próximo a & 631 & $225 \% \mid$ & $00 \%$ & $00 \% \mathbf{l}$ & h-pt-hf141.txt & \\
\hline 8 & e SPA de hidromassagem aquecidos, sauna a vapor, e uma charmosa área de & 189 & $49 \%$ & $00 \%$ & $00 \%$ & h-pt-p46.txt & \\
\hline 9 & com serviço completo: Piscina, sauna a vapor e hidromassagem fria. Piscina & 573 & $184 \%$ & $05 \%$ & $05 \%$ & h-pt-p140.txt & \\
\hline 10 & A Pousada Afrika dispốe de piscina, sauna a vapor, quartos com vista para o mar & 160 & $52 \% \mathbf{I}$ & $07 \%$ & $07 \%$ & h-pt-p144.txt & \\
\hline 11 & Piscina térmica coberta e com cascata Sauna a vapor Jardim da piscina com espelho & 1,413 & $441 \%$ & $09 \%$ & $09 \%$ & h-pt-h21-5s.txt & \\
\hline 12 & - Estacionamento $\cdot$ Garagem Privativa $\cdot$ Sauna a vapor $\cdot$ Piscina $\cdot$ Praia . & 160 & $23 \%$ & $03 \% \mid$ & $03 \%$ & h-pt-p136.txt & \\
\hline 13 & a Pousada Temática Arraial Velho possui sauna a vapor, sala de leitura, chafarizes, & 351 & $84 \%$ & $09 \%$ & $09 \%$ & h-pt-p28.txt & \\
\hline
\end{tabular}

Figura 93 - Linhas de concordância de sauna, ordenadas pelos dois colocados à direita.

Consideramos relevante mencionar na Nota ao tradutor a necessidade de especificar sauna seca ao traduzir sauna em inglês, uma vez que steam room é a sauna a vapor.

Analisando as linhas de sauna em português, notamos que ao serem mencionados os dois tipos de sauna, existe uma preferência pela ordem sauna seca e a vapor (13) ou sauna seca e úmida (18). Ou seja, a ordem dos elementos da colocação é convencionalizada, pois não há nenhuma ocorrência de sauna a vapor e seca e apenas 2 de sauna úmida e seca. Também julgamos interessante incluir esse dado na Nota ao tradutor.

\subsubsection{Treatment room}

A colocação treatment room(s) aparece 37 vezes no corpus. Trata-se de uma sala, especialmente parte de um spa, destinada a tratamentos estéticos, massagens, dentre outros.

Everyone deserves a little $R \& R$, especially in Sin City. From body treatments to facials, and massages to waxing in one of our treatment rooms, everything you need to rejuvenate after a great night getting your fantasy on is a phone call away.

Elevate your senses to the next level as our certified and experienced spa professionals provide signature treatments in our 6,000-square-foot spa, featuring ten treatment rooms. 
Para identificar o equivalente, partimos de uma tradução prima facie com a palavra tratamento. Analisamos as 115 concordâncias ordenadas pelos colocados à esquerda e encontramos duas ocorrências de sala de tratamento, também parte de um spa:

O Spa possui 07 salas de tratamento, sendo dois ofurôs à Beira do Rio, uma Sala Conjugada, onde você poderá fazer seu tratamento a dois, Sala de Cromoterapia, Sala de Névoa, onde você faz sua massagem envolta em uma névoa de água, experimentando uma sensação especial de relaxamento.

\begin{tabular}{|c|c|c|c|}
\hline \multicolumn{3}{|c|}{ c Concord } & \multirow[t]{2}{*}{ 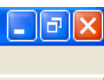 } \\
\hline File Edit & View Compute Settings Window Help & & \\
\hline \multicolumn{2}{|c|}{ N Concordance } & Set $\mid$ Tag $\mid$ Word \# $\mid$ t. \# os. || & H. os. l. t. A \\
\hline 32 & tornando a própria existência uma arte. Opçốes de tratamento DRENAGEM LINFÁTICA E MANUAL & $824 \quad 405 \%$ & $09 \%$ \\
\hline 33 & 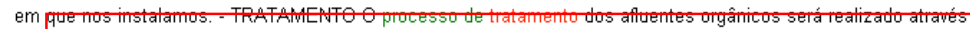 & $907317 \%$ & $06 \%$ \\
\hline 34 & cdntemporâneo e decoraçẫo clean com cinco salas de tratamento, duas suítes para tratamentos simultâneos, & $1,585796 \%$ & $06 \%$ \\
\hline 35 & loja com produtos exclusivos. O Spa possui 07 salas de tratamento, sendo dois ofurôs à Beira do Rio, uma Sala & $520246 \%$ & $04 \%$ \\
\hline 36 & \multirow{2}{*}{ 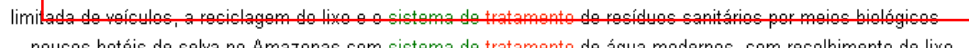 } & $267 \quad 58 \% \mathbf{l}$ & $09 \%$ \\
\hline 37 & & $90 \%$ & $01 \% \mathbf{l}$ \\
\hline 38 & resort. Săo iniciativas como reflorestamento, sistema de tratamento de esgoto de última geraçăo, central de & $44 \%$ & $04 \%$ \\
\hline 39 & - Eneraia solar nara acuecimento de ácua - Sistema de tratamento de efluentes anrovado nela CETESB - Pocos & F $5 \%$ & ח $3 \% \mathbf{I}$ \\
\hline
\end{tabular}

Figura 94- Linhas de concordância de tratamento, ordenadas pelos dois colocados à esquerda.

Verificamos que os principais usos de tratamento dizem respeito aos tipos de serviços oferecidos nos spas ou salões de beleza: tratamento facial (9), tratamento estético (5), tratamento estético (7), tratamento de beleza (3). Entretanto, analisando cada linha de concordância, não identificamos a menção ao local onde esses tratamentos são realizados. Foi possível constatar apenas os dois exemplos acima no contexto que buscamos e uma ocorrência de suites para tratamento. Dessa forma, apesar da diferença no número de ocorrências (37 em inglês e 2 em português), adotamos sala de tratamento como equivalente de treatment room.

\subsubsection{Well-appointed room}

O corpus apresentou 13 ocorrências de well-appointed room(s) e 4 de wellappointed guest room(s). Iniciamos a pesquisa confirmando o significado de appointed no dicionário:

Appoint $=$ To furnish; equip: a house that is comfortably appointed.

[Free Online Dictionary: http://www.thefreedictionary.com/appoint] 
O verbo tem, portanto, acepções semelhantes relacionadas ao contexto de um apartamento de hotel: decorar (mobiliar) e equipar.

Relax in a well appointed room or suite with cable TV, CD player and luxury linens.

Enjoy the pure elegance of this well-appointed room on the first floor.

No primeiro exemplo acima, well-appointed está mais relacionado ao sentido de "equipado", em virtude da menção aos itens no apartamento. No segundo exemplo, transparece a noção de "decorado", em função de pure elegance.

Identificamos três colocações com appointed room em que o sentido de decorado parece ser o prevalente, pois os adjetivos relacionam-se ao requinte das acomodações.

Beautifully appointed room (6)

Experience the luxury of our beautifully appointed rooms, inventive cuisine, pampering body massage treatments, and a boutique of local wares and crafts.

\section{Elegantly appointed room (4)}

Relax and repose in these elegantly appointed rooms, featuring a delightful array of amenities ensuring a restful stay.

\section{Luxurously appointed room (2)}

Here you'll find luxuriously appointed rooms providing you with a charming country feeling not found at any other Midwestern resort.

Em posse dessas informações, iniciamos a busca pela lista de colocados de apartamento(s), a partir da qual selecionamos: equipado (94), decorado (27) e mobiliado (12).

O passo seguinte foi analisar as concordâncias de cada um desses adjetivos. Assim, fizemos um levantamento das principais colocações adverbiais contendo tais adjetivos, dentro do contexto de acomodações. Vale lembrar que nem sempre foi possível identificar a colocação direta, ou seja, base e colocado na sequência. 
Consideramos também os casos em que o advérbio ou adjunto adverbial estava nas imediações do adjetivo, conforme exemplos a seguir.

Validamos os equivalentes a seguir, tanto na acepção de "equipado" como de “decorado", e incluímos uma Nota ao tradutor no verbete alertando para essa diferença. Appointed: no sentido de "equipado".

\section{equipado}

\section{totalmente equipado (8 ocorrências no contexto)}

Bem estar, localização, segurança e privacidade. É isso e muito mais que você vai desfrutar no Ômega Flat. São 42 apartamentos de padrão superior, totalmente equipados e mobiliados, com espaços internos bem divididos.

\section{bem equipado (4)}

Lider na hotelaria da América Latina, o Crowne Plaza oferece a seus hóspedes uma atenciosa equipe, apartamentos modernos e bem equipados, pacote completo para negócios, além de ótimas opções de gastronomia.

Appointed no sentido de "decorado" ou "mobiliado":

\section{Decorado}

\section{bem decorado (11)}

Apartamento com uma área de $52 \mathrm{~m}^{2}$, bem decorado, aconchegante e com a total privacidade que você merece.

cuidadosamente decorado (6)

Apartamento cuidadosamente decorado com flores, pétalas de rosas e sais de banho.

\section{decorado com requinte (5)}

São 112 apartamentos decorados com requinte e charme em um ambiente agradável e sofisticado, todos equipados com 1 linha telefônica, banheira, mesa de trabalho (...)

finamente decorado (4) 
São 163 apartamentos finamente decorados e equipados com: Telefone, televisão, arcondicionado, mini-bar, cofre individual (...)

\section{decorado com bom gosto (4)}

Decorados com muito bom gosto em cores quentes, tropicais e design planejado, nossos 171 apartamentos e suites são confortáveis e relaxantes.

\section{decorado com charme (3)}

$O$ apartamento Standart é decorado com muito charme e possui toda a estrutura necessária para o conforto do hóspede e a comodidade de estar localizado no $1^{\circ}$ andar do hotel.

\section{decorado com elegância (2)}

Planejados e decorados com elegância e praticidade, todos os apartamentos possuem: ar condicionado, sala de estar, cozinha totalmente equipada (...) 


\subsection{O modelo de verbete}

Apresentaremos nesta seção nosso modelo de verbete com base nos dados analisados anteriormente.

A imagem a seguir mostra a chave do verbete, isto é, a estrutura definida para apresentar os dados linguísticos. Logo abaixo, temos uma tabela com os códigos utilizados e o seu significado. O objetivo da proposta abaixo é apresentar as informações de maneira clara, de fácil visualização e entendimento.

Na sequência, são apresentadas as entradas do glossário.

\section{Chave do verbete}

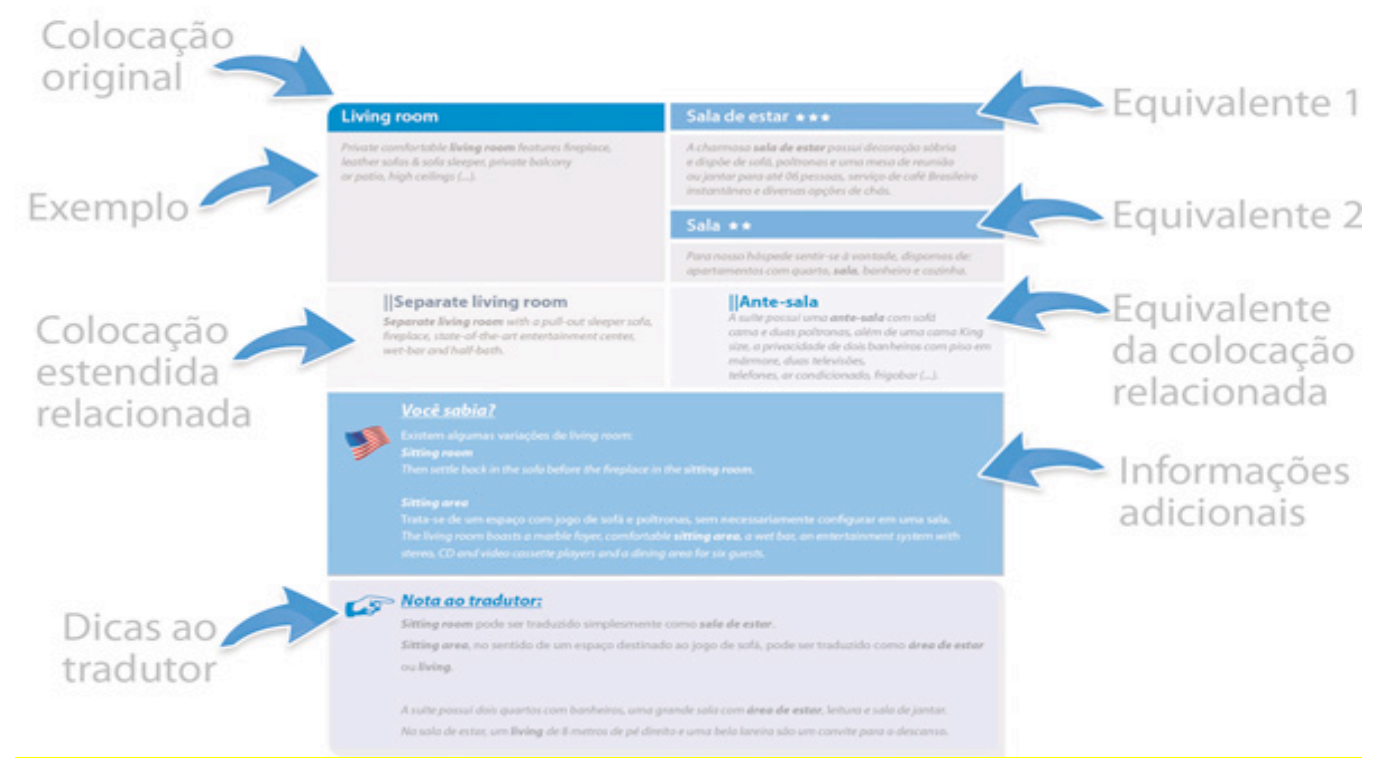

\section{Tabela de códigos}

\begin{tabular}{ll}
$\star \star$ & Mais frequente \\
$\star \star$ & $2^{\circ}$ mais frequente \\
$\star$ & Menos frequente \\
$=$ & Variante \\
$\Rightarrow \quad$ & Remissiva \\
॥ & Colocação estendida relacionada \\
\hdashline & Ordem flexível \\
[ ] & Palavraopcional
\end{tabular}

CAIXA ALTA Forma base do verbo

Itálico Exemplos

Negrito Colocação/equivalente no contexto

Informação referente ao inglês

(2) Informação referente ao português

Você sabia? Infomações adicionais

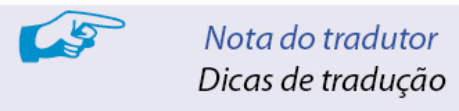




\section{Accessible room}

Many of our accessible rooms also provide a roll-in shower with a built-in shower bench in the bathroom.

$=$ Handicap (ped) accessible room

= Wheelchair accessible room

= Disability accessible room
Apartamento para portadores de necessidades especiais $\star \star \star$

Preocupado em atender melhor o seu público, o hotel disponibiliza ainda apartamentos para portadores de necessidades especiais.

Apartamento adaptado para portadores de necessidades especiais $\star \star$

Dispomos de apartamentos adaptados para portadores de necessidades especiais.

Apartamento para deficientes [físicos] $\star$

Dispomos de um apartamento para deficientes físicos, com porta mais larga e barras de apoio no banheiro.

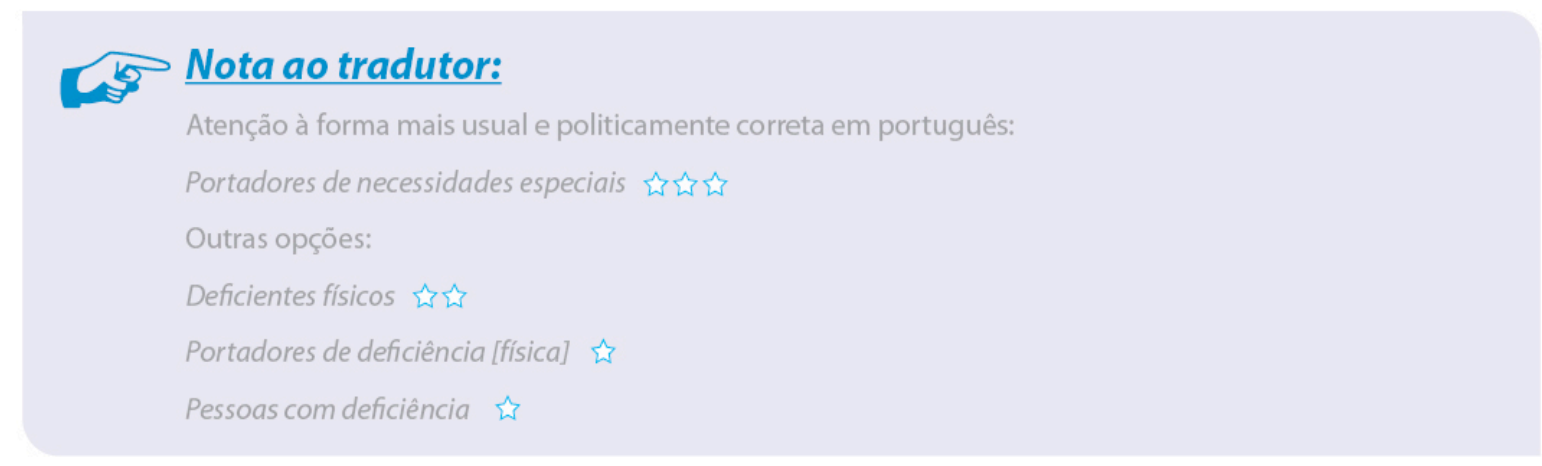




\section{Banquet room}

Exquisite banquet rooms and impeccable service create the ideal ambiance for both business gatherings and intimate receptions.

$\Rightarrow$ Meeting room Você sabia?

\section{Salão para banquetes}

Salões para banquetes com capacidade de acomodar até 300 pessoas simultaneamente.

\section{BOOK [a, your, this] room}

$\rightarrow$ RESERVE [a, your, this] room

\section{Comfortable room}

Leisure travelers enjoy our comfortable rooms, serene surroundings and close proximity to all beautiful fun attractions in Charleston.

\section{Є. Apartamento confortável $\star \star \star ~$}

O Praia Mansa Suite Hotel possui 110 confortáveis apartamentos de 1 e 2 dormitórios equipados com ar condicionado, cofre, frigobar, TV a cabo, acesso a internet, sala de estar e copa.

\section{ЄApartamento aconchegante $\star \star$}

Descanse em nossos aconchegantes apartamentos com vista para a cidade do Rio de Janeiro, sentindo o primor de cada detal he e vivendo nossa decoração clássica, requintada e acolhedora.

\section{Apartamento acolhedor $\star$}

Espaçosos e acolhedores, nossos apartamentos oferecem 1, 2 e 3 quartos. 


\section{Conference room}

Small meetings receive all the advantages of larger gatherings at The Waldorf Astoria, including the hotel's cutting-edge technology and distinctively appointed conference rooms, accommodating meetings of up to 100 .

\section{Salão de convenções $\star \star \star \star$}

Dispomos de restaurante internacional, american bar saläo de convençôes com capacidade para 40 pessoas em forma de auditório com equipamentos de áudio/ vídeo e serviço de coffee break.

\section{Sala de convenções $\star \star$}

No The Palace você encontra conforto e qualidade nos 132 apartamentos de luxo, além de completa infra-estrutura para executivos com sala de convençōes, conexẫo Internet banda larga, restaurante com culinária internacional, piscina, sauna e fitness center.

\section{Sala de conferência $\star$}

OTropical da Bahia oferece salas de conferência que podem ser adaptadas a vários tipos de eventos.

\section{Nota ao tradutor:}

Ao mencionar o número de pessoas que o salão de convençōes comporta, é usual utilizar a expressão com capacidade para:

Para grupos e empresas o Hotel oferece amplo salão de convençôes, $150 \mathrm{~m}^{2}$, com capacidade para

130 pessoas ou mais. 


\section{Connecting room}

Adjacent rooms, connecting rooms or specific room location and types of rooms or bedding are on a "request basis only" and are subject to availability at the time of check-in.

\section{Apartamento conjugado $\star \star \star$}

Há 3 apartamentos conjugados disponíveis: de um lado uma cama de casal, uma de solteiro e um banheiro e, separado por duas portas, um outro apartamento com três camas de solteiro e um banheiro.

\section{Apartamento comunicante $\star \star$}

A área total do apartamento standard é $38 \mathrm{~m}^{2}$.

Os apartamentos comunicantes são térreos.

\section{Apartamento interligado $\star$}

Dois apartamentos interligados por uma porta que pode ser fechada, permitindo a privacidade entre os quartos.

\section{Deluxe room}

All seventeen deluxe rooms and suites feature sleek modern design and contemporary furnishings.

= Deluxe guest room

$\Rightarrow$ Standard room Você sabia?

\section{Apartamento luxo $\star \star \star$}

Apartamento luxo: confortável apartamento de 42 metros quadrados com decoração leve e sofisticada. 


\section{Dining room}

The Suite includes a living room and dining room, fireplace, full kitchen, 1,100 square foot private outdoor terrace, oversize bedroom with private sitting area, spacious master bath with soaking tub and half bath for guests.

\section{||Formal dining room}

Perfectly suited for dinners for 10, the formal dining room includes an elegant dining table and sideboard, as well as a full bar with seating. A baby grand piano adds the final touch for enchanting evenings in.

\section{||Private dining room}

From a five-course dinner in the private dining room to an elaborate ballroom gala, the ladies and gentlemen of our distinguished Northern California luxury resort specialize in creating events guests will remember for a lifetime.

\section{Sala de jantar}

As suites dispõem também de sala de jantar para 4 pessoas, sala de estar e hidromassagem.

\section{||Sala de jantar}

A charmosa e ampla sala de jantar, também com vista para o mar, possui mesa retangular em madeira nobre e 16 confortáveis cadeiras, além de uma mesa auxiliar, cadeira e um discreto lavabo.

\section{||Sala privativa}

O Eau oferece 122 lugares, um terraço ao ar livre e uma sala privativa, que proporciona um ambiente exclusivo para qualquer tipo de evento, desde uma reunião informal até uma comemoração especial ou um importante jantar de negócios.

\section{Nota ao tradutor:}

Formal dining room refere-se a uma sala de jantar completa, com mobiliário mais sofisticado.

Em português, é simplesmente sala de jantar.

\section{Elegant room}

$\Rightarrow$ Luxurious room 


\section{Fitness room}

Our fitness room has treadmills, exercise bike, universal weight machine, stretching mats and TV to make your workout enjoyable.

\section{Sala de ginástica $\star \star \star$}

O hotel dispõe de sala de ginástica, com aparelho multifuncional para exercícios físicos, bicicleta horizontal, aparelho para abdominais e saco de pancadas.

\section{Academia $\star \star$}

Exercite-se na nossa academia: infra-estrutura com aparelhos para musculação, bicicletas ergométricas, esteiras e step. Temos monitoramento cardiovascular durante os exercícios.

\section{Academia de ginástica $\star \star$}

Há, ainda, uma piscina térmica, coberta, ideal para relaxamento, e uma academia de ginástica equipada com modernos aparelhos Technogym, referência no setor de fitness.

\section{Sala de musculação *}

Sala de musculação cuidadosamente equipada, além da sauna seca, ducha circular e repouso.

\section{Sala de fitness $\star$}

Com uma vista privilegiada para a represa, nossa sala de fitness dispõe de 4 esteiras, 2 bicicletas horizontais, 2 bicicletas verticais e total aparelhagem de musculaçäo.

\section{Você sabia?}

Fitness center $t \star \star \star$ Mesmo que fitness room, mas muitas vezes ligado a um spa.

Fitness center equipped with two treadmills, 1 elliptical, 1 stationary bike, free weights and a weight bench. Within Icon Brickell, the hotel stands steps from the 28,000-square-foot spa and fitness center, 300-foot infinity pool on Biscayne Bay, poolside bar and fireplace, and life-size chess set.

Fitness facility $\star \star$ Mesmo que fitness room.

These exceptional residences offer you more seclusion, while giving you full access to all the resort amenities, like the swimming pool, fitness facility and preferred golf course tee times.

Exercise room $\star$ Mesmo que fitness room.

Our exercise room for resort guests features cardiovascular equipment as well as a universal gym.

Gym $\star$ Mesmo que fitness room, mas também usado para designar o aparelho de ginástica. Guests can work out in the fully-equipped, modern gym.

The fitness facility at The Club features Kinesis circuit training, computerized aerobic equipment, a multi-purpose aerobic gym, weight machines and spin studio.

Fitness center é usado como sinônimo de academia de ginástica; porém, alguns hotéis usam essc denominaçâo para estruturas maiores:

A infra-estrutura de lazer e entretenimento do Porto d'Aldeia Resort engloba ainda estádio com campo de futebol gramado, quadras de tênis, playground, saläo de jogos, fitness center com sauna seca e sala de musculaçäo, piscinas com toboáguas. 


\section{Function room}

From events of 10 to 400 guests, our wide selection of function rooms provide unique and impressive space for any conference or catered event.

\section{Game room}

The Hershey game room has a great variety of classic and new arcade games, as does the Forest Game Room where you can also enjoy ping pong, foosball and billiards.

\section{Sala de eventos $\star \star \star$}

O Aquarius Hotel está preparado para sediar, em grande estilo, seus seminários e convençôes, dispondo para isso de sala de eventos, totalmente equipada, saläo de festas para até 250 pessoas e salas de reuniōes capazes de acomodar de 40 a 250 participantes.

\section{Salão de eventos $\star \star$}

No salão de eventos, você poderá realizar encontros empresariais, reuniões, palestras, etc. O local possui excelente infra-estrutura com: internet wi-fi, sistemas de áudio e vídeo, computador e capacidade para até 90 pessoas.

\section{Salão de jogos $\star \star \star$}

O salão de jogos dentro do hotel possui uma bela mesa antiga de sinuca, uma de bilhar, uma mesa redonda para carteado e ainda pequenas mesas para xadrez.

\section{Sala de jogos $\star \star$}

A sala de jogos oferece diversäo em amplo espaço: mesa de ping pong, mesa de sinuca, pebolim. 


\section{Guest room}

The six distinctive guest rooms are themed to create individuality with the utmost attention to detail. All six guest rooms have a large private bath, HD TV with Dish Network, internet and luxurious linens.

= Guestroom

||Guest rooms and suites

Our 826 guest rooms and suites offer a peaceful and soothing antidote to the bustle of Las Vegas.

\section{Apartamento $\star \star \star$}

O Boa Vista Resort possui 123 apartamentos, todos decorados com capricho e equipados com TV por assinatura SKY, ar-condicionado, frigobar, telefone, ducha quente, secador de cabelo, cofre digital, varanda privativa com rede.

\section{Quarto $\star \star$}

A pousada possui 33 quartos com banheiro privativo, ventilador de teto, televisão, roupas de cama e frigobar.

\section{||Apartamentos e suítes \\ O hotel possui 174 apartamentos e suítes com ar condicionado, música ambiente, cofre e fechadura eletrônicos, telefone com discagem direta, tv a cabo, internet gratuita, telefone no banheiro, secador de cabelo.}

\section{Você sabia?}

Guest room: designação mais usual para a acomodação do hóspede no hotel.

Stylish and spaciously designed guest rooms feature cable satellite television, free high-speed Internet, microwave and refrigerator.

Bedroom: designa o dormitório em uma suite ou apartamento.

The Royal Suite is an elaborate two-bedroom suite, offering 1,700 square feet of living space and features both a king-bedded and twin-bedded bedroom.

Suite: caracteriza-se por possuir um determinado número de dormitórios, banheiro, sala de estar e, às vezes, cozinha. É, portanto, uma categoria superior a guest room. Our suites are $50 \%$ larger than traditional hotel rooms with separate spaces for living, dining, sleeping and working. There are studio, one and two bedroom floor plans to maximize efficiency and ease. A fully equipped kitchen enables our guests to enjoy relaxing meals within the privacy of their own suite.

Apartment: uma unidade de autosserviço com diversos cômodos, especialmente para estadias prolongadas.

Just opened for extended stay, this apartment features one bedroom with queen sized poster bed and a full separate office equipped with full size desk. It includes a living room and a fully equipped and functional kitchen with large side by side refrigerator, gas stove, double sinks, dishwasher, etc. This unit features a separate entry for privacy.

\section{Você sabia?}

Quarto é sinônimo de apartamento em muitos contextos. Mas atenção a algumas diferenças:

1) Quarto pode fazer parte de um apartamento, suíte ou chalet.

O hotel possui 23 amplos apartamentos, 19 com um quarto com cama de casal (para 2 pessoas) e 4 apartamentos duplos, com dois quartos com cama de casal (para 4 pessoas).

Em inglês, usa-se bedroom nesse sentido: This spacious two-bedroom suite can be configured as a three-bedroom suite with the addition of a connecting room.

2) Quarto pode ser um tipo de acomodação mais simples que o apartamento, como em pousadas. Nossos apartamentos contam com confortáveis instalaçôes, pois possuem ar-condicionado, tv a cores e banheiro. Temos apartamentos duplos, triplos, quádruplos e nossa diária inclui café da manhã. Dispomos também de quartos duplos e triplos mais simples: com ventilador e tv.

A pousada possui 33 quartos com banheiro privativo, ventilador de teto, televisão, roupas de cama e frigobar.

\section{Nota ao tradutor:}

1) Apartment é pouco recorrente. Assim como guest room, pode ser traduzido como apartamento. Na versão para o inglês, traduza apartamento preferencialmente por guest room. 


\section{Hotel room}

The hotel rooms in the Beaver Village Lodge sleep between one and six people, offering two distinct room categories.

\section{Apartamento $\star \star \star$}

O Boa Vista Resort possui 123 apartamentos, todos decorados com capricho e equipados com TV por assinatura SKY, ar-condicionado, frigobar, telefone, ducha quente, secador de cabelo, cofre digital, varanda privativa com rede.

\section{Quarto $\star \star$}

A pousada possui 33 quartos com banheiro privativo, ventilador de teto, televisão, roupas de cama e frigobar.

\section{Você sabia?}

Hotel room tem valor negativo, no sentido de um apartamento comum e pequeno,

quando precedido de adjetivos como average, typical, traditional, bland, cookie-cutter, little, boxy:

Free yourself from the confines of your average hotel room.

Gone are the days of cramped little hotel rooms. Welcome to the spacious Ft. Myers Beach condo rentals.

\section{Nota ao tradutor:}

Não é necessário traduzir hotel. Em geral essa referência está no contexto.

\section{In-room coffee maker}

In the morning, you'll find piping fresh coffee and a complimentary continental breakfast waiting for you in the cozy Fireside room, or use the in-room coffee maker to brew your own.

\section{Cafeteira}

Apartamento com $285 \mathrm{~m}^{2}$, decorado em estilo europeu. Possui agradáveis e espaçosas salas de estar e jantar com copa privativa, o que permite o preparo de refeições no local. A copa guarda geladeira, cafeteira e microondas.

\section{Nota ao tradutor:}

Não é necessário traduzir in-room. Em geral, a referência ao apartamento está implícita no contexto.

\section{In-room dining}

$\Rightarrow$ Room service 


\section{In-room safe}

One king or two queen beds, business desk and reading chair, in-room safe, ceiling fan, $25^{\prime \prime}$ television, high-speed internet, large dormer window or standard windows.

\section{Cofire $\star \star \star$}

Suítes de $48 \mathrm{~m}^{2}$, com 1 quarto, saleta com sofá-cama mini copa, frigobar, forno microondas, TV a cabo, ar condicionado, cofre, secador de cabelos, varanda (...).

\section{Cofre individual $\star \star$}

Nos apartamentos do Hotel Beira Mar, você conta com ar-condicionado, minibar, TV a cabo, cofre individual, serviço de quarto e acesso à internet sem fio (wi-fi) em todo o hotel.

\section{Cofre eletrônico $\star \star$}

Espaçosa área com duas confortáveis camas de solteiro, poltronas, banheiro exclusivo e varanda privativa para desfrutar da belissima paisagem segundo sua localizaçāo. A unidade possui também, TV a cabo, internet, ar quente e frio, cofre eletrônico, frigobar e telefone.

\section{Cofre digital $\star$}

Apartamentos Single Studio: São equipados com ar-condicionado, telefone, correio de voz, rádio, TV a cabo, internet e cofre digital.

\section{Wota ao tradutor:}

Não é necessário traduzir in-room. Em geral, a referência a apartamento está implícita no contexto.

\section{Laundry room}

You will have the comfort of two baths, laundry room, living room, dining room and kitchen. Every kitchen comes equipped with granite countertops and appliances.

\section{Lavanderia $\star \star \star$}

Uma das excelentes opçôes oferecidas pelo Pietra Flat é uma casa totalmente equipada, com ampla sala, três suítes, churrasqueira, jardim, e dependência com mini-suíte e lavanderia.

\section{Lavanderia de autosserviço *}

O staff está sempre disposto a ajudar e dar informaçōes sobre a cidade e sobre os serviços que oferecemos, que säo: internet wi-fi ou em computadores disponíveis na sala de estar, lavanderia de autosserviço, guarda-bagagens, aluguel de automóveis, reservas de passeios e passagens. 


\section{Living room}

Private comfortable living room features fireplace, leather sofas \& sofa sleeper, private balcony or patio, high ceilings (...).

\section{||Separate living room}

Separate living room with a pull-out sleeper sofa, fireplace, state-of-the-art entertainment center, wet-bar and half-bath.

\section{Sala de estar $\star \star \star$}

A charmosa sala de estar possui decoração sóbria e dispõe de sofá, poltronas e uma mesa de reunião ou jantar para até 06 pessoas, serviço de café Brasileiro instantâneo e diversas opções de chás.

\section{Sala $\star \star$}

Para nosso hóspede sentir-se à vontade, dispomos de: apartamentos com quarto, sala, banheiro e cozinha.

\section{||Ante-sala}

A suite possui uma ante-sala com sofá cama e duas poltronas, além de uma cama King size, a privacidade de dois ban heiros com piso em mármore, duas televisões, telefones, ar condicionado, frigobar (...).

\section{Você sabia?}

Existem algumas variaçōes de living room:

Sitting room

Then settle back in the sofa before the fireplace in the sitting room.

Sitting area

Trata-se de um espaço com jogo de sofá e poltronas, sem necessariamente configurar em uma sala.

The living room boasts a marble foyer, comfortable sitting area, a wet bar, an entertainment system with stereo, CD and video cassette players and a dining area for six guests.

\section{Nota ao tradutor:}

Sitting room pode ser traduzido simplesmente como sala de estar.

Sitting area, no sentido de um espaço destinado ao jogo de sofá, pode ser traduzido como área de estar ou living.

A suíte possui dois quartos com banheiros, uma grande sala com área de estar, leitura e sala de jantar. Na sala de estar, um living de 8 metros de pé direito e uma bela lareira são um convite para o descanso. 


\section{Luxurious room}

With 2000 luxurious rooms, including 110 lavish suites, our spectacular 18-story glass atrium welcomes you to the hotel, offering sweeping views of the Potomac River.

\section{Apartamento elegante $\star \star \star$}

Os 115 apartamentos elegantes foram projetados para o máximo de conforto.

\section{Apartamento luxuoso $\star \star$}

No Atlante Plaza você vai encontrar 241 confortáveis e luxuosos apartamentos dignos das cinco estrelas do hotel.

\section{Apartamento charmoso $\star \star$}

Säo 15 charmosos apartamentos comportáveis, totalmente reformados com: TV (sistema TV aberta e 2 can ais de vídeo) frigobar, telefone, ventilador.

\section{Belo apartamento *}

Oferecemos belos apartamentos para que você possa realizar um possível sonho.

\section{Apartamento requintado $\star$}

Entre seus atrativos estão os requintados apartamentos de $35 \mathrm{~m}^{2}$ de design sofisticado e discreto com um dormitório, banheiro, sala e mini-cozinha, acesso à internet banda larga, além de tv a cabo, ar condicionado e cofre digital.

\section{Apartamento sofisticado}

Apartamento Luxo Twin: sofisticado apartamento de 42 metros quadrados com 2 camas. 


\section{Meeting room}

Our contemporary meeting room boasts 350 square feet of affordable space that can accommodate up to 12 guests, boardroom style.

\section{Sala de reuniões $\star \star \star$}

Em nosso Business Center 24 horas, nossos hóspedes têm acesso gratuito à internet nas workstations e contam ainda com uma sala de reuniỏes privativa.

\section{Sala de reunião $\star \star \star$}

O Hotel Nacional oferece 08 salas de reunião com capacidade de até 80 pessoas, garantindo um espaço de trabalho ideal durante a estada no hotel.

\section{Vocêsabia?}

Meeting room pode ser:

- uma sala de reuniōes parte das instalaçōes de negócios do hotel ou na própria suíte: Our contemporary meeting room boasts 350 square feet of affordable space that can accommodate up to 12 guests, boardroom style.

Our hotel offers two convenient suites that each feature a business meeting room connected to a guest bedroom.

- um espaço para eventos de diversas naturezas:

Choose from 14 distinct meeting rooms to suit the size and style of your next business or social function. Our fully appointed, private meeting rooms feature: accommodations and meeting space for groups of 10 to a 1,000 people.

É comum especificar os tipos de disposição que as salas de reuniōes recebem para os eventos: The meeting room can accommodate 110 guests for theater settings, 70 guests for banquet settings and 60 guests for classroom seating. U-shape and conference settings are also available.

Em inglês, esse arranjo recebe o nome de: setup, layout, seating, style. Em português: estilo, montagem, layout, configuração, formato.

Os mais comuns são:

classroom $=$ escolar $/ \mathrm{u}$-shape $=$ formato $\mathrm{u} /$ reception $=$ coquetel $/$ hollow square $=$ quadrado $/$ banquet $=$ banquete $/$ boardroom $/$ conference $=$ mesa única $/$ theater $=$ auditório $/$ herringbone $=$ espinh a de peixe

\section{Nota ao tradutor:}

Meeting room, no sentido de um espaço para eventos, é um salão.

OHotel Plaza Praia Suites possui 3 salöes com o conforto e o espaço perfeito para realizar o seu evento. 


\section{Powder room}

Bathrooms: one full bathroom; plus one powder room.

= Guest powder room

\section{Lavabo}

Suíte E - Suíte Master, duplex, com dois dormitórios, um lavabo, dois banheiros, um grande living, amplo dormitório e closet, quatro varandas.

\section{Vocês sabia?}

Outra forma de dizer powder room é half bath/bathroom.

A wet bar, pantry, guest half bath and oversized dining table make entertaining a dream.

One and a/one half baths refere-se a um banheiro completo mais um lavabo.

A grand foyer welcomes guests into the distinguished atmosphere, which pervades throughout every square inch of these magnificent one-bedroom, one and one-half baths suites.

\section{RESERVE [a, your, this] room}

Our online booking service is the most convenient way to reserve a room.

\section{FAZER [a, sua, uma] reserva $\star \star \star$}

Para fazer a sua reserva no Victory Suites, efetue o cadastro em nosso sistema.

EFETUAR [a, sua, uma] reserva $\star \star$

Para efetuar sua reserva ou solicitar informaçōes adicionais, favor entrar em contato conosco pelo email.

\section{SOLICITAR [a, sua, uma] reserva $\star \star$}

Preencha esse formulário para solicitar uma reserva.

\section{REALIZAR [a, sua, uma] reserva $\star$}

Para realizar uma reserva, o cliente deverá fazer um depósito bancário de $25 \%$ do valor total das diárias.

\section{Vocêsabia?}

Book ou reserve?

Os dois são sinôminos, mas alguns usos são mais característicos:

To book é mais usado nas expressōes book a reservation, booknow, book online.

A two night deposit is required to book a reservation.

Save up to $30 \%$ on your reservation at the Bay Inn \& Suites SeaWorld San Diego when you book online! Book Now!

To reserve é mais comum na expressão reserve a/your/this room.

In order to reserve your room a vaild credit card number will be required.

\section{Nota ao tradutor:}

Ao traduzir a forma imperativa de booke reserve (Book now ou Reserve [your/a] room now), prefira Faça [agoral já] sua reserva. É dispensável a menção a apartamento, quarto.

Faça agora mesmo sua reserva!

Faça já sua reserva aqui ou consulte nossos parceiros para a compra de pacotes. 


\section{Room amenities}

Room amenities include a king-size bed, private bath, and a flat-screen cable TV.

$=$ Guest room amenities

$=$ In-room amenities

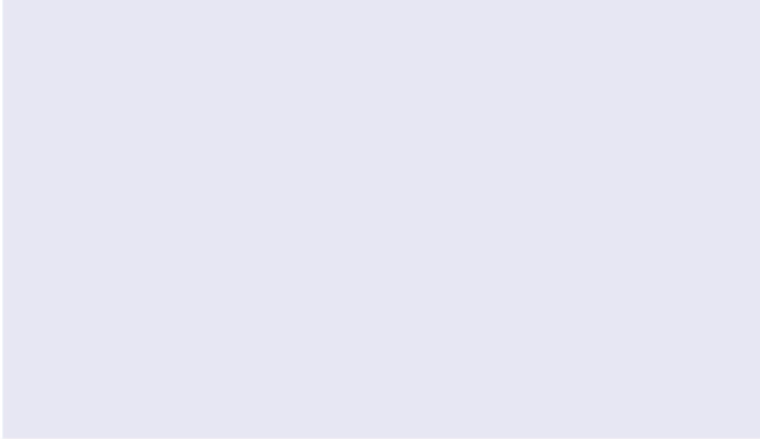

\section{Facilidades $\star \star \star$}

Facilidades: acesso à internet banda larga, aquecimento central, ar condicionado com controle individual, TV a cabo.

\section{Características $\star \star$}

Disponibilizamos 80 confortáveis apartamentos (...), todos com decoraçäo em tons suaves e possuindo as seguintes características: TV a cabo: mais de 40 canais, telefone, cofre, senha eletrônica (...).

\section{Comodidades $\star$}

São 396 acomodações distribuidas entre apartamentos e suites, com todas as comodidades: wireless, workstation no quarto, TV a cabo, cofres individuais, telefone com discagem direta, frigobar, room-service.

\section{Você sabia?}

Usa-se amenities em português para referir-se aos itens no banheiro (shampoo, condicionador, creme, etc.). Banheiro com banheira, box com chuveiro, telefone, secador, roupäo, balança e kit completo de amenities Todas as unidades estão equipadas com: (...); secador de cabelo; amenities (shampoo / condicionador).

Em inglês, usa-se toiletries nesse sentido.

Bathroom toiletries include shampoos, hair conditioners, body gels and lotions, facial cotton towels, and shower caps.

\section{Nota ao tradutor:}

É comum introduzir a relação dos itens do apartamento com as seguintes estruturas:

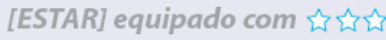

Todos os apartamentos estão equipados com frigobar, telefone, TV a cabo, calefação, ventilador de teto, cofre (...). POSSUIR 记政

As acomodações do Mabu possuem ar condicionado, TVLCD, Tv a cabo, WC com ducha, secador de cabelos, telefone, frigobar, amenities, internet wireless, tomadas identificadas para $110 \mathrm{~V}$ e $220 \mathrm{~V}$. 


\section{[One/first night's] room and tax}

Cancellation is 6 pm day of arrival to avoid a cancellation fee of one night's room and tax.

$=[$ one/first night $]$ room and tax

$=$ [your/one night] room charge plus tax

$=$ [one/first night's] room rate and tax

\section{[Uma/primeira] diária e taxas}

As reservas devem ser canceladas em até $72 \mathrm{~h}$ antes

da data de chegada, caso contrário, será cobrado

o valor de uma diária e taxas.

\section{Você sabia?}

A expressão one night's room and tax refere-se especialmente à cobrança para confirmação ou cancelamento da reserva, nesse caso, o valor de uma diária mais impostos. No Brasil, a política de muitos hotéis nesses casos é cobrar uma porcentagem sobre o valor total da hospedagem.

\section{Room BE equipped with}

$\Rightarrow$ Room FEATURE

\section{Room BOAST}

$\Rightarrow$ Room FEATURE 


\section{Room FEATURE}

\section{Apartamento [SER/ESTAR]}

\section{equipado com $\star \star \star \star$}

This room features a queen bed and private bath. gas fireplace, mini wet-bar with microwave oven and

Apartamento equipado com cama box.

ar-condicionado, cofre, frigobar, telefone e tv a cabo e banheiro com ducha higiênica e secador de cabelo.

$T V$ and $a C D$ player.

\section{Apartamento POSSUIR «}

= guest room FEATURE

Nossos apartamentos possuem ar-condicionado, frigobar, cofre, TV via satélite e a cabo, canais de som, controles de cabeceira, camas box-spring, ducha, secador PABX inteligente e varanda com rede.

\section{Apartamento TER}

Todos os 315 apartamentos têm decoração moderna e funcional com: som ambiente, vinte e três canais de programaçấo, ar condicionado central, TV em cores, frigobar, secador de cabelos e banheira.

\section{Apartamento OFERECER *}

O apartamento oferece uma delicios a cama queen size, ar condicionado, secador de cabelo, TV a cabo com diversos canais nacionais e internacionais, cofre e conexão de internet $100 \%$ Wi-Fi.

\section{Apartamento DISPOR DE}

Cada apartamento dispõe de: ar condicionado, banheiro, mini bar, cofre pessoal, televisão a cabo telefone (...)

\section{Vocêsabia?}

Os verbos mais usados com room para indicar os recursos do apartamento são:

Room FEATURE tit

Our spacious room features contemporary decor with stylish furnishings including one king Hyatt Grand Bed ${ }^{\text {mw }}$, state-of-the-art media and work center with a 42" flat-panel high-definition television (...)

Room HAVE $t * \star *$

The main room has two queen-size beds, a table and two chairs plus a work desk.

Room OFFER «

This large room offers two beautiful queen-sized beds, antique furnishings, bright morning sun -private bath right outside your door.

Room INCLUDE $\star$ *

Each quest room includes free high-speed Internet and cable satellite television with $\mathrm{HBO}^{\text {* }}$

Room BE equipped with

The room is equipped with wall mounted flat screen television and DVD capabilities.

Room BOAST *

This expansive 362 square foot room boasts a private, full size bath with shower and for the clothes-horse a large walk in closet. 
Room HAVE

$\Rightarrow$ Room FEATURE

\section{Room INCLUDE}

$\Rightarrow$ Room FEATURE

\section{Room OFFER}

$\Rightarrow$ Room FEATURE 


\section{Room rate}

Room rates for 2011 are $\$ 194.00$ plus tax for one person and $\$ 199.00$ plus tax for two people per night.

$=$ Nightly rate

= Daily rate

$=$ Night's room rate

= Nightly room rate

\section{Diária $\star \star \star$}

Quartos individuais: $R \$ 120,00$ a diária para casal.

\section{Tarifa $\star \star$}

Tarifas especiais para: carnaval, semana santa, reveillon e feriados nacionais.

\section{Vocêsabia? \\ Rate $t \star \star t$ valor cobrado pelo uso das acomodaçōes. \\ At check-in, guests paying the nightly rate will be charged for their entire stay. \\ All rooms at this special rate include breakfast \& happy hour for up to 2 guests.}

Fee $\star \star$ termo mais específico, principalmente o valor cobrado para usar determinado serviço, instalação, comodidade, ou como multa ou penalidade.

Your resort fee includes the following amenities: USA Today delivered every weekday morning, in-room high-speed Internet access [...]

If you smoke, you will be charged a substantial cleaning fee to return the room to its proper condition. Cancellation is $6 \mathrm{pm}$ day of arrival to avoid a cancellation fee of one night's room and tax.

Charge $\star$ termo mais genérico, empregado frequentemente para se referir à cobrança adicional, em especial, por pessoa extra, serviços, comodidades. É o termo preferencial na expressão for/at no additional charges.

The sitting room has a comfortable sofa bed that may accommodate a third person for an additional charge. Age limits for children occupying parents' or guardians' guest rooms at no additional charge may vary at some properties.

Diária $\star \star \star$ preço pago para uso das acomodaçōes, período de estadia no hotel (cada 24 horas) e horário de início e encerramento desse periodo (check-in/ check-out).

Para o período de baixa estaçâa, o hotel solicita o pré-pagamento de 1 diária para garantir a reserva. Diárias românticas, com direito ao delicioso "Festival de Inverno" e suite especial!

Comentários valem diárias no Bavária Sport Hotel.

As diárias se encerram às 12:00 (check-out) e se iniciam às 14:00 (check-in).

Tarifa $\star \star$ preço cobrado pelo uso das acomodaçōes, com destaque para alguma especificidade - tarifa balcão, tarifa promocional, tarifas especiais. No plural, é a forma mais utilizada nas abas dos sites de hotéis. Tarifas especiais para o mercado de embaixadas e organismos Internacionais.

Taxa $\star \star$ termo mais específico, relacionado principalmente a encargos e impostos, como taxa de serviço e taxa de turismo.

Cobramos taxa de serviço de $10 \%$ sobre os extras. Além disso, é cobrada uma taxa de turismo no valor de $R \$ \$ 1,50$, que será repassada ao Convention Bureau da cidade.

Nos preços serão acrescidos $10 \%$ de taxa de serviços e $5 \%$ de ISS.

Custo $\star$ termo mais genérico, principalmente uma cobrança extra por serviços e atividades em geral. Destaque para sem custo adicional.

Politica para crianças: máximo 2 crianças menores de 12 anos de idade no mesmo apartamento dos pais sem custo adicional. As atividades listadas abaixo não têm custo adicional e podem ser realizadas a qualquer momento de sua estadia conosco. pesca, tênis, caminhada, cinema, fitness centre (...)

Tarifário « conjunto ou tabela de preços pelo uso das acomodaçôes do hotel. Termo usado pelos sites para indicar a seção que mostra o valor das diárias.

\section{Nota ao tradutor:}

Atenção para as traduções:

Rate $=$ diária $/$ tarifa $\quad$ Fee $=$ tarifa $/$ taxa $\quad$ Charge $=$ custo 


\section{Room service}

If you're not interested in sampling one of New York's many restaurants, stay in and order room service from $6 a \mathrm{~m}-11 \mathrm{am}$ for breakfast and $5 \mathrm{pm}-12$ midnight for dinner at The Roosevelt Hotel.

\section{||24-hour room service}

Your dining options include our 24-hour room service.

\section{Room service $\star \star \star$}

Room service: café da manhä, almoço e jantar até as 22 horas (sem taxa de serviço).

\section{Serviço de quarto $\star \star$}

Caso prefira relaxar no conforto de seu apartamento, você poderá também optar por um leque de bebidas e comidas, através do serviço de quarto.

\begin{abstract}
||Room service $\mathbf{2 4}$ horas $\star \star \star$ Os Chalés da Fazenda Salsalito oferecem todo o conforto para sua estadia com room service 24 horas, ar-condicionado, quartos com TV e até uma pequena cozinha para suas próprias incursões gastronômicas.
\end{abstract}

\section{||Serviço de quarto 24 horas $\star \star ~$}

Para sua maior comodidade e conforto,

o Praia do Forte EcoResort \& Thalasso Spa dispõe de serviço de quarto 24 horas.

\section{Vocêsabia?}

Outra forma de dizer room service é in-room dining [service].

Four Seasons in-room dining is a fine-dining experience within the comfort and convenience of your guest room or suite. It is ideal for time-zone-hopping travellers, impromptu meetings or simply for quiet, private dining. Choose from an extensive menu, day or night.

\section{Sitting room}

$\Rightarrow$ Living room

\section{Spacious room}

This spacious room has two queen-sized beds with quilts, and top quality furniture, a full bath and wonderful view of the serene outdoors.

Spacious guest room

Large [guest] room

Oversized [guest] room

\section{Apartamento amplo $\star \star \star \star$}

A pousada possui acomodações com vista para o mar e amplos apartamentos de ótimo padrão.

\section{Apartamento espaçoso $\star \star$}

Apartamentos espaçosos, conforto e comodidade para o hóspede é a combinação perfeita que o Águas do Iguaçu Hotel oferece em todos os seus apartamentos. 


\section{Standard room}

Discover our comfortable guest rooms situated along the peaceful Long Branch Creek. Business travelers find our standard rooms an ideal value with just the right amenities.

$=$ Standard guest room

\section{Apartamento standard}

Os Apartamentos Standard contam com os seguintes equipamentos: TV colorida c/ 8 canais; ar condicionado; telefone; cama de casal; sofá bicama; banheiro.

\section{Você sabia?}

As categorias mais comuns de apartamentos e suítes em inglês são:

Standard room / Deluxe room / King room / Queen room

Double room

Executive suite / Deluxe suite / Luxury suite / Presidential suite / Junior suite / Penthouse suite /

Master suite / Family suite / Grand suite

As mais comuns em português sáo:

Apartamento luxo / Apartamento Standard / Apartamento superior / Apartamento casal /

Apartamento duplo, double / Apartamento single, solteiro, individual / Apartamento quádruplo /

Apartamento triplo

Suíte máster / Suíte luxo / Suíte presidencial / Suíte júnior / Suíte executiva / Suíte standard /

Suite nupcial / Suite casal

\section{Steam room}

Relax in the eucalyptus steam room and red cedar sauna.

\section{Treatment room}

Everyone deserves a little R\&R, especially in Sin City. From body treatments to facials, and massages to waxing in one of our treatment rooms, everything you need to rejuvenate after a great night getting your fantasy on is a phone call away.

\section{Sauna a vapor $\star \star \star$}

A sauna a vapor, de utilização mista, pode ser usada 24 hs, também conta com um design único e possui vistd para a piscina.

\section{Sauna úmida $\star \star$}

Três piscinas aquecidas e cobertas, contando ainda com sauna seca masculina, sauna seca feminina, sauna úmida masculina e sauna úmida feminina.

\footnotetext{
1. Sauna (em inglês) refere-se à sauna seca (dry sauna) e steam room, à sauna a vapor ou úmida. Newly remodeled, the award-winning Spa offers a variety of indulgent services [...]. It is comprised of: two couple's rooms, separate men's and women's sauna and steam rooms

2. Ao se referir às duas juntas, é mais usual a ordem sauna seca e a vapor ou sauna seca e úmida.
}

\section{Sala de tratamento}

OSpa possui 07 salas de tratamento, sendo dois ofurôs à Beira do Rio, uma Sala Conjugada, onde você poderá fazer seu tratamento a dois, Sala de Cromoterapia, Sala de Névoa, onde você faz sua massagem envolta em uma névoa de água, experimentando uma sensaçāo especial de relaxamento. 


\section{Well-appointed room}

Apartamento totalmente equipado $\star \star \star$ bem equipado $\star \star$

You will enjoy all the comforts of home with a queen size bed, as this well-appointed room offers a kitchen equipped with refrigerator, stove, microwave, convection oven and Keurig coffee maker with coffee.

Enjoy the pure elegance of this well-appointed room on the first floor.

= Well-appointed guest room

= Beautifully appointed [guest] room

= Elegantly appointed [guest] room

= Luxurously appointed [guest] room

São 42 apartamentos totalmente equipados e mobiliados, com espaços internos bem divididos. com roupas de cama e banho trocadas a cada 3 dias, ar condicionado, TV a cabo, telefone, cozinh a completa com microondas e uma vista muito especial do mar.

Apartamento bem decorado $\star \star \star \star$ cuidadosamente decorado $\star \star$ finamente decorado * O Residencial conta com apartamentos bem equipados

Apartamento bem decorado, aconchegante e com a total privacidade que você merece.

Apartamento cuidadosamente decorado com flores, pétalas de rosas e sais de banho.

São 163 apartamentos finamente decorados e equipados com: Telefone, televisäo, ar-condicionado, mini-bar, cofre individual (...)

Apartamento decorado com requinte $\star \star$

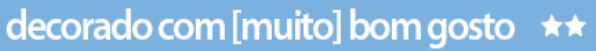
decorado com [muito] charme $\star \star$ decorado com elegância $\star \star$

São 112 apartamentos decorados com requinte $e$ charme em um ambiente agradável e sofisticado (...) Decorados com muito bom gosto em cores quentes, tropicais e design planejado, nossos 171 apartamentos e suítes são confortáveis e relaxantes.

O apartamento Standart é decorado com muito charme e possui toda a estrutura necessária para o conforto do hóspede e a comodidade de estar localizado no $1^{\circ}$ andar do hotel.

Planejados e decorados com elegância e praticidade, todos os apartamentos possuem: ar condicionado, sala de estar, cozinha totalmente equipada (...)

\section{Nota ao tradutor:}

Appointed tem dois sentidos comuns: "equipado" e"decorado". Na primeira acepção, o contexto está relacionado aos itens oferecidos nas acomodações, prefira [bem, totalmente] equipado na tradução; na segunda acepção, está relacionado à noção de requinte das acomodações; nesse caso, prefira decorado e as variações sugeridas acima. 


\section{Considerações finais}

Esta pesquisa teve como objetivo a elaboração de uma proposta de glossário bilíngue de colocações da área de hotelaria, dedicado ao tradutor. Tal proposta suscitou reflexões sobre uma série de questões, como aspectos culturais referentes à área da hotelaria, necessidades do tradutor, noção de equivalência pelo contexto, critérios para a compilação de um corpus, um fazer terminológico pautado na noção de palavra-chave, organização e apresentação de um glossário de colocações bilíngue, dentre tantas outras.

Debruçamo-nos sobre uma área técnica relevante do ponto de vista socioeconômico e cultural, cuja demanda por traduções parece ser diametralmente oposta à oferta de materiais de referência, sobretudo de obras bilíngues. Inicialmente, já havíamos constatado a falta de rigor e alcance nos dicionários disponíveis; mas, após a pesquisa, verificamos um abismo entre as obras oferecidas, as necessidades do tradutor e a linguagem real de uso no âmbito da hotelaria.

Este estudo beneficiou-se da interdisciplinaridade entre LC, Tradução, Terminologia e Fraseologia. Na primeira área, encontramos subsídios para nos pautarmos em uma visão empírica da linguagem como sistema probabilístico, favorecendo a primazia dos dados extraídos de um corpus representativo. Da Tradução, valemo-nos das reflexões sobre as necessidades do tradutor e da noção de equivalência pelo contexto. Nesse sentido, ficaram patentes as vantagens de um cotejo criterioso do contexto no momento da investigação linguística, o que aprofundou o entendimento das colocações originais e ampliou as opções indicadas ao tradutor na forma de equivalentes e informações adicionais. Em relação à Terminologia, adotamos uma perspectiva textual, que enfatiza a centralidade do texto na pesquisa linguística, e nos preocupamos em dar conta de uma terminologia in vivo, de cunho essencialmente descritivo, visando a elaboração de uma proposta terminográfica mais próxima da realidade da língua em uso. Por fim, os estudos de Fraseologia ampliaram nosso entendimento sobre a natureza e formação das colocações.

Em relação às colocações, pudemos corroborar algumas proposições encontradas na literatura. Primeiramente, verificamos que elas constituem de fato um fenômeno 
difuso na língua de especialidade, confirmando a tendência fraseológica da linguagem defendida no principio idiomático de Sinclair. Atestamos que o significado de uma palavra emerge fundamentalmente da relação que ela trava com as demais ao seu redor e com o seu contexto de uso. Room ilustra bem essa afirmação. Não se pode determinar seu significado a priori, mas unicamente pelo seu contexto e colocados: guest room 'apartamento'; living room - 'sala'; banquet room - 'salão para banquetes'; room rate - 'diária'; steam room - 'sauna a vapor'; room service - 'room service'. Além disso, observamos que a palavra room pode ser omitida na tradução muitas vezes, por estar implícita no contexto, como em in-room safe - 'cofre'; room amenities - 'facilidades'; reserve your room - 'faça sua reserva'. Essa constatação também nos remete ao conceito de high context culture, segundo o qual uma cultura tem menos necessidade de explicitar as informações, privilegiando uma forma de comunicação mais econômica. Por fim, constatamos que as colocações não chegam de fato a representar um problema de entendimento, mas certamente de produção. Retomando o exemplo anterior, 'reserve your room ' tende a ser traduzido como 'reserve seu quarto', forma possível, porém bem menos usual em face dos dados do corpus, que apontam para 'faça sua reserva'.

A metodologia empregada mostrou-se adequada para a obtenção dos resultados esperados (e muitos inesperados). A etapa de compilação do corpus, apesar de longa e trabalhosa, revelou-se uma das mais cruciais para esta pesquisa, pois, antes mesmo da análise dos dados, aprofundou nossa compreensão sobre a tipologia textual sob investigação e possibilitou o reconhecimento de diversos aspectos culturais da área da hotelaria. O ferramental disponibilizado pelo software WordSmith Tools (Scott, 2007, versão 5) viabilizou a exploração dos dados e possibilitou a adoção de critérios estatísticos que conferiram mais confiabilidade aos resultados.

Optamos por realizar o estudo aprofundado de uma única palavra-chave, room, apresentando o percurso trilhado para o estabelecimento de cada um de seus colocados e equivalentes. Além disso, o estudo de room possibilitou a investigação de diversas áreas que compõem as descrições dos hotéis, como tipos de acomodações, tarifas, recursos do hotel, recursos dos apartamentos, áreas de lazer, serviços, eventos, dentre outras.

A partir de um corpus com pouco mais de 500 mil palavras em cada idioma, foram levantadas 33 colocações de room em inglês que integraram entradas principais e 72 equivalentes, os quais somados aos 15 padrões adicionais em português e 36 em 
inglês, chegam a 156 padrões. Além disso, elaboramos 13 Notas ao tradutor e 13 seções Você sabia?, que trazem respectivamente dicas de tradução e explicações para diferenças de sentido entre palavras relacionadas, bem como notas culturais.

Ao elaborar a estrutura do verbete, decidimos apresentar as colocações originais em ordem alfabética, sem diferenciá-las por tipo ou extensão. Originais e equivalentes foram apresentados lado a lado, juntamente com símbolos adotados para guiar o leitor pelas informações do glossário e fornecer dados adicionais de maneira simples e visual.

A despeito dos resultados obtidos, este estudo apresentou limitações. Uma delas está relacionada ao uso do corpus etiquetado morfossintaticamente, que apresentou um nível elevado de erros de classificação em português, diferentemente do inglês, que demonstrou melhores resultados. Outra limitação refere-se à constatação, apenas no momento da análise dos dados, da presença de textos de autenticidade questionável em português, ou seja, textos que aparentavam ser traduções a partir do inglês. Entretanto, nem sempre essa suspeita pôde ser confirmada ou refutada. No que tange ao software WordSmith Tools, empregamos apenas suas ferramentas mais comuns, mas reconhecemos a necessidade de dominar as funcionalidades mais complexas e interpretar dados mais elaborados.

Concluindo, gostaríamos de mencionar dois possíveis desdobramentos para esta pesquisa utilizando o corpus compilado por nós. O principal deles é a conclusão desta obra terminológica e sua disponibilização ao público-alvo. Outra possibilidade é a realização de estudo terminológico na direção português - inglês, a fim de verificar em que medida os resultados se assemelhariam aos que obtivemos até aqui.

Por fim, alinhando-nos a Krieger e Finatto:

A organização e a divulgação de terminologias por meio de instrumentos de referência elaborados em mais de um idioma consiste em um trabalho que cumpre um papel social maior, pois aproxima mundos, facilitando a comunicação e a recuperação da informação no campo do conhecimento especializado (2004: 68).

esperamos que este estudo seja o embrião para a elaboração de uma obra terminológica completa, que de fato auxilie o trabalho do tradutor, cumprindo assim devidamente o seu papel social maior. 


\section{Referências bibliográficas}

ADAMS L.; PENNER, R. and RUTES, W. (2001). Hotel Design Planning and Development. WW Norton \& Company: New York, London.

ALDRIGUI, M. (2007). Meios de Hospedagem. São Paulo: Aleph.

ANDRADE, N.; BRITO, P. L. e JORGE, W. E. (2007). Hotel: Planejamento e projeto. $9^{a}$ edição. São Paulo: Editora Senac.

AUBERT, F. (1996). Introdução à metodologia de pesquisa terminológica bilíngue. Cadernos de Terminologia. São Paulo: Humanitas, FFLCH/USP.

AZENHA JR., J. (1999). Tradução técnica e condicionantes culturais: primeiros passos para um estudo integrado. São Paulo: Humanitas/FFLCH-USP.

BAKER, M. (1992). In other words: a coursebook on translation. Routledge.

BENSON, M. (1989). The Structure of Collocational Dictionary. International Journal of Lexicography 2. p. 1-14.

BERBER SARDINHA, A. P. (1998). Size of a representative corpus. Resumo de discussão sobre CORPORA, lista de discussão, 26/08/1998. Disponível em http://nora.hd.uib.no/corpora/1998-3/0120.html [Acesso em 15/10/2010]

BERBER SARDINHA, A. P. (2004). Linguística de Corpus. Barueri: Manole.

BEVILACQUA, C. R. (2001). Unidades fraseológicas especializadas: novas perspectivas para sua identificação e tratamento. In. KRIEGER, M.G. e MACIEL, A.M.B. (orgs) Temas em Terminologia.: São Paulo / Porto Alegre: Humanitas FFLCH/USP / Editora da Universidade, p. 106 a 117.

BEVILACQUA, C. R. (2004). Unidades fraseológicas especializadas eventivas: descripción y reglas de formación en el ámbito de la energía solar. Tese (Doutorado em Linguística Aplicada) - Instituto Universitário de Linguística Aplicada, Universidad 
Pompeu Fabra, Barcelona, IULA/UPF. Disponível em: < http://tdx.cat/bitstream/handle/ 10803/7515/tcrb.pdf?sequence=1>. Acesso em: 10 jun. 2010.

BEVILACQUA, C. R. (2004). Fraseologia: perspectiva da língua comum e da língua especializada. In. Revista Língua \& Literatura. Ano VI e VII, número 10 e 11. p. 73-86.

BIBER, D. (1988). Variation across speech and writing. Cambridge: Cambridge University Press.

BIBER, D. (1995). Dimensions of register variations: a cross-linguistic comparison. Cambridge: Cambridge University Press.

BIBER, D.; CONRAD, S.; REPPEN, R. (1998). Corpus linguistics: investigating language structure and use. Cambridge: Cambridge University Press.

BLAIS, E. (1993). La phraséologie. une hypothèse de travail. In: Terminologies Nouvelles, Bruxelas, v. 10, p. 50-56.

BOURIGAULT, D. e SLODZIAN, M. (2004 [1988]). Conceito básico da linguística das linguagens especializadas. [tradução de Maria José Bocorny Finatto]. In. KRIEGER e ARAÚJO (orgs) (2004) A Terminologia em foco. Cadernos de Tradução 17. Porto Alegre, Instituto de Letras da UFRGS, out-dez.

BYRNE, J. (2006). Technical Translation: Usability Strategies for Translating Technical Documentation. The Netherlands: Springer.

CABRÉ, M. T. (1993). La Terminología: teoría, metodología, aplicaciones. Barcelona. Antártida/Empúries.

CABRÉ, M. T. (1999). Terminología: representación y comunicación. Una teoría de base comunicativa y otros artículos. Barcelona: Universitat Pompeu Fabra, Instituto Universitario de Lingüística Aplicada [Serie Monografias, 3].

CHESTERMAN, A. (1998). Constrastive functional analysis. Amsterdam: John Benjamins. 
CHURCH, K and HANKS, P. (1991). Word Association Norms, Mutual Information and Lexicography. Computational Linguistics: 16:1.

COWIE, A. P. (org.) (2004). Phraseology Theory, Analysis, and Applications, New York: Oxford University Press.

DIAS, R. N. S. (2006). As diferentes categorias dos hotéis da Rede Accor na cidade de São Paulo: as dimensões avaliativas dos folders do Hotel Formule 1 e do Hotel Sofitel São Paulo. Dissertação (Mestrado em Lingüística Aplicada e Estudos da Linguagem) Pontifícia Universidade Católica de São Paulo, Brasil.

FILLMORE. C. J. (1979). Innocence: a second idealization for Linguistics. Berkeley Linguistic Society 5, p. 63-76.

FINATTO, M. J. B.; KRIEGER, M. G. (2004). Introdução à Terminologia. Teoria \& prática. São Paulo: Contexto.

FIRTH, J. R. (1950). Personality and language in society. Reprinted in Firth (1957). Papers in linguistics. 1934-1951 (p. 177-189). London: Oxford University Press.

FIRTH, J. R. (1957). Papers in linguistics - 1934-1951. Oxford: Oxford University Press.

FISHBACK, H. (1998). Prefácio de editor convidado. In: Translation and Medicine, American Association Series, Vol. X, p. 1-12.

FONSECA, L. C. (2007). A tradução de binômios nos contratos de common law à luz da Linguística de Corpus. Dissertação (Mestrado em Estudos Lingüísticos e Literários em Inglês) - Faculdade de Filosofia, Letras e Ciências Humanas da Universidade de São Paulo, São Paulo.

GREGSON, P. W. (org.) (2009). Hotelaria na Prática. Editora Manole: Barueri.

HALL, E. T. (1976). Beyond culture. New York: Anchor Press/Doubleday.

HALL, E. T. (1993). The Dance of Life. New York: Doubleday. 
HALLIDAY, M. A. K. (1991). Corpus studies and probalistic grammar. In: AIJMER, K.; ALTENBERG, B. (orgs.). English corpus linguistics: studies in honor of Jan Svartvik. Londres: Longman. p. 30-43.

HALLIDAY, M. A. K. (1991). Corpus studies and probabilistic grammar. In: AIJMER, K.; ALTENBERG, B. English Corpus Linguistics. London: Longman.

HAUSMANN, F. J. (1989). Die Markierung im allgemeinen einsprachigen Wörterbuch: eine Übersicht. In. Hausmann, F. J. et al. (ed.), vol. 1, p. 649-657.

HAUSSMANN, F. J. (1985a). Kollokationen im deutschen Wörterbuch. Ein Beitrag zur Theorie des lexikographischen Beispiels. In. BERGNHOLZ, H.; Mugdan, J. (ed.), Lexikographie und Grammatik. Tübigen: Niemeyer, p. 118-129.

HOEY, M. (1997). A word beyond collocation: New perspectives on vocabulary teaching. In. LEWIS, M. (org.). Teaching collocation further development in the lexical approach. Hove, LTP. p. 224-43.

HOEY, M. (2000). A world beyond collocation: New perspectives on vocabulary teaching. In: LEWANDOWSKA-TOMASZCZYK, B.; MELIA, P.J. (orgs). (1997). Practical applications in language corpora. Lodz: Lodz University Press. p.2-22.

HOFFMANN, L. (2004 [1999]). Por uma terminologia textual. [tradução de Sandra Dias Loguercio]. In. KRIEGER e ARAÚJO (orgs) (2004) A Terminologia em foco. Cadernos de Tradução 17. Porto Alegre, Instituto de Letras da UFRGS, out-dez.

KALVERKÄMPFER, H. (1983). Textuelle Fachsprachen-Linguistik als Aufgabe. In. Zeitschrift für Literaturwissenschaft and Linguistik, v. 51/52, n ${ }^{\circ} 13$, p. 124-166.

KATAN, D. (2004). Translating Cultures. An Introduction for Translators, Interpreters and Mediators. Manchester, St. Jerome.

KENNEDY, G. (1998). An introduction to corpus linguistics. Nova York: Longman.

KRIEGER, M. G. (2001). Terminologia Revisitada. In. KRIEGER, M. G. \& MACIAL, A. M. B. (orgs) In. Temas em Terminologia: São Paulo / Porto Alegre: Humanitas FFLCH/USP / Editora da Universidade. p. 47 - 60. 
KRIEGER, M. G. \& FINATTO, M. J. B. (2004). Introdução à Terminologia: Teoria e Prática. Editora Contexto: São Paulo.

LAINÉ, C.; PAVEL; S.; BOILEAU, M. (1992). La phrasélogie - nouvelle dimension de la recherche terminologique. Travaux du module canadien du RINT. L'Actualité terminologique, Canadá, v. 25, n. 3, p. 5-9.

LAVIOSA, S. (2002). Corpus-based translation studies: theory, findings, applications. Amsterdam: Rodopi.

LEECH. G. (1992). Corpora and theories of linguistic performance. In: SVARTVIK, J. (org.). Directions in corpus linguistics. Proceedings of Nobel Symposium 82, Stockholm, 4-8 August 1991. Berlim/Nova York, De Gruyter. p. 105-27.

LERAT, P. (1995). Les Langues spécialisées. Paris: PUF. P. 201.

MACIEL, A. M. B. (2010). Pressupostos sociocognitivos na descrição terminológica e produção terminográfica. In. ISQUIERDO, A. N. e FINATTO, M. J. B. (orgs). As Ciências do Léxico: Lexicologia, Lexicografia, Terminologia. v. IV. Campo Grande, MS: Ed. UFMS; Porto Alegre: Editora da UFRGS.

MACIEL, A. M. B. (2010). Linguagens especializadas e terminologia: o passado projetando o futuro. In. PERNA, C. L.; DELGADO, H. K.; FINATTO, M. J. (orgs.) Linguagens especializadas em corpora: Modos de dizer e interfaces de pesquisa [recurso eletrônico]. Porto Alegre: EDIPUCRS. p. 6-27.

MANCA, E. (2004). Translation by Collocation: The Language of Tourism in English and Italian. Birmingham, UK: Tuscan Word Centre (TWC).

MANCA, E. (2008). From phraseology to culture: Qualifying adjectives in the language of tourism. In: Römer, U. and Schulze, R. (eds.). Patterns, meaningful units and specialized discourses: Special Issue of International Journal of Corpus Linguistics 13:3 (2008). 2008. 144 pp. (pp. 368-385).

MATUDA, S. (2011). A fraseologia do futebol: um estudo bilingue português-inglês direcionado pelo corpus. Dissertação (Mestrado em Estudos Lingüísticos e Literários 
em Inglês) - Faculdade de Filosofia, Letras e Ciências Humanas da Universidade de São Paulo, São Paulo.

McENERY, T. \& WILSON, A. (2001). Corpus Linguistics. 2nd Edition. Edinburgh: Edinburgh University Press.

MEL'CUK, I. A.; CLAS, A.; POLGUÈRE, A. (1995). Introduction à la lexicologie explicative et combinatoire. Louvain-la-Neuve: Duculot.

MITTMANN, B. (1999). The treatment of collocations in OALDS5, LDOCE3, COBUILD2 and CIDE' in T. Herbst and K. Popp (eds.) The Perfect Learners' Dictionary. Tübigen: Max Niemeyer Verlag. Lexicographica: Series Maior, 95: 1001111.

ORENHA, A. (2004). A compilação de um glossário bilíngue de colocações, na área de Negócios, baseada em corpus comparável. Dissertação (Mestrado em Estudos Lingüísticos e Literários em Inglês) - Faculdade de Filosofia, Letras e Ciências Humanas da Universidade de São Paulo, São Paulo.

ORENHA-OTTAINO, A. (2008). Algumas contribuições advindas compilação de corpora especializados via Web e WebBootCat para a tradução, terminologia e fraseologia. In. Tagnin, S. E. O. e Vale, O. A. (orgs) Avanços da Linguística de Corpus no Brasil, São Paulo: Humanitas.

PALMER, H. E. (1933). Second Interim Report on English Collocations, Tokyo: Kaiatakusha.

PARTINGTON, A. (1998). Patterns and meanings: using corpora for English language research and teaching. Amsterdã/Filadélfia: John Benjamins.

QUIRK, R. et al. (1985). A comprehensive grammar of the English language. Londres, Longman.

SANCHEZ, A.; CANTOS, P. (1996). Cumbre - Curso de Español. Madrid, SGEL. 
SANTORINI, B. Part-of-Speech tagging guidelines for the Penn Treebank Project.

Disponível em: <http://www.ims.uni-stuttgart.de/projekte/corplex/TreeTagger/PennTreebank-Tagset.pdf $>$. Acesso em: 25 mar. 2011.

SCOTT, M. (2007). Wordsmith Tools, version 5. Oxford: Oxford University Press.

SINCLAIR, J. (1991). Corpus, Concordance, Collocation. Oxford: Oxford University Press.

SINCLAIR, J. (1996). The search for units of meaning. Textus, 9 (1), 71-106.

SINCLAIR, J. (2004). Trust the text: language, corpus and discourse. London: Routledge.

SINCLAIR, J. JONES, S. DALEY, R. (2004). English Collocation Studies: The OSTI Report, London: Continuum.

SNELL-HORNBY, M. et al. (1998). Handbuch Translation. Tübigen: Stauffenburg, 1998.

STUBBS, M. (1996). Text and Corpus Analysis. Routledge. London.

TAGNIN, S. E. O. (1989). Expressões Idiomáticas e Convencionais. São Paulo: Ática.

TAGNIN, S. E. O. (2003). Os Corpora: instrumentos de auto-ajuda para o tradutor. In: Cadernos de Tradução (UFSC), Florianópolis, v. 9, n. 2002/1, p. 191-213.

TAGNIN, S. E. O. (2005). O jeito que a gente diz: expressões convencionais e idiomáticas. São Paulo: Disal.

TEIXEIRA, E. D. (2008). A Linguística de Corpus a serviço do tradutor: proposta de um dicionário de Culinária voltado para a produção textual. Dissertação (Doutorado em Estudos Linguísticos e Literários em Inglês) - Faculdade de Filosofia, Letras e Ciências Humanas, Universidade de São Paulo. Brasil.

TEMMERMAN, R. (2000). Towards a new way of terminology description. The sociocognitive approach. Amsterdam/Philadelphia: John Benjamins Publishing Company.. 
TOGNINI-BONELLI, E. (2001). Corpus Linguistics at Work. Amsterdam/Philadelphia: John Benjamins.

VARANTOLA, K. (2002). Disposable corpora as intelligent tools in translation. Cadernos de Tradução, Florianópolis, n. 9, p. 171-189.

VICTOR, D. A. (1992). International Business Communication, London: Harper Collins.

ZANETTIN, F. (2002). CEXI: Designing and English Italian translational corpus. In: B. Ketteman \& G. Marko. Teaching and learning by doing corpus analysis. (Proceedings of the $4^{\text {th }}$ International TALC, Graz, 14-24 July 2000. (p. 329-343) Amsterdam/New York: Rodopi.

ZILIO, L. (2009). Colocações especializadas e 'Komposita': um estudo constrastivo alemão-português na área de cardiologia. Dissertação (Mestrado em Letras) - Instituto de Letras, Universidade Federal do Rio Grande do Sul.

\section{Dicionários}

BENSON, M. E. BENSON \& R. ILSON (1997 [1980]). The BBI Combinatory Dictionary of English. Amsterdam/Philadelphia: John Benjamins.

CATUREgli, M. G. (1999). Dicionário Inglês - Português Turismo, Hotelaria e Comércio Exterior. 2a Edição. São Paulo: Aleph.

GARCIA, M. X. (2004). Vocabulário Para Turismo - Português / Inglês. Série Mil \& Um Termos. São Paulo: SBS.

TAGNIN, S. E. O. e TEIXEIRA, E. D. (2008). Vocabulário Para Culinária InglêsPortuguês - Série Mil \& Um Termos. São Paulo: SBS.

Longman Dictionary of Contemporary English (2009). Essex: Pearson Education Limited

Oxford Collocations Dictionary for Students of English (2003). Oxford: Oxford University Press. 


\section{Anexos}

\section{ANEXO A}

Palavras-chave do corpus em inglês

\begin{tabular}{|c|c|c|c|c|}
\hline $\mathbf{N}$ & Key word & Freq. & $\%$ & RC. Freq. \\
\hline 1 & SUITES & 1844 & 0,3424 & 249 \\
\hline 2 & ROOM & 3586 & 0,6659 & 28821 \\
\hline 3 & HOTEL & 2548 & 0,4731 & 10911 \\
\hline 4 & INTERNET & 1188 & 0,2206 & 97 \\
\hline 5 & ROOMS & 1863 & 0,3459 & 5347 \\
\hline 6 & SUITE & 1458 & 0,2707 & 1460 \\
\hline 7 & OUR & 4377 & 0,8128 & 93455 \\
\hline 8 & AMENITIES & 1119 & 0,2078 & 510 \\
\hline 9 & SPA & 1107 & 0,2056 & 514 \\
\hline 10 & CENTER & 980 & 0,182 & 503 \\
\hline 11 & COMPLIMENTARY & 933 & 0,1732 & 318 \\
\hline 12 & YOUR & 4274 & 0,7936 & 134393 \\
\hline 13 & GUESTS & 1273 & 0,2364 & 3285 \\
\hline 14 & DINING & 1120 & 0,208 & 1717 \\
\hline 15 & RESORT & 1137 & 0,2111 & 2101 \\
\hline 16 & GUEST & 982 & 0,1823 & 2233 \\
\hline 17 & ACCOMMODATIONS & 592 & 0,1099 & 43 \\
\hline 18 & VEGAS & 550 & 0,1021 & 0 \\
\hline 19 & BEDROOM & 994 & 0,1846 & 4031 \\
\hline 20 & RESERVATION & 660 & 0,1226 & 643 \\
\hline 21 & OFFERS & 986 & 0,1831 & 5844 \\
\hline 22 & CHECK & 1035 & 0,1922 & 7129 \\
\hline 23 & LOCATED & 752 & 0,1396 & 2500 \\
\hline 24 & RESERVATIONS & 611 & 0,1135 & 976 \\
\hline 25 & BREAKFAST & 842 & 0,1564 & 4247 \\
\hline 26 & ENJOY & 932 & 0,1731 & 6439 \\
\hline 27 & POOL & 820 & 0,1523 & 4455 \\
\hline 28 & MASSAGE & 524 & 0,0973 & 634 \\
\hline 29 & SPACIOUS & 516 & 0,0958 & 641 \\
\hline & & 222 & & \\
\hline
\end{tabular}




\begin{tabular}{|c|c|c|c|}
\hline $\mathrm{BEACH}$ & 741 & 0,1376 & 3719 \\
\hline INN & 581 & 0,1079 & 1498 \\
\hline WIRELESS & 477 & 0,0886 & 513 \\
\hline VEGAS & 421 & 0,0782 & 216 \\
\hline SERVICE & 1416 & 0,2629 & 30252 \\
\hline BED & 1061 & 0,197 & 14727 \\
\hline OUTDOOR & 522 & 0,0969 & 1054 \\
\hline ACCESS & 939 & 0,1744 & 10860 \\
\hline AVAILABLE & 1257 & 0,2334 & 27025 \\
\hline CONDO & 303 & 0,0563 & 4 \\
\hline FITNESS & 505 & 0,0938 & 1571 \\
\hline DOWNTOWN & 351 & 0,0652 & 186 \\
\hline PRIVATE & 1026 & 0,1905 & 17643 \\
\hline LAS & 370 & 0,0687 & 340 \\
\hline CITY & 275 & 0,0511 & 0 \\
\hline NO & 275 & 0,0511 & 0 \\
\hline FLORIDA & 275 & 0,0511 & 0 \\
\hline $\mathrm{BEACH}$ & 275 & 0,0511 & 0 \\
\hline VEGAS & 272 & 0,0505 & 0 \\
\hline TUB & 357 & 0,0663 & 296 \\
\hline YORK & 275 & 0,0511 & 4 \\
\hline ONLINE & 269 & 0,05 & 0 \\
\hline NEW & 267 & 0,0496 & 0 \\
\hline OUT & 266 & 0,0494 & 0 \\
\hline LUXURY & 482 & 0,0895 & 1756 \\
\hline WATER & 274 & 0,0509 & 22 \\
\hline GOLF & 564 & 0,1047 & 3352 \\
\hline SPORTS & 259 & 0,0481 & 2 \\
\hline CONCIERGE & 275 & 0,0511 & 29 \\
\hline FEATURES & 745 & 0,1383 & 8723 \\
\hline MENU & 445 & 0,0826 & 1567 \\
\hline STAY & 798 & 0,1482 & 11960 \\
\hline DELUXE & 276 & 0,0513 & 98 \\
\hline REFRIGERATOR & 313 & 0,0581 & 289 \\
\hline SQUARE & 648 & 0,1203 & 6843 \\
\hline $\mathrm{COM}$ & 311 & 0,0577 & 281 \\
\hline$S$ & 1009 & 0,1874 & 23425 \\
\hline
\end{tabular}




\begin{tabular}{|c|c|c|c|c|}
\hline 67 & SHOWER & 422 & 0,0784 & 1618 \\
\hline 68 & PERFECT & 590 & 0,1096 & 5595 \\
\hline 69 & VACATION & 294 & 0,0546 & 290 \\
\hline 70 & FREE & 920 & 0,1708 & 20566 \\
\hline 71 & BATH & 509 & 0,0945 & 3818 \\
\hline 72 & LUXURIOUS & 313 & 0,0581 & 496 \\
\hline 73 & WEDDING & 474 & 0,088 & 3218 \\
\hline 74 & PARKING & 390 & 0,0724 & 1557 \\
\hline 75 & BAR & 612 & 0,1136 & 7694 \\
\hline 76 & QUEEN & 560 & 0,104 & 5894 \\
\hline 77 & FIREPLACE & 320 & 0,0594 & 668 \\
\hline 78 & BEDS & 417 & 0,0774 & 2179 \\
\hline 79 & NON & 359 & 0,0667 & 1241 \\
\hline 80 & COFFEE & 553 & 0,1027 & 6356 \\
\hline 81 & ORLANDO & 249 & 0,0462 & 200 \\
\hline 82 & SERVICES & 923 & 0,1714 & 24866 \\
\hline 83 & OCEAN & 380 & 0,0706 & 1967 \\
\hline 84 & ARRIVAL & 439 & 0,0815 & 3342 \\
\hline 85 & LOUNGE & 346 & 0,0642 & 1427 \\
\hline 86 & CANCELLATION & 281 & 0,0522 & 550 \\
\hline 87 & FEATURING & 312 & 0,0579 & 930 \\
\hline 88 & RESTAURANT & 434 & 0,0806 & 3410 \\
\hline 89 & DVD & 178 & 0,0331 & 0 \\
\hline 90 & WHIRLPOOL & 218 & 0,0405 & 116 \\
\hline 91 & KING & 666 & 0,1237 & 12471 \\
\hline 92 & FULL & 941 & 0,1747 & 28294 \\
\hline 93 & SOFA & 304 & 0,0564 & 920 \\
\hline 94 & DESK & 449 & 0,0834 & 4077 \\
\hline 95 & VIEWS & 546 & 0,1014 & 7503 \\
\hline 96 & MIAMI & 250 & 0,0464 & 357 \\
\hline 97 & MICROWAVE & 277 & 0,0514 & 630 \\
\hline 98 & MEETING & 807 & 0,1499 & 20590 \\
\hline 99 & SPEED & 539 & 0,1001 & 7670 \\
\hline 100 & CUISINE & 256 & 0,0475 & 482 \\
\hline 101 & RATES & 623 & 0,1157 & 11556 \\
\hline 102 & EQUIPPED & 327 & 0,0607 & 1596 \\
\hline 103 & AREA & 992 & 0,1842 & 34697 \\
\hline
\end{tabular}


PLEASE OFFER

INDOOR

WITH

DC

FEE

IRONING

BATHROOM

RESTAURANTS

RELAX

CASINO

DEPOSIT

LAUNDRY

TRAVELERS

LIVING

AVAILABILITY

WASHINGTON

ENTERTAINMENT

CABLE

BALCONY

$\#$

DRYER

FAVORITE

LCD

GOURMET

MARBLE

EVENT

TV

CHICAGO

SLEEPER

PACKAGES

EXPERIENCE

COMFORT

LAKE

OVERSIZED

SPECIAL

WOODLOCH
$652 \quad 0,1211 \quad 13809$

$685 \quad 0,1272 \quad 15655$

$279 \quad 0,0518 \quad 896$

$6247 \quad 1,16 \quad 659997$

$338 \quad 0,0628 \quad 1963$

$373 \quad 0,0693 \quad 2898$

$222 \quad 0,0412 \quad 312$

$345 \quad 0,0641 \quad 2324$

$306 \quad 0,0568 \quad 1576$

$313 \quad 0,0581 \quad 1731$

$202 \quad 0,0375 \quad 214$

$325 \quad 0,0603 \quad 2011$

$230 \quad 0,0427 \quad 509$

$147 \quad 0,0273 \quad 6$

$643 \quad 0,1194 \quad 15600$

$311 \quad 0,0577 \quad 1924$

$357 \quad 0,0663 \quad 3120$

$312 \quad 0,0579 \quad 2005$

$303 \quad 0,0563 \quad 1884$

$251 \quad 0,0466 \quad 916$

$12375 \quad 2,2979 \quad 2 E+06$

$180 \quad 0,0334 \quad 175$

$144 \quad 0,0267 \quad 20$

$161 \quad 0,0299 \quad 84$

$168 \quad 0,0312 \quad 119$

$265 \quad 0,0492 \quad 1296$

$516 \quad 0,0958 \quad 10299$

$428 \quad 0,0795 \quad 6294$

$248 \quad 0,0461 \quad 1025$

$167 \quad 0,031 \quad 130$

$270 \quad 0,0501 \quad 1500$

$690 \quad 0,1281 \quad 21084$

$335 \quad 0,0622 \quad 3233$

$351 \quad 0,0652 \quad 3844$

$148 \quad 0,0275 \quad 63$

$692 \quad 0,1285 \quad 21868$

$121 \quad 0,0225 \quad 0$ 


\begin{tabular}{|c|c|c|c|}
\hline LOBBY & 241 & 0,0448 & 1117 \\
\hline JACUZZI & 149 & 0,0277 & 84 \\
\hline CUSTOM & 255 & 0,0474 & 1449 \\
\hline VALET & 143 & 0,0266 & 70 \\
\hline COMFORTABLE & 337 & 0,0626 & 3850 \\
\hline MAKER & 222 & 0,0412 & 923 \\
\hline SIZE & 520 & 0,0966 & 12554 \\
\hline KITCHEN & 425 & 0,0789 & 7673 \\
\hline SMOKING & 301 & 0,0559 & 2887 \\
\hline LOCATION & 333 & 0,0618 & 3977 \\
\hline BATHROOMS & 175 & 0,0325 & 341 \\
\hline SPACE & 510 & 0,0947 & 12601 \\
\hline ONLINE & 194 & 0,036 & 597 \\
\hline DÉCOR & 134 & 0,0249 & 65 \\
\hline SIGNATURE & 222 & 0,0412 & 1066 \\
\hline RELAXING & 197 & 0,0366 & 679 \\
\hline LINENS & 124 & 0,023 & 34 \\
\hline INCLUDE & 542 & 0,1006 & 15147 \\
\hline TREATMENTS & 206 & 0,0383 & 868 \\
\hline ELEGANT & 245 & 0,0455 & 1720 \\
\hline COZY & 117 & 0,0217 & 23 \\
\hline BANQUET & 167 & 0,031 & 352 \\
\hline LODGING & 165 & 0,0306 & 331 \\
\hline FLOOR & 460 & 0,0854 & 10909 \\
\hline FACIAL & 179 & 0,0332 & 550 \\
\hline DAILY & 393 & 0,073 & 7519 \\
\hline WEDDINGS & 157 & 0,0292 & 300 \\
\hline DISNEY & 173 & 0,0321 & 487 \\
\hline DINNER & 356 & 0,0661 & 5886 \\
\hline PETS & 176 & 0,0327 & 533 \\
\hline ADDITIONAL & 383 & 0,0711 & 7339 \\
\hline EN & 222 & 0,0412 & 1437 \\
\hline FURNISHINGS & 164 & 0,0305 & 416 \\
\hline CONDOMINIUMS & 102 & 0,0189 & 5 \\
\hline CLICK & 178 & 0,0331 & 624 \\
\hline CONVENIENCE & 194 & 0,036 & 910 \\
\hline MOHONK & 96 & 0,0178 & 0 \\
\hline
\end{tabular}




$\begin{array}{lrrrr}178 & 363 & 0,0674 & 6749 \\ 179 & \text { INCLUDES } & 307 & 0,057 & 4309 \\ 180 & \text { UNIQUE } & 204 & 0,0379 & 1153 \\ 181 & \text { INTIMATE } & 128 & 0,0238 & 120 \\ 182 & \text { SOUTIQUE } & 434 & 0,0806 & 10585 \\ 183 & \text { BUSINESS } & 771 & 0,1432 & 35127 \\ 184 & \text { SHUTTLE } & 161 & 0,0299 & 442 \\ 185 & \text { REQUEST } & 306 & 0,0568 & 4438 \\ 186 & \text { EVENTS } & 419 & 0,0778 & 10303 \\ 187 & \text { MEETINGS } & 321 & 0,0596 & 5312 \\ 188 & \text { CHEF } & 167 & 0,031 & 600 \\ 189 & \text { ACCOMMODATE } & 206 & 0,0383 & 1372 \\ 190 & \text { INCLUDING } & 618 & 0,1148 & 24007 \\ 191 & \text { PET } & 206 & 0,0383 & 1394 \\ 192 & \text { OVERLOOKING } & 174 & 0,0323 & 743 \\ 193 & \text { CARD } & 325 & 0,0603 & 5628 \\ 194 & \text { DOUBLE } & 367 & 0,0681 & 7815 \\ 195 & \text { GTS } \\ 196 & \text { ATTRACTIONS } & 179 & 0,0332 & 886 \\ 197 & \text { CATERING } & 216 & 0,0401 & 1755 \\ 198 & 89 & 0,0165 & 2 \\ 199 & \text { GUESTROOMS } & 151 & 0,028 & 447 \\ 200 & \text { SIZED } & 90 & 0,0167 & 6 \\ & \text { USD } & 117 & 0,0217 & 122\end{array}$




\section{Anexo B}

Lista de colocados de $\operatorname{room}(s)$

\begin{tabular}{|c|c|c|c|c|}
\hline $\mathbf{N}$ & Word & With & Relation & Texts \\
\hline 1 & ROOM & room ${ }^{*}$ & 7,6563 & $\overline{316}$ \\
\hline 2 & ROOMS & room* & 7,5753 & 291 \\
\hline 3 & THE & room* & 3,6983 & 258 \\
\hline 4 & AND & room* & 3,7461 & 280 \\
\hline 5 & IN & room* & 4,9793 & 277 \\
\hline 6 & A & room* & 4,0226 & 259 \\
\hline 7 & WITH & room* & 4,4385 & 245 \\
\hline 8 & OF & room* & 3,5485 & 236 \\
\hline 9 & GUEST & room* & 6,6573 & 177 \\
\hline 10 & TO & room* & 3,3397 & 223 \\
\hline 11 & OUR & room* & 4,2089 & 185 \\
\hline 12 & FOR & room ${ }^{*}$ & 3,6776 & 187 \\
\hline 13 & DINING & room* & 5,8694 & 130 \\
\hline 14 & LIVING & room* & 6,5707 & 145 \\
\hline 15 & ARE & room* & 4,389 & 156 \\
\hline 16 & IS & room* & 3,7776 & 150 \\
\hline 17 & YOUR & room* & 3,665 & 162 \\
\hline 18 & ALL & room* & 4,8414 & 166 \\
\hline 19 & THIS & room* & 5,0063 & 114 \\
\hline 20 & OR & room* & 3,8826 & 151 \\
\hline 21 & SUITES & room* & 4,6107 & 128 \\
\hline 22 & MEETING & room* & 5,7981 & 108 \\
\hline 23 & AVAILABLE & room* & 4,9846 & 140 \\
\hline 24 & TWO & room* & 4,7148 & 117 \\
\hline 25 & HOTEL & room* & 3,8696 & 122 \\
\hline 26 & SERVICE & room* & 4,6758 & 106 \\
\hline 27 & PRIVATE & room* & 5,1103 & 110 \\
\hline 28 & AMENITIES & room* & 4,8641 & 115 \\
\hline 29 & ONE & room* & 4,3086 & 113 \\
\hline 30 & KING & room* & 5,5306 & 85 \\
\hline 31 & PER & room* & 5,8362 & 87 \\
\hline 32 & SPACIOUS & room* & 5,8559 & 107 \\
\hline
\end{tabular}




\begin{tabular}{|c|c|c|c|c|}
\hline 33 & ON & room* & 3,5289 & 107 \\
\hline 34 & BED & room* & 4,7718 & 105 \\
\hline 35 & FEATURES & room* & 5,244 & 100 \\
\hline 36 & HAS & room* & 5,0128 & 91 \\
\hline 37 & AT & room* & 3,0954 & 106 \\
\hline 38 & QUEEN & room* & 5,4763 & 87 \\
\hline 39 & HAVE & room* & 4,7928 & 93 \\
\hline 40 & $\mathrm{EACH}$ & room* & 5,2006 & 90 \\
\hline 41 & RATES & room* & 5,1762 & 101 \\
\hline 42 & SUITE & room* & 3,9302 & 84 \\
\hline 43 & SMOKING & room* & 6,1768 & 85 \\
\hline 44 & AN & room* & 3,499 & 90 \\
\hline 45 & INTERNET & room* & 4,0823 & 89 \\
\hline 46 & STANDARD & room* & 6,3714 & 54 \\
\hline 47 & YOU & room* & 2,567 & 79 \\
\hline 48 & ACCESS & room* & 4,3442 & 79 \\
\hline 49 & 2 & room* & 0 & 76 \\
\hline 50 & COFFEE & room* & 5,0852 & 65 \\
\hline 51 & FULL & room* & 4,3067 & 80 \\
\hline 52 & $\mathrm{BE}$ & room* & 3,4826 & 76 \\
\hline 53 & OFFERS & room* & 4,2158 & 78 \\
\hline 54 & TAX & room* & 6,0294 & 67 \\
\hline 55 & WILL & room* & 3,4046 & 81 \\
\hline 56 & FREE & room* & 4,243 & 74 \\
\hline 57 & VIEW & room* & 5,2149 & 45 \\
\hline 58 & SAFE & room* & 6,5214 & 51 \\
\hline 59 & BEDROOM & room* & 4,1063 & 57 \\
\hline 60 & RATE & room* & 5,2792 & 67 \\
\hline 61 & 1 & room* & 0 & 66 \\
\hline 62 & FROM & room* & 2,9928 & 69 \\
\hline 63 & NON & room $^{*}$ & 5,5371 & 74 \\
\hline 64 & SEPARATE & room* & 5,6321 & 58 \\
\hline 65 & DELUXE & room* & 5,8635 & 39 \\
\hline 66 & FEATURE & room ${ }^{*}$ & 5,632 & 60 \\
\hline 67 & AREA & room* & 4,0042 & 71 \\
\hline 68 & DOUBLE & room* & 5,4251 & 57 \\
\hline 69 & CHECK & room* & 3,815 & 60 \\
\hline
\end{tabular}




\begin{tabular}{|c|c|c|c|c|}
\hline 70 & AS & room* & 3,1034 & 59 \\
\hline 71 & SIZE & room* & 4,7473 & 50 \\
\hline 72 & BEDS & room* & 5,0344 & 63 \\
\hline 73 & OFFER & room* & 4,3024 & 64 \\
\hline 74 & ACCESSIBLE & room* & 6,5066 & 48 \\
\hline 75 & SPA & room* & 3,5775 & 49 \\
\hline 76 & BATH & room* & 4,6819 & 52 \\
\hline 77 & TYPE & room $^{*}$ & 6,4543 & 45 \\
\hline 78 & CAN & room $^{*}$ & 3,6303 & 57 \\
\hline 79 & NUMBER & room $^{*}$ & 5,6968 & 46 \\
\hline 80 & APPOINTED & room* & 6,04 & 53 \\
\hline 81 & GUESTS & room* & 3,3259 & 54 \\
\hline 82 & COMPLIMENTARY & room* & 3,7742 & 61 \\
\hline 83 & INCLUDE & room* & 4,5234 & 60 \\
\hline 84 & SERVICES & room* & 3,7379 & 60 \\
\hline 85 & BREAKFAST & room* & 3,8704 & 54 \\
\hline 86 & KITCHEN & room* & 4,8567 & 51 \\
\hline 87 & FIREPLACE & room* & 5,2305 & 37 \\
\hline 88 & LARGE & room* & 4,9014 & 58 \\
\hline 89 & MORE & room* & 3,8907 & 57 \\
\hline 90 & ALSO & room* & 4,09 & 55 \\
\hline 91 & BOOK & room* & 5,2927 & 60 \\
\hline 92 & MOST & room* & 4,4151 & 55 \\
\hline 93 & NIGHT & room* & 4,4973 & 54 \\
\hline 94 & THAT & room* & 2,9726 & 60 \\
\hline 95 & SITTING & room* & 6,2114 & 42 \\
\hline 96 & EQUIPPED & room* & 5,0868 & 49 \\
\hline 97 & THESE & room* & 5,0453 & 40 \\
\hline 98 & CENTER & room $^{*}$ & 3,4837 & 52 \\
\hline 99 & POOL & room $^{*}$ & 3,721 & 54 \\
\hline 100 & INCLUDING & room* & 4,1088 & 51 \\
\hline 101 & COMFORTABLE & room* & 4,9632 & 50 \\
\hline 102 & STEAM & room* & 6,7944 & 31 \\
\hline 103 & MAKER & room* & 5,4805 & 37 \\
\hline 104 & UP & room* & 3,6881 & 46 \\
\hline 105 & $S$ & room* & 3,2742 & 38 \\
\hline 106 & WIRELESS & room* & 4,355 & 49 \\
\hline
\end{tabular}


107

108

109

110

111

112

113

114

115

116

117

118

119

120

121

122

123

124

125

126

127

128

129

130

131

132

133

134

135

136

137

138

139

140

141

142

143

\begin{tabular}{|c|c|c|c|}
\hline OUT & room* & 3,7352 & 52 \\
\hline SOFA & room* & 4,9826 & 46 \\
\hline NOT & room* & 3,8884 & 54 \\
\hline CONFERENCE & room* & 4,959 & 44 \\
\hline BAR & room* & 3,9731 & 35 \\
\hline INCLUDES & room* & 4,7267 & 41 \\
\hline HOTELARIA & room* & 4,1272 & 63 \\
\hline SPACE & room* & 4,2134 & 46 \\
\hline LOCATED & room* & 3,6301 & 37 \\
\hline WE & room* & 2,6769 & 49 \\
\hline CABLE & room* & 4,9415 & 43 \\
\hline BY & room* & 2,8037 & 44 \\
\hline WELL & room $^{*}$ & 4,2424 & 41 \\
\hline $\mathrm{HIGH}$ & room* & 3,608 & 47 \\
\hline EVERY & room* & 4,0394 & 46 \\
\hline TV & room* & 4,3959 & 51 \\
\hline BOARD & room* & 5,1019 & 41 \\
\hline RESERVATIONS & room $^{*}$ & 3,8581 & 41 \\
\hline RESERVE & room* & 5,894 & 52 \\
\hline SQUARE & room* & 3,7486 & 28 \\
\hline SPEED & room* & 4,0143 & 48 \\
\hline SOME & room* & 4,7135 & 43 \\
\hline LUXURIOUS & room* & 4,7734 & 43 \\
\hline RESERVATION & room* & 3,6971 & 38 \\
\hline 24 & room* & 0 & 31 \\
\hline ONLY & room* & 4,1071 & 41 \\
\hline INN & room* & 3,8295 & 30 \\
\hline MAY & room* & 3,7759 & 41 \\
\hline FLOOR & room* & 4,1399 & 40 \\
\hline OUTDOOR & room* & 3,9575 & 37 \\
\hline HOME & room* & 3,5445 & 47 \\
\hline FITNESS & room* & 3,9783 & 41 \\
\hline VIEWS & room* & 3,8657 & 29 \\
\hline BUSINESS & room* & 3,3678 & 41 \\
\hline THREE & room* & 4,5516 & 34 \\
\hline MICROWAVE & room* & 4,7892 & 32 \\
\hline BANQUET & room* & 5,5192 & 31 \\
\hline
\end{tabular}




\begin{tabular}{|c|c|c|c|c|}
\hline 144 & TREATMENT & room* & 4,8191 & 26 \\
\hline 145 & DECORATED & room* & 5,7763 & 40 \\
\hline 146 & ADDITIONAL & room* & 4,2932 & 38 \\
\hline 147 & IRONING & room* & 5,08 & 35 \\
\hline 148 & TURISMO & room* & 4,7711 & 49 \\
\hline 149 & HOUR & room* & 4,3654 & 29 \\
\hline 150 & ENJOY & room* & 2,981 & 35 \\
\hline 151 & ELEGANT & room* & 4,9086 & 35 \\
\hline 152 & IRON & room* & 4,981 & 36 \\
\hline 153 & DESK & room* & 4,0049 & 33 \\
\hline 154 & HAIR & room* & 5,134 & 31 \\
\hline 155 & EXECUTIVE & room* & 4,7517 & 25 \\
\hline 156 & 3 & room* & 0 & 34 \\
\hline 157 & SHOWER & room* & 4,064 & 26 \\
\hline 158 & INFORMATION & room* & 4,2892 & 28 \\
\hline 159 & WHIRLPOOL & room* & 5,0169 & 26 \\
\hline 160 & BATHROOM & room* & 4,3236 & 35 \\
\hline 161 & $\mathrm{COZY}$ & room* & 5,8837 & 33 \\
\hline 162 & GARDEN & room* & 5,2463 & 17 \\
\hline 163 & REFRIGERATOR & room* & 4,4641 & 35 \\
\hline 164 & TABLE & room* & 4,5692 & 28 \\
\hline 165 & FEATURING & room* & 4,437 & 32 \\
\hline 166 & MAIN & room* & 5,2961 & 28 \\
\hline 167 & 10 & room* & 0 & 35 \\
\hline 168 & WHICH & room* & 4,2264 & 40 \\
\hline 169 & PERFECT & room ${ }^{*}$ & 3,4522 & 29 \\
\hline 170 & SPECIAL & room* & 3,2221 & 33 \\
\hline 171 & SELECT & room* & 5,0494 & 32 \\
\hline 172 & POWDER & room* & 7,2992 & 13 \\
\hline 173 & AVAILABILITY & room ${ }^{*}$ & 4,376 & 33 \\
\hline 174 & FULLY & room* & 4,3374 & 30 \\
\hline 175 & REQUEST & room* & 4,3654 & 35 \\
\hline 176 & OCEAN & room* & 4,053 & 10 \\
\hline 177 & CONNECTING & room* & 6,7159 & 23 \\
\hline 178 & COMPLETE & room* & 4,5248 & 27 \\
\hline 179 & TUB & room* & 4,143 & 28 \\
\hline 180 & GAME & room* & 5,3786 & 26 \\
\hline
\end{tabular}




$\begin{array}{lrlll}181 & \text { JACUZZI } & \text { room }^{*} & 5,3689 & 18 \\ 182 & \text { CHARGE } & \text { room }^{*} & 4,8332 & 35 \\ 183 & \text { FACILITIES } & \text { room }^{*} & 4,1451 & 27 \\ 184 & \text { ACCOMMODATIONS } & \text { room }^{*} & 3,3786 & 33 \\ 185 & \text { LAUNDRY } & \text { room }^{*} & 4,7426 & 28 \\ 186 & \text { AIR } & \text { room }^{*} & 4,9587 & 29 \\ 187 & \text { PHONE } & \text { room }^{*} & 4,859 & 25 \\ 188 & \text { ACCOMMODATE } & \text { room }^{*} & 4,8659 & 30 \\ 189 & \text { FOOT } & \text { room }^{*} & 4,1601 & 19 \\ 190 & \text { PREFERENCES } & \text { room }^{*} & 6,8721 & 20 \\ 191 & \text { NIGHTS } & \text { room }^{*} & 5,0081 & 28 \\ 192 & \text { DAILY } & \text { room }^{*} & 3,8975 & 30 \\ 193 & \text { FUNCTION } & \text { room }^{*} & 5,7346 & 23 \\ 194 & \text { RESORT } & \text { room }^{*} & 2,3649 & 27 \\ 195 & \text { TOTAL } & \text { room }^{*} & 5,2213 & 28 \\ 196 & \text { BALCONY } & \text { room* }^{*} & 4,5444 & 30 \\ 197 & \text { THAN } & \text { room* }^{*} & 4,1475 & 28 \\ 198 & \text { GREAT } & \text { room* }^{*} & 4,019 & 21 \\ 199 & 00 & \text { room* }^{*} & 0 & 29 \\ 200 & \text { OWN } & \text { room* }^{*} & 4,4121 & 31\end{array}$

